UNIVERSIDADE DE SÃO PAULO
ESCOLA DE ENGENHARIA DE SÃO CARLOS
PROGRAMA DE PÓS-GRADUAÇÃO EM CIÊNCIAS DA ENGENHARIA AMBIENTAL

MARIA RITA RAIMUNDO E ALMEIDA

Aplicação da abordagem sistêmica para análise da efetividade da Avaliação de Impacto Ambiental no Brasil: um estudo para os estados de São Paulo e Sul de Minas Gerais 



\section{Aplicação da abordagem sistêmica para análise da efetividade da Avaliação de Impacto Ambiental no Brasil: um estudo para os estados de São Paulo e Sul de Minas Gerais}

Tese apresentada à Escola de Engenharia de São Carlos, Universidade de São Paulo para obtenção do título de Doutor em Ciências da Engenharia Ambiental.

Orientador: Prof. Dr. Marcelo Montaño

São Carlos 
AUTORIZO A REPRODUÇÃO TOTAL OU PARCIAL DESTE TRABALHO, POR QUALQUER MEIO CONVENCIONAL OU ELETRÔNICO, PARA FINS DE ESTUDO E PESQUISA, DESDE QUE CITADA A FONTE.

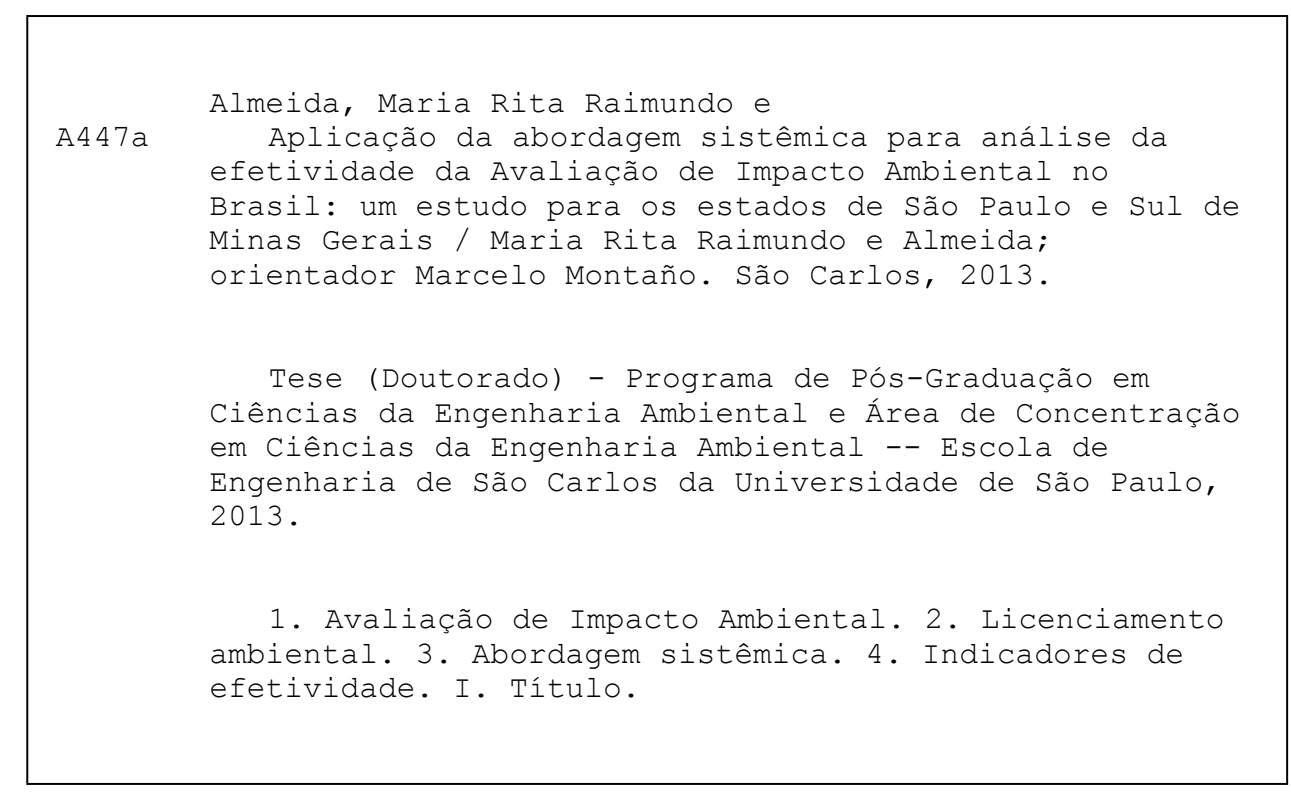




\section{FOLHA DE JULGAMENTO}

Candidata: Engenheira MARIA RITA RAIMUNDO E ALMEIDA.

Título da tese: "Aplicação da abordagem sistêmica para análise da efetividade da avaliação de impacto ambiental no Brasil: um estudo para os estados de São Paulo e Minas Gerais".

Data da defesa: $17 / 12 / 2013$

\section{Comissão Julgadora:}

Prof. Dr. Marcelo Montaño (Orientador)

(Escola de Engenharia de São Carlos/EESC)

Prof. Titular Marcelo Pereira de Souza

(Faculdade de Filosofia, Letras e Ciências Humanas/USP)

Prof. Dr. Evandro Mateus Moretto

(Escola de Artes, Ciências e Humanidades/USP)

Prof. Dr. Reginaldo de Camargo

(Universidade Federal de Uberlândia/UFU)

p/ Prof. Dr. Alberto de Freitas Castro Fonseca

(Universidade Federal de Ouro Preto/UFOP)
Resultado:

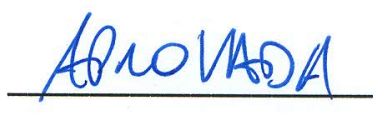

APROUADA
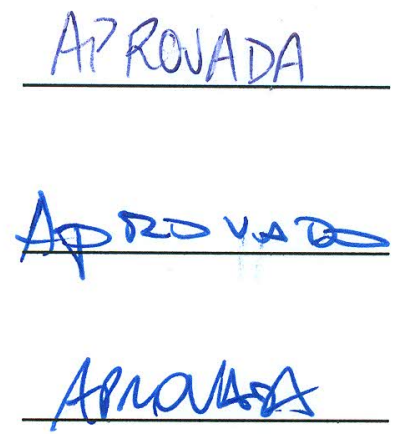

Coordenador do Programa de Pós-Graduação em Ciências da Engenharia Ambiental:

Prof. Associado Frederico Fabio Mauad

Presidente da Comissão de Pós-Graduação:

Prof. Titular Denis Vinicius Coury 

À minha avó, meu exemplo de vida. 



\section{AGRADECIMENTOS}

À minha mãe, Ana Maria, e ao meu pai, Sebastião, por tudo que eu sou, pelo amor, apoio e dedicação em todos esses anos.

Aos meus irmãos, Marcelo e Marcos, aos meus primos, tios e aos demais membros agregados à minha família pelo incentivo e pelas infinitas colaborações para a minha formação pessoal e acadêmica.

Aos meus amigos, alguns de longe e outros de perto, por compartilhar sonhos, aflições, angústias, conquistas, choros e risos.

Ao meu orientador, Prof. Marcelo Montaño, Mindu, pela confiança que depositou no meu trabalho e pela participação e incentivo nos momentos de decisão sobre a minha vida profissional.

À Fundação de Amparo à Pesquisa do Estado de São Paulo (FAPESP) pelo apoio financeiro.

Aos técnicos dos órgãos ambientais de diferentes estados que contribuíram com o meu trabalho respondendo aos questionários e, especialmente, aos técnicos da Supram Sul de Minas e da Cetesb de São Paulo pela atenção, disponibilização dos estudos e fornecimento de informações, sem as quais não seria possível desenvolver este trabalho.

Enfim, a todas as pessoas que, de uma maneira ou de outra, contribuíram para o meu crescimento pessoal e profissional.

E a Deus por ter colocado estas pessoas no meu caminho e ter me dado a oportunidade de realizar este trabalho.

Meu singelo, muito obrigada! 

"O todo sem a parte não é todo, A parte sem o todo não é parte, Mas se a parte o faz todo, sendo parte, Não se diga, que é parte, sendo todo".

(Gregório de Matos) 



\section{RESUMO}

ALMEIDA, M. R. R. Aplicação da abordagem sistêmica para análise da efetividade da Avaliação de Impacto Ambiental no Brasil: um estudo para os estados de São Paulo e Sul de Minas Gerais. 2013. 172f. Tese (Doutorado em Ciências da Engenharia Ambiental) Escola de Engenharia de São Carlos, Universidade de São Paulo, São Carlos, 2013.

A Avaliação de Impacto Ambiental (AIA), uma ferramenta internacionalmente difundida e estabelecida, apresenta limitações em relação à influência que exerce sobre as decisões tomadas, que sugerem um baixo grau de efetividade para o instrumento. Nesse contexto, a análise de sua efetividade tem sido realizada a partir de diferentes abordagens, com prevalência de estudos focados em procedimentos específicos e/ou partes do processo de AIA, ou, ainda, orientados para a verificação do cumprimento de critérios ou diretrizes para sua aplicação. Diante de sua complexidade, sugere-se, então, que tanto a AIA quanto os fatores intervenientes em sua efetividade sejam compreendidos a partir de um enfoque mais amplo, que considere as relações existentes entre as etapas do processo, seus componentes e atores envolvidos. O desenho da pesquisa realizada se orienta por elementos desenvolvidos no campo da Teoria Geral dos Sistemas e, como tal, assume que as diferentes relações entre os componentes de sistemas complexos fazem emergir propriedades que condicionam o seu próprio funcionamento. Adotando-se como objeto de estudo os sistemas de AIA e licenciamento ambiental implementados nos estados de São Paulo e Minas Gerais (Sul de Minas), o presente trabalho é voltado para a identificação e discussão dos fatores intervenientes na efetividade da aplicação dos instrumentos envolvidos, a partir de um enfoque sistêmico. Dentre as ferramentas sistêmicas existentes foi escolhida a Soft Systems Methodology (SSM) - conhecida por fomentar o aprendizado dos atores envolvidos e aplicada a sistemas não quantificáveis como a AIA - para identificar as lacunas e propor ações para melhoria destes dois sistemas. Os resultados obtidos permitem apontar diferenças na organização e capacidade de resposta dos sistemas estudados, concentradas na estruturação do órgão ambiental, na definição do escopo, nas janelas de participação, na quantidade de atores envolvidos nas arenas de decisão e no tempo de trâmite dos processos. As principais limitações identificadas para os dois sistemas estão em consonância com o que aponta a literatura internacional, que incluem a participação, a consideração de alternativas para o projeto, a avaliação de efeitos cumulativos e a influência de fatores externos na tomada de decisão. A abordagem utilizada apresentou-se como interessante para avaliar os sistemas de 
AIA, contribuindo para um melhor entendimento de sua organização e funcionamento.

Palavras-chave: Avaliação de Impacto Ambiental. Licenciamento ambiental. Abordagem sistêmica. Indicadores de efetividade. 


\begin{abstract}
ALMEIDA, M. R. R. Application of the systems approach to analyze the effectiveness of Environmental Impact Assessment in Brazil: a study in the states of São Paulo and South of Minas Gerais. 2013. 172Pp. Doctoral thesis - Escola de Engenharia de São Carlos, Universidade de São Paulo, São Carlos, 2013.
\end{abstract}

Environmental Impact Assessment (EIA), an internationally widespread and established tool, has limitations with respect to its influence on decision-making, suggesting a low degree of effectiveness for the instrument. In this context, its effectiveness analysis has been carried out from different approaches, with a prevalence of studies focused on specific procedures and/or parts of the EIA process, or even targeted for the verification of compliance with criteria or guidelines for its implementation. Given its complexity, it is suggested, then, that both the EIA as intervening factors in its effectiveness are understood from a broader approach that considers the relationships between the steps of the process, its components and actors involved. The design of the research is guided by elements developed in the field of General Systems Theory and, as such, assumes that the different relationships between components of complex systems are emerging properties that determine its own functioning. Adopted as the study object the EIA and environmental licensing systems implemented in the states of São Paulo and Minas Gerais (Sul de Minas), the present work is focused on the identification and discussion of the factors involved in the effectiveness of the application of the instruments involved, based on a systemic approach. Among the existing systemic tools was chosen the Soft Systems Methodology (SSM ) - known to foster learning of the actors involved and applied to non-quantifiable systems like EIA - to identify gaps and propose actions for the improvement of these two systems. The results may point out differences in the organization and responsiveness of the studied systems, concentrated in environmental agency structuring, in the scope, in the participation windows, in the number of actors involved in the decision arenas and in the processes time. The main constraints identified for the two systems are in line with the international literature points, which include participation, consideration of project alternatives, the assessment of cumulative effects and the influence of external factors in decision-making. The approach presented as interesting to evaluate the EIA systems, contributing to a better understanding of its organization and operation.

Keywords: Environmental Impact Assessment. Environmental licensing. Systems approach. Effectiveness indicators. 



\section{LISTA DE FIGURAS}

Figura 1 - Processo de Avaliação de Impacto Ambiental

Figura 2 - Procedimento geral do licenciamento ambiental na fase de LP segundo a Resolução Conama ${ }^{\circ} 237 / 1997$

Figura 3 - Fases da "Soft Systems Methodology" (SSM). 49

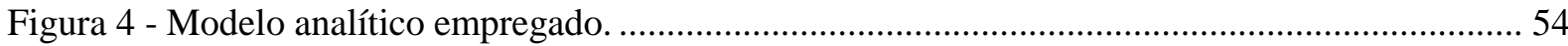

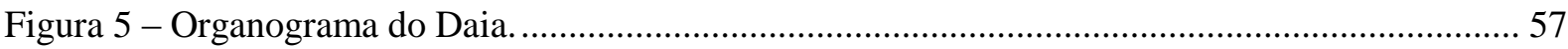

Figura 6 - Localização das Supram e suas respectivas sedes. ............................................................... 59

Figura 7 - Procedimentos comuns aos estados avaliados; em vermelho estão as etapas que apresentaram especificidades.

Figura 8 - Tipos de procedimentos para a definição do escopo dos estudos ambientais...................... 82

Figura 9 - Processo de Avaliação de Impacto Ambiental e Licenciamento Ambiental em SP. 88

Figura 10 - Critérios de classificação do empreendimento, segundo o potencial poluidor/degradador e o porte do empreendimento. 90

Figura 11 - Processo de Avaliação de Impacto Ambiental e Licenciamento Ambiental em MG 94

Figura 12 - (A) Aplicação dos indicadores de efetividade aos processos de SP cuja licença ambiental foi deferida. (B) Aplicação dos indicadores de efetividade aos processos de SP cuja licença ambiental foi indeferida ou o processo arquivado/paralisado. 96

Figura 13 - Tempo de tramitação dos processos de SP. 97

Figura 14 - (A) Aplicação dos indicadores de efetividade aos processos de licenciamento preventivo no Sul de MG. (B) Aplicação dos indicadores de efetividade aos processos de licenciamento corretivo no Sul de MG. 104

Figura 15 - Tempo de tramitação dos processos do Sul de MG. 105

Figura 16 - Rede de comunicação na Arena 1 de decisão em SP. 114

Figura 17 - Rede de comunicação na Arena 2 de decisão em SP. 115

Figura 18 - Rede de comunicação na Arena 3 de decisão em SP 116

Figura 19 - Rede de comunicação na Arena 4 de decisão em SP....................................................... 118

Figura 20 - Rede de comunicação na Arena 1 de decisão no Sul de MG............................................ 120

Figura 21 - Rede de comunicação na Arena 2 de decisão no Sul de MG........................................... 121

Figura 22 - Rede de comunicação na Arena 3 de decisão no Sul de MG........................................... 122

Figura 23 - Rede de comunicação na Arena 4 de decisão no Sul de MG............................................ 123

Figura 24 - Comparação entre as arenas de decisão de SP e Sul de MG............................................. 126 



\section{LISTA DE TABELAS}

Tabela 1 - Indicadores de efetividade aplicados na análise dos sistemas de AIA por diferentes autores .38

Tabela 2 - Deficiências nos Estudos de Impacto Ambiental. .42

Tabela 3 - Distribuição dos processos de licenciamento com EIA/Rima tramitados na Cetesb de 2004jan/2012 e dos processos analisados, de acordo com a tipologia do empreendimento. .63

Tabela 4 - Relação dos processos de licenciamento com EIA/Rima analisados no estado de SP.........64

Tabela 5 - Relação dos processos de licenciamento analisados no estado de MG (regional Sul)........66

Tabela 6 - Agrupamento dos indicadores de efetividade nas etapas do processo de Avaliação de

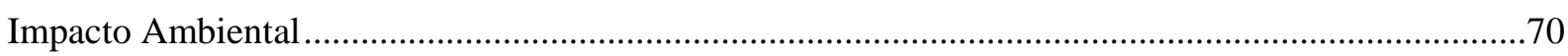

Tabela 7 - Conjunto de indicadores selecionados para a avaliação dos processos de licenciamento com

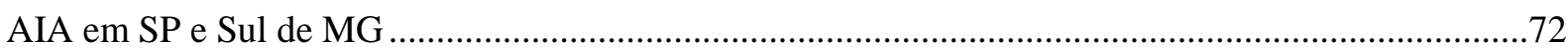

Tabela 8 - Modelo para a caracterização das arenas de decisão.........................................................76

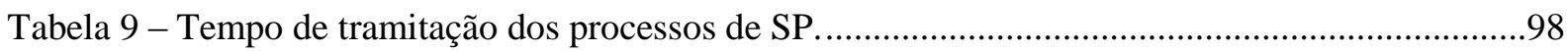

Tabela 10 - Tempo de tramitação dos processos do Sul de MG............................................................106

Tabela 11 - Características de competência e comunicação nas Arenas de decisão em SP. ...............119

Tabela 12 - Características de competência e comunicação nas Arenas de decisão no Sul de MG....124

Tabela 13 - Desafios e propostas da Abema para a melhoria do licenciamento ambiental no Brasil. 146 



\section{LISTA DE SIGLAS}

AAE - Avaliação Ambiental Estratégica

AAF - Autorização Ambiental de Funcionamento

Abema - Associação Brasileira de Entidades Estaduais de Meio Ambiente

AI - Área de influência

AIA - Avaliação de Impacto Ambiental

Aneel - Agência Nacional de Energia Elétrica

BA - Bahia

CATWOE - Costumers, Actors, Transformation process, Weltanschauung, Owners and Environmental constraints

CBRN - Coordenadoria de Biodiversidade e Recursos Naturais

CE - Ceará

CERH - Conselho estadual de Recursos Hídricos

Cetesb - Companhia Ambiental do Estado de São Paulo

CNI - Confederação Nacional da Indústria

Conama - Conselho Nacional de Meio Ambiente

Codema - Conselho Municipal de Meio Ambiente

CONDEPHAAT - Conselho de Defesa do Patrimônio Histórico, Arqueológico, Artístico e Turístico

Consema - Conselho Estadual do Meio Ambiente do Estado de São Paulo

Copam - Conselho Estadual de Política Ambiental de Minas Gerais

CPLEA - Coordenadoria de Planejamento Ambiental Estratégico e Educação Ambiental

DAEE - Departamento de Águas e Energia Elétrica

Daia - Departamento de Avaliação de Impacto Ambiental

Decont - Departamento de Controle da Qualidade Ambiental

DEPRN - Departamento Estadual de Proteção de Recursos Naturais

DIENI - Divisão de Infraestrutura, Energia e Irrigação

DN - Deliberação Normativa

DOE - Diário Oficial do Estado

DOE-MG -Diário Oficial do Estado de Minas Gerais

DNPM - Departamento Nacional de Produção Mineral

DUSM - Departamento de Uso do Solo Metropolitano 
EAS - Estudo Ambiental Simplificado

EIA - Estudo de Impacto Ambiental

ES - Espírito Santo

FCE - Formulário de Caracterização do Empreendimento

Feam - Fundação Estadual do Meio Ambiente

FIEB - Federação das Indústrias do Estado da Bahia

FOB - Formulário de Orientação Básica

Funai - Fundação Nacional do Índio

GRAPROHAB - Grupo de Análise e Aprovação de Projetos Habitacionais do Estado de São Paulo

IAIA - International Association for Impact Assessment (Associação Internacional para a Avaliação de Impactos)

Ibama - Instituto Brasileiro de Meio Ambiente e Recursos Renováveis

IC - informações complementares

ICMBio - Instituto Chico Mendes de Conservação da Biodiversidade

IEF - Instituto Estadual de Florestas

Igam - Instituto Mineiro de Gestão das Águas

$(\mathrm{IMP})^{3}$ - IMProving the IMPlementation of Environmental IMPact Assessment

Iphan - Instituto do Patrimônio Histórico e Artístico Nacional

IPT - Instituto de Pesquisas Tecnológicas

LA - Licenciamento Ambiental

LI - Licença de Instalação

LI+LO - Licença de Instalação concomitante com a Licença de Operação

LIC - Licença de Instalação Corretiva

LI+LO - Licença de Instalação concomitantemente com a Licença de Operação

LO - Licença de Operação

LOC - Licença de Operação Corretiva

LP - Licença Prévia

LP+LI - Licença Prévia concomitante com a Licença de Instalação

MCE - Memorial de Caracterização de Empreendimento

MG - Minas Gerais

MMA - Ministério de Meio Ambiente

MP - Ministério Público

MPF - Ministério Público Federal 
ONG - Organização não Governamental

ONU - Organização das Nações Unidas

PA - Pará

PAC - Programa de Aceleração do Crescimento

PCA - Plano de Controle Ambiental

PCH - Pequenas Centrais Hidrelétricas

PE - Pernambuco

PLURIS - Planejamento Urbano, Regional, Integrado e Sustentável

PNMA - Política Nacional de Meio Ambiente

PPG-SEA - Programa de Pós Graduação em Ciências da Engenharia Ambiental

PR - Paraná

PT - Plano de Trabalho

Rada - Relatórios de Avaliação do Desempenho Ambiental

RAP - Relatório Ambiental Preliminar

RAS - Relatório Ambiental Simplificado

RCA - Relatório de Controle Ambiental

Rima - Relatório de Impacto Ambiental

RS - Rio Grande do Sul

SEAQUA - Sistema Estadual de Administração da Qualidade Ambiental, Proteção, Controle e Desenvolvimento do Meio Ambiente e Uso Adequado dos Recursos Naturais

Semad - Secretaria de Estado do Meio Ambiente e Desenvolvimento Sustentável

Siam - Sistema Integrado de Informação Ambiental

Sisema - Sistema Estadual do Meio Ambiente e Recursos Hídricos de Minas Gerais

Sisnama - Sistema Nacional do Meio Ambiente

SMA - Secretaria de Meio Ambiente

SNA - Social Network Analysis (Análise da Rede Social)

SP - São Paulo

SSM - Soft Systems Methodology

SUPRAM - Superintendência Regional de Regularização Ambiental

SWOT - Strengths, Weaknesses, Opportunities and Threats (Forças, Fraquezas, Oportunidades e Ameaças)

TAC - Termo de Ajustamento de Conduta

TCU - Tribunal de Contas da União

TE - Teoria da Estruturação 
TGS - Teoria Geral dos Sistemas

TR - Termo de Referência

UC - Unidade de Conservação

URC - Unidade Regional Colegiada 


\section{SUMÁRIO}

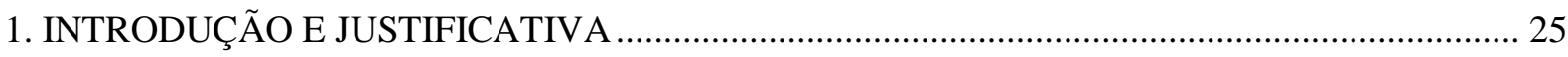

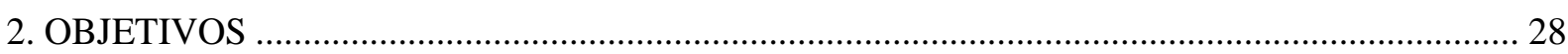

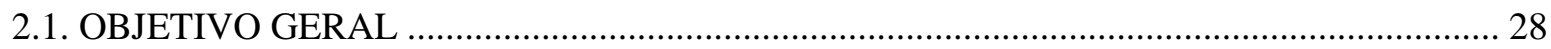

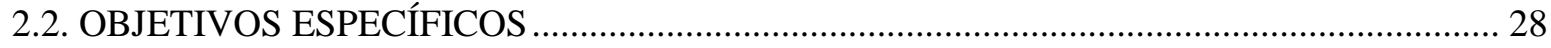

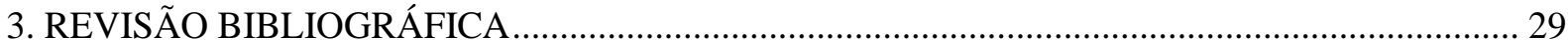

3.1. O PROCESSO DE AVALIAÇÃO DE IMPACTO AMBIENTAL ........................................... 29

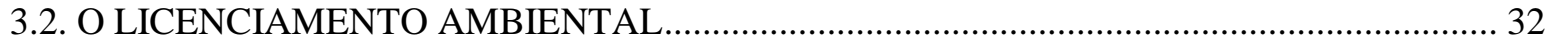

3.3. A EFETIVIDADE DA AVALIAÇÃO DE IMPACTO AMBIENTAL ..................................... 34

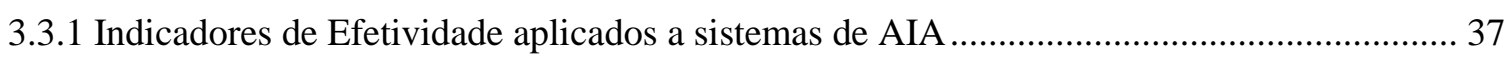

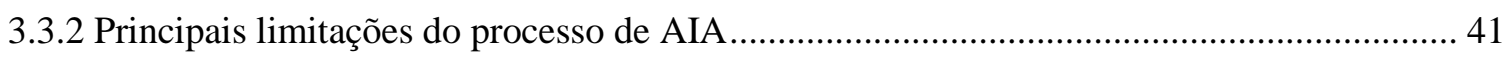

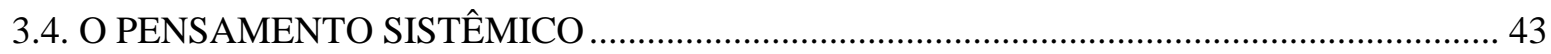

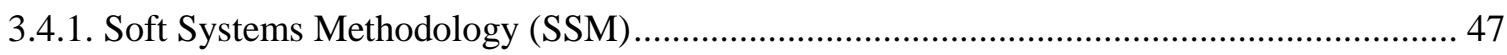

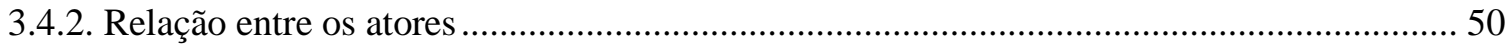

3.5. A ABORDAGEM SISTÊMICA APLICADA À AVALIAÇÃO DE IMPACTO AMBIENTAL 52

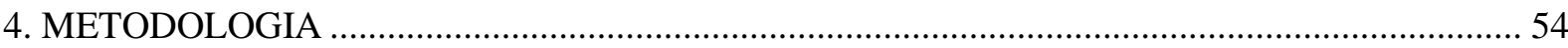

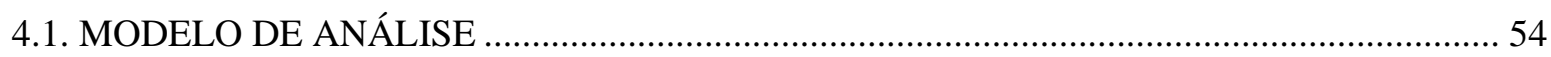

4.2. CARACTERIZAÇÃO DOS OBJETOS DE ESTUDO: OS ÓRGÃOS AMBIENTAIS DE SÃO

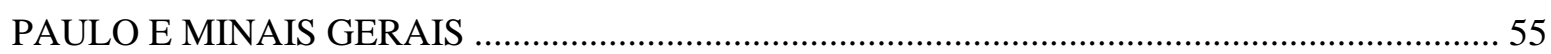

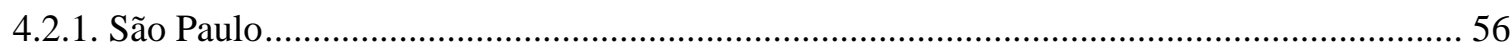

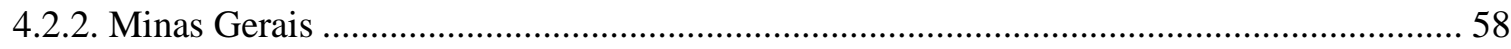

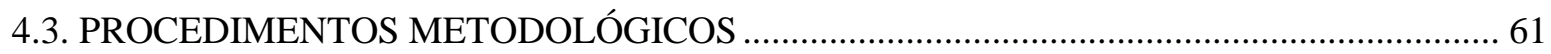

4.3.1. Levantamento do quadro geral de aplicação da AIA no Brasil ............................................. 61

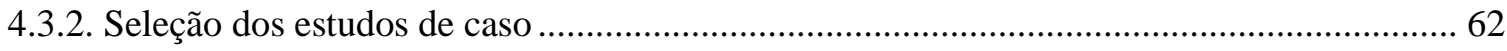

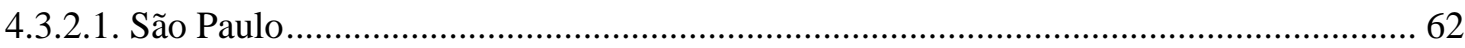

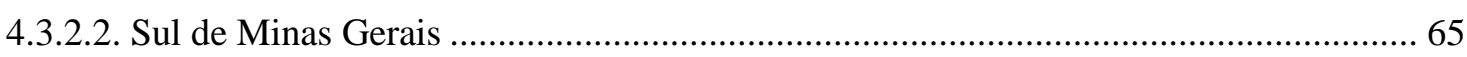

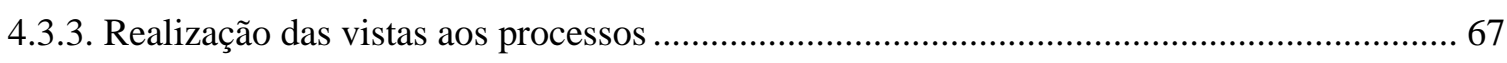

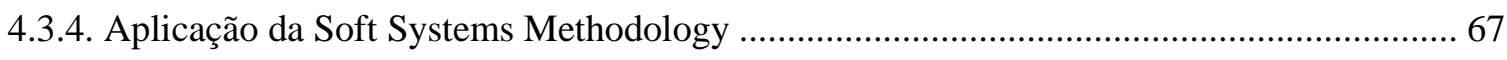

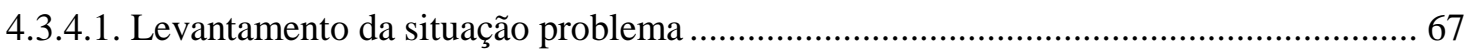

a) Procedimentos de licenciamento com Avaliação de Impacto Ambiental nos estados de

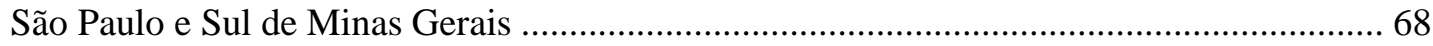

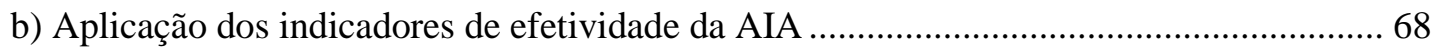

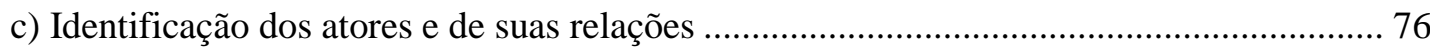


d) Análise de conteúdo aplicada à documentação encontrada nos processos analisados. ..... 77

4.3.4.2. Identificação de modelos relevantes para a situação proposta ........................................ 77

4.3.4.3. Comparação da situação problema com o modelo .......................................................... 77

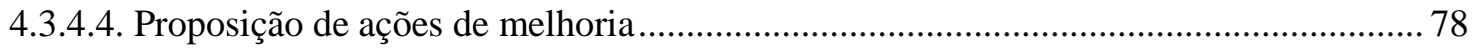

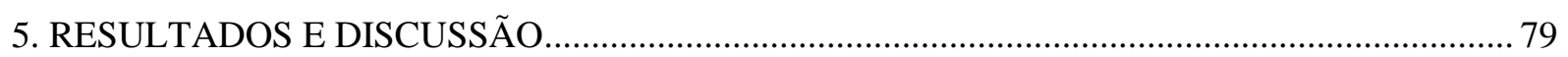

5.1. QUADRO GERAL DO LICENCIAMENTO COM AIA NO BRASIL ..................................... 79

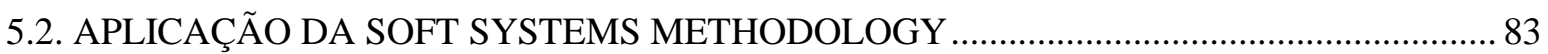

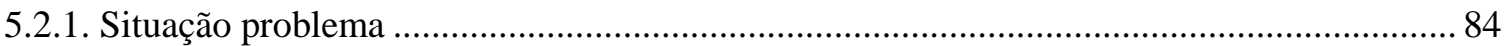

5.2.1.1. Procedimentos de licenciamento com Avaliação de Impacto Ambiental nos estados de

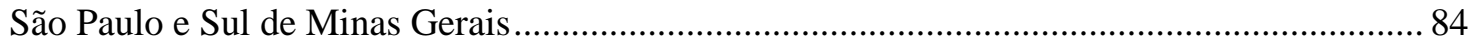

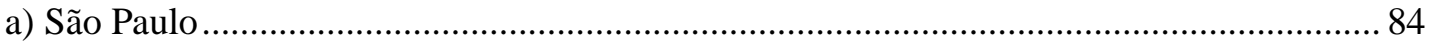

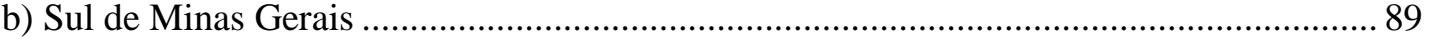

5.2.1.2. Aplicação dos indicadores de efetividade....................................................................... 94

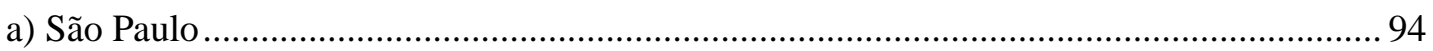

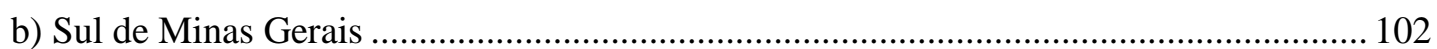

c) Considerações sobre as diferenças e semelhanças entre SP e Sul de MG ........................ 110

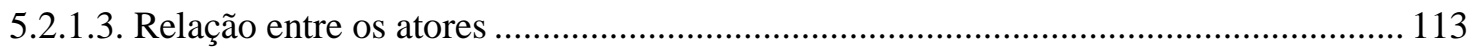

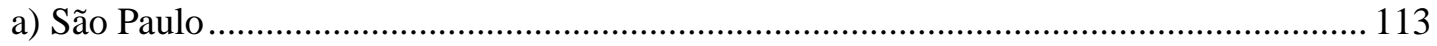

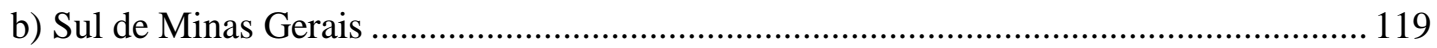

c) Considerações sobre as diferenças nas arenas de decisão em SP e Sul de MG................ 124

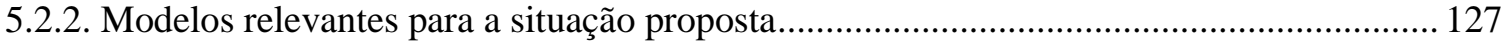

5.2.3. Comparação da situação problema com o modelo ............................................................. 132

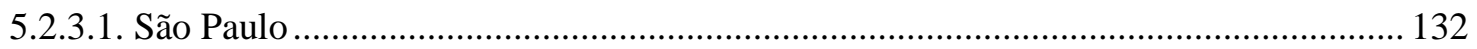

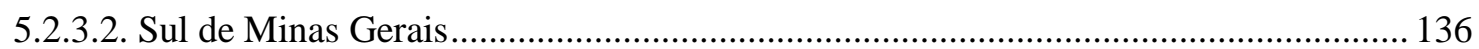

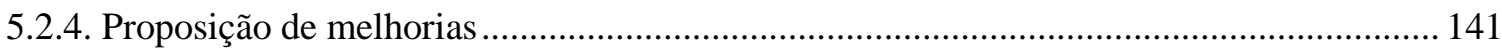

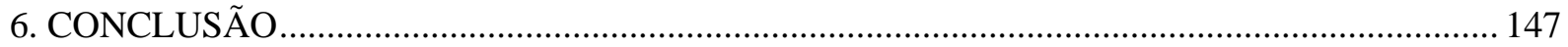

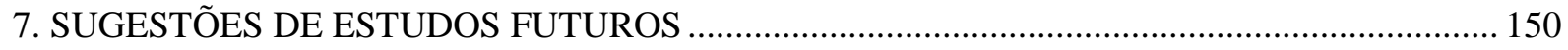

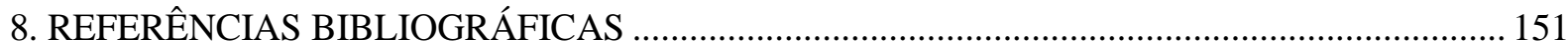

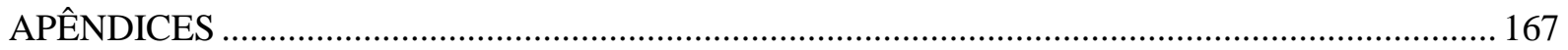




\section{INTRODUÇÃO E JUSTIFICATIVA}

A Avaliação de Impacto Ambiental (AIA) é uma ferramenta internacionalmente aceita e estabelecida (JAY et al., 2007; SÁNCHEZ, 2008), constituindo o instrumento de verificação dos efeitos da ação antrópica sobre o meio mais amplamente empregado no mundo: 191 dos 193 membros das Nações Unidas têm legislação que refira ao uso da AIA (MORGAN, 2012). Introduzida em 1969 nos Estados Unidos, a AIA compreende o processo de identificar, prever, avaliar e mitigar os efeitos relevantes de natureza biofísica, social e outros efeitos de atividades ou projetos de desenvolvimento, antes que decisões importantes sejam tomadas (IAIA, 1999).

A introdução da AIA no Brasil remonta ao contexto estabelecido após a primeira reunião sobre meio ambiente promovida pela Organização das Nações Unidas (ONU), em Estocolmo (1972), em que os efeitos sobre o ambiente passam a ser considerados efetivamente nocivos para o desenvolvimento dos países e, portanto, haveriam de ser controlados. O mesmo contexto também envolve as instituições e agências multilaterais de desenvolvimento que, pressionadas pela opinião pública após sucessivas notícias de impactos significativos causados por projetos apoiados por tais instituições, passaram a adotar regulamentos e requisitos para a verificação dos possíveis efeitos ambientais negativos decorrentes dos projetos em financiamento.

A partir de então, reproduzindo um processo que se verifica em muitos países, a AIA passa para o corpo institucional brasileiro - inicialmente em alguns estados pioneiros como o Rio de Janeiro, Minas Gerais e São Paulo até que, finalmente, atinge o status de instrumento de política ambiental e passa a orientar a atuação dos órgãos de controle ambiental no Brasil. Na esfera da União sua introdução ocorreu com a promulgação da Lei Federal nº 6.938 de 1981, ocasião em que a AIA e o licenciamento ambiental foram incluídos entre os instrumentos da Política Nacional do Meio Ambiente (PNMA), sendo regulamentados pelo Decreto Federal $n^{\circ}$ 99.274 de 1990 e pelas Resoluções Conama nº 01 de 1986 e n 237 de 1997.

Apesar de seus mais de 40 anos de prática institucionalizada ao redor do planeta, do potencial de utilização que apresenta e mesmo levando-se em conta os inúmeros benefícios que a AIA inegavelmente tem trazido para o processo de desenvolvimento, muitas críticas são feitas quanto à eficácia de seus procedimentos (conforme, por exemplo, MORGAN, 2012) amparadas, sobretudo, pelo distanciamento verificado entre teoria e prática. 
Diversos estudos têm sido realizados para avaliar a efetividade da AIA, contribuindo para que os resultados obtidos sejam continuamente analisados, proporcionando aprendizagem para os envolvidos no processo e sendo importante para o aprimoramento contínuo desse instrumento (AGRA FILHO; MARINHO; SANTOS, 2007). Contudo, o objetivo da maioria destes estudos concentra-se na análise de somente parte do processo e/ou procedimentos, como são os casos de Canelas et al. (2005), Peterson (2010) e Badr, Zahran e Cashmore (2011) que concentraram sua análise na qualidade dos estudos ambientais; Rajadam e Das (2011) que avaliaram a etapa de triagem; Nadeem e Fischer (2011) que preocuparam-se com a participação, entre outros; ou na simples verificação do cumprimento de critérios contidos em guias e roteiros metodológicos - trabalhos como o de Ahmad e Wood (2002), Badr (2009) e Marara et al. (2011) - que muitas vezes não contemplam sequer as melhores práticas para o instrumento. Ainda, existem indícios de que parte das deficiências encontradas por estes trabalhos são advindas das relações entre as etapas do processo e entre os atores envolvidos, como por exemplo, a má qualidade dos estudos de impacto ambiental pode estar relacionada a deficiências na etapa de triagem e/ou escopo (ALMEIDA, 2010).

Por sua complexidade e capacidade de interferir na tomada de decisão, a AIA não admite ser compreendida de modo reducionista, como um instrumento que opera tão somente a partir de um conjunto de procedimentos. Algumas características da AIA, relacionadas ao arranjo entre suas etapas, permitem visualizar o instrumento como um sistema, alinhando-se com a descrição de Kast e Rosenweig (1987) de que sistema seria um todo complexo.

Portanto, parece plausível recorrer ao campo da Teoria Geral dos Sistemas para abordar a AIA de modo a considerar as múltiplas possibilidades de interação entre suas partes, assumindo a concepção de que "o todo possui propriedades que não podem ser explicadas em termos de seus constituintes individuais" (CHRISTOFOLETTI, 1989, p. 4). No todo surgem propriedades, denominadas de emergentes, que, conforme Checkland (1999), não podem ser deduzidas do estudo e observação das partes isoladas tendo em vista que se estabelecem a partir das diferentes relações entre os componentes do sistema, condicionando seu próprio funcionamento.

Dentro do conjunto de metodologias com enfoque sistêmico está a Soft Systems Methodology (SSM) que tem sido desenvolvida para aplicação em sistemas não quantificáveis como a AIA. A SSM ajuda o tomador de decisão a lidar com problemas complexos por meio de uma modelagem qualitativa, que permite explorar as diferentes visões sobre o problema, determinar pontos importantes e guiar a discussão sobre o assunto (ACCIOLY; FIGUEIREDO, 2011). 
Frente à necessidade de aperfeiçoamento das metodologias e abordagens aplicados em estudos relacionados à efetividade da AIA, inclusive em âmbito internacional, e tendo em vista a escassez de trabalhos neste campo no Brasil, entende-se como pertinente o objetivo da presente tese de Doutorado, que se propõe a explorar a abordagem sistêmica para o estudo da efetividade da Avaliação de Impacto Ambiental no Brasil.

Para este fim, foram analisados os sistemas de AIA e licenciamento ambiental estabelecidos nos estados de São Paulo (SP) e Minas Gerais (MG). No caso de São Paulo, a análise foi concentrada na atuação do Departamento de Avaliação de Impacto Ambiental (Daia) da Companhia Ambiental do Estado de São Paulo (Cetesb); para Minas Gerais, o foco se deu na Superintendência Regional de Regularização Ambiental (Supram) Sul de Minas. 


\section{OBJETIVOS}

\subsection{OBJETIVO GERAL}

Análise da efetividade dos sistemas de licenciamento com Avaliação de Impacto Ambiental no Brasil a partir da abordagem sistêmica, com enfoque nos estados de São Paulo e Minas Gerais/Sul de Minas.

\subsection{OBJETIVOS ESPECÍFICOS}

- Delimitação do quadro geral dos procedimentos de AIA e licenciamento no Brasil, a partir da descrição dos sistemas estaduais e federal, procurando-se situar os sistemas de SP e MG/Sul de Minas no conjunto de especificidades e similaridades encontradas;

- Compreensão das estruturas de organização e funcionamento dos sistemas de AIA e licenciamento dos estados de São Paulo e Minas Gerais/Sul de Minas para identificação dos fatores intervenientes na efetividade da aplicação dos instrumentos;

- Identificação de lacunas e proposição de ações para melhoria do desempenho dos sistemas de licenciamento com AIA dos estados de São Paulo e Sul de Minas Gerais. 


\section{REVISÃO BIBLIOGRÁFICA}

\subsection{O PROCESSO DE AVALIAÇÃO DE IMPACTO AMBIENTAL}

A AIA é um instrumento de política ambiental capaz de assegurar, desde o início do processo, que se faça um exame sistemático dos impactos ambientais de uma ação proposta e de suas alternativas (MOREIRA, 1992). Sendo o impacto ambiental entendido como a mudança em um parâmetro ambiental, num determinado período e numa determinada área, que resulta de uma dada atividade, comparada com a situação que ocorreria se essa atividade não tivesse sido iniciada (WATHERN,1988).

Para cumprir seu papel, a AIA conta com um conjunto de procedimentos concatenados (Figura 1), onde uma etapa acaba por ter influência nas seguintes. O processo é iniciado com a apresentação da proposta de projeto pelo empreendedor diante de uma organização responsável pela tomada de decisão, que pode ser uma empresa privada, um organismo financeiro, uma agência de desenvolvimento ou um órgão governamental; sendo este último o caso mais geral (SÁNCHEZ, 2008) e onde se insere o processo de licenciamento ambiental. Uma vez conhecida a proposta, pode-se estimar seu potencial de causar impacto, o que é função do potencial poluidor do empreendimento (relacionado às exigências que o tipo de projeto faz ao meio onde será implantado e do porte) e da resiliência ${ }^{1}$ do meio em que ele será inserido.

A triagem, realizada pelo órgão ambiental, pode ser definida como o procedimento para determinar se a proposta deverá ou não estar sujeita a AIA, e em caso afirmativo, a que nível de detalhe (IAIA, 1999). No caso de negativa, o projeto passa para o que Sánchez (2008) se refere como um "licenciamento ambiental convencional" ou simplificado, sem utilização de AIA. Os critérios utilizados no julgamento da significância de impactos podem ser objetivos (pré-determinados) ou subjetivos (CANTER; CANTY, 1993) e são baseados em listas positivas, listas negativas, critérios de corte (relativos ao porte dos empreendimentos), localização do empreendimento, recursos ambientais potencialmente afetados e na análise caso a caso.

\footnotetext{
${ }^{1}$ Resiliência é a capacidade de tolerar e absorver mudanças, mantendo sua estrutura e seu padrão geral de comportamento.
} 


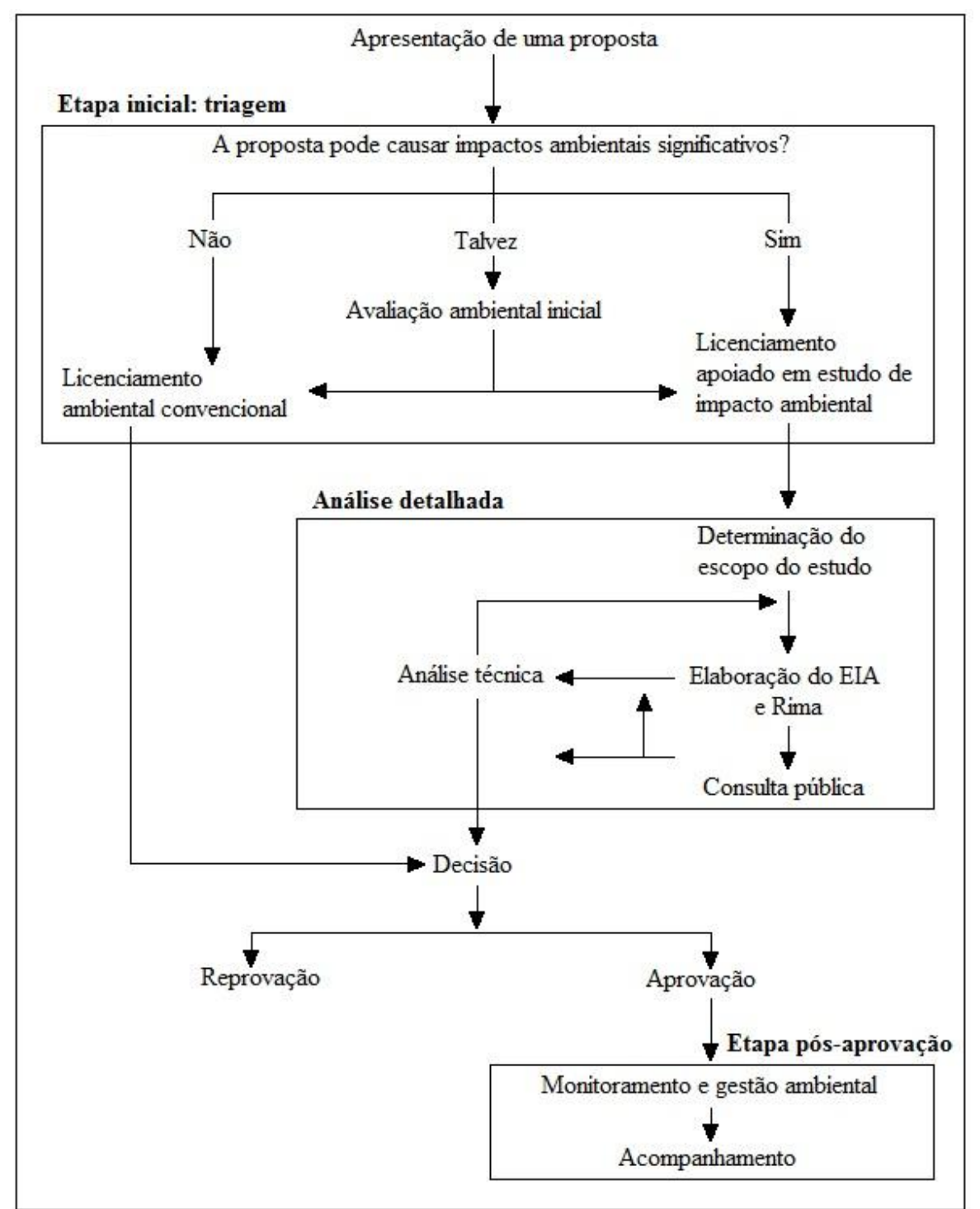

Figura 1 - Processo de Avaliação de Impacto Ambiental.

Fonte: SÁNCHEZ (2008).

$\mathrm{Na}$ fase de escopo são determinadas a profundidade e a abrangência do estudo a ser apresentado, caso na triagem seja verificada a necessidade de elaboração de estudo ambiental detalhado. A delimitação do âmbito é um processo de adição e remoção de uma lista de questões a serem consideradas na avaliação, como fatores ambientais do diagnóstico, impactos, medidas ambientais. Culmina com a elaboração de um Termo de Referência (TR) por parte do órgão ambiental, contendo os tópicos a serem abordados no estudo ambiental.

O princípio para a elaboração de um Estudo de Impacto Ambiental (EIA), ou outro tipo de estudo, é simples, mas deve apresentar uma síntese clara e concisa da caracterização do empreendimento, condição do meio onde será implantado o projeto, prováveis impactos ambientais, propostas de medidas de mitigação, importância dos impactos residuais e 
sugestões para a necessidade de estudos de acompanhamento (ROSS; MORRISONSAUNDERS; MARSHALL, 2006), devendo ser elaborado por equipes multidisciplinares.

A análise técnica é, mais comumente, realizada pelo órgão (ou órgãos) ambiental do governo responsável pelo licenciamento do empreendimento. Tem como objetivo verificar e determinar se o estudo de impacto ambiental é uma avaliação adequada de relevância dos impactos ambientais a serem causados pelo projeto e se existe qualidade suficiente para a tomada de decisões (EPA, 2003).

A participação do público de alguma forma deve ser considerada tanto na realização adequada e justa de um governo democrático como nas atividades de tomada de decisão (SHEPHERD; BOWLER, 1997) e, assim, como um componente fundamental do processo de AIA (HARTLEY; WOOD, 2005). Uma das formas de participação presentes na legislação brasileira é a audiência pública na fase de análise dos estudos. A audiência pública é uma reunião que tem por finalidade expor aos interessados as informações e os resultados obtidos pelo EIA/Rima sobre uma obra ou atividade potencialmente causadora de significativo impacto ambiental, dirimindo dúvidas e recolhendo dos presentes críticas e sugestões a respeito para subsidiar a decisão quanto ao seu licenciamento ambiental (CONAMA, 1987).

A decisão resultante do processo de AIA diz respeito à viabilidade ambiental do projeto da maneira como ele foi proposto em termos de sua concepção tecnológica e localização. Atestar a viabilidade ambiental dos projetos previamente à sua implantação constitui a finalidade precípua da AIA associada ao licenciamento como instrumentos de política e gestão do meio ambiente (MONTAÑO; SOUZA, 2008). Comprovada a viabilidade do projeto, ele pode ser aprovado e obter as licenças necessárias para sua implantação e operação.

Uma vez implantado, acontecem as etapas pós-aprovação (que envolvem o monitoramento e o acompanhamento). O objetivo geral do monitoramento é determinar se os impactos reais de um projeto proposto correspondem aos impactos previstos no EIA (BADR, 2009) e se as medidas propostas são suficientes para mitigação dos impactos. Além disso, visa assegurar a implementação da atividade de forma satisfatória e promover ajustes e correções necessárias nos procedimentos.

Por sua vez, o acompanhamento é realizado pelo órgão ambiental a fim de verificar os compromissos assumidos pelo empreendedor, quando da implantação do empreendimento, e para validar a licença ambiental emitida, caso o empreendimento persista na condição de adequado e viável ambientalmente. 


\subsection{O LICENCIAMENTO AMBIENTAL}

A Avaliação de Impacto Ambiental no Brasil foi considerada, de acordo com a Lei Federal $\mathrm{n}^{\circ}$ 6.938/1981, um instrumento da Política Nacional do Meio Ambiente. Sua função é oferecer informações que subsidiem a tomada de decisão quanto à viabilidade ambiental de projetos a serem implantados, já que examina as consequências futuras de uma ação proposta (SÁNCHEZ, 2008). Em sua utilização no Brasil, o emprego da AIA está associado ao licenciamento ambiental, servindo a AIA como suporte para a emissão das licenças ambientais nos casos de empreendimentos com potencial de causar significativo impacto ambiental. Em outras palavras, a emissão das licenças ambientais para empreendimentos com potencial de causar impacto significativo está condicionada aos resultados do processo de AIA.

O licenciamento ambiental é

"o procedimento administrativo pelo qual o órgão ambiental competente licencia a localização, instalação, ampliação e a operação de empreendimentos e atividades poluidoras ou daquelas que, sob qualquer forma, possam causar degradação ambiental, considerando as disposições legais e regulamentares e as normas aplicáveis ao caso" (CONAMA, 1997).

É um procedimento burocrático necessário, pois permite ao Estado regular as condições para que uma empresa inicie ou desenvolva uma atividade, ao mesmo tempo em que limita os seus eventuais efeitos negativos (CERQUEIRA; ALVEZ, 2010). Pode ser considerado o mais importante mecanismo de controle do poder público com relação às atividades econômicas que interferem fortemente no meio ambiente (COSTA; MARTINS; PEGADO, 2009).

As principais legislações federais, atualmente, introdutoras e reguladoras do licenciamento ambiental são a Lei Federal n 6.938/1981 (PNMA), o Decreto Federal nº 99.274 de 1990, a Resolução Conama n 237/1997 e a Lei Complementar n 140/2011.

A PNMA tem sua importância, pois além de estabelecer o licenciamento e a revisão de atividades efetiva ou potencialmente poluidoras como um de seus instrumentos, estabelece em seu Art. 10:

"A construção, instalação, ampliação e funcionamento de estabelecimentos e atividades utilizadores de recursos ambientais, efetiva ou potencialmente poluidores ou capazes, sob qualquer forma, de causar degradação ambiental dependerão de prévio licenciamento ambiental" (BRASIL, 1981). 
Porém, é a Resolução Conama $n^{\circ}$ 237/1997 que vai regulamentar o processo de licenciamento ambiental brasileiro. Além de trazer definições, esta resolução lista os empreendimentos sujeitos ao licenciamento, estabelece prazos e validade das licenças, elenca as etapas envolvidas no processo (Figura 2) e estipula as competências (complementada pelo que rege a Lei Complementar $n^{\circ}$ 140/2011), enumerando as atividades que devem ser licenciadas pela União, Estados e Municípios. Ainda, estabelece três tipos de licença ambiental:

- Licença Prévia (LP): concedida na fase de planejamento da atividade ou empreendimento e quando expedida aprova a localização e a concepção do projeto, atestando a sua viabilidade ambiental e estabelecendo os requisitos básicos e condicionantes para as próximas fases.

- Licença de Instalação (LI): autoriza a instalação do empreendimento ou atividade de acordo com as especificações constantes dos planos, programas e projetos aprovados, incluindo as medidas de controle ambiental, e demais condicionantes, da qual constituem motivo determinante; é emitida uma vez cumprida as condicionantes estipuladas pela LP.

- Licença de Operação (LO): autoriza a operação da atividade ou empreendimento, após a verificação do efetivo cumprimento do que consta das licenças anteriores, com as medidas de controle ambiental e condicionantes determinadas para a operação.

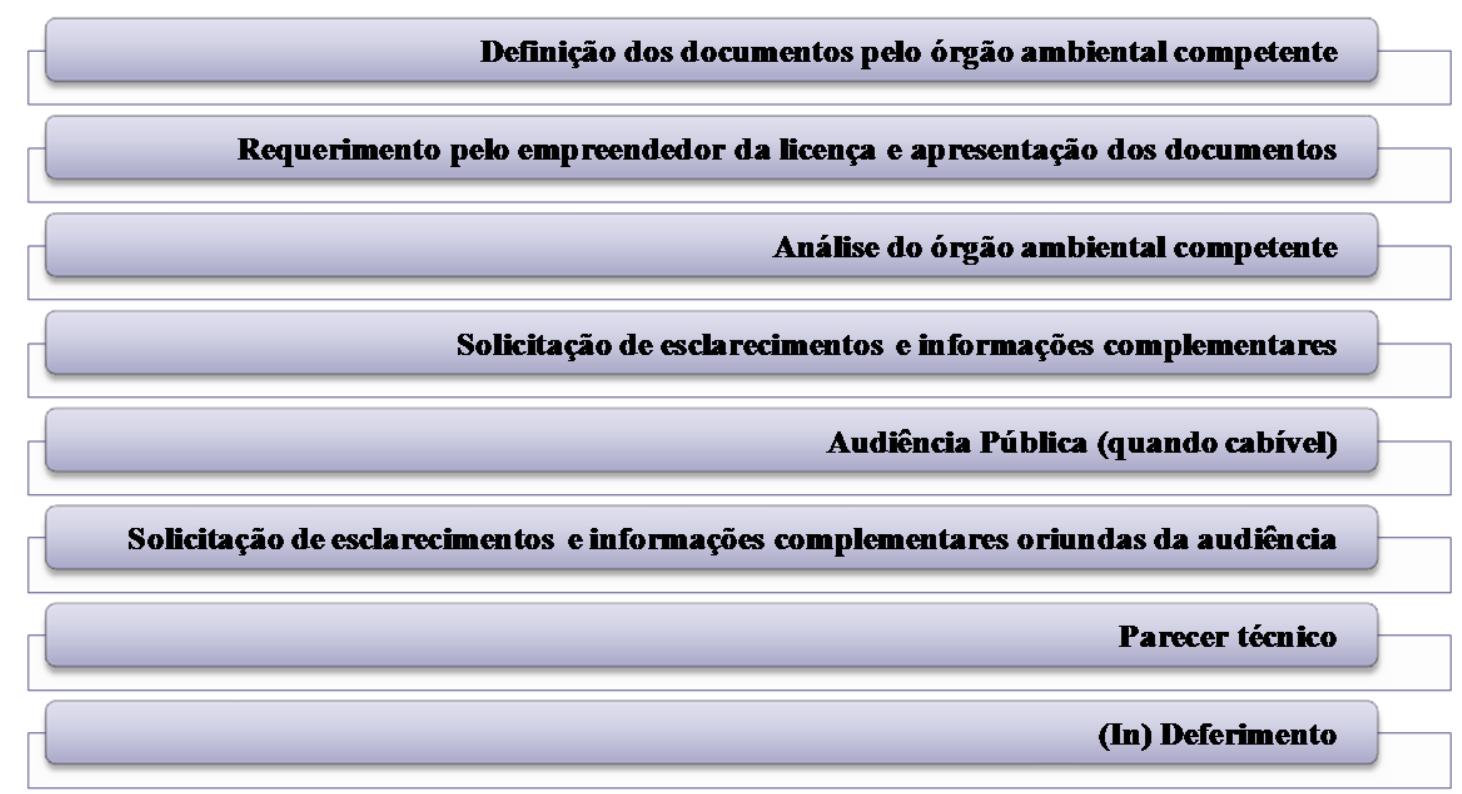

Figura 2 - Procedimento geral do licenciamento ambiental na fase de LP segundo a Resolução Conama ${ }^{\circ}$ 237/1997. 


\subsection{A EFETIVIDADE DA AVALIAÇÃO DE IMPACTO AMBIENTAL}

Todo instrumento após sua aplicação precisa passar por um processo de verificação da efetividade de sua prática. O que é muito relevante no caso da AIA, já que ela é um processo intrinsecamente complexo e talvez, por isso, sua implementação não seja inteiramente satisfatória (MOON, 1998).

Neste trabalho, foi utilizado o conceito de efetividade proposto por Sadler (1996) e reafirmado por outros autores como Macintosh (2010), no qual a efetividade da Avaliação de Impacto Ambiental pode ser compreendida em termos procedimentais, substantivos e transactivos (em tradução livre do termo em inglês transactive). A efetividade procedimental (ou processual) avalia se a AIA é realizada em conformidade com princípios de boas práticas enquanto que a efetividade substantiva observa se a AIA está atingindo seus objetivos, influenciando a tomada de decisões ou alterando os resultados ambientais do projeto. E, por fim, a efetividade transactiva relacionada à finalização do processo de AIA com o menor custo e no menor tempo possível para uma dada situação.

A maior parte da literatura aborda questões processuais/procedimentais, com uma proporção muito menor focada em questões substantivas: ambas são importantes na avaliação da efetividade global, mas os aspectos processuais são mais passíveis de estudo e análise, enquanto considerações substantivas levantam questões mais difíceis (CASHMORE et al., 2004).

Os estudos realizados sobre a efetividade da AIA podem se concentrar apenas nas etapas do processo ou analisar se o sistema cumpre determinados critérios frente às regulamentações e melhores práticas. Se um sistema de AIA não atender a uma parcela significativa dos critérios de avaliação não gera os benefícios a que se destina na proteção do ambiente (WOOD, 2003).

Um dos casos mais comuns é analisar a efetividade da AIA a partir da qualidade dos estudos ambientais: Ministèrie de L'environnement (1985) na França; Lee e Brown (1992), European Comission (1996) e Hickie e Wade (1998) no Reino Unido; Lee e Dancey (1993) na Irlanda; Pardo (1997) na Espanha; Mwalyosi e Hughes (1998) na Tanzânia; Steinemann (2001) nos Estados Unidos; Canelas et al. (2005) na Espanha e Portugal; Androulidakis e Karakassis (2006) na Grécia; Pinho, Maia e Monterosso (2007) em Portugal; Agra Filho (1993) e Omena e Santos (2008) no Brasil; Sandham e Pretorius (2008) na África do Sul; Peterson (2010) na Estônia; e Badr, Zahran e Cashmore (2011) no Egito. 
Ainda, as pesquisas podem envolver a análise de partes dos estudos ambientais, como previsões de impactos (WOOD; DIPPER; JONES, 2000), efeitos cumulativos dos impactos (WÄRNBÄC; HILDING-RYDEVIKA, 2009), implementação das medidas mitigadoras (PRADO FILHO; SOUZA, 2004), entre outras; e na análise de etapas do processo: triagem (RAJARAM; DAS, 2011), participação pública (FURIA; WALLACE-JONES, 2000; ROTHMAN, 2001; BAKER; MCLELLAND， 2003; ALMER; KOONTZ， 2004; O'FAIRCHEALLAIGH, 2010; NADEEM; FISCHER, 2011), monitoramento (AHAMMED; NIXON, 2006) e tempo gasto entre etapas (MIDDLE; MIDDLE, 2010).

As pesquisas que se propõem a analisar o sistema de AIA como um todo tem sido conduzidas com base em diferentes procedimentos metodológicos. Alguns deles, de interesse para a elaboração do desenho da presente pesquisa, são apresentados brevemente a seguir.

Wende (2002) utilizou testes estatísticos para avaliar a hipótese de que a AIA é capaz de promover alterações espaciais no empreendimento que favorecem a proteção ambiental, procurando identificar quais fatores apresentam maior relevância na efetividade da AIA. Este trabalho considerou a efetividade em termos substantivos, focando no grau de consideração dos resultados do estudo ambiental na tomada de decisão e das modificações técnicas e especiais devido às exigências da AIA.

A identificação de forças e fraquezas (análise SWOT: Strengths, Weaknesses, Opportunities and Threats ou Forças, Fraquezas, Oportunidades e Ameaças.) foi utilizada no sistema de AIA da Índia para descrever a situação do arranjo institucional, administrativo e processual implantado (PALIWAL, 2006); e na Lituânia para caracterizar a prática da AIA e prover recomendações para futuras melhorias (KRUOPIENE்;ŽIDONIENĖ; DVARIONIENE், 2009).

Uma análise descritiva da AIA foi realizada por Zubair (2001) no Sri Lanka, apoiando-se em 500 processos. A análise descritiva também foi utilizada por Kakonge (2006) na Gâmbia e por Pölönen, Hokkanen e Jalava (2011) na Finlândia.

Morrison-Saunders e Bailey (2009) analisaram a efetividade do processo de AIA através da análise das relações entre consultores e reguladores, verificando como era a abertura, cooperação, comunicação e negociação entre eles.

Por sua vez, Jalava et al. (2010) basearam-se em uma listagem de questões de melhores práticas para analisar a qualidade dos estudos e o sistema de AIA finlandês; as questões foram respondidas segundo a opinião de especialistas. Botetzagias (2008) desenvolveu e aplicou um questionário para analisar o sistema de AIA e auditoria da Grécia através da visão de pessoas que trabalham na área. 
O método da triangulação (revisão de literatura - questionários - entrevistas) foi usado pelo projeto "IMProving the IMPlementation of Environmental IMPact Assessment" (IMP) ${ }^{3}$ para reunir os dados necessários à avaliação da AIA na União Europeia, a partir de várias fontes: a revisão da literatura constitui a base do triângulo e os lados cobrem as ferramentas de comunicação com os proponentes e executores da AIA (questionários e entrevistas) (PINHO; MCCALLUM; CRUZ, 2010). Assim, o (IMP) ${ }^{3}$ lida com três tipos diferentes de dados qualitativos: base jurídica e discussões científicas relevantes à AIA e aplicação da política, como previsto na literatura; provenientes da análise de questionários sobre a aplicação efetiva da AIA nos estados-Membros; e sobre a avaliação dos pontos fortes e fracos da aplicação da AIA, adquirida a partir da análise das entrevistas (PINHO; MCCALLUM; CRUZ, 2010).

Heinma e Põder (2010) caracterizaram a eficácia do sistema de AIA da Estônia quantificando a porcentagem de projetos com significativo efeito ambiental implementados sem AIA e a frequência relativa dos projetos que passaram por este processo, mas onde ela não teve nenhuma influência sobre a tomada de decisão.

No Brasil, o Tribunal de Contas da União (TCU) publicou em 2008 o resultado de uma auditoria do sistema operacional de licenciamento ambiental federal (LIMA; MAGRINI, 2010). O objetivo era ajudar a melhorar os mecanismos de revisão e aprovação de licenças ambientais, vital para a economia nacional. A metodologia envolveu a aplicação de técnicas como mapeamento de processos, análise SWOT, entrevistas, questionários, visitas de inspeção, acompanhamento das audiências públicas e análise de documentos. Após a análise SWOT, os questionários foram elaborados e enviados para os órgãos ambientais de todos os 27 estados brasileiros e entrevistas foram realizadas com diretores e especialistas de entidades públicas e privadas e universidades.

Na pesquisa de Macintosh (2010), as informações foram obtidas através da análise de processos por critérios extensamente utilizados, avaliação de documentos e entrevistas com atores do processo de AIA, principalmente aqueles ligados ao órgão governamental. $\mathrm{O}$ autor destaca que esta abordagem multifacetada permitiu-lhe obter maior profundidade de informações sobre os fatores causais e aumento da confiabilidade dos resultados. A desvantagem, entretanto, é que esta abordagem é intensiva em recursos, o que limita o número de projetos que podem ser estudados. Diante de sua experiência, o autor destacou que a realização de entrevistas pela Internet forneceu uma série de benefícios: conveniência para os inquiridos, redução do tempo de resposta, eliminação de qualquer risco de parcialidade na elaboração das respostas (problema comum em entrevistas por telefone e face a face) e diminuição dos custos para o levantamento dos dados. 
Em muitos casos, as entrevistas aplicadas nos estudos anteriormente descritos envolvem a participação de diferentes atores, como acadêmicos, consultores elaboradores de estudos ambientais, funcionários dos órgãos ambientais, funcionários de agências financiadoras e grupos de interesse. Esta variedade de entrevistados ajuda a melhor compreender as diferentes perspectivas da AIA e minimizar o viés de um grupo em particular (MARARA et al., 2011).

\subsubsection{Indicadores de Efetividade aplicados a sistemas de AIA}

Outro modo recorrentemente encontrada na literatura para abordar a efetividade da AIA é através da aplicação de listas de verificação a partir de um conjunto de critérios ou indicadores a serem avaliados.

Os indicadores de efetividade utilizados para avaliar os sistemas de AIA mais descritos na literatura são os propostos por Ahmad e Wood (2002). Estes autores unificaram e propuseram estes critérios tendo como base trabalhos anteriores e utilizando-os para analisar comparativamente os sistemas de AIA de três jurisdições do centro leste e norte da África Egito, Turquia e Tunísia. A partir daí, estes indicadores foram utilizados para avaliar os sistemas de AIA em países do Oriente Médio e Norte da África (EL-FADL; EL-FADEL, 2004); no Paquistão (NADEEM; HAMEED, 2008); novamente no Egito (BADR, 2009); e na Colômbia (TORO; REQUENA; ZAMORANO, 2010). Algumas adaptações destes indicadores foram feitas por Zeremariam e Quinn (2007) na Eritréia; Kolhoff, Runhaar e Driessen (2009) em países em desenvolvimento; Ruffeis et al. (2010) na Etiópia; Haydar e Pediaditi (2010) na Síria; Clausen, Hoa Vu e Pedrono (2011) no Vietnã; e Marara et al. (2011) em três países do leste da África (Ruanda, Quênia e Tanzânia).

Além destes, outros indicadores são encontrados na literatura. Glasson e Salvador (2000) destacaram os pontos fortes e fracos do sistema de AIA brasileiro através da comparação com a prática do Reino Unido, descrevendo a situação de cada país e usando uma lista de verificação para compará-los. Os estudos de Hinte, Gunton e Day (2007) basearam-se em uma listagem de questões de melhores práticas, sendo feita segundo a opinião dos autores e aplicando-se a gasodutos no Canadá. A Tabela 1 apresenta os conjuntos de indicadores e os autores que o utilizaram. Os indicadores presentes nesta tabela serão empregados para a seleção daqueles que serão aplicados no presente estudo. 
Tabela 1 - Indicadores de efetividade aplicados na análise dos sistemas de AIA por diferentes autores (continua)

\begin{tabular}{lc}
\multicolumn{1}{c}{ CONJUNTOS DE INDICADORES } & $\begin{array}{c}\text { AUTORES QUE OS } \\
\text { UTILIZARAM }\end{array}$ \\
\hline 1. LEGISLAÇÃO & \\
1.1. Disposições legais para AIA & \\
1.2. Mecanismos de contestação das decisões pelo empreendedor e/ou público & \\
1.3. Especificações de limite de tempo & \\
1.4. Disposições formais sobre AAE & \\
2. ADMINISTRAÇÃO & \\
2.1. Competência das autoridades & Ahmad e Wood (2002) \\
2.2. Corpo técnico revisor da AIA & \\
2.3. Especificação das responsabilidades das autoridades no processo & Wood (2003) \\
2.4. Nível de integração com outros órgãos de planejamento e controle de poluição & \\
3. PROCESSO & El-Fadl e El-Fadel (2004) \\
3.1. Categorias específicas de triagem & \\
3.2. Sistematização da triagem & Nadeem e Hameed (2008) \\
3.3. Sistematizção do escopo & Badr (2009) \\
3.4. Exigência da consideração de alternativas & \\
3.5. Especificidade nos estudos ambientais & Toro, Requena e \\
3.6. Sistematização da análise/revisão dos estudos & Zamorano (2010) \\
3.7. Participação pública no processo & \\
3.8. Sistematização da tomada de decisão & \\
3.9. Exigência de planos ambientais de gestão & \\
3.10. Exigência de mitigação para os impactos & \\
3.11. Exigência de monitoramento dos impactos & \\
3.12. Experiência em AAE & \\
MEDIDAS INSTITUCIONAIS & \\
1. Existência de diretrizes gerais e/ou específicas, incluindo os procedimentos de \\
autoridades setoriais \\
2. Acompanhamento da implementação do sistema de AIA \\
3. Envolvimento de especialistas na AIA (universidades, institutos, consultorias) \\
4. Treinamento e capacitação & \\
\hline ASPECTOS INSTIO & \\
\hline
\end{tabular}

ASPECTOS INSTITUCIONAIS DO SISTEMA DE AIA

1.1. Existe política ambiental documentada aos níveis nacional, regional e local?

1.2. Existem instituições ou organizações ambientais com responsabilidades e funções claramente definidas no processo de AIA?

1.3. O sistema de AIA é baseado em provisão legal clara e específica?

1.4. Existem recursos adequados para realização da AIA de forma efetiva?

2. PROCESSO DE AIA

2.1. Ocorre a triagem das ações de importância ambiental?

2.2. É definido o escopo para as ações causadoras de impactos e existem diretrizes específicas para este processo?

2.4. A mitigação dos impactos é considerada nas várias fases do processo de AIA?

2.5. Os estudos ambientais atendem ao escopo estabelecido e estudos inadequados são evitados?

Zeremeriam e Quinn (2007)

2.6. Os estudos ambientais são publicamente revistos e o proponente responde às questões levantadas?

Ruffeis et al. (2010)

2.7. As conclusões do estudo e da análise influenciam a tomada de decisão?

2.8. São realizados acompanhamento e auditoria pós implantação do projeto?

3. OUTRAS CARACTERÍSTICAS DO SISTEMA DE AIA

3.1. Os impactos relevantes de todas as ações significativas são avaliados?

3.2. Existe a consideração, pelo proponente, dos impactos ambientais das alternativas propostas?

3.3. A consulta e a participação ocorrem antes e após a publicação do estudo?

3.4. O sistema de AIA é monitorado e, se necessário, alterações são realizadas?

3.5. Os custos financeiros e o tempo são aceitáveis para os envolvidos e são compensados pelos benefícios ambientais?

3.6. A AIA se aplica a programas, planos e políticas, além de projetos? 
Tabela 1 - Indicadores de efetividade aplicados na análise dos sistemas de AIA por diferentes autores (continuação)

\section{CONJUNTOS DE INDICADORES}

LEGISLAÇÃO

1. Disposições legais para AIA

2. Disposições de AIA incorporadas em legislações relevantes

3. Desenvolvimento participativo da legislação

4. Clareza nos objetivos e escopo da AIA

5. Mecanismos de contestação das decisões pelo empreendedor e/ou público

6. Especificações de limite de tempo

7. Disposições alinhadas com a legislação pertinente

8. Disposições legais para financiamento

9. Coerência do quadro regulamentador da AIA

ESTRUTURA DAS PRINCIPAIS ORGANIZAÇÕES GOVERNAMENTAIS

1. Autoridade competente para AIA e determinação da aceitabilidade ambiental

2. Responsabilidade pela decisão da triagem

3. Responsabilidade pela decisão do escopo

4. Responsabilidade pela revisão do processo separado do corpo de AIA

5. Especificação das autoridades setoriais responsáveis pelo processo de AIA PROCESSO

1. Bom relacionamento entre os envolvidos

2. Categorias específicas de triagem

3. Sistematização da triagem

4. Sistematização do escopo

5. Participação pública no escopo

6. Especificidade nos estudos ambientais

7. Mecanismos de garantia da qualidade para elaboradores dos estudos

8. Sistematização da análise/revisão dos estudos

9. Participação pública na revisão dos estudos

10. Sistematização da tomada de decisão

11. Exigência de transparência e responsabilidade

12. Exigência do resumo não técnico dos estudos

13. Exigência da consideração de alternativas

14. Exigência de mitigação dos impactos

15. Exigência de compensação

16. Exigência de monitoramento de impactos

17. Exigência de plano de monitoramento ambiental

QUESTÕES INFORMAIS

As medidas processuais acima mencionadas podem ser aplicadas para identificar questões informais?

1. O sistema de AIA é baseado em legislações/disposições claras e específicas?

2. Os impactos ambientais relevantes de todas as ações significativas são avaliados?

3. Existe evidência de consideração, pelo proponente, dos impactos ambientais das alternativas propostas?

4. Existe triagem das ações de importância ambiental?

5. Existem diretrizes para a definição do escopo?

6. Os estudos atendem ao conteúdo prescrito e estudos inadequados são evitados?

7. Existe publicidade dos estudos e o proponente responde às questões levantadas?

8. As conclusões do estudo e da análise influenciam a tomada de decisão?

9. O monitoramento dos impactos é realizado e se relaciona com os estágios iniciais do processo de AIA?

10. A mitigação dos impactos é considerada nas diferentes fases do projeto?

11. A consulta e a participação ocorrem antes e após a publicação do estudo?

12. O sistema de AIA é monitorado e, se necessário, alterações são realizadas?

13. Os custos financeiros e o tempo são aceitáveis para os envolvidos e são compensados pelos benefícios ambientais?

14. A AIA se aplica a programas, planos e políticas, bem como a projetos?
Kolhoff, Runhaar e

Driessen (2009) 
Tabela 1 - Indicadores de efetividade aplicados na análise dos sistemas de AIA por diferentes autores (continuação)

\section{CONJUNTOS DE INDICADORES}

AUTORES QUE OS

UTILIZARAM

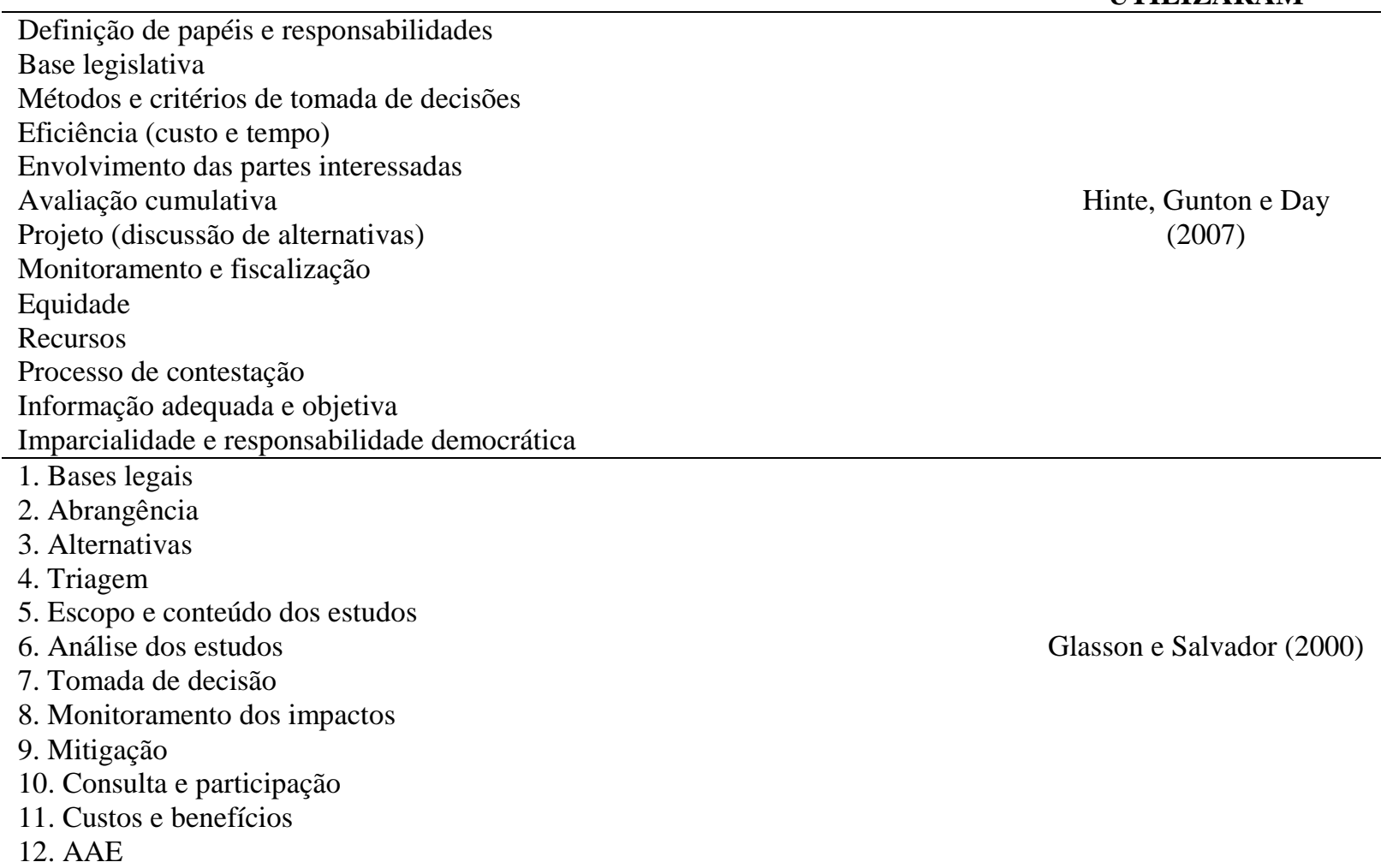

12. $\mathrm{AAE}$

1. AIA é requerida como uma etapa significativa no ciclo do projeto

2. Existe capacidade adequada para realizar a AIA

3. Existem capacidade e independência suficiente dos tomadores de decisão

4. Triagem dos projetos é realizada com a determinação do âmbito do escopo

5. AIA abrange todas as fases dos projetos desde a pré-construção até a operação

6. Participação pública e divulgação de informações necessárias são realizadas

Clausen, Hoa Vu e

Pedrono (2011)

7. Os resultados e as conclusões da AIA são aplicados e monitorados

8. Existem mecanismos para avaliação complexas, como impactos cumulativos

9. Política e prática da AIA segundo exigências internacionais e melhores práticas

1. QUADRO LEGAL

a. Provisão legal da AIA

b. Provisão de recursos

c. Existência de um corpo jurídico competente

d. Especificações legais de tempo limite

e. Qualidade dos guias

2. QUADRO ADMINISTRATIVO

a. Existência de autoridades competentes

b. Autonomia da autoridade competente

c. Coordenação com outras agências

d. Especificação de responsabilidades setoriais no processo

Marara et al. (2011)

3. QUADRO PROCESSUAL

a. Integração da AIA no processo de planejamento

b. Influência da AIA no processo de tomada de decisão

c. Participação pública no processo

d. Qualidade de atividades de acompanhamento, incluindo a execução

4. CONTEXTO ESTABELECIDO

a. Vontade política

b. Consciência ambiental do público em geral

c. Disponibilidade de recursos financeiros

d. Especialistas na condução da AIA 


\subsubsection{Principais limitações do processo de AIA}

As limitações encontradas no processo de AIA, conforme apontado pelas pesquisas realizadas em diversos países, decorrem de todas as etapas. Na triagem ocorre a ausência de critérios para a definição do tipo de estudo ambiental a ser realizado, a definição do escopo dá-se de forma generalizada (NADEEM; HAMEEDA, 2008) e a excessiva padronização faz com que as especificidades locais não sejam adequadamente consideradas (APPIAHOPOKU, 2001); a proposição de alternativas tecnológicas e locacionais é incipiente ou inexistente (HICKIE; WADE, 1998; STEINEMANN, 2001; PINHO; MAIA; MONTERROSO, 2007; KRUOPIENEA; ŽIDONIENEB; DVARIONIENEA, 2009; POPE et al., 2013) ou abrange alternativas ambientalmente inviáveis (ZUBAIR, 2001).

Ainda, a literatura aponta que os estudos ambientais têm baixa qualidade, com inadequada definição da área de influência, diagnósticos superficiais e incompletos (GOMES et al., 2009; PANIGRAHI; AMIRAPU, 2012), bases inadequadas de dados (HICKIE; WADE, 1998; ZUBAIR, 2001), inapropriada identificação, previsão e avaliação de impactos (APPIAHOPOKU, 2001; PANIGRAHI; AMIRAPU, 2012), tratamento insuficiente de impactos cumulativos (ZUBAIR, 2001; WÄRNBÄC; HILDING-RYDEVIKA, 2009; POPE et al., 2013) e proposição de medidas que não são a solução para o impacto (PRADO FILHO; SOUZA, 2004); a equipe elaboradora do estudo, muitas vezes, é despreparada e inexperiente, além de não ser multidisciplinar (TORO; REQUENA; ZAMORANO, 2009); a participação pública não é efetiva e capaz de influenciar a tomada de decisão (PARDO; 1997; FURIA; WALLACE-JONES，2000; SONERYD，2004; ALMER; KOONTZ，2004; NADEEM; HAMEED 2008; PANIGRAHI; AMIRAPU, 2012; POPE et al., 2013) e possui apenas um papel meramente informativo ou consultivo (CORTNER, 2000; SONERYD, 2004).

Por fim, são descritas limitações por falta de qualificação dos atores envolvidos no processo (TORO; REQUENA; ZAMORANO, 2009; KRUOPIENEA; ŽIDONIENEB; DVARIONIENEA, 2009); implementação inadequada dos programas de monitoramento (AHAMMED; NIXON, 2006; NADEEM; HAMEED, 2008; TORO; REQUENA; ZAMORANO, 2009; PANIGRAHI; AMIRAPU, 2012) e fraca integração com o processo de tomada de decisão em níveis estratégicos de planejamento (PANIGRAHI; AMIRAPU, 2012).

No Brasil, estudos realizados pelo Ministério Público Federal (MPF) em 2004 e pelo Tribunal de Contas da União (TCU) em 2008 apontam para as principais deficiências da AIA 
no país. No caso do trabalho do MPF, foram identificadas as principais deficiências que se relacionam com a elaboração dos estudos ambientais, apresentadas na Tabela 2.

Tabela 2 - Deficiências nos Estudos de Impacto Ambiental.

\begin{tabular}{|c|c|}
\hline Elemento & Deficiências \\
\hline $\begin{array}{c}\text { Termo de referência } \\
\text { (TR) }\end{array}$ & $\begin{array}{l}\text { As exigências arroladas foram desconsideradas; } \\
\text { As recomendações foram repassadas às etapas posteriores à emissão da Licença Prévia, } \\
\text { figurando como condicionantes das demais licenças. }\end{array}$ \\
\hline $\begin{array}{l}\text { Objetivos do } \\
\text { empreendimento }\end{array}$ & $\begin{array}{l}\text { Adoção dos objetivos do conjunto total de obras interdependentes como justificativa } \\
\text { para aprovação de apenas um dos trechos/projetos; } \\
\text { Omissão, ou registro superficial, da relação do projeto com o conjunto de obras ao qual } \\
\text { se filia, possibilitando a conclusão pela sua independência. }\end{array}$ \\
\hline $\begin{array}{l}\text { Estudos de } \\
\text { alternativas } \\
\text { tecnológicas e } \\
\text { locacionais }\end{array}$ & $\begin{array}{l}\text { Ausência de proposição de alternativas; } \\
\text { Apresentação de alternativas reconhecidamente inferiores à selecionada; } \\
\text { Prevalência dos aspectos econômicos sobre os ambientais; } \\
\text { Comparação de alternativas a partir de base diferenciada. }\end{array}$ \\
\hline $\begin{array}{l}\text { Delimitação das áreas } \\
\text { de influência (AI) }\end{array}$ & $\begin{array}{l}\text { Desconsideração da bacia hidrográfica; } \\
\text { Delimitação das AI sem alicerce nas características e vulnerabilidades dos ambientes } \\
\text { naturais e realidades sociais regionais. }\end{array}$ \\
\hline $\begin{array}{l}\text { Diagn } \\
\text { ambi }\end{array}$ & $\begin{array}{l}\text { Prazos insuficientes para a realização de pesquisas de campo; } \\
\text { Caracterização da área baseada, principalmente, em dados secundários; } \\
\text { Ausência ou insuficiência de informações sobre a metodologia utilizada; } \\
\text { Proposição de execução de atividades de diagnóstico em etapas do licenciamento } \\
\text { posteriores à Licença Prévia; } \\
\text { Falta de integração dos dados de estudos específicos. }\end{array}$ \\
\hline $\begin{array}{l}\text { Identificação, } \\
\text { caracterização e } \\
\text { análise de impactos }\end{array}$ & $\begin{array}{l}\text { Não identificação ou identificação parcial de determinados impactos; } \\
\text { Indicação de impactos genéricos; } \\
\text { Identificação de impactos mutuamente excludentes; } \\
\text { Subutilização ou desconsideração de dados dos diagnósticos; } \\
\text { Omissão de dados e/ou justificativas quanto à metodologia utilizada para arrogar pesos } \\
\text { aos atributos dos impactos; } \\
\text { Minimização dos impactos negativos e supervalorização dos positivos; } \\
\text { Não avaliação da cumulatividade e sinergia de impactos. }\end{array}$ \\
\hline $\begin{array}{l}\text { Mitigação e } \\
\text { compensação de } \\
\text { impactos }\end{array}$ & $\begin{array}{l}\text { Proposição de medidas que não mitigam o impacto; } \\
\text { Indicação de medidas mitigadoras pouco detalhadas; } \\
\text { Indicação de obrigações ou impedimentos técnicos e legais como propostas de medidas } \\
\text { mitigadoras; } \\
\text { Ausência de avaliação da eficiência das medidas propostas; } \\
\text { Não incorporação de propostas dos grupos sociais afetados; } \\
\text { Proposição de Unidade de Conservação da categoria de uso sustentável para a aplicação } \\
\text { dos recursos, em casos não previstos pela legislação; } \\
\text { Ausência de informações detalhadas acerca dos recursos financeiros destinados aos } \\
\text { programas e projetos ambientais. }\end{array}$ \\
\hline $\begin{array}{l}\text { Programas de } \\
\text { acompanhamento e } \\
\text { monitoramento } \\
\text { ambiental }\end{array}$ & $\begin{array}{l}\text { Erros conceituais na indicação de monitoramento; } \\
\text { Ausência de proposição de monitoramento de impactos específicos; } \\
\text { Proposição de monitoramento insuficiente; } \\
\text { Prazos incompatíveis com épocas de ocorrência de impactos. }\end{array}$ \\
\hline $\begin{array}{l}\text { Relatório de Impacto } \\
\text { Ambiental (Rima) }\end{array}$ & $\begin{array}{l}\text { O Rima é um documento incompleto; } \\
\text { Emprego de linguagem inadequada à compreensão do público; } \\
\text { Distorção de resultados, no sentido de minorar os impactos negativos; } \\
\text { As complementações do EIA não são incorporadas ao Rima. }\end{array}$ \\
\hline
\end{tabular}

Fonte: adaptado de MPF (2004). 
Já o TCU auditou o sistema operacional de licenciamento ambiental federal, através de informações coletados em todos os 27 estados brasileiros. Entre as principais conclusões da equipe de auditoria estão (LIMA; MAGRINI, 2010):

- Falta de coordenação entre Instituto Brasileiro do Meio Ambiente e dos Recursos Naturais Renováveis (Ibama) e outros órgãos governamentais envolvidos no licenciamento;

- Ausência ou conflito na definição de poderes para realizar o licenciamento ambiental;

- Dificuldades de comunicação entre os órgãos governamentais;

- Deficiências nas bases de dados utilizadas na elaboração do diagnóstico ambiental;

- Falta compartilhamento de informação entre o Ibama e órgãos estaduais e municipais do meio ambiente;

- Excesso de pessoal associado à falta de especialização em determinadas áreas;

- Estrutura física deficiente, tanto na falta de espaço para as pessoas como na falta de local apropriado para armazenar os registros dos processos de licenciamento ambiental;

- Ausência de qualificação adequada de pessoal;

- Ausência de um sistema de informações que permita o armazenamento e compartilhamento de dados sobre estudos ambientais, pareceres e notas técnicas;

- Ausência de regulamentação específica para determinados tipos de atividades;

- Deficiências nos estudos ambientais componentes do processo;

- Sobreposição de fases de licenciamento, sem clara definição da divisão destas fases;

- Sobreposição de medidas compensatórias com idêntica redação para as mesmas comunidades;

- Deficiências na supervisão do cumprimento das condições e medidas mitigadoras.

\subsection{O PENSAMENTO SISTÊMICO}

A abordagem sistêmica oferece um modelo complementar às correntes de pensamento cartesiano. Para muitos, as raízes dessa nova forma de pensar tiveram origem com antigos filósofos ocidentais e orientais. Aristóteles, por exemplo, já argumentava que o todo era mais do que a soma das partes. Também são destacadas as obras de Platão e de outros filósofos posteriores - como Spinoza, Kant, Hegel e Marx (JACKSON, 2000). Já nos tempos modernos, os conceitos fundamentais do pensamento sistêmico foram desenvolvidos no início 
do século XX em disciplinas como Biologia, Ecologia, Psicologia e Cibernética (CAPRA, 1997).

O termo Teoria Geral dos Sistemas (TGS) foi proposto pela primeira vez por Von Bertalanffy, na década de 1930. Mas, foi somente por volta de 1940 e 1950 que esta forma de pensamento veio a se tornar institucionalizada, estabelecendo a ideia de "sistemas" como uma importante estrutura conceitual para lidar com a complexidade de fenômenos do mundo real (CHECKLAND, 1981). Seu desenvolvimento ocorreu, mais precisamente, em 1956 com Boulding, sendo a TGS vista como aplicável a todas as disciplinas e como integrador de diferentes áreas (ROUNTREE, 1977). Ainda, em 1960, tem papel importante no desenvolvimento das ideias fundamentais da dinâmica dos sistemas, o cientista Jay Forrester, que estava interessado em modelar o comportamento dinâmico de sistemas, tais como as populações nas cidades e as cadeias de suprimentos industriais (MINGERS; WHITE, 2010).

Entretanto, conforme Jackson (2000), até a década de 1970 a abordagem sistêmica ainda era dominada pela óptica funcionalista. Só a partir da década de 1980 que o pensamento sistêmico ganhou novos rumos, constituindo duas vertentes designadas por "pensamento sistêmico soft", no início daquela década, e "pensamento sistêmico hard", no fim dos anos de 1980 e início dos 1990.

A abordagem "hard" aplica-se a sistemas quantificáveis com problemas bem definidos tecnicamente e, muitas vezes, implica na utilização de simulações. Já a abordagem "soft" é mais apropriada para situações mal definidas que envolvam seres humanos e considerações culturais (sistemas não quantificáveis). Contudo, Checkland (2000) afirma que estas definições não seriam exatamente verdadeiras e que a diferenciação decorreria de como o observador encara o problema: no pensamento sistêmico "hard" o enfoque é dado ao sistema, enquanto que no pensamento sistêmico "soft", o enfoque é dado ao processo. Assim, o pensamento sistêmico "hard" assume que o mundo é um conjunto de sistemas que podem ser sistematicamente projetados para alcançar os objetivos definidos. Na tradição "soft", o mundo é considerado como problemático, mas admitindo-se, também, que o processo de investigação sobre as situações problemáticas que compõem o mundo pode ser organizado como um sistema.

Para Accioly e Figueiredo (2011), as abordagens "soft" ajudam o tomador de decisão a lidar com problemas complexos por meio de uma modelagem qualitativa, que permite explorar as diferentes visões sobre o problema, determinar pontos importantes e guiar a discussão sobre o assunto. 
Seja através de abordagens "hard" ou "soft", o pensamento sistêmico é interdisciplinar e pode agir como ponte entre as ciências físicas, naturais e sociais (CABRERA; COLOSI; LOBDELL, 2008). Ele permeia a cultura popular e inúmeros campos científicos, tais como planejamento, educação (INELMEN, 2010), gerenciamento e negócios, saúde pública, segurança (LEVESON, 2011), sociologia e psicologia (PARPINELLI; LUNARDELLI, 2006), desenvolvimento humano, agricultura, sustentabilidade, ciências ambientais, ecologia, biologia (MATURANA; VARELA, 1980), ciências da terra e demais ciências físicas. Outros exemplos de aplicação do pensamento sistêmico são enumerados no trabalho de Mingers e White (2010).

Assim, considerando os desenvolvimentos teóricos, podemos distinguir três grandes fases do desenvolvimento do pensamento sistêmico: os primeiros anos, de 1920 a 1960, quando os conceitos fundamentais foram desenvolvidos dentro e através de uma série de disciplinas; entre os anos de 1970 e 1990, com a aplicação de metodologias específicas, tais como sistemas "soft", "hard", entre outras; e o surgimento mais recente das teorias do caos e da complexidade (MINGERS; WHITE, 2010). Corroborando com estes aspectos de evolução da abordagem de sistemas, Rountree (1977) destaca três frentes: a primeira é o desenvolvimento da Teoria Geral dos Sistemas; a segunda é o desenvolvimento de metodologias sistêmicas; e terceira é a aplicação da teoria e metodologia voltadas para resolução de problemas práticos.

Como exemplo desta terceira frente, nos últimos anos, o conceito de sistemas dinâmicos tem sido abordado a partir das concepções de Peter Senge divulgadas em seu livro "A Quinta Disciplina" (SENGE, 1990), o qual preconiza o pensamento sistêmico e conceitos de sistemas dinâmicos como parte da abordagem de aprendizado organizacional.

O primeiro aspecto do pensamento sistêmico diz respeito à relação entre as partes e o todo, sendo que as propriedades das partes somente podem ser entendidas através da dinâmica do todo (CAPRA, 1985). Ou seja, o todo é maior que a simples soma das partes, sendo definido pelo conjunto de suas partes constituintes e, principalmente, pelas relações e interações existentes entre elas (BERTALANFFY, 1975). Estas relações e interações são chamadas de propriedades emergentes, não podem ser deduzidas do estudo e observação das partes isoladas (CHECKLAND, 1999), e condicionam o funcionamento do próprio todo. São estas propriedades que produzem a integridade organizacional e identidade do todo (ROUNTREE, 1977). Toda a argumentação está, portanto, centrada na constatação de que, em situações ricas em complexidade, os elementos, quando observados exercendo um papel em um conjunto, não se comportam da mesma maneira como quando examinados individualmente, devido às diversas formas de interação que desenvolvem (BERTALANFFY, 1975). 
Assim, o pensamento sistêmico estuda o todo como resultado das conexões entre suas partes (O'CONNOR; MCDERMOTT, 1997). O pensamento sistêmico transforma uma questão focada de um aspecto singular em uma visão de múltiplas questões (DANIELS; WALKER, 2012).

Segundo Capra (1996), as principais características do pensamento sistêmico são: 1) O foco é deslocado das partes para o todo. A principal razão é que as propriedades sistêmicas (ou emergentes) são destruídas quando um sistema é dissecado em elementos isolados. 2) Sistemas estão aninhados dentro de outros sistemas. Sendo assim, algumas propriedades de um sistema só são visíveis, ou detectáveis, em certos níveis de sistema. Esta segunda característica descreve a propriedade da hierarquia e reflete o nível de organização do sistema e o grau de agregação das variáveis. Assim, um sistema pode ser parte de um sistema maior, enquanto, ao mesmo tempo, pode ser construído de subsistemas, que podem ser eles próprios constituídos por subsistemas (ROUNTREE, 1977).

Sistema é um agregado ou uma combinação de coisas ou partes, formando um todo complexo ou integral (KAST; ROSENWEIG, 1987). Um sistema pode ser uma unidade funcional (compostos por equipamentos, maquinário, coisas reais) ou conceitual (compostos por conceitos, hipóteses, ideias). Cada parte ou elemento do conjunto influencia o comportamento de outros elementos, bem como o comportamento de cada elemento influencia o comportamento do conjunto (RAPOPORT, 1986).

Quanto à sua natureza, sistemas podem ser fechados ou abertos. Os sistemas são considerados fechados quando não apresentam intercâmbio de matéria e energia com o meio externo, não recebendo influências externas e também não influenciando o exterior. Sistemas estritamente fechados não podem existir como objetos no mundo real (ROBB, 1986). Já os sistemas abertos são os sistemas que apresentam trocas com o ambiente; estes sistemas apresentam entradas, um processo de transformação, saídas e um processo de "feedback" ou retroalimentação.

A fronteira de um sistema deve ser vista como uma característica necessária, embora artificial. Os limites dos sistemas não devem ser encarados como linhas rígidas, mas como elementos nos quais os fatores vão diminuindo seu efeito sobre o comportamento do sistema (ROUNTREE, 1977).

Diferentes metodologias e ferramentas oferecem suporte ao desenvolvimento do pensamento sistêmico. Elas são, basicamente, destinadas a revelar as relações que caracterizam um sistema (SCHIUMA; CARLUCCI; SOLE, 2012). Dentre estas ferramentas, destacam-se os mapas e os diagramas. No caso dos primeiros, podem ser produzidos mapas 
de situação, mapas de afinidade e mapas de cenários (DANIELS; WALKER, 2012). Para o segundo, podem-se ser destacados:

- Diagrama de Influência: o processo de modelagem em sistemas dinâmicos inicia-se com o entendimento dos ciclos de realimentação que compõem o sistema; são utilizados para compreender a estrutura geral do sistema, e não seus detalhes, sendo, portanto, mantidos deliberadamente simples (ACCIOLY; FIGUEIREDO, 2011).

- Diagramas de círculos de causalidade (ou diagrama de loop causal): consiste em um arranjo circular de variáveis conectadas por suas relações causais, no qual uma causa inicial propaga-se ao longo das ligações do círculo, de modo que cada variável tem um efeito na próxima, até que a última retroalimentação afete a primeira variável; permite identificar e organizar os principais componentes de um sistema, entretanto sem considerar a precisão e o nível em que eles são afetados (NARDELLI; GRIFFITH, 2003). Incentiva o usuário a conceituar os sistemas do mundo real, transformando uma descrição verbal em uma estrutura de retroalimentação (GOODMAN, 1989).

- Sociograma: explora as conexões entre os diversos atores sociais e outros componentes do problema, permitindo a visualização de sua amplitude e complexidade; tem como produto a geração de um mapa de interdependências (NARDELLI; GRIFFITH, 2003).

Finalmente, Schiuma, Carlucci e Sole (2012) destacam metodologias de pensamento sistêmico particularmente relevantes na gestão, como: Avaliação do Ciclo de Vida, "Spiral Dynamics", "System Dynamics", "Business Dynamics" e "Soft Systems Methodology" (SSM). Tendo sido adotada no presente trabalho, esta última será descrita a seguir.

\subsubsection{Soft Systems Methodology (SSM)}

Foi o artigo "Towards a systems-based methodology for real-world problem solving" de Peter Checkland, em 1972, que inicializou o desenvolvimento da SSM, argumentando que era necessária uma metodologia de uso prático em problemas do mundo real (CHECKLAND, 2000). A SSM cresceu a partir do reconhecimento das limitações da engenharia de sistemas para lidar com as complexidades das relações humanas, incluindo situações de gestão (CHECKLAND, 2000).

De acordo com Checkland (2000), a SSM baseia-se em quatro princípios: as pessoas têm diferentes visões de mundo e agem de acordo com o significado para elas; muitas 
interpretações para qualquer objetivo determinado são possíveis; ocorre uma mudança na ideia de um problema óbvio que exija solução, para a ideia de uma situação que algumas pessoas, por várias razões, consideram como problemática; e, principalmente, que a metodologia SSM é um sistema de aprendizado e não de resolução de problemas.

Rose (1997) aponta a SSM como sendo:

- uma ferramenta de estruturação de problemas: SSM pode equiparar-se a outras abordagens pelo empréstimo da abordagem "soft". O resultado do estudo seria, por exemplo, um conjunto de "questões de pesquisa" a serem respondidas por outros meios;

- uma ferramenta de pesquisa ajustável: como ferramenta metodológica qualitativa, baseada em atividades, interpretativa, participativa e empregando sistemas, pode ser ajustada à área e ao objetivo da pesquisa;

- uma ferramenta de triangulação: resultados obtidos com outro método podem ser confirmados, refutados ou amplificados;

- uma ferramenta de teste ou geração de teoria;

- uma ferramenta de coordenação ou diretiva: o processo de pesquisa em si pode ser conceituado como um intencional sistema de atividade humana. Os modelos podem, então, ser construídos, o que pode, por exemplo, definir as diferentes atividades de investigação e suas dependências lógicas.

Checkland (1981) descreve a SSM a partir de um conjunto de sete atividades organizadas em torno de um processo de aprendizagem circular (o chamado "Modelo de sete fases"), ilustrado na Figura 3. O "Modelo de sete fases" consiste em: 1) explorar uma situação problemática não estruturada; 2) expressá-la; 3) construir definições sucintas de sistemas relevantes; 4) elaborar modelos conceituais desses sistemas; 5) comparar os modelos conceituais com a situação problemática expressada; 6) reunir mudanças culturalmente possíveis e sistemicamente desejáveis; e 7) sugerir ações para transformação da situação problemática.

Dentro da fase 3, segundo Checkland e Scholes (1999), para a definição dos sistemas relevantes, pode ser empregada a Análise CATWOE, composta por 6 elementos: os "Costumers" (os beneficiários e as vítimas da atividade), os "Actors" (aqueles que estão envolvidos nas atividades), o "Transformation process" (processo de transformação das entradas nas saídas da atividade proposta), a "Weltanschauung" (a visão ou imagem do mundo que torna significativa as definições do contexto), os "Owners" (aqueles que podem 
interromper a atividade) e "Environmental constraints" (restrições ambientais que afetam a situação).

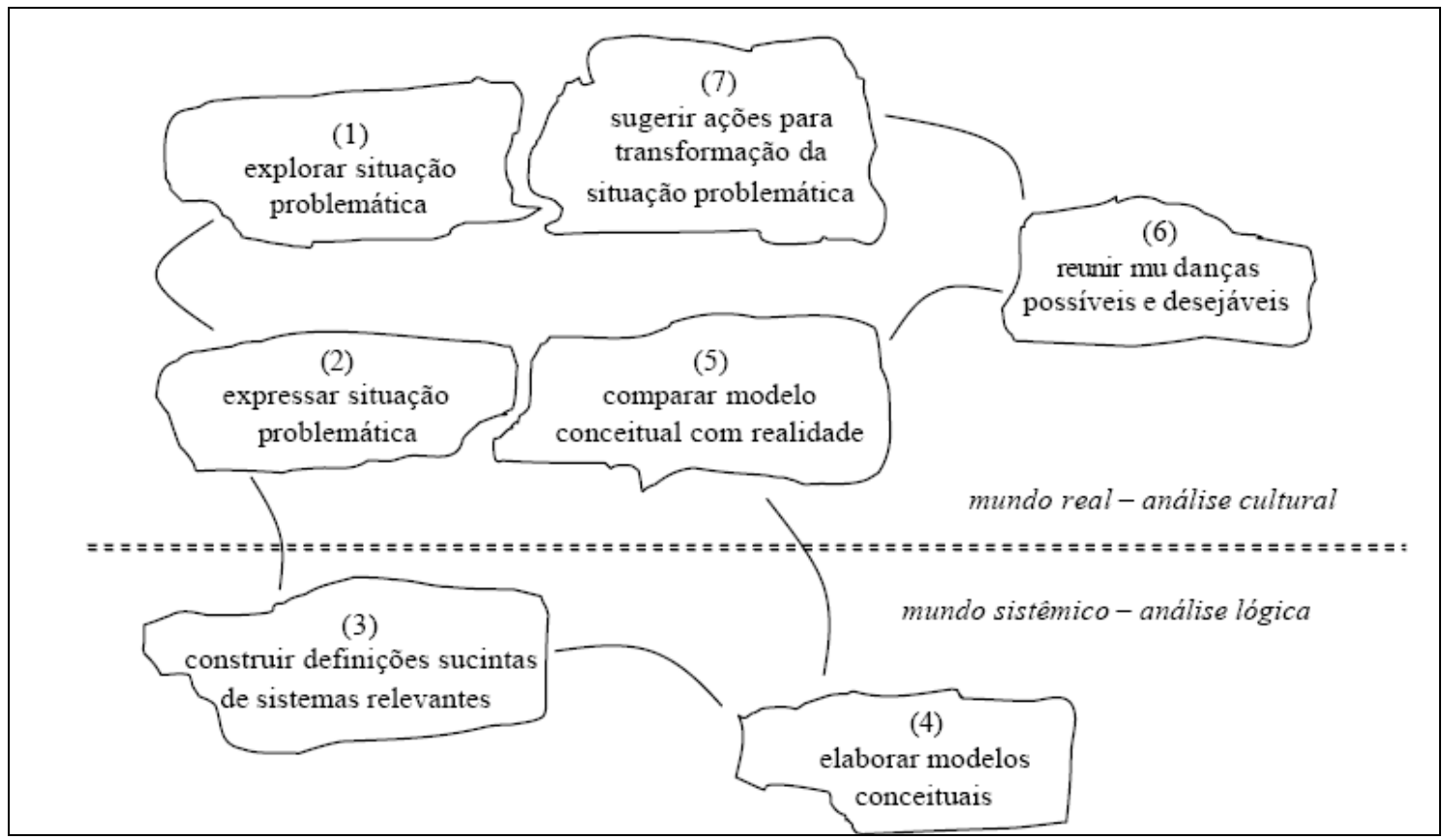

Figura 3 - Fases da "Soft Systems Methodology" (SSM).

Fonte: Bellini; Rech; Borenstein (2004), baseado em Checkland (1985).

Assim, a SSM oferece uma forma de fomentar o aprendizado dos atores envolvidos, aumentando o escopo de aspectos organizacionais por eles apreciados, a partir da explicitação e do debate acerca de diversas perspectivas relacionadas à mesma problemática (CHECKLAND, 1981). Em essência, a SSM favorece o pensamento sistêmico e organiza uma agenda para se discutirem problemas e soluções (PATCHING, 1992).

Checkland (2000) chama a atenção para a linha que separa os estágios 3 e 4 dos demais, sendo uma separação entre o mundo sistêmico, que envolve uma análise lógica, e o mundo real, que envolve uma análise cultural.

Ainda, como evolução de seu "Modelo de sete fases", Checkland (2000) propõe que os sete estágios poderiam ser comprimidos em quatro atividades: 1) informar-se sobre uma situação problema, incluindo questões culturais e políticas; 2) formular alguns modelos relevantes para a situação proposta; 3) usando os modelos, debater a situação pensando: a) nas mudanças que poderiam melhorar a situação e que podem ser consideradas como desejáveis e (culturalmente) viáveis e b) nas acomodações entre os interesses conflitantes; 4) tomar uma ação que vise à melhoria de performance dentro da situação. 
A SSM, que era originalmente tida como uma ferramenta de modelagem, passa a ser vista como uma ferramenta de aprendizagem, que propicia a comparação do mundo real com alguns modelos idealizados e oferece uma maneira estruturada de pensar sobre o mundo real. Ao estruturar o pensamento sobre o mundo real, a SSM possibilita entender o funcionamento do sistema, bem como identificar as propriedades que emergem e condicionam este funcionamento.

\subsubsection{Relação entre os atores}

Uma das ferramentas que integram o pensamento sistêmico são os sociogramas, utilizados para explorar as conexões/relações entre os diversos atores.

Os atores envolvidos em uma dada situação que têm poder para modificá-la são comumente designados pelo termo "stakeholder". Segundo Freeman (1984) e Nutt e Backoff (1992), stakeholder é qualquer grupo ou indivíduo que pode afetar (ou é afetado) o desempenho de uma organização ou situação; já para El-Gohary, Osman e El-Diraby (2006), stakeholders são aqueles que têm um interesse legítimo em algo.

O poder pode ser entendido como resultado da criação da ordem social (HAUGAARD, 2003) e como uma propriedade relacional, pois os resultados são dependentes do comportamento dos atores envolvidos (HANSEN et al., 2013). Como tal, Yukl (1998) define três grupos de poder: o poder devido à posição ocupada - autoridade organizacional; o poder pessoal derivado do carisma nas relações humanas; e o poder político formalmente investido ou convenientemente transitório para se atingir os objetivos. Pires (1988) entende o poder como associado à capacidade transformativa dos atores envolvidos.

Em cada um destes grupos o poder pode se manifestar de diferentes formas (GREENE; ELFREES, 1999): o poder coercitivo ocasionado pelo medo; o poder de ligação com pessoas influentes ou importantes; o poder da recompensa baseado em incentivos; o poder legitimado devido à posição organizacional ou hierarquia; o poder de referência gerado pela admiração; o poder devido à posse ou acesso à informação; e o poder provocado pelo conhecimento.

Várias abordagens são utilizadas para análise das relações de poder, sendo a Teoria da Estruturação (TE) de Anthony Giddens uma delas. A TE é baseada na premissa de que as dinâmicas de poder estão presentes nos processos de desenvolvimento em todos os tempos, 
sendo capaz de intervir no mundo, ou abster-se de tal intervenção. Ainda de acordo com a TE, todos os atores possuem algum tipo de poder (GIDDENS, 1984).

A TE é ao mesmo tempo uma teoria sobre como os atores se comportam dentro das estruturas e uma teoria sobre como as estruturas são (re)formuladas pelos atores (GIDDENS, 1984), ou seja, a estrutura deve ser entendida, simultaneamente, como condição e resultado da ação (PIRES, 1988).

As estruturas são definidas por regras e recursos. As regras são normas processuais, que podem ser formais (por escrito) ou informais (por exemplo, valores ou normas) (Ibid.). Recursos referem-se aos os meios de comunicação através dos quais o poder é exercido (GIDDENS, 1979). Os atores influenciam as estruturas através do agenciamento, ou seja, da sua capacidade de interferir em eventos, não necessariamente de modo intencional (GIDDENS, 1984). Estruturas e agenciamentos não existem nem se perpetuam por si mesmos ou a partir da mera influência direta de uma sobre a outra, mas pela interação entre elas (Ibid).

Recentemente, o campo da Avaliação de Impacto tem recebido aporte de trabalhos voltados para a interpretação das diferentes arenas estabelecidas para o exercício do poder (HANSEN et al., 2013), que passa a constituir um foco de pesquisa necessário para o seu desenvolvimento (HAYES; WESTRUP, 2012; CASHMORE; RICHARDSON, 2013; CASHMORE; AXELSSON, 2013).

É importante, portanto, identificar os atores envolvidos (stakeholders), o modo como se estabelecem as relações entre eles e onde estas relações acontecem (arenas de decisão). Para tanto, tem sido amplamente empregado o método de Análise de Redes Sociais (Social Network Analysis), que entende a rede como sendo estabelecida a partir do conjunto de relações ou ligações sociais entre um grupo de atores (EMIRBAYER; GOODWIN, 1994), tomadas como estruturas emergentes, próprias de sistemas complexos e dinâmicos (KLÜVER; SCHMIDT, 1999). A Análise de Redes Sociais visa compreender as ligações entre as entidades ou atores sociais e as implicações dessas ligações para a estrutura e dinâmica do sistema (SOCZKA, 2005). 


\subsection{A ABORDAGEM SISTÊMICA APLICADA À AVALIAÇÃO DE IMPACTO} AMBIENTAL

A abordagem sistêmica tem oferecido recursos conceituais e metodológicos para compreensão, diagnóstico e aprimoramento em diferentes áreas, como administração, educação, saúde, política, entre outras (SENGE, 1990); além de contribuir para a compreensão da complexidade de fatores que afetam o desempenho dos sistemas estudados (HARRISON; SHIROM, 1999).

Deste modo, o processo de licenciamento com AIA pode ser caracterizado como sistema aberto, cuja organização e funcionamento são descritos a partir da relação entre suas etapas e/ou entre os atores envolvidos. Tais sistemas se submetem a uma constante interação da organização com o seu ambiente (ROBBINS; COULTER, 1998), onde uma coleção de objetos recebe entradas do ambiente externo e/ou de outros objetos do sistema, e transforma as entradas em saídas (OSLOM, 2006).

De acordo com a concepção apresentada por Chiavenato (2000), sistemas compreendem: entradas (input) - o que o sistema recebe do ambiente externo para ser processado; processos - mecanismos que convertem as entradas em saídas; saídas (Output) - resultados da combinação dos fatores de produção; e retroalimentação (Feedback) - mecanismo de comunicação entre os parâmetros do sistema que compara os resultados obtidos com o padrão preestabelecido, a fim de corrigir os desvios, mantendo assim, o equilíbrio dos elementos interdependentes. Assim, o sistema aberto AIA recebe insumos/fluxos de informações do seu meio, processa esses insumos e, então, gera produtos, serviços ou novos fluxos.

A natureza do sistema Licenciamento com AIA será admitida como soft, pois envolve situações mal definidas e não quantificáveis. Para estes casos em que os problemas fogem ao escopo da utilização de dados quantitativos, a SSM é apontada como uma ferramenta consistente (ESPEJO et al., 1996). A flexibilidade da SSM é evidenciada pela alta autonomia interpretativa atribuída ao agente, tanto no que tange à composição de modelos acerca do problema real quanto no design dos modelos ideais (DONAIRES, 2008).

A literatura não aprofunda a discussão sobre os casos em que a SSM seja de aplicação mais recomendada, apenas enfatiza a sua conveniência para situações sociais complexas, em que a mensuração e o controle são impraticáveis ou ineficientes (BELLINI; RECH; BORENSTEIN, 2004). Ao revisarem as aplicações da SSM, Water, Schinkel e Rozier (2007) verificaram que existem centenas de exemplos documentados do uso bem sucedido em muitos campos 
diferentes, que vão desde a Ecologia, aos serviços públicos e aplicações de negócio. De modo complementar, Muniz, Possamai e Abreu (2013) observaram que ela é mais utilizada no campo da gestão como um todo, englobando desde o desenvolvimento e melhoria de sistemas empresariais à gestão da inovação em serviços para comunidades e regiões.

Pela grande variedade de temas, áreas do conhecimento e interesses práticos em que pode ser empregada, a SSM apresenta-se como uma ferramenta com grande potencial de uso no campo do pensamento sistêmico (MINGERS; WHITE, 2010), sendo consolidada em círculos acadêmicos como a mais desenvolvida abordagem soft (ROSE, 1997). Logo, tem sido explorada em uma grande variedade de campos de pesquisa, bem como serve a interesses práticos igualmente diversos. 


\section{METODOLOGIA}

A metodologia utilizada no presente projeto de pesquisa é de natureza qualitativa e, essencialmente, descritiva. O trabalho analisou os sistemas de Licenciamento Ambiental com Avaliação de Impacto Ambiental em alguns estados brasileiros e de maneira mais aprofundada nos estados de SP e Sul de MG, buscando aplicar a abordagem sistêmica para avaliar a prática destes dois instrumentos de política ambiental.

\subsection{MODELO DE ANÁLISE}

Para melhor organização das etapas envolvidas na presente pesquisa e posterior interpretação dos dados coletados, as etapas do processo de Avaliação de Impacto Ambiental propostas por Sánchez (2008) aliadas ao processo de Licenciamento Ambiental, foram agrupadas em três fases, conforme definido a seguir e apresentado na Figura 4. Além das etapas, a figura indica as possíveis relações existentes, que se manifestam principalmente através de fluxos de informações. Este modelo foi empregado para a análise dos dois sistemas estudados.

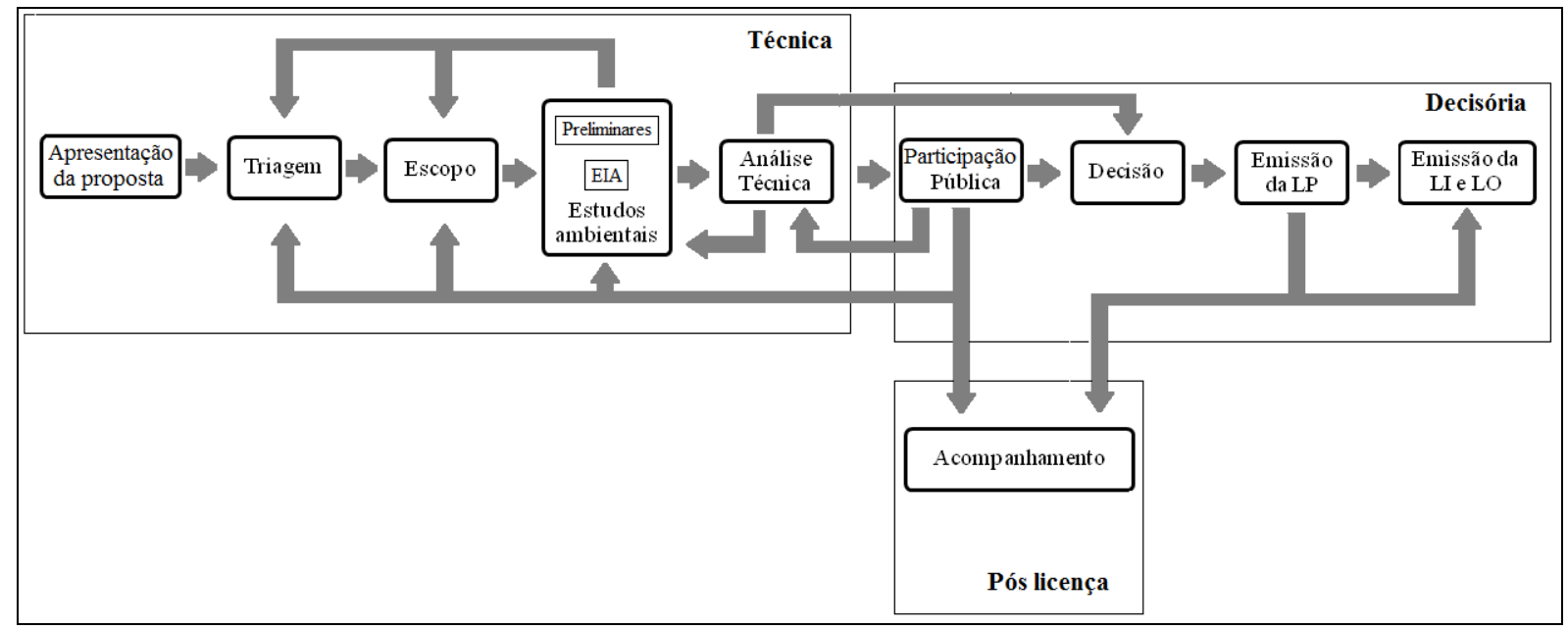

Figura 4 - Modelo analítico empregado. 
- Técnica: engloba as atividades voltadas para a especificação dos requisitos para elaboração dos estudos ambientais e análise técnica por parte do órgão ambiental (apresentação da proposta, triagem, definição do escopo, elaboração dos estudos ambientais e análise técnica); nesta fase predominam a circulação de informações referentes à caracterização do empreendimento/concepção tecnológica e meio a ser afetado, manifestações e pareceres de base técnica, mediados por elementos normativos de caráter procedimental;

- Decisória: voltada para a delimitação de condicionantes para a viabilidade ambiental do empreendimento e requisitos para a gestão, inclui as etapas de participação pública, tomada de decisão, emissão da licença prévia (LP) e emissão das licenças de instalação e operação (LI e LO); predominam a circulação de informações referentes às ações e programas de mitigação, controle e compensação de impactos, mediados por pareceres técnicos e manifestações da sociedade;

- Pós-licença: inclui ações voltadas para o acompanhamento do cumprimento das condicionantes estabelecidas pelo órgão ambiental, monitoramento dos impactos e adequação das medidas de controle ao longo da implantação, operação e desativação (se for o caso) do empreendimento; predomina o fluxo de informações referentes ao desempenho ambiental dos empreendimentos, mediadas por relatórios de monitoramento e acompanhamento.

A divisão proposta assemelha-se à utilizada por Sadler (1996), que ilustra o que seria uma abordagem do ciclo de vida aplicada à AIA, já que interconecta estágios pré e pós-tomada de decisão.

\subsection{CARACTERIZAÇÃO DOS OBJETOS DE ESTUDO: OS ÓRGÃOS AMBIENTAIS DE SÃO PAULO E MINAIS GERAIS}

De modo a contextualizar a esfera de atuação dos órgãos ambientais no que diz respeito ao processo de licenciamento e AIA, apresenta-se a seguir uma caracterização de sua estrutura e organização para os estados de SP e MG. Segundo o Art. $6^{\circ}$ da Política Nacional do Meio Ambiente - PNMA (Lei n 6.938/1981), os órgãos ou entidades estaduais responsáveis pela execução de programas, projetos e pelo controle e fiscalização de atividades capazes de provocar a degradação ambiental são considerados Órgãos Seccionais do Sistema Nacional do Meio Ambiente - Sisnama (BRASIL, 1981). 


\subsubsection{São Paulo}

No estado de São Paulo é o Sistema Estadual de Administração da Qualidade Ambiental, Proteção, Controle e Desenvolvimento do Meio Ambiente e Uso Adequado dos Recursos Naturais - SEAQUA que organiza, coordena e integra as ações de órgãos e entidades para a execução da Política Estadual do Meio Ambiente, visando à proteção, controle e desenvolvimento do meio e uso sustentável dos recursos naturais (SÃO PAULO, 1997).

A Companhia Ambiental do Estado de São Paulo (Cetesb), que recebeu o status de "Agência Ambiental Paulista" a partir da Lei 13.542/2009, atua na qualidade de órgão executor do SEAQUA. Entre outras funções, tem a atribuição de proceder ao licenciamento ambiental de estabelecimentos e atividades utilizadoras de recursos ambientais, considerados efetiva e potencialmente poluidores, bem como capazes, sob qualquer forma, de causar degradação ambiental (SÃO PAULO, 2009a). De acordo com esta mesma lei, ocorreu a unificação e a centralização do licenciamento na estrutura da Cetesb, sendo ela a única porta de entrada para os pedidos de licenciamento ambiental, que eram expedidas por outros departamentos do sistema estadual de meio ambiente. As mudanças incluíram também a celebração de convênios com Prefeituras para a descentralização do licenciamento de atividades e empreendimentos de pequeno impacto local, que está fora do escopo da presente pesquisa.

Em 2011, divulgou-se um plano para a instalação de 56 novas agências da Cetesb, ampliando a rede de 35 unidades instaladas até aquele momento (CETESB, 2011). Estas Agências Ambientais realizam o licenciamento ambiental nos casos de sua competência ou encaminham para o órgão central da Cetesb. São de responsabilidade das agências regionais os processos de licenciamento que não envolvam a análise do EIA/Rima. Neste caso, o processo é conduzido na sede do órgão ambiental, na cidade de São Paulo.

Internamente, a Cetesb passou por uma alteração em sua estrutura organizacional, criando novos departamentos, divisões e setores, dentro das quatro diretorias existentes - Diretoria de Gestão Corporativa, Diretoria de Licenciamento e Gestão Ambiental, Diretoria de Tecnologia, Qualidade e Avaliação Ambiental e Diretoria de Avaliação de Impacto Ambiental. Esta última diretoria tem as atribuições de desenvolver arcabouço técnico e metodológico para a avaliação de impacto ambiental; estabelecer critérios e propor normas para orientar a elaboração dos estudos de impacto ambiental para fins de licenciamento; e elaborar pareceres 
técnicos para dar embasamento à tomada de decisão quanto ao licenciamento ambiental (SMA, 2011).

Cabe ao Departamento de Avaliação de Impacto Ambiental (Daia) coordenar o processo de avaliação de impacto ambiental e prover subsídios ao licenciamento de atividades que possam causar significativo impacto ao meio ambiente (CETESB, 2011). O organograma do Daia é apresentado na Figura 5.

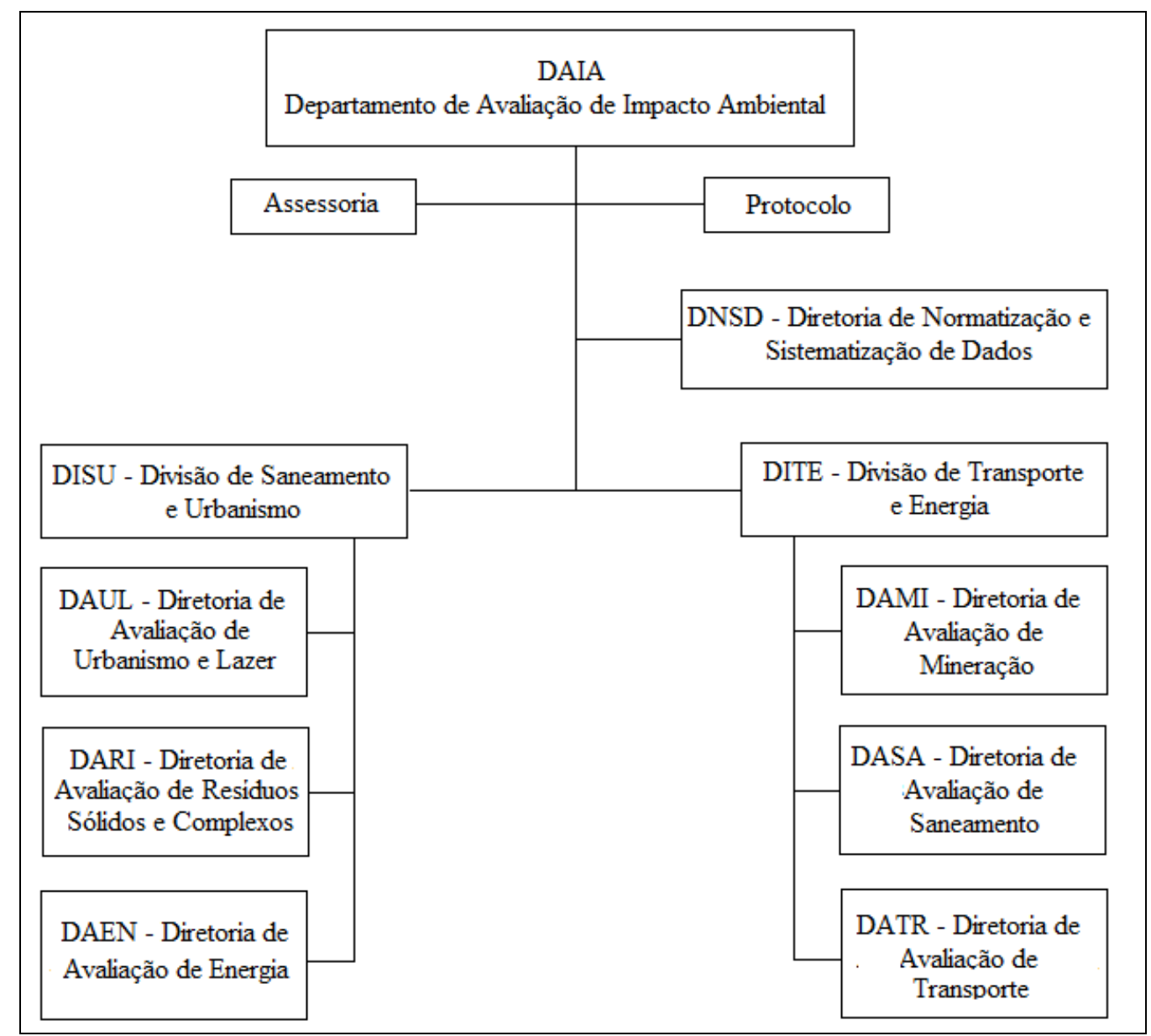

Figura 5 - Organograma do Daia.

Fonte: DAIA (2011).

Atrelado a este corpo técnico, o Conselho Estadual do Meio Ambiente (Consema) tem função importante nos processos de licenciamento com EIA/Rima. O Consema é um conselho paritário, composto de 36 membros, sendo metade de seus representantes oriunda de órgãos do Estado e a outra metade da sociedade civil. Além da Presidência e da Secretaria Executiva que coordenam as ações do Conselho, sua estrutura é formada por dois órgãos permanentes, o Plenário e as Câmaras Técnicas, e um temporário, as Comissões Especiais. Cabe às 
Comissões Especiais preparar as matérias, sobretudo normas, diretrizes, propostas de resolução, entre outras, a serem apreciadas pelo Plenário ou, em seu nome, acompanhar determinadas atividades ligadas à área de meio ambiente. Às Câmaras Técnicas cabe discutir a viabilidade ambiental de empreendimentos sujeitos a EIA/Rima e aprová-los ou reprová-los, em nome do Plenário, a não ser que este avoque a si sua apreciação (SÃO PAULO, 2009b).

As normas que atualmente regem o processo de licenciamento no âmbito da Secretaria do Meio Ambiente de São Paulo são derivadas do Decreto Estadual no 47.400/2002 e da Resolução SMA $\mathrm{n}^{\circ}$ 54, de 30 de novembro de 2004. Nelas estão contidos todos os procedimentos para a obtenção da licença ambiental no âmbito do Daia, bem como a possibilidade de simplificação para o licenciamento de atividades e empreendimentos de pequeno potencial de impacto ambiental.

\subsubsection{Minas Gerais}

O Sistema Estadual do Meio Ambiente e Recursos Hídricos de Minas Gerais (Sisema) é formado pela Secretaria de Estado do Meio Ambiente e Desenvolvimento Sustentável (Semad), pelos Conselhos Estaduais de Política Ambiental (Copam) e de Recursos Hídricos (CERH) e pelos órgãos vinculados: Fundação Estadual do Meio Ambiente (Feam), Instituto Estadual de Florestas (IEF) e Instituto Mineiro de Gestão das Águas (Igam).

A Semad atua como secretaria executiva do Copam e do CERH, exercendo a coordenação e o planejamento do Sisema como um todo, visando alcançar o desenvolvimento sustentável (MINAS GERAIS, 1995). O Copam é um conselho normativo, consultivo, colegiado e deliberativo que formula a política estadual do meio ambiente, através de suas Deliberações Normativas, tendo inclusive, poder de polícia, o que o legitima a aplicar sanções previstas em lei, como multas ou até mesmo embargos e suspensão das atividades (MINAS GERAIS, 1977).

A Feam executa e implanta políticas de preservação e proteção do meio ambiente, monitora a qualidade do ar, água e solo, promove a educação e a pesquisa ambiental, fiscaliza projetos e empresas, além de subsidiar o Copam no licenciamento ambiental e apoiar tecnicamente as instituições do Sisema (MINAS GERAIS, 2008b); o IEF propõe, coordena e executa a atividade agrícola, pecuária e florestal (MINAS GERAIS, 1962); e o Igam é 
responsável por planejar e promover ações direcionadas à preservação da quantidade e da qualidade das águas de Minas Gerais (MINAS GERAIS, 2008a).

Existem, ainda, as Superintendências Regionais de Regularização Ambiental (Supram) que tem por finalidade planejar, supervisionar, orientar e executar as atividades relativas à política estadual de proteção do meio ambiente e de gerenciamento dos recursos hídricos formulada e desenvolvida pela Semad dentro de suas áreas de abrangência territorial, sendo nove no total: Central-Metropolitana, Alto São Francisco, Jequitinhonha, Leste de Minas, Noroeste, Norte de Minas, Sul de Minas, Triângulo Mineiro e Zona da Mata (SEMAD, 2013a) - Figura 6.

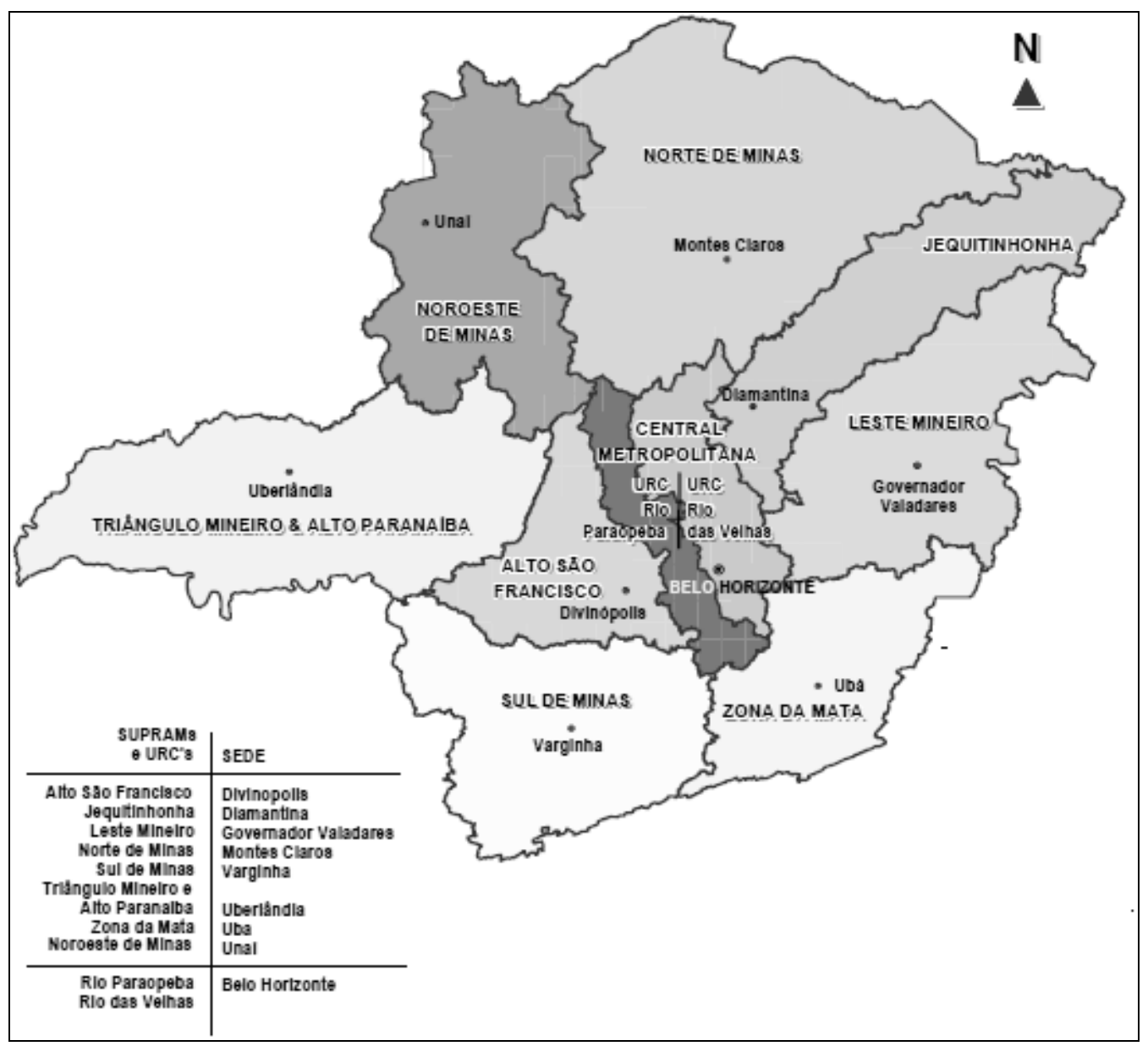

Figura 6 - Localização das Supram e suas respectivas sedes.

Fonte: adaptado Semad (2013b).

Até 2003, todo o processo de licenciamento ambiental era realizado de modo centralizado, em Belo Horizonte, e de forma segmentada: ao IEF cabia a avaliação dos impactos sobre a vegetação e regularização de reservas legais e intervenção em áreas de preservação permanente; ao Igam, a análise e concessão do uso dos recursos hídricos; e à Feam, a 
avaliação dos impactos concernentes aos resíduos sólidos, ruídos, efluentes líquidos e atmosféricos, provenientes de atividades industriais, minerárias e obras de infraestrutura (RODRIGUES, 2010).

Contudo, com a Lei Delegada $n^{\circ}$ 62/2003 (MINAS GERAIS, 2003), iniciou-se um processo de mudanças na organização interna e nas funções dos órgãos e instituições integrantes do Sisema. Foi, então, adotado um modelo interdisciplinar, compartilhado pela Feam, IEF e Igam e onde um parecer único é fornecido para cada processo de licenciamento ambiental. Além da unificação das entidades, foi estabelecida a regionalização na qual, sob o aspecto técnico-operacional, todos os processos de regularização ambiental passam a ser formalizados nas respectivas Supram. De outro modo, é responsabilidade de cada Supram o licenciamento ambiental de empreendimentos em sua região de abrangência.

O presente trabalho volta-se para a Supram Sul de Minas, com sede na cidade de Varginha e responsável por 178 municípios localizados no Sul do estado de MG, com uma área de $62.830,85 \mathrm{~km}^{2}$ e uma população de 2.711 .546 habitantes no ano de 2002 (SEMAD, 2013b).

A superintendência foi criada em 15 de dezembro de 2003, trabalhando inicialmente com o licenciamento de empreendimentos das classes 3 e 4 (de médio potencial de impacto, conforme a legislação estadual) e, após 2006, também com os empreendimentos classes 5 e 6. A maior parte dos processos de licenciamento arrolados neste órgão é em caráter corretivo, voltados para empreendimentos instalados sem a obtenção da licença ambiental e que, posteriormente, procuram a sua regularização.

Dentro do sistema de licenciamento, além do corpo técnico das Supram, tem papel importante o Copam. Ele é formado por uma presidência, uma secretaria executiva, uma plenária (sua formação é paritária entre o poder público e a sociedade civil e responsável pela edição das deliberações normativas deste conselho), Câmara Normativa Recursal, Câmaras Temáticas (Energia e Mudanças Climáticas; Mineração e Infraestrutura; Atividades Agrossilvopastoris; Instrumentos de Gestão Ambiental; e Proteção à Biodiversidade e de Áreas Protegidas) e as unidades regionais colegiadas - URC (no total de 10, conforme a Figura 6) (MINAS GERAIS, 2007). Tem destaque as URC, que são responsáveis pelas decisões sobre o (in)deferimento das licenças ambientais em sua área de abrangência, para os casos de processos de licenciamento que contam com a AIA, excetuando-se os processos de emissão de Autorização Ambiental de Funcionamento (AAF).

As principais legislações estaduais que tratam sobre o licenciamento ambiental são o Decreto Estadual $n^{\circ}$ 44.844/2008 e a Deliberação Normativa n. ${ }^{\circ}$ 74, de 09 de setembro de 2004, que estabelece critérios para classificação, segundo o porte e potencial poluidor, de 
empreendimentos e atividades modificadoras do meio ambiente passíveis de autorização ou de licenciamento ambiental no nível estadual (empreendimentos classe 1, 2, 3, 4, 5 e 6), determina normas para indenização dos custos de análise de pedidos de autorização e de licenciamento ambiental, e dá outras providências (COPAM, 2004). Ainda existem DN que regulamentam as especificidades do processo de licenciamento para diferentes tipos de empreendimentos, como por exemplo, a DN $\mathrm{n}^{\text {o }} 130 / 2009$ que trata de atividades agrossilvopastoris. No período de abril a julho de 2012, a Semad lançou um Chamamento Público com o objetivo de convidar a sociedade civil organizada e as pessoas jurídicas para apresentarem propostas de alteração de texto, dos parâmetros de porte e potencial poluidor, inclusão ou exclusão de atividades passíveis de regularização ambiental no Estado, constantes do Anexo Único da Deliberação Normativa (DN) Copam nº 74/2004 (SEMAD, 2012).

Visando sanar uma deficiência desta deliberação em relação à ausência de critérios locacionais na definição da classe do empreendimento, encontra-se em discussão a implementação de um sistema de análise do fator locacional associado ao grau de vulnerabilidade ambiental da área onde se localizará o empreendimento, podendo este variar de 0 a 2, de acordo com a vulnerabilidade do meio. Assim, além dos critérios de porte e potencial poluidor, o enquadramento dos empreendimentos em classes, que passariam a ser 8 , levaria em consideração a vulnerabilidade do meio, dada pelo Zoneamento Ecológico Econômico do Estado de Minas Gerais, aprovado pela DN Copam n ${ }^{\circ}$ 129/2008. (Maior detalhamento sobre os procedimentos para o enquadramento dos empreendimentos em classes será apresentado no Item 5.2.1.1.b).

\subsection{PROCEDIMENTOS METODOLÓGICOS}

\subsubsection{Levantamento do quadro geral de aplicação da AIA no Brasil}

Para o estabelecimento dos procedimentos licenciamento com AIA nos estados brasileiros foi enviado um questionário aos funcionários dos 27 (incluindo o Distrito Federal) órgãos ambientais estaduais e também do órgão ambiental federal (Ibama). A fim de possibilitar a abrangência de todos os estados brasileiros, a aplicação do questionário foi realizada via correio eletrônico. Primeiramente, foi estabelecido contato através dos endereços de e-mail 
disponíveis nas páginas do órgão ambiental ou que fizessem parte da base de dados do grupo de pesquisa. O funcionário respondente deveria, necessariamente, fazer parte do corpo técnico do órgão ambiental e ter conhecimento de todo o processo de AIA e licenciamento.

O modelo de questionário e sua aplicação via correio eletrônico passaram por uma fase de testes com o órgão ambiental do estado do Espírito Santo (escolhido pela disponibilidade em cooperar do técnico do órgão ambiental), visando verificar a clareza das questões apresentadas e avaliar a adequabilidade do instrumento em relação aos objetivos estabelecidos. O questionário visou obter informações sobre as legislações norteadoras e os procedimentos realizados para cada etapa do processo: critérios para triagem, definição do escopo e existência de termos de referência específicos, tipos de estudos ambientais e casos onde se aplicam, critérios para a análise técnica, formas de participação pública, elementos orientadores para a tomada de decisão e meios de acompanhamento (Apêndice I).

De modo complementar às informações levantadas pelos questionários, foi realizada uma análise de conteúdo das informações disponíveis nas páginas dos respectivos órgãos ambientais e das legislações apontadas e demais documentos citados nas respostas do questionário.

\subsubsection{Seleção dos estudos de caso}

\subsubsection{São Paulo}

Para o estado de SP, foram dadas vistas a 20 processos de licenciamento instruídos com base em EIA/Rima (como as análises realizadas não foram de natureza quantitativa, este número foi considerado suficiente para o desenvolvimento da pesquisa, suficiente em termos de representatividade e executável dentro do tempo disponível para a realização da pesquisa). Para a seleção destes processos, inicialmente, foi solicitada ao Daia/Cetesb uma listagem dos processos de licenciamento que tramitaram neste órgão, desde a promulgação da Resolução SMA n 54/2004 até janeiro de 2012, época que se iniciou os trabalhos de campo. Nesta relação estava disponível o tipo de estudo ambiental envolvido no processo. De acordo com a listagem disponibilizada, no referido período, tramitaram no Daia/Cetesb 254 processos de licenciamento com AIA, cujos EIA/Rima já haviam sido protocolados (não era de interesse do 
presente trabalho, por objetivar analisar o sistema como um todo, processos de licenciamento com AIA que ainda estavam na fase de definição de escopo). Estes processos foram agrupados conforme as seguintes tipologias:

- Saneamento (aterros industriais e/ou sanitários, sistemas de tratamento de resíduos sólidos industriais e urbanos, locais para transbordo de resíduos sólidos, sistemas de abastecimento e tratamento de água, sistemas de tratamento e disposição de esgoto sanitário, obras de drenagem, dragagens e obras de transposição de bacia hidrográfica);

- Loteamento e parcelamento do solo (condomínios, conjuntos habitacionais, distritos industriais, estruturas de lazer, loteamentos, loteamentos mistos com uso industrial e projetos urbanísticos);

- Dutos (gasodutos e dutos diversos);

- Transporte (aeroportos, corredores de transporte, ferrovias, trens metropolitanos, terminais de carga, portos e rodovias);

- Atividades industriais (refinarias, usinas de açúcar e álcool, extração mineral e demais indústrias);

- Geração de energia (hidrelétricas, termoelétricas e linhas de transmissão).

De acordo com a representatividade de cada uma destas tipologias no número total e considerando uma amostragem preestabelecida de 20 processos a serem analisados em cada estado, determinou-se o número de processos a serem levantados para cada categoria (Tabela 3).

Tabela 3 - Distribuição dos processos de licenciamento com EIA/Rima tramitados na Cetesb de 2004jan/2012 e dos processos analisados, de acordo com a tipologia do empreendimento.

\begin{tabular}{lccc}
\hline Categoria de empreendimento & $\begin{array}{c}\mathbf{N}^{\circ} \text { total de } \\
\text { processos }\end{array}$ & $\mathbf{\%}$ & $\begin{array}{c}\mathbf{N}^{\circ} \text { de processos a serem } \\
\text { analisados }\end{array}$ \\
\hline Saneamento & 40 & 15,8 & 3 \\
\hline Loteamento e parcelamento do solo & 44 & 17,3 & 3 \\
\hline Dutos & 8 & 3,1 & 1 \\
\hline Transporte & 23 & 9,1 & 2 \\
\hline Atividades industriais & 126 & 49,6 & 10 \\
\hline Geração de energia & 13 & 5,1 & $\mathbf{2 0}$ \\
\hline Total & $\mathbf{2 5 4}$ & $\mathbf{1 0 0 , 0}$ & \\
\hline
\end{tabular}

Dentro de cada categoria, a seleção dos processos foi feita de modo aleatório, através de sorteio. Caso o processo escolhido não estivesse disponível para consulta no órgão ambiental, ele era substituído aleatoriamente por outro dentro da mesma categoria de tipologia de empreendimento. Em relação à amostra, vale dizer que foi necessário inverter o número de 
processos para as categorias Transporte (um processo analisado) e Geração de energia (dois processos analisados), por conta da indisponibilidade de processos no momento da coleta de dados.

A relação dos processos analisados é apresentada a seguir, na Tabela 4.

Tabela 4 - Relação dos processos de licenciamento com EIA/Rima analisados no estado de SP.

\begin{tabular}{|c|c|c|c|c|c|c|}
\hline $\begin{array}{l}\text { Categoria } \\
\left(\mathbf{n}^{\circ} \text { de }\right. \\
\text { processos })\end{array}$ & Processo & Ano & Tipo de Empreendimento & $\begin{array}{l}\text { Licença } \\
\text { envolvida }\end{array}$ & Projeto & Situação \\
\hline \multirow{3}{*}{$\begin{array}{l}\text { Saneamento } \\
\text { (3) }\end{array}$} & 13705 & 2002 & $\begin{array}{c}\text { Sistema de tratamento de resíduos } \\
\text { sólidos industriais }\end{array}$ & LP & Novo & $\begin{array}{l}\text { Licença } \\
\text { emitida }\end{array}$ \\
\hline & 13522 & 2004 & $\begin{array}{l}\text { Modernização da estação de } \\
\text { transbordo de resíduos sólidos }\end{array}$ & LP & Novo & Indeferido \\
\hline & 13522 & 2007 & $\begin{array}{c}\text { Central de triagem, tratamento e } \\
\text { disposição de resíduos sólidos } \\
\text { domiciliares } \\
\end{array}$ & LP & Modernização & $\begin{array}{l}\text { Licença } \\
\text { emitida }\end{array}$ \\
\hline \multirow{3}{*}{$\begin{array}{l}\text { Loteamento } \\
\qquad(3)\end{array}$} & 13558 & 2004 & Loteamento residencial & LP & Novo & $\begin{array}{l}\text { Licença } \\
\text { emitida }\end{array}$ \\
\hline & 13503 & 2007 & Loteamento residencial & LP & Novo & $\begin{array}{l}\text { Licença } \\
\text { emitida }\end{array}$ \\
\hline & 13638 & 2007 & Distrito industrial & LP & Novo & $\begin{array}{l}\text { Licença } \\
\text { emitida }\end{array}$ \\
\hline Duto (1) & 13602 & 2007 & Gasoduto & LP & Novo & $\begin{array}{l}\text { Licença } \\
\text { emitida }\end{array}$ \\
\hline $\begin{array}{l}\text { Transporte } \\
\text { (1) }\end{array}$ & 13509 & 2005 & Ampliação de Aeroporto & LP & Ampliação & $\begin{array}{c}\text { Processo } \\
\text { paralisado }\end{array}$ \\
\hline \multirow{10}{*}{$\begin{array}{l}\text { Indústria } \\
\qquad(10)\end{array}$} & 13734 & 2004 & $\begin{array}{c}\text { Usina de açúcar e álcool - } \\
\text { implantação de unidade } \\
\text { agroindustrial }\end{array}$ & LP & Novo & $\begin{array}{l}\text { Licença } \\
\text { emitida }\end{array}$ \\
\hline & 13572 & 2005 & Indústria alimentícia & LP & Ampliação & $\begin{array}{l}\text { Licença } \\
\text { emitida }\end{array}$ \\
\hline & 13625 & 2005 & $\begin{array}{l}\text { Mineração - Lavra de granito, } \\
\text { feldspato e areia para construção } \\
\text { civil e indústria cerâmica }\end{array}$ & LP & Correção & Arquivado \\
\hline & 13702 & 2005 & $\begin{array}{c}\text { Usina de açúcar e álcool - } \\
\text { ampliação industrial e agrícola }\end{array}$ & LP & Ampliação & Indeferido \\
\hline & 13534 & 2007 & $\begin{array}{c}\text { Mineração - Lavra e } \\
\text { beneficiamento de granito para } \\
\text { produção de brita }\end{array}$ & LP & Novo & $\begin{array}{l}\text { Licença } \\
\text { emitida }\end{array}$ \\
\hline & 13545 & 2007 & $\begin{array}{c}\text { Ampliação da produção de } \\
\text { biodiesel e solventes especiais }\end{array}$ & LP & Ampliação & $\begin{array}{l}\text { Licença } \\
\text { emitida }\end{array}$ \\
\hline & 13854 & 2007 & $\begin{array}{l}\text { Usina de açúcar e álcool - } \\
\text { ampliação industrial }\end{array}$ & LP & Ampliação & $\begin{array}{l}\text { Licença } \\
\text { emitida }\end{array}$ \\
\hline & 1683 & 2008 & Indústria automotiva & LP e LI & Novo & $\begin{array}{l}\text { Licença } \\
\text { emitida }\end{array}$ \\
\hline & 13 & 2009 & $\begin{array}{l}\text { Destilaria de álcool e usina de } \\
\text { açúcar }\end{array}$ & LP & Ampliação & $\begin{array}{l}\text { Licença } \\
\text { emitida }\end{array}$ \\
\hline & 3827 & 2009 & $\begin{array}{c}\text { Usina de açúcar e álcool - } \\
\text { ampliação industrial e agrícola }\end{array}$ & LP & Ampliação & $\begin{array}{l}\text { Licença } \\
\text { emitida }\end{array}$ \\
\hline \multirow{2}{*}{$\begin{array}{l}\text { Geração de } \\
\text { energia ( } 2)\end{array}$} & 13724 & 2007 & Termoelétrica & LP & Novo & Indeferido \\
\hline & 258 & 2009 & $\begin{array}{c}\text { Implantação de Pequena Central } \\
\text { Hidrelétrica }\end{array}$ & LP & Novo & Arquivado \\
\hline
\end{tabular}




\subsubsection{Sul de Minas Gerais}

Para o Sul de Minas, também foi solicitada a relação dos processos que tramitaram na Supram Sul de Minas desde a edição da DN Copam n ${ }^{\circ}$ 74/2004 até janeiro de 2012. Contudo, foi verificado que esta relação não apresentava o tipo de estudo ambiental envolvido no processo, não sendo, portanto, útil para a escolha dos processos. Assim, foi necessário o desenvolvimento de outro método para a seleção dos casos a serem analisados.

A solicitação de vistas é feita a partir do número de identificação do processo que se deseja examinar, número este não disponibilizado pelo órgão ambiental. Porém, como a solicitação das licenças e a comunicação da realização de audiência pública devem ter publicidade em jornais, entre eles no Diário Oficial do Estado de Minas Gerais (DOE-MG), o levantamento do número de identificação dos processos no órgão ambiental foi feito através de sites de busca e da página do DOE-MG na internet. Assim, foram identificados, ao acaso, processos de licenciamento com AIA, que se acreditava terem sido subsidiados por EIA/Rima, com tramitação na Supram Sul de Minas posterior à publicação da DN Copam n 74/2004. Uma vez identificado o número do processo, era verificada sua disponibilidade para vistas na Supram Sul de Minas. Este procedimento foi repetido até que 22 processos fossem identificados, 17 deles instruídos com base em EIA/Rima (Tabela 5).

Logo, não foi possível distribuir a amostra coletada em MG segundo a mesma distribuição adotada para o estado de SP, em termos de representatividade de cada categoria de empreendimento. Mesmo assim, foram utilizadas as mesmas categorias para agrupar os processos, sendo que na amostra coletada em MG não havia nenhum empreendimento de Transporte.

A organização dos processos em MG é diferente de SP, sendo que o mesmo empreendimento recebe um número de processo diferente para cada etapa do licenciamento (LP, LI e LO). Assim, os processos 03405/2006/001/2007, 03405/2006/002/2008 e 03405/2006/003/2009 tratavam do mesmo empreendimento de gasoduto nas diferentes etapas do licenciamento (LP, LI e LO) e os processos 10889/2009/001/2010 e 10889/2009/002/2010 do mesmo empreendimento de contenção de enchentes (LP e LI). 
Tabela 5 - Relação dos processos de licenciamento analisados no estado de MG (regional Sul).

\begin{tabular}{|c|c|c|c|c|c|c|}
\hline $\begin{array}{l}\text { Categoria } \\
\left(\mathrm{n}^{\circ} \text { de }\right. \\
\text { processos })\end{array}$ & Processo & $\begin{array}{c}\text { Tipo de } \\
\text { Empreendimento }\end{array}$ & $\begin{array}{l}\text { Licença } \\
\text { envolvida }\end{array}$ & $\begin{array}{c}\text { Classe } \\
(*)\end{array}$ & $\begin{array}{c}\text { Estudo } \\
\text { envolvido }\end{array}$ & Situação \\
\hline \multirow{3}{*}{$\begin{array}{l}\text { Saneamento } \\
\text { (3) }\end{array}$} & $10202 / 2008 / 002 / 2008$ & $\begin{array}{l}\text { Sistema de tratamento de } \\
\text { resíduos sólidos } \\
\text { industriais }\end{array}$ & LP & 6 & EIA/Rima & $\begin{array}{l}\text { Licença } \\
\text { emitida }\end{array}$ \\
\hline & $10889 / 2009 / 001 / 2010$ & $\begin{array}{l}\text { Sistema integrado de } \\
\text { contenção de enchente }\end{array}$ & LP & 6 & EIA/Rima & $\begin{array}{l}\text { Licença } \\
\text { emitida }\end{array}$ \\
\hline & $10889 / 2009 / 002 / 2010$ & $\begin{array}{l}\text { Sistema integrado de } \\
\text { contenção de enchente }\end{array}$ & LI & 6 & - & $\begin{array}{l}\text { Licença } \\
\text { emitida }\end{array}$ \\
\hline $\begin{array}{c}\text { Loteamento } \\
(1)\end{array}$ & $13129 / 2010 / 001 / 2011$ & Distrito industrial & LP & 5 & EIA/Rima & $\begin{array}{l}\text { Licença } \\
\text { emitida }\end{array}$ \\
\hline \multirow{3}{*}{ Duto (3) } & 03405/2006/001/2007 & Gasoduto & LP & 5 & EIA/Rima & $\begin{array}{l}\text { Licença } \\
\text { emitida }\end{array}$ \\
\hline & 03405/2006/002/2008 & Gasoduto & LI & 5 & - & $\begin{array}{l}\text { Licença } \\
\text { emitida }\end{array}$ \\
\hline & 03405/2006/003/2009 & Gasoduto & LO & 5 & - & $\begin{array}{l}\text { Licença } \\
\text { emitida }\end{array}$ \\
\hline \multirow{12}{*}{$\begin{array}{l}\text { Indústria } \\
\text { (12) }\end{array}$} & $00229 / 1995 / 005 / 2005$ & $\begin{array}{l}\text { Mineração - Lavra de } \\
\text { rochas ornamentais }\end{array}$ & $\begin{array}{c}\text { Renovação } \\
\text { de LO }\end{array}$ & 3 & Rada & $\begin{array}{l}\text { Licença } \\
\text { emitida }\end{array}$ \\
\hline & $13635 / 2006 / 001 / 2008$ & $\begin{array}{l}\text { Mineração - Pilha de } \\
\text { rejeito/estéril }\end{array}$ & $\mathrm{LP}+\mathrm{LI}$ & 3 & RCA & $\begin{array}{l}\text { Licença } \\
\text { emitida }\end{array}$ \\
\hline & 00085/1980/085/2009 & $\begin{array}{c}\text { Mineração - Ampliação } \\
\text { de Barragem de } \\
\text { contenção de } \\
\text { rejeitos/resíduos }\end{array}$ & $\mathrm{LP}+\mathrm{LI}$ & 3 & EIA/Rima & $\begin{array}{l}\text { Licença } \\
\text { emitida }\end{array}$ \\
\hline & 00287/1994/009/2009 & $\begin{array}{l}\text { Mineração - Lavra de } \\
\text { rochas ornamentais }\end{array}$ & LOC & 5 & EIA/Rima & $\begin{array}{l}\text { Licença } \\
\text { emitida }\end{array}$ \\
\hline & 00116/2000/004/2010 & $\begin{array}{l}\text { Mineração - Lavra de } \\
\text { sienito }\end{array}$ & LOC & 3 & EIA/Rima & $\begin{array}{l}\text { Licença } \\
\text { emitida }\end{array}$ \\
\hline & 07060/2010/001/2010 & $\begin{array}{l}\text { Mineração - Lavra de } \\
\text { mármores e granitos }\end{array}$ & LP+LI & 3 & EIA/Rima & $\begin{array}{l}\text { Licença } \\
\text { emitida }\end{array}$ \\
\hline & 00085/1980/091/2011 & $\begin{array}{l}\text { Mineração - Ampliação } \\
\text { de Barragem de } \\
\text { contenção de } \\
\text { rejeitos/resíduos }\end{array}$ & $\mathrm{LP}+\mathrm{LI}$ & 6 & EIA/Rima & $\begin{array}{l}\text { Licença } \\
\text { emitida }\end{array}$ \\
\hline & 00259/2000/008/2011 & $\begin{array}{l}\text { Mineração - Extração de } \\
\text { granito }\end{array}$ & LOC & 3 & EIA/Rima & $\begin{array}{l}\text { Licença } \\
\text { emitida }\end{array}$ \\
\hline & 00362/2007/003/2011 & $\begin{array}{l}\text { Mineração - Obras de } \\
\text { infraestrutura, pilha de } \\
\text { rejeitos, e lavra de rochas } \\
\text { ornamentais }\end{array}$ & LIC & 3 & EIA/Rima & $\begin{array}{l}\text { Licença } \\
\text { emitida }\end{array}$ \\
\hline & $00812 / 2012 / 001 / 2012$ & $\begin{array}{l}\text { Mineração - Pilha de } \\
\text { rejeito }\end{array}$ & LOC & 3 & EIA/Rima & $\begin{array}{l}\text { Licença } \\
\text { emitida }\end{array}$ \\
\hline & $16872 / 2008 / 002 / 2010$ & $\begin{array}{c}\text { Mineração - Ampliação } \\
\text { da extração de água } \\
\text { mineral }\end{array}$ & LIC & 3 & EIA/Rima & $\begin{array}{l}\text { Licença } \\
\text { emitida }\end{array}$ \\
\hline & $20842 / 2005 / 007 / 2012$ & $\begin{array}{l}\text { Mineração - Ampliação } \\
\text { da Lavra de bauxita }\end{array}$ & $\mathrm{LP}+\mathrm{LI}$ & 3 & EIA/Rima & $\begin{array}{l}\text { Licença } \\
\text { emitida }\end{array}$ \\
\hline \multirow{3}{*}{$\begin{array}{l}\text { Geração de } \\
\text { energia (3) }\end{array}$} & 00508/2001/002/2005 & $\begin{array}{l}\text { Implantação de Pequena } \\
\text { Central Hidrelétrica }\end{array}$ & LP & 5 & EIA/Rima & Indeferido \\
\hline & $03522 / 2008 / 001 / 2008$ & Termelétrica & LP & 6 & EIA/Rima & Arquivado \\
\hline & $18872 / 2009 / 001 / 2009$ & Termelétrica & LP & 6 & EIA/Rima & $\begin{array}{l}\text { Licença } \\
\text { emitida }\end{array}$ \\
\hline
\end{tabular}

(*) Classe do empreendimento segundo a DN Copam n ${ }^{\circ} 74 / 2004$. 


\subsubsection{Realização das vistas aos processos}

Tanto em São Paulo como no Sul de Minas, através de formulário específico, foram solicitadas vistas aos processos selecionados. Assim, de acordo com a disponibilidade destes processos e dos técnicos, foram agendadas as visitas aos órgãos ambientais (Daia/Cetesb, localizado na cidade de São Paulo, e Supram Sul de Minas, localizada na cidade de Varginha) no período de junho de 2012 a fevereiro de 2013.

Os processos solicitados eram disponibilizados para consulta in loco no órgão ambiental, sendo as partes de interesse fotografadas para uma posterior análise e extração de dados.

\subsubsection{Aplicação da Soft Systems Methodology}

A Soft Systems Methodology (SSM) foi aplicada seguindo as quatro etapas propostas por Checkland (2000):

1. informar-se sobre uma situação problema;

2. formular modelos relevantes para a situação proposta;

3. usando os modelos, debater a situação;

4. tomar uma ação que vise a melhoria de performance dentro da situação.

\subsubsection{Levantamento da situação problema}

A identificação da situação dos sistemas de licenciamento com AIA nos estados de São Paulo e Sul de Minas Gerais foi feita com base nas seguintes atividades:

a) levantamento dos procedimentos adotados em cada estado;

b) aplicação de indicadores de efetividade para as amostras selecionadas;

c) identificação dos atores envolvidos e suas relações;

d) análise de conteúdo aplicada a toda a documentação encontrada nos processos analisados. 


\section{a) Procedimentos de licenciamento com Avaliação de Impacto Ambiental nos estados de} São Paulo e Sul de Minas Gerais

Os procedimentos de licenciamento com Avaliação de Impacto Ambiental nos dois estados foram identificados a partir das informações obtidas pela aplicação dos questionários aos funcionários do corpo técnico dos órgãos ambiental (conforme descrito no item 4.3.1); análise de legislações e informações e cartilhas de orientação disponíveis nas páginas dos respectivos órgãos ambientais; e análise de conteúdo aplicada aos processos de licenciamento selecionados.

\section{b) Aplicação dos indicadores de efetividade da AIA}

Para a seleção dos indicadores de efetividade a serem utilizados na etapa da SSM de definição da situação problema foram considerados os indicadores levantados na revisão da literatura, apresentados no item 3.3.1 e dispostos na Tabela 1. Destes indicadores foram aproveitados aqueles que se relacionam com as etapas do processo de AIA, sendo agrupados em indicadores que tratam da triagem, escopo, elaboração do estudo, análise técnica do estudo (fase técnica); participação, decisão (fase decisória); e monitoramento/acompanhamento (fase pós-licença). A partir deste agrupamento e de acordo com as características dos sistemas avaliados, foram selecionados os indicadores de efetividade a serem aplicados sobre os sistemas dos estados de SP e MG/Sul de Minas. A relação dos indicadores encontrados na literatura para as diferentes etapas do processo de AIA e os indicadores selecionados para aplicação são apresentados na Tabela 6.

Indicadores que tratavam sobre as etapas de triagem e monitoramento não foram aplicados, por não constarem dentre as informações coletadas nos processos selecionados. No caso de $\mathrm{SP}$, os processos são distribuídos às agências regionais da Cetesb após a emissão da LP e estabelecimento de condicionantes. No caso de $\mathrm{MG}$, os processos são reabertos sob outra numeração. Ainda, optou-se por incluir dois indicadores que não foram identificados na revisão da literatura (detalhamento do TR e realização de vistorias), mas que contemplavam referências de melhores práticas (no caso do primeiro) e características dos sistemas analisados (no caso do segundo). 
Dentre os 16 indicadores selecionados, 3 deles (Escopo participativo, Consideração de alternativas e Audiência pública) foram divididos em dois grupos, a fim de contemplar tanto a efetividade procedimental como a substantiva - conforme a clássica definição de Sadler (1996) apresentada no item 3.3.

A relação dos 19 indicadores aplicados para o diagnóstico da situação dos sistemas de licenciamento com AIA em SP e Sul de MG é apresentada na Tabela 7, bem como a justificativa para sua escolha, o tipo de efetividade avaliada, o objeto do processo analisado e a escala de avaliação. Estes indicadores foram aplicados individualmente a cada um dos processos analisados (20 processos em SP e 17 processos da Supram Sul de Minas).

A fim de complementar os resultados da aplicação dos indicadores (relacionados às efetividades procedimental e substantiva), foram aplicados indicadores relacionados ao tempo de tramitação dos processos (relacionados à efetividade transactiva).

No estado de São Paulo, o tempo de tramitação do processo foi considerado em 4 etapas: análise do PT, que compreendeu o período entre o protocolo do PT e a emissão do TR pelo órgão ambiental; elaboração do EIA/Rima, que incluiu o tempo entre a emissão do TR e a entrega do EIA/Rima; análise do EIA e das Informações complementares (IC), que ocorreu desde a entrega do EIA/Rima até a emissão do parecer técnico pelo órgão ambiental sobre a viabilidade do projeto, incluindo todos os pedidos de complementação; e, por fim, tramitação no Consema que se estendeu desde a emissão do parecer técnico até a decisão final do Consema com o (in)deferimento da licença ambiental.

Diferentemente de SP, em MG o tempo de tramitação dos processos foi considerado em apenas 2 etapas: análise do EIA e das IC, que ocorreu desde a entrega do EIA/Rima até a emissão do parecer técnico pelo órgão ambiental sobre a viabilidade do projeto, incluindo todos os pedidos de complementação; e tramitação no Copam, que se estendeu desde a emissão do parecer técnico até a decisão final do Copam com o (in)deferimento da licença ambiental. Isto porque em MG não existe a etapa de análise do PT, pois os TR já estavam previamente estabelecidos e eram disponibilizados na página do órgão ambiental.

Ainda, não foi possível avaliar o tempo empreendido na etapa de elaboração do EIA/Rima: a princípio esta etapa compreenderia os dias gastos entre a emissão do Formulário de Orientações Básicas (FOB) e a entrega do EIA/Rima. Contudo, os FOB que fazem parte dos documentos dos processos foram geralmente documentos retificadores, datados no mesmo dia de entrega do EIA/Rima ou muito próximos a esta entrega, não sendo, portanto, uma medida real do tempo que se costuma despender na elaboração dos EIA/Rima protocolados na Supram Sul de Minas. 


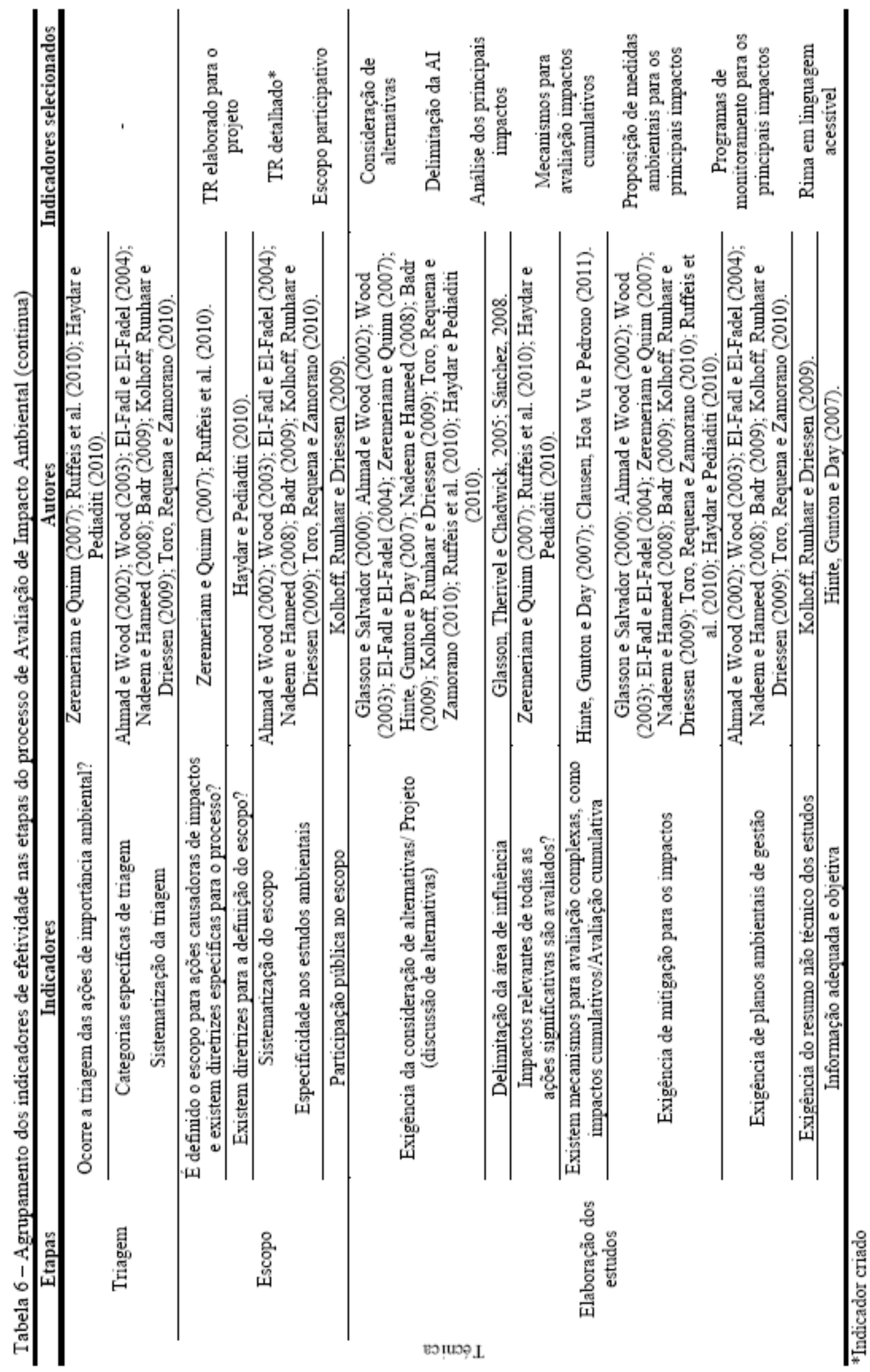




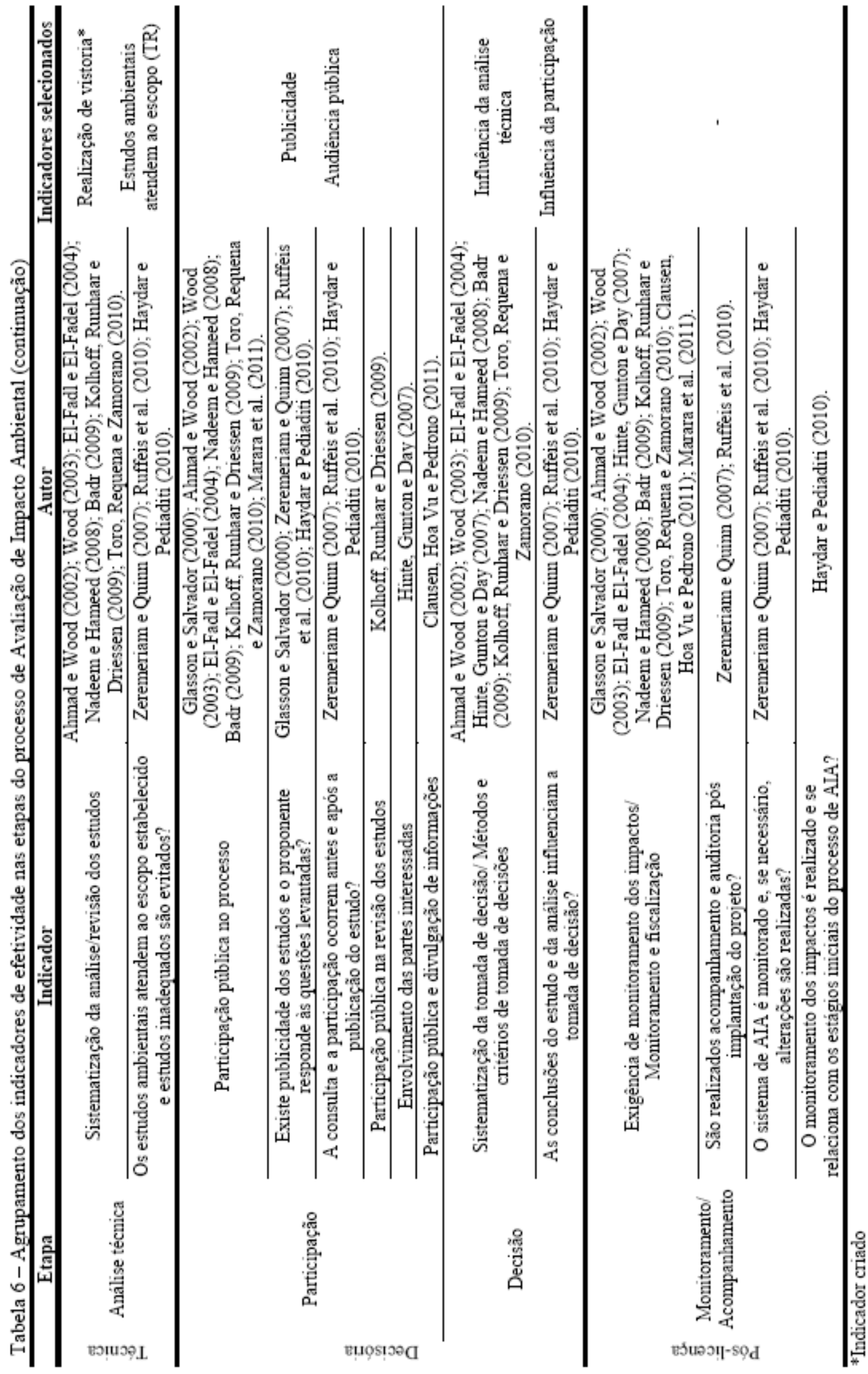




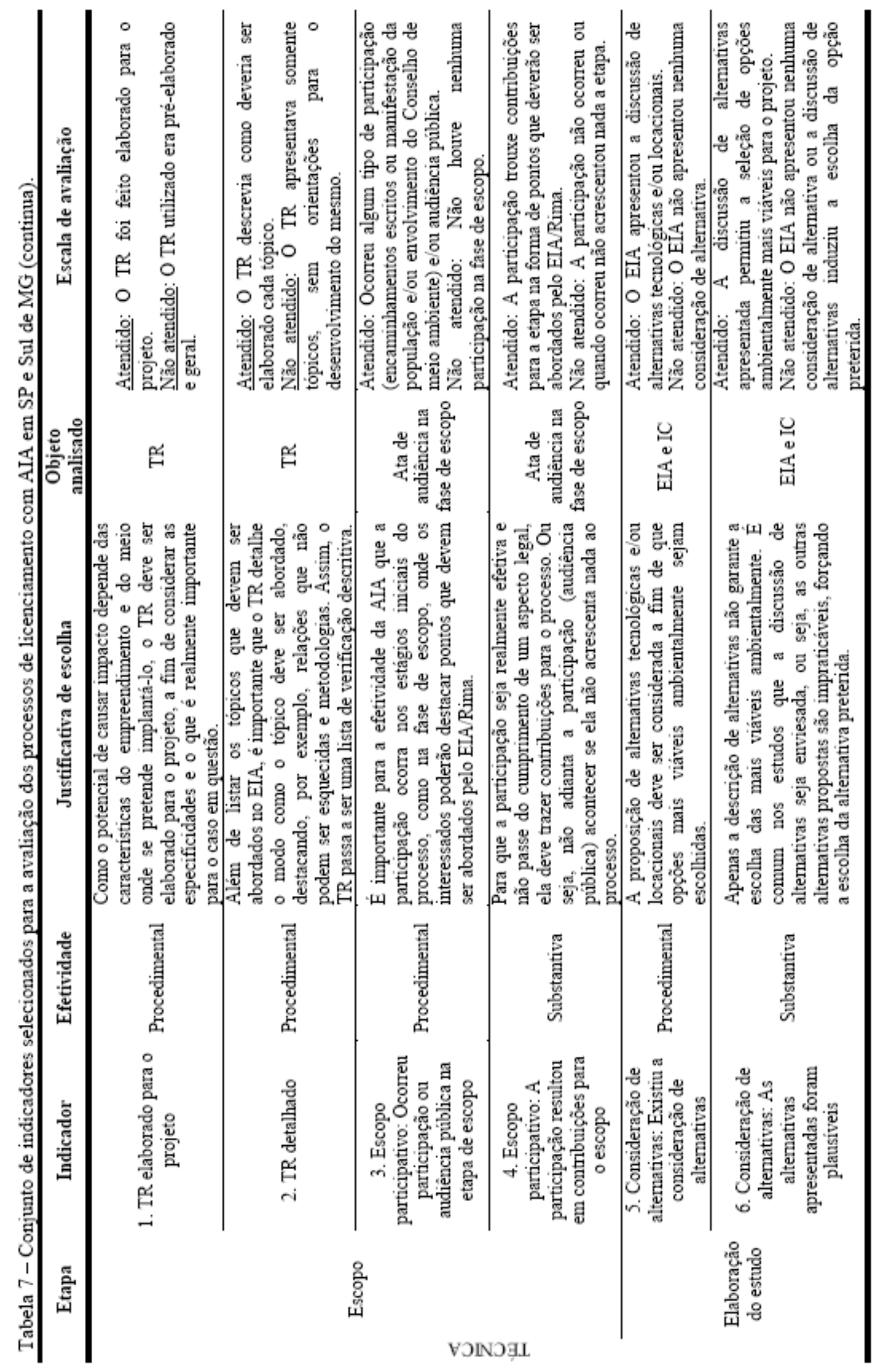




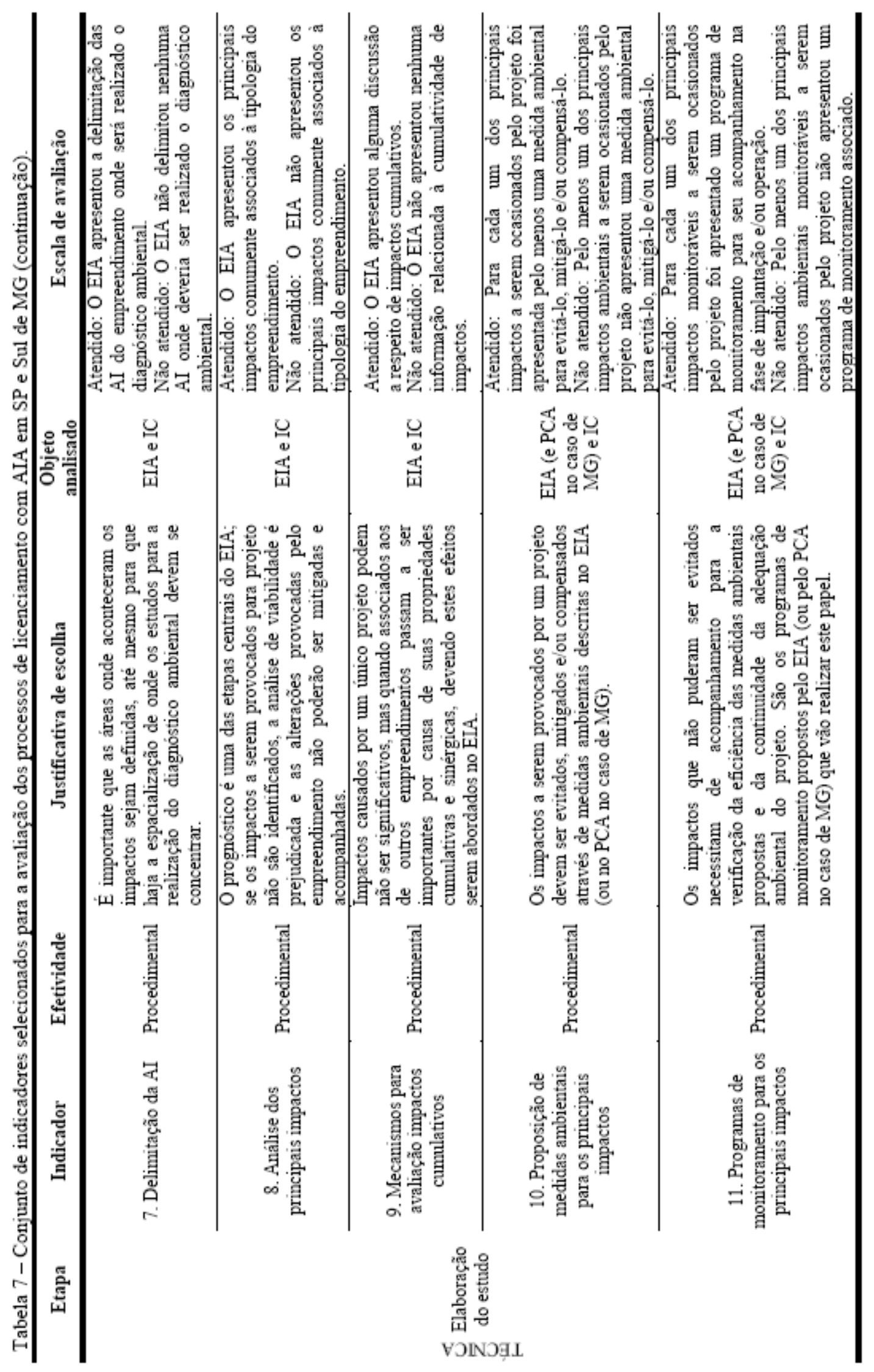




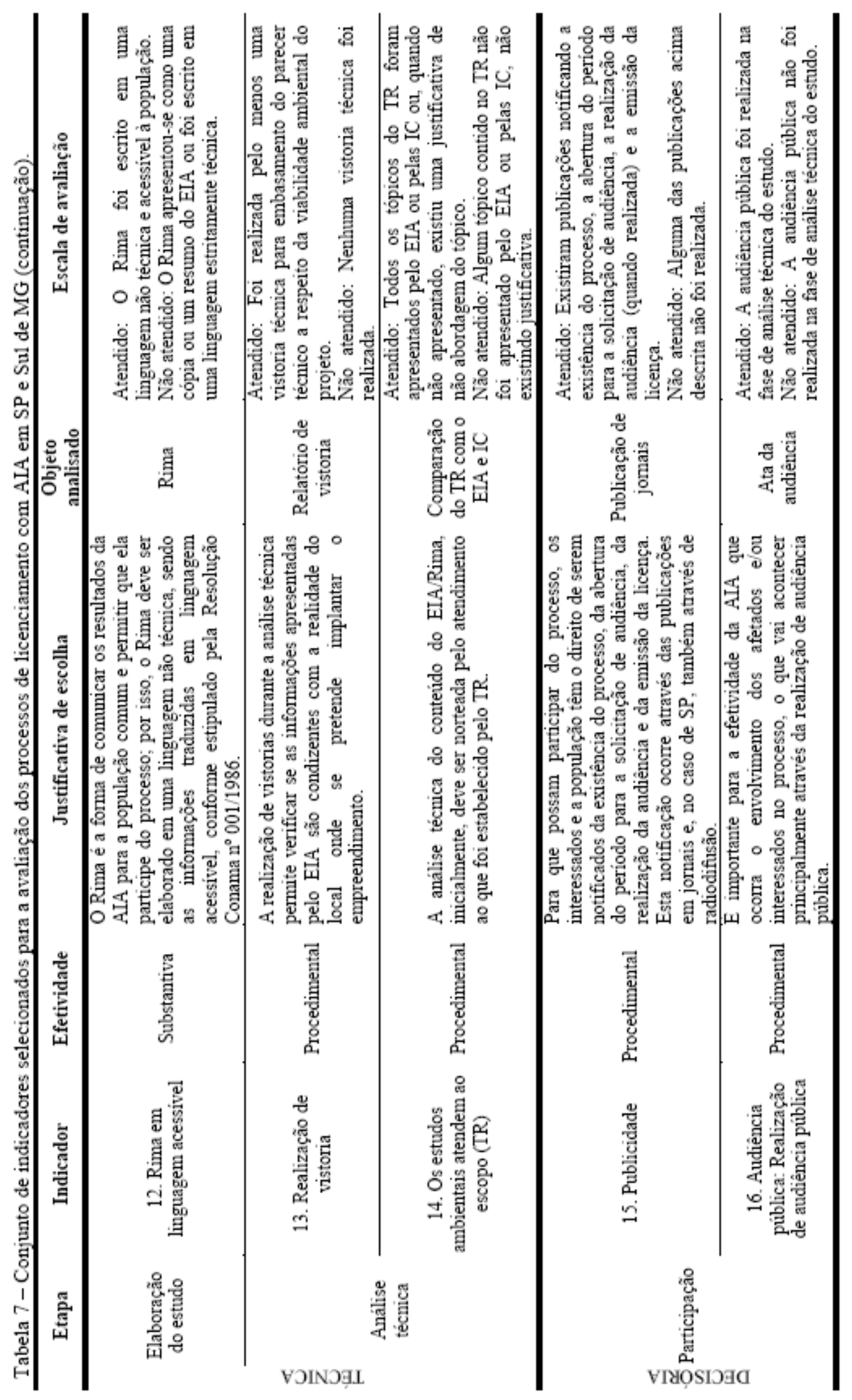




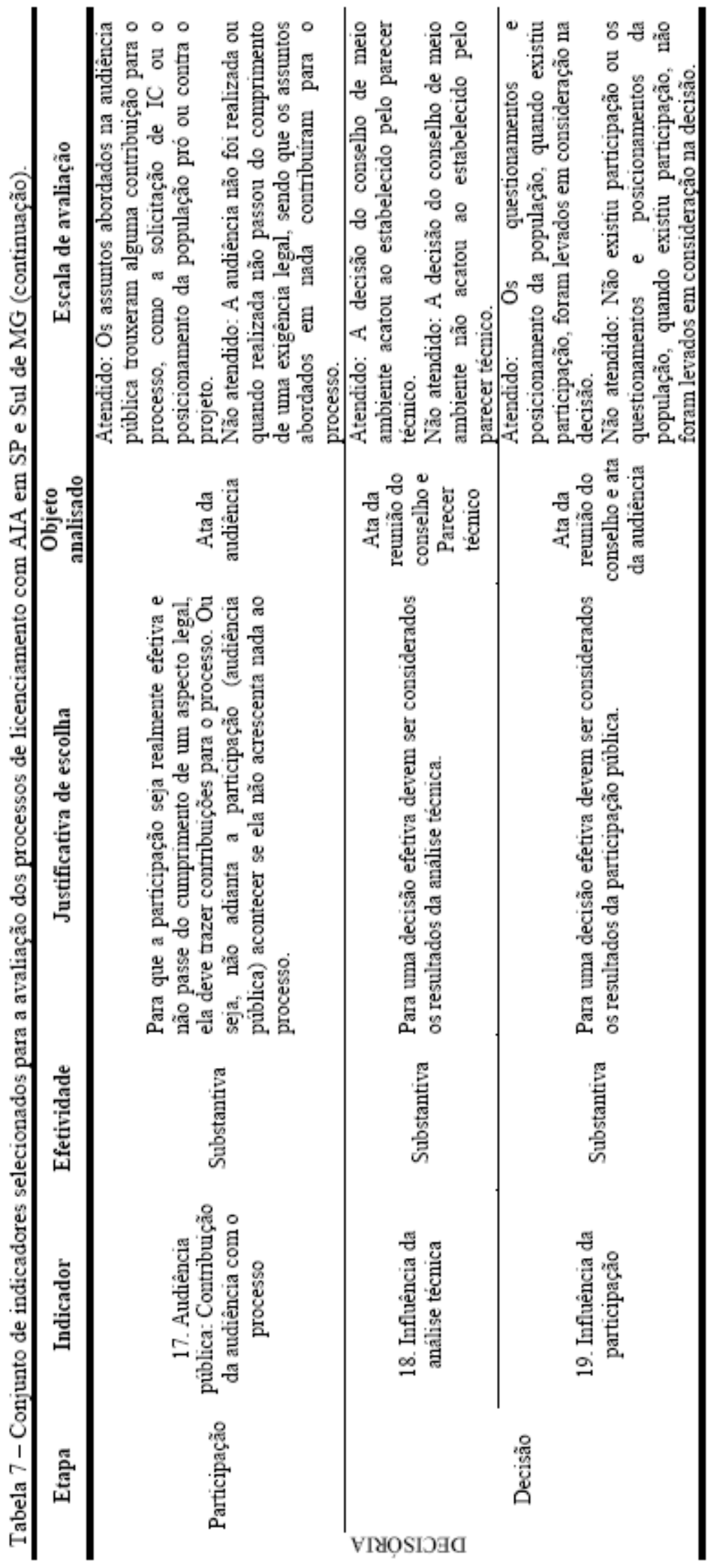




\section{c) Identificação dos atores e de suas relações}

A identificação e avaliação das relações entre os atores envolvidos nos processos de licenciamento com AIA nos estados de São Paulo e Sul de Minas Gerais foi realizada de forma similar ao que foi proposto por Hansen et al. (2013). Assim, os procedimentos contaram com as seguintes fases:

1. Identificação das Arenas de decisão: as Arenas de decisão estão relacionadas com as fases do processo que envolvem escolhas e que influenciam os resultados do processo. Cada etapa do processo de licenciamento com AIA, para cada estado, foi varrida a fim de identificar estas arenas;

2. Identificação dos atores envolvidos: atores são entendidos como indivíduos ou grupos com interesse na decisão. Foram identificados, através das vistas aos processos, os participantes atuantes dentro de cada uma das arenas de decisão apontadas pela etapa anterior;

3. Mapeamento das relações - Análise da Rede Social ou Social Network Analysis (SNA): dentro de cada arena de decisão foram identificadas as relações entre os atores envolvidos. Vale lembrar que a SNA é uma metodologia de abordagem sistêmica;

4. Análise da dinâmica do poder: a análise da dinâmica do poder baseou-se nas características (competências e formas de comunicação) das arenas de decisão, valendo-se do esquema descrito na Tabela 8.

Tabela 8 - Modelo para a caracterização das arenas de decisão.

\section{Competência formal de \\ Competência informal de decisão decisão}

Comunicação A comunicação é realizada A comunicação é realizada através de meios Formal através de meios formais e a decisão é tomada de acordo com legislações, participação e embasamento técnico.

\section{formais.}

A decisão é feita:

- por outros que não aqueles que têm a competência formal e/ou;

- focando em outra questão que não a formal e/ou;

- em outro momento que não o formal e/ou; - em outro lugar que não o indicado formalmente.

Comunicação A comunicação é realizada Informal tanto: - com outros atores além daqueles com competência formal de decisão e/ou;

- focando em outra questão que não a formal.

A comunicação é realizada tanto:

- com outros atores além daqueles com competência formal de decisão e/ou;

- relacionada a outras questões que não as formais.

A decisão é feita:

- por outros que não aqueles que têm a competência formal e/ou;

A decisão é tomada de acordo - focando em outra questão que não a formal e/ou; com legislações, participação e embasamento técnico.
- em outro momento que não o formal e/ou;

- em outro lugar que não o indicado formalmente. 


\section{d) Análise de conteúdo aplicada à documentação encontrada nos processos analisados.}

A análise de conteúdo foi aplicada aos documentos constantes dos processos analisados, com vistas à identificar informações relevantes para a aplicação e posterior interpretação dos indicadores de efetividade, bem como a quaisquer informação útil para a descrição da situação problema.

Ainda, foram realizadas algumas entrevistas não estruturadas e informais com os atores envolvidos com o processo de licenciamento com AIA em São Paulo e Sul de Minas Gerais a fim de levantar informações que pudessem contribuir para o entendimento do funcionamento dos sistemas e, consequentemente, da situação problema.

\subsubsection{Identificação de modelos relevantes para a situação proposta}

O modelo considerado relevante para a análise da situação proposta baseou-se nos critérios teóricos da AIA e nas melhores práticas internacionalmente disseminadas para este instrumento. Com base na revisão da literatura foram descritas como deveria ser e funcionar cada uma das etapas do processo de AIA - modelo conceitual, sendo considerado o modelo de análise apresentado no item 4.1 (Figura 4), que inclui as relações entre as diferentes etapas da AIA.

\subsubsection{Comparação da situação problema com o modelo}

De acordo com a comparação entre a situação dos sistemas de licenciamento com AIA nos estados de São Paulo e Sul de Minas Gerais (mundo real) e o modelo conceitual de como estes sistemas deveriam funcionar (mundo ideal), foram identificadas quais eram os pontos fortes (contribuem) e fracos (atrapalham) para a efetividade dos sistemas, sobretudo em relação à manutenção dos fluxos de informação e produtos. 
4.3.4.4. Proposição de ações de melhoria

Nesta etapa, foram indicadas possíveis ações para melhorar a efetividade dos sistemas, com base nos resultados encontrados e em revisão de literatura, contrastados com o modelo conceitual. 


\section{RESULTADOS E DISCUSSÃO}

\subsection{QUADRO GERAL DO LICENCIAMENTO COM AIA NO BRASIL}

Como a Resolução Conama n 237/1997, em seu Artigo 12, permite que o órgão ambiental competente defina, se necessário, procedimentos específicos para o processo (CONAMA, 1997), cada estado brasileiro possui seu próprio sistema de licenciamento com AIA. Cada sistema é estabelecido de acordo com o contexto presente em cada estado, sendo realizadas adaptações e simplificações.

Foram enviados questionários para os órgãos ambientais de todos os 27 estados brasileiros (incluindo o Distrito Federal) e para o órgão federal (Ibama), mas o índice de devolução com as respostas foi baixo, por volta de 33\% (9 questionários respondidos). Rahman (2001) e Gomes (2004) consideram índices de devolução por volta de $20 \%$ como já sendo aceitáveis para questionários aplicados via correio eletrônico. Contudo, o objetivo de delimitar o quadro geral dos procedimentos de AIA e licenciamento no Brasil não pode ser alcançado, sendo as especificidades e similaridades encontradas apenas para alguns estados. O questionário aplicado foi bastante prospectivo, sendo que a avaliação de cada etapa foi realizada de forma a identificar as grandes diferenças entre os estados analisados.

A análise do quadro geral do licenciamento com AIA no Brasil baseou-se nos estados da Bahia (BA), Ceará (CE), Espírito Santo (ES), Minas Gerais (MG), Pará (PA), Paraná (PR), Pernambuco (PE), Rio Grande do Sul (RS) e São Paulo (SP). Coincidentemente, estes estados, com exceção do ES e PA, estavam entre os integrantes do Programa Nacional do Meio Ambiente II - Fase 1 (2000-2006) que apoiou a implantação de projetos de aperfeiçoamento dos procedimentos de licenciamento (MMA, 2009), ou seja, são estados preocupados em participar de ações que buscam melhorias para seus sistemas.

A primeira diferença diz respeito ao quadro institucional. Alguns estados contavam apenas com um órgão seccional central, como foi o caso do ES e CE. Contudo, a maioria dos estados vem passando por um movimento de desconcentração e descentralização do órgão ambiental. Para os estados de BA, PA, PE, PR, RS e SP foram criadas agências ou unidades regionais que realizam o licenciamento ambiental nos casos de empreendimentos que geram baixo impacto e por isso são licenciados através de estudos ambientais mais simplificados; nos casos de estudos mais complexos, como o Estudo de Impacto Ambiental e respectivo 
Relatório de Impacto Ambiental (EIA/Rima), o processo é encaminhado para o órgão central que possui um corpo técnico mais robusto. Em MG, a situação é diferente: cada unidade regional é responsável por todos os processos de licenciamento, sejam eles realizados através de estudos mais simplificados ou de EIA/Rima. Segundo a Cetesb (2011), a criação de agências regionais amplia a atuação do órgão ambiental dentro do estado. $O$ processo de descentralização nestes órgãos ambientais estaduais também tem contado com iniciativas para a celebração de convênios com as prefeituras, que, uma vez provada sua capacidade técnica, dentre outros requisitos, passam a ser responsáveis pelo licenciamento de empreendimentos que causem apenas impactos locais.

Atentando-se para o processo de licenciamento em si, na Figura 7 são apresentados os procedimentos comuns aos estados analisados, sendo destacado em vermelho as etapas que apresentaram especificidades. São comuns aos estados às etapas de apresentação da proposta, triagem, estudos ambientais, análise técnica, emissão das licenças e acompanhamento.

A apresentação da proposta é feita por meio de formulários e documentos que informam a tipologia, o porte e a localização do empreendimento. A triagem é realizada, na maioria das vezes, por meio de listagens positivas e critérios de corte relacionados ao porte, baseados principalmente no Art. $2^{\circ}$ da Resolução Conama 01/1986 e no Anexo I da Resolução Conama 237/1997. As listas positivas e os critérios de corte também estão presentes nas legislações estaduais, sendo que em alguns estados, como MG, por exemplo, os empreendimentos são divididos em classes conforme seu porte e potencial poluidor. Aliados a isto, também são verificadas as características do projeto e/ou da sua localização que podem tornar o empreendimento de significativo impacto ambiental e a repercussão social e econômica do empreendimento, cabendo uma análise caso a caso.

Apesar de cada estado adotar uma terminologia diferente para os estudos ambientais destinados a avaliar a viabilidade ambiental dos empreendimentos, eles podem ser agrupados em três categorias: o EIA/Rima destinados a empreendimentos que tem grande potencial de causar impactos significativos; estudos mais simplificados como o Relatório de Controle Ambiental (RCA) no CE, ES, MG e PA e o Relatório Ambiental Preliminar (RAP) em PE, PR e SP, destinados a empreendimentos cujo potencial de causar impacto é médio; e estudos ainda mais simples para empreendimentos com baixo potencial de causar impacto, como o Estudo Ambiental Simplificado (EAS) na BA, SP e CE e o Relatório Ambiental Simplificado (RAS) no PA, PE, PR e RS. Outros estudos também podem estar envolvidos no processo, dirigidos aos planos de controle ambiental, licenciamento corretivo, monitoramento, entre outros. 


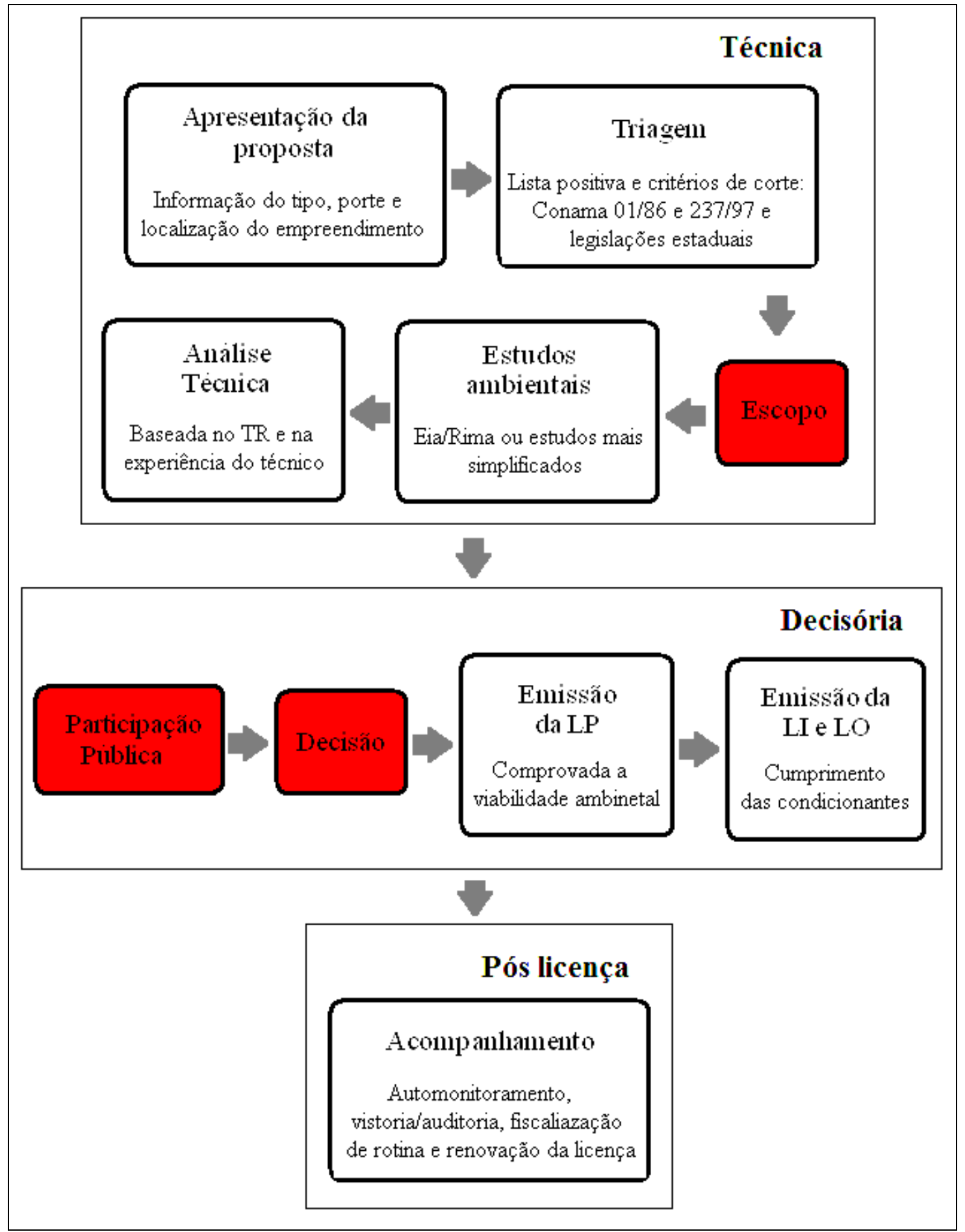

Figura 7 - Procedimentos comuns aos estados avaliados; em vermelho estão as etapas que apresentaram especificidades.

A análise técnica é feita com base na comparação do estudo com o TR e na experiência do técnico analista, verificando se todos os tópicos foram contemplados de maneira satisfatória e sendo possível o requerimento de informações complementares. 
Uma vez que a decisão é favorável à implantação do empreendimento, ocorre a emissão da LP; e, sendo comprovado o cumprimento das condicionantes através de documentação e vistorias, a emissão da LI e da LO.

O acompanhamento dos empreendimentos é feito através de fiscalizações de rotina, realização de vistorias e auditorias, análise de laudos de automonitoramento (que são exigências contidas nas licenças) e, principalmente, na revalidação da licença. Segundo apontado pelo técnico do órgão ambiental do ES, existe uma defasagem do número de servidores, o que não permite a realização do controle e monitoramento na frequência desejada.

Quanto às especificidades, elas estão presentes nas fases de escopo, participação e tomada de decisão. O escopo pode ser definido de duas formas (Figura 8): após a definição do tipo de estudo, o Termo de referência (TR) é emitido pelo órgão ambiental diretamente a partir das informações prestadas na apresentação da proposta; ou, após a definição do tipo de estudo, o empreendedor/consultoria apresenta um Plano de Trabalho (PT) que, uma vez avaliado pelo órgão ambiental, resulta no TR. A primeira situação ocorre nos estados de BA, CE, MG, PA, PE, PR e RS; e a segunda, em SP, sendo as duas possibilidades encontradas no estado do ES. O PT anterior à emissão do TR permite o diálogo entre consultoria e órgão ambiental em torno das questões fundamentais a serem abordadas no estudo.

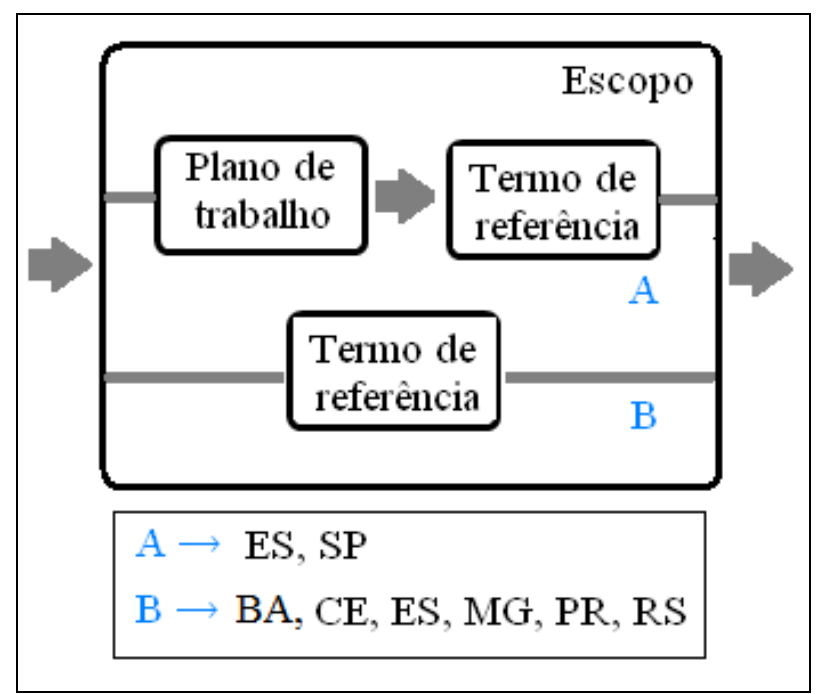

Figura 8 - Tipos de procedimentos para a definição do escopo dos estudos ambientais.

Com exceção do $\mathrm{CE}$, onde a participação fica restrita apenas a realização de audiência pública para avaliação do EIA/Rima e de PE onde a participação não é possível nas fases de triagem e escopo, os demais estados possibilitam a participação dos envolvidos em todos os 
processos, independente do tipo de estudo e em suas diversas fases - triagem, definição do escopo e tomada de decisão, seja através de solicitação de audiência pública ou do envio de contribuições escritas para o órgão licenciador. Isto está em concordância com os princípios internacionais de boas práticas, que indica que a participação do público deve ocorrer o mais cedo possível, começando na pré-avaliação e continuar por todo o processo (VASCONCELOS; HAMILTON; BARRETT, 2010). Contudo, na maioria das vezes, a prática mostra que, mesmo nestes estados onde a participação poderia ocorrer nas diferentes fases, ela fica restrita às audiências públicas associadas à etapa de análise técnica do EIA/Rima, que nem sequer acontecem em todos os processos.

No que se refere à decisão, a grande diferença é que nos estados do CE, ES, MG, PA e SP a decisão final sobre a viabilidade do empreendimento, e consequente emissão da licença ambiental, é dada pelo Conselho Estadual de Meio Ambiente; enquanto que nos estados de BA, PE, PR e RS, a decisão não passa pelo Conselho, sendo dada pelo próprio corpo técnico do órgão ambiental. Quando a decisão é dada pelo Conselho ela tende a ser menos influenciada por pressões externas (comparada com quando a decisão é dada por um único agente, como no caso das licenças emitidas pelo Ibama) e o envolvimento do Conselho no processo decisório não deixa de ser mais uma forma de participação, já que sua formação envolve diferentes segmentos da sociedade.

As diferenças encontradas entre os sistemas estaduais de licenciamento com AIA justificam ainda mais a escolha dos estados de São Paulo e Sul de Minas Gerais para uma análise mais aprofundada e avaliação da efetividade por meio de uma abordagem sistêmica. Apesar das fases de participação e tomada de decisão serem semelhantes, o quadro institucional e a etapa de escopo são bem distintas. Assim, será possível avaliar um sistema de licenciamento totalmente descentralizado (MG) e outro centralizado quando se trata de EIA/Rima (SP); e um sistema com a definição padronizada de escopo (MG) e outro com escopo sendo definido especificamente para cada caso (SP).

\subsection{APLICAÇÃO DA SOFT SYSTEMS METHODOLOGY}

A seguir serão apresentados os resultados da aplicação da SSM, segundo as 4 fases descritas por Checkland (2000): informar-se sobre uma situação problema; formular modelos 
relevantes para a situação proposta; usando os modelos, debater a situação; e tomar uma ação que vise a melhoria de performance dentro da situação.

\subsubsection{Situação problema}

O levantamento da situação em cada estado baseou-se no levantamento dos procedimentos adotados, na aplicação dos indicadores de efetividade e na identificação dos atores envolvidos e suas relações. Complementarmente na realização destes passos, foram também utilizadas informações resultantes da leitura da documentação componente dos processos de licenciamento analisados.

5.2.1.1. Procedimentos de licenciamento com Avaliação de Impacto Ambiental nos estados de São Paulo e Sul de Minas Gerais

\section{a) São Paulo}

As principais normas que regulamentam o processo de Licenciamento com AIA no estado de São Paulo são derivadas da Resolução SMA n 54/2004, que estabelece os procedimentos para o licenciamento ambiental no âmbito da atuação do Daia. Além destas, o Decreto Estadual $n^{\circ} 47.400 / 2002$ estabelece os prazos de validade das licenças, de análise, de entrega das complementações, entre outros.

As especificações de tempo presentes nestas legislações estaduais seguem as diretrizes da Resolução Conama n 237/1997: o empreendedor/consultoria tem no máximo 180 dias para a elaboração do EIA/Rima, 15 dias após sua entrega para dar publicidade ao requerimento de licença e 4 meses para responder aos pedidos de IC (o órgão ambiental pode estabelecer prazos menores para a entrega de IC, sendo no máximo de 4 meses); o órgão ambiental tem prazo máximo de 180 dias para analisar tecnicamente o EIA/Rima (são descontados os tempos gastos com as respostas das IC); e os interessados tem prazo de 45 dias após publicação do requerimento de licença para solicitar a realização de audiência pública. Não 
foi verificado na legislação o prazo que o corpo técnico do órgão ambiental tem para analisar o PT e emitir o TR.

Existem dois tipos de licenciamento no estado de SP: o chamado licenciamento convencional, voltado para atividades poluidoras e que não conta com a AIA; e o licenciamento apoiado no processo de AIA. O primeiro caso, que não é de interesse na presente pesquisa, é voltado para atividades poluidoras, geralmente, localizadas em áreas urbanas e que irão utilizar a estrutura existente de abastecimento de água e coleta de esgoto, por exemplo. Nestes casos, a incerteza sobre os impactos são reduzidas e, na maioria das vezes, existem padrões de qualidade para avaliar as alterações provocadas pela atividade. $\mathrm{O}$ estudo envolvido é o Memorial de Caracterização de Empreendimento (MCE), onde é avaliado o fluxo de massa e energia dentro do empreendimento, focando-se nas entradas e saídas do processo que ocorre no projeto. Também existe a emissão da LP, LI e LO.

A seguir, serão descritas as fases do processo de licenciamento apoiado na AIA, a partir do modelo de análise proposto.

\section{$\underline{\text { Técnica }}$}

De acordo com a Resolução SMA $n^{\circ}$ 54/2004, existem quatro possibilidades para inicialização do processo de licenciamento:

- para empreendimentos ou atividades considerados de impacto ambiental muito pequeno e não significativo, o início ocorre com a protocolização do Estudo Ambiental Simplificado (EAS) na SMA/DAIA ou nas Agências Ambientais. Após a análise do EAS, poderá ser considerada a necessidade de estudos ambientais mais aprofundados;

- para atividades ou empreendimentos considerados potencialmente causadores de degradação, com a protocolização do Relatório Ambiental Preliminar (RAP). Após a análise do RAP, poderá ser considerada a necessidade de estudos ambientais mais aprofundados;

- para atividades ou empreendimentos considerados como efetivamente causadores de significativa degradação, com a protocolização do Plano de Trabalho (PT) para emissão do Termo de Referência para posterior elaboração do EIA/Rima;

- quando não se conhece a magnitude e a significância dos impactos ambientais, com a protocolização de Consulta Prévia com vistas à definição do estudo ambiental mais adequado.

O presente estudo concentrou-se na análise dos processos de licenciamento apoiado em AIA, cujo estudo solicitado era o EIA/Rima. Assim, a triagem é baseada no potencial do 
empreendimento em causar impacto e degradação ambiental e/ou na fragilidade da área; existem linhas de corte pré-estabelecidas por cada setor que compõem o Departamento de Avaliação Ambiental de Empreendimentos para as diferentes tipologias de empreendimentos, sendo orientadas pela lista positiva contida Art. $2^{\circ}$ e no Anexo 1 da Resolução Conama 237/1997 (atividades que devem passar por licenciamento) e, para o caso de necessidade de EIA/Rima, pelo Art. $2^{\circ}$ da Resolução Conama 001/1986. Não esquecendo que em alguns casos a triagem pode ser feita caso a caso e são consideradas questões como sensibilidade e legislações da área onde se pretende instalar o empreendimento, interesse social, entre outras.

No caso da necessidade de elaboração de EIA/Rima, a definição do escopo começa com a entrega do Plano de Trabalho (PT) pelo empreendedor/consultoria no órgão ambiental. Este PT deve ser elaborado a partir do diagnóstico simplificado da área de influência do projeto e apresentar a compilação de todas as variáveis que o empreendedor entenda como significativas para a avaliação da viabilidade ambiental de sua proposta (BARRETTO; MONTAÑO, 2012) e que devem ser abordados no EIA/Rima. O órgão ambiental ao receber o PT comunica ao Consema, que é chamado a envolver-se no processo de elaboração do TR e pode avocar ou não sua participação. Existe ainda a possibilidade de ocorrer consulta pública para auxiliar na análise do PT, sendo um canal de negociação do empreendedor com a população para o arranjo do empreendimento. Uma vez analisado e aprovado, o PT dá origem ao Termo de Referência (TR). Existem empreendimentos que, devido à proximidade e similaridade dos projetos, a emissão do TR é conjunta (como foi o caso de Processo 258/2009). O PT anterior à emissão do TR permite o diálogo entre consultoria e órgão ambiental em torno das questões fundamentais a serem abordadas no estudo.

Seguindo as orientações do TR, a consultoria, elabora, então, o EIA/Rima. Após seu protocolo, passa-se a fase de análise do EIA/Rima por parte do órgão ambiental, no caso o Daia. Este órgão conta com divisões internas e diversos setores focados em áreas específicas como efluentes, emissões atmosféricas, atividades industriais, entre outros. Estes setores são chamados a participar da análise do EIA/Rima, emitindo pareceres em suas áreas de atuação, principalmente, com enfoque técnico.

Ainda, são chamadas a participar da análise do EIA/Rima outras entidades ambientais como o CBRN (Coordenadoria de Biodiversidade e Recursos Naturais, antigo Departamento Estadual de Proteção dos Recursos Naturais - DEPRN), o Comitê de Bacia, a Fundação Florestal, o Departamento de Águas e Energia Elétrica (DAEE), o Instituto do Patrimônio Histórico e Artístico Nacional (Iphan), entre outros, para darem sua contribuição na análise da viabilidade do empreendimento nos temas de sua competência. O envolvimento destes atores 
no processo será melhor discutido no item 5.2.1.3.a) deste trabalho, mas pode-se adiantar que este envolvimento visa melhorar a qualidade do processo de AIA, tornando mais robusta a análise técnica.

A análise do EIA/Rima por parte do Daia tem por base o TR: inicialmente, é verificado se todos os itens relacionados no TR foram analisados e, posteriormente, se esta análise aconteceu de forma satisfatória, obedecendo a critérios técnicos, e se a abordagem e os resultados apresentados são suficientes para orientar a tomada de decisão. Uma vez verificado que as informações apresentadas no estudo não são suficientes para a análise da viabilidade ambiental do empreendimento, informações complementares (IC) podem ser requisitadas. $\mathrm{O}$ Daia tem contato com o recurso da internet para solicitar IC: quando a IC é simples, sua solicitação tem sido feita via correio eletrônico, o que resulta em economia de tempo e em respostas mais rápidas.

O parecer resultante da análise técnica do estudo e de suas complementações contém a aprovação ou reprovação do estudo (baseada na suficiência das informações apresentadas para a tomada de decisão) e também a resposta técnica quanto à viabilidade ambiental do empreendimento, que será utilizada pelo Consema na tomada de decisão.

\section{Decisória}

Como já relatado, o sistema de licenciamento de São Paulo permite a participação da sociedade não somente na fase de decisão, mas durante todo o processo, como na definição do tipo de estudo e na elaboração do escopo (seja através de solicitação de audiência pública ou do envio de contribuições escritas para o órgão licenciador), sendo que esta participação pode ocorrer sob a forma de audiência pública ou através do envio de manifestações por escrito ao órgão ambiental. Além disso, a participação pode ocorrer mesmo quando o estudo em questão não é um EIA/Rima. Contudo, a participação é certa em todos os processos na fase de análise e decisão dos processos com EIA/Rima e esta participação se dá sob a forma de audiência pública. A dinâmica das audiências públicas (quando realizar, quem pode solicitar, composição da mesa e roteiro da audiência) é determinada pela Deliberação Consema $\mathrm{n}^{\circ}$ 50/1992, sendo o Consema responsável por presidi-la.

Com base nos resultados da audiência pública e amparado tecnicamente pelo Parecer final do Daia, o Consema toma a decisão sobre a viabilidade ambiental do empreendimento. Todos os processos passam pela apreciação do Consema, sendo que, em alguns casos, o empreendedor e a consultoria podem ser chamados a participar da reunião, a fim de prestar 
informações e esclarecimentos. Então, o conselho delibera sobre a viabilidade ambiental do empreendimento, deferindo ou indeferindo a licença ambiental, com ou sem condicionantes. Quando da aprovação, a SMA concede a LP com um elenco de exigências que devem ser cumpridas para continuação do processo e emissão das demais licenças (LI e LO).

\section{Pós-licença}

Uma vez cumpridas as exigências, a LP, a LI e a LO são emitidas e o empreendimento entra em funcionamento.

A tarefa de acompanhamento e monitoramento da maioria dos projetos no estado de SP normalmente fica a cargo da Cetesb, na figura de suas agências regionais; em raros casos, ocorre a atuação do Daia, CBRN (antigo DEPRN), DUSM e demais órgãos (DIAS; SÁNCHEZ, 2001). Por isto, o monitoramento e a fiscalização dos empreendimentos submetidos à AIA equiparam-se aos mesmos padrões aplicados àqueles que não passaram por este processo. A sociedade também pode participar do processo de acompanhamento, fiscalizando e denunciando as ações do empreendimento implantado (SÁNCHEZ, 2008).

É importante destacar que as etapas do processo contam com publicidade em jornais e rádios, de modo a manter a população informada da existência e do andamento do processo e das decisões tomadas.

A Figura 9 apresenta o resumo da interação entre as etapas do processo de licenciamento e AIA no estado de SP.

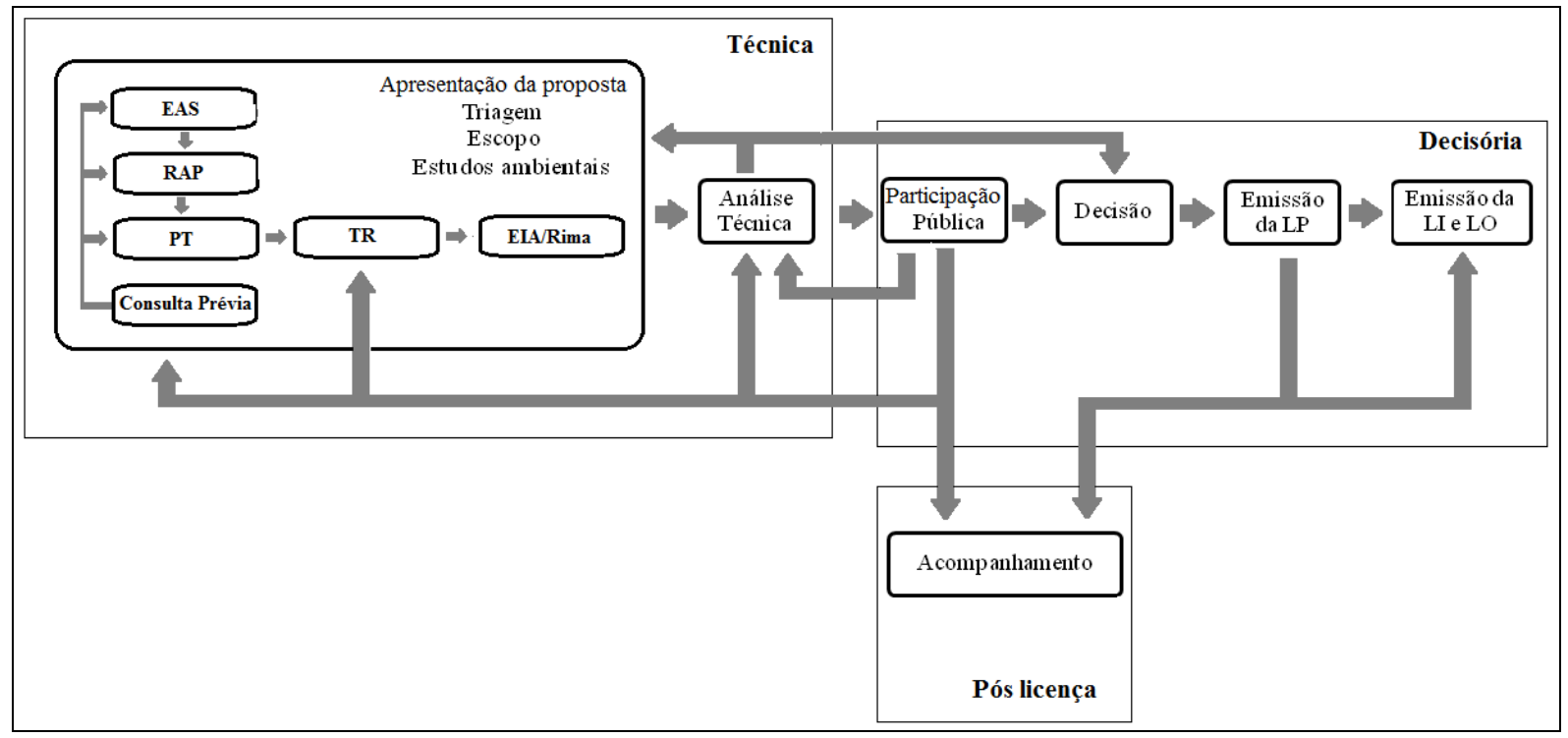

Figura 9 - Processo de Avaliação de Impacto Ambiental e Licenciamento Ambiental em SP. 


\section{b) Sul de Minas Gerais}

As principais diretrizes jurídicas do processo de Licenciamento no estado de Minas Gerais são a Deliberação Normativa (DN) do Copam $n^{\circ} 74 / 2004$, que trata de custos e classifica os empreendimentos em 6 classes de acordo com o porte e o potencial poluidor; a Resolução Semad n 390/2005, que estabelece normas para a integração dos processos de autorização ambiental de funcionamento (AAF), licenciamento ambiental, de outorga de direito de uso de recursos hídricos e de autorização para exploração florestal; e o Decreto ${ }^{\circ} 44.844 / 2008$, que entre outras funções, estabelece normas para o licenciamento ambiental e AAF.

As especificações de tempo seguem as diretrizes da Resolução Conama ${ }^{\circ}$ 237/1997 complementadas pelo Decreto $\mathrm{n}^{\circ} 44.844 / 2008$, sendo os mesmo utilizados em SP. Assim, entre outros prazos, o empreendedor/consultoria tem no máximo 180 dias para a elaboração do EIA/Rima, 15 dias após sua entrega para dar publicidade ao requerimento de licença e 4 meses para responder aos pedidos de IC (o órgão ambiental pode estabelecer prazos menores para a entrega de IC, sendo no máximo de 4 meses); o órgão ambiental tem prazo máximo de 180 dias para analisar tecnicamente o EIA/Rima (são descontados os tempos gastos com as respostas das IC); e os interessados tem prazo de 45 dias após publicação do requerimento de licença para solicitar a realização de audiência pública.

Apesar da regionalização do licenciamento nas Supram, todas elas seguem os mesmos procedimentos; contudo, cada unidade pode criar alguns mecanismos próprios, mas de certo modo existe uma unidade procedimental no estado. A seguir, serão descritas as fases do processo de licenciamento apoiado na AIA, a partir do modelo de análise proposto.

\section{$\underline{\text { Técnica }}$}

O processo de licenciamento ambiental em Minas Gerais é iniciado com o recebimento da solicitação de licenciamento do empreendedor/consultoria, mediante o preenchimento do FCE (Formulário de Caracterização do Empreendimento) com informações, principalmente, acerca do porte e localização do projeto em questão.

A etapa de triagem obedece, inicialmente, a Resolução Conama $n^{\circ} 237 / 1997$, onde é verificada a necessidade ou não do licenciamento ambiental. Nos casos negativos, é emitida uma Certidão de Dispensa. Nos casos afirmativos, com base nas informações do FCE e na DN 
74/2004, o empreendimento é classificado em uma das 6 classes, de acordo com seu porte e potencial poluidor/degradador:

- Classe 1: pequeno porte e pequeno ou médio potencial poluidor;

- Classe 2: médio porte e pequeno potencial poluidor;

- Classe 3: pequeno porte e grande potencial poluidor ou médio porte e médio potencial poluidor;

- Classe 4: grande porte e pequeno potencial poluidor;

- Classe 5: grande porte e médio potencial poluidor ou médio porte e grande potencial poluidor;

- Classe 6: grande porte e grande potencial poluidor.

Para classificar o empreendimento nas classes, são consideradas as listagens de tipologias de empreendimentos constantes nos anexos da DN nº 74/2004. Para cada uma das tipologias, esta norma classifica a atividade em um potencial poluidor (pequeno, médio ou grande), que é intrínseco a ela e está de acordo com suas interferências no solo, ar e água; e em um porte (pequeno, médio ou grande) que depende de algum quesito deste empreendimento, que pode ser produção bruta, área útil, volume de matéria-prima processada, entre outros. De posse das informações de potencial poluidor e porte, é utilizada a Tabela A-1 da DN n ${ }^{\circ} 74 / 2004$ (Figura 10) e tem-se a classe do empreendimento.

\begin{tabular}{|c|c|c|c|c|}
\hline & \multicolumn{3}{|c|}{$\begin{array}{c}\text { Potencial poluidor/degradador geral da } \\
\text { atividade }\end{array}$} \\
\hline & & $\mathrm{P}$ & $\mathrm{M}$ & $\mathrm{G}$ \\
\hline \multirow{3}{*}{$\begin{array}{c}\text { Porte do } \\
\text { Empreendimento }\end{array}$} & $\mathrm{P}$ & 1 & 1 & 3 \\
\hline & $\mathrm{M}$ & 2 & 3 & 5 \\
\hline & $\mathrm{G}$ & 4 & 5 & 6 \\
\hline
\end{tabular}

Figura 10 - Critérios de classificação do empreendimento, segundo o potencial poluidor/degradador e o porte do empreendimento.

Fonte: Copam (2004).

Esta classificação dos empreendimentos é norteadora da triagem quanto ao tipo de licenciamento. Empreendimentos classes 1 e 2 não necessitam da elaboração de estudos de impacto para obtenção da licença, apenas solicitam a AAF (é o chamado licenciamento convencional); a AAF é de natureza declaratória, para atividades de menor porte e de menor potencial poluidor, que se sujeitam apenas ao cadastro, à apresentação de documentos de natureza formal e à assinatura de termo de responsabilidade (VIANA; BURSZTYN, 2010), sem envolvimento do Copam e nem a realização de vistoria. Já para os empreendimentos 
classes de 3 a 6 , o processo de licenciamento é apoiado na AIA, existindo a necessidade da elaboração de estudos ambientais, que podem ser o EIA/Rima ou o RCA (Relatório de Controle Ambiental). A necessidade de elaboração de EIA/Rima é definida de acordo com o Art. $2^{\circ}$ da Resolução Conama 001/1986 e também de acordo com a discricionariedade do órgão ambiental (triagem caso a caso), que, em função da localização e das características do empreendimento, pode julgar necessária a elaboração do EIA/Rima. O RCA é apresentado em caso de dispensa de EIA/Rima para empreendimentos e/ou atividades em que o porte e/ou o potencial poluidor/degradador geram impactos ambientais de menor importância. Não existe regulamentação legal para o RCA estabelecendo seu conteúdo e aplicação quando da dispensa de EIA/Rima, mas em termos práticos isto já é consolidado. O RCA pode ser considerado um EIA/Rima menos aprofundado e, atualmente, o TR que orienta a sua elaboração o transformou em um formulário, onde estudos e informações mais aprofundados são apresentados em anexo.

Ainda, a classificação dos empreendimentos permite que, para todos os empreendimentos classes 3 e 4, possa haver a solicitação de LP concomitante com a LI (LP+LI) e, especificamente para empreendimentos agrossilvopastoris, a LI seja solicitada concomitantemente com a LO (LI+LO).

As listagens das atividades que promovem o enquadramento em classes dos empreendimentos tem sido objeto de diversas alterações, resultando em novas DN.

O processo de triagem culmina com a emissão, pelo Sistema Integrado de Informação Ambiental (Siam), do Formulário de Orientação Básica (FOB), que apresenta qual a classe em que o empreendimento foi enquadrado e lista a documentação e o tipo de estudo de impacto (EIA/Rima ou RCA) necessários à formalização do processo.

Tanto nos casos de EIA/Rima como RCA, o escopo é definido por Termos de Referência pré existentes. No endereço eletrônico <http://www.meioambiente.mg.gov.br/noticias/1/1167termos-de-referencia-para-elaboracao-de-estudo-de-impactorelatorio-de-impacto-ambientaleiarima> é disponibilizado um TR geral para a elaboração do EIA/Rima e alguns TR específicos para determinadas atividades, como atividades agrossilvopastoris, minerárias, indústria química, indústria alimentícia, infraestrutura de energia, infraestrutura de saneamento, parcelamento do solo, serviços de segurança e sistema de tratamento térmico de resíduos sólidos urbanos com geração de energia elétrica.

Após a elaboração e protocolo dos estudos no órgão ambiental, a análise do processo é realizada por meio do exame da documentação (a análise do estudo baseia-se no cumprimento do TR: inicialmente, é verificado se todos os itens relacionados no TR foram analisados e, 
posteriormente, se esta análise aconteceu de forma satisfatória, obedecendo a critérios técnicos, e se a abordagem e os resultados apresentados são suficientes para orientar a tomada de decisão) e da realização de vistoria (ocorre em todos os processos) ao empreendimento pela equipe técnica, que no modelo interdisciplinar, é formada por representantes do IEF, Igam e Feam. Nos casos de maior complexidade são realizadas reuniões multidisciplinares para a avaliação do estudo. Em poucos casos são envolvidas outras entidades ambientais na análise técnica.

A análise dos estudos pode apontar que as informações prestadas são insuficientes para a tomada de decisão e, então, IC são solicitadas. Finalizada a análise, um parecer técnico único é emitido, sendo revisto e aprovado pelo gerente e diretor da área técnica e encaminhado para a Procuradoria Jurídica. Nesta etapa, com a resposta do jurídico, o parecer é encaminhado para julgamento pelas URC do Copam.

\section{$\underline{\text { Decisória }}$}

A oportunidade de participação pública acaba por acontecer somente antes da emissão da licença, através da realização de audiências públicas para conhecimento e participação da população, bem como para solicitação de informações complementares aos documentos apresentados: as Audiências Públicas de empreendimentos ou atividades sujeitas a EIA/Rima serão realizadas durante o processo de análise e tramitação do EIA, antes da apresentação ao Copam do Parecer Técnico por ela elaborado (COPAM, 1994). Os procedimentos para realização de uma audiência pública são expressos na Deliberação Normativa do Copam n ${ }^{\circ}$ $12 / 1994$.

A figura da audiência pública não é comum nos processos de licenciamento da Supram Sul de Minas. Embora, ocorra toda a publicidade com a divulgação em jornais do período para a solicitação de audiência, os agentes que poderiam pedir sua realização (próprio órgão ambiental, Copam, Poder Público Estadual ou Municipal, Ministério Público, entidade civil ou grupo de 50 ou mais cidadãos), raramente, o fazem, possivelmente por não terem contribuições a fazer para o processo ou por mero desinteresse.

As decisões sobre a viabilidade ambiental do empreendimento são tomadas pelas URC do Copam. Os processos são colocados em votação diante a plenária e, em geral, as decisões são tomadas por consenso, excetuando-se os processos polêmicos. A presença do empreendedor na reunião da URC do Copam que vai decidir sobre a viabilidade do projeto de seu interesse não é obrigatória. Contudo, quando ocorre algum destaque no processo por parte dos 
conselheiros, o empreendedor ou a consultoria quando presentes podem prestar os esclarecimentos necessários, evitando que o processo saia de pauta e vá para outra reunião. Os esclarecimentos aos destaques dos processos também podem ser realizados pelos técnicos da Supram.

Por fim, dado o parecer final e, no caso de aprovação do empreendimento, a LP é concedida. Com o cumprimento das condicionantes e exigências contidas na LP e também a apresentação do Plano de Controle Ambiental (PCA), onde são minuciosamente descritas todas as medidas ambientais e programas de monitoramento, é emitida a LI; cumprida as demais condicionantes e exigências, a LO é expedida e o empreendimento entra em funcionamento. As decisões finais a respeito da emissão da LI e LO também são tomadas pelo Copam.

\section{Pós-licença}

Nas etapas pós-licenciamento, são acompanhados pela Supram os programas de monitoramento através dos Relatórios de Avaliação do Desempenho Ambiental (Rada), que garante a legalidade ambiental do empreendimento e a renovação da licença ambiental. Assim como em SP, a sociedade pode participar do processo de acompanhamento, denunciando as ações do empreendimento implantado.

A Figura 11 apresenta o resumo das relações entre as etapas do processo de licenciamento e AIA no estado de MG.

Vale destacar que em MG, é comum a existência do licenciamento em caráter corretivo, ou seja, o empreendimento foi implantado ou está em operação de forma irregular e, então, busca sua regularização ambiental. Neste caso, estão envolvidos dois tipos de licença: Licença de Instalação Corretiva (LIC) ou a Licença de Operação Corretiva (LOC); e o processo pode eliminar a emissão de algumas licenças. O licenciamento corretivo não envolve penalidades somente nos casos da implantação do empreendimento ser anterior a legislação ou por denúncia espontânea, mas conta, na maioria das vezes, com a celebração de um Termo de Ajustamento de Conduta (TAC) junto ao Ministério Público (MP).

A modalidade do licenciamento corretivo foi criada visando a regularização ambiental de empreendimentos que tiveram sua instalação anterior à implementação das normas ambientais de regularização ambiental. No entanto, ela tem sido utilizada como artimanha do empreendedor para a obtenção da licença ambiental: o empreendimento é instalado sem passar pelo processo de licenciamento e, após a denúncia voluntária (o que isenta o 
empreendedor de multa), o empreendedor solicita o licenciamento corretivo. Uma vez instalado o empreendimento, todos os impactos da fase de planejamento e instalação já estão consolidados e, a própria desativação do projeto pode acarretar mais impactos, sendo, neste contexto, a licença acaba por ser emitida.

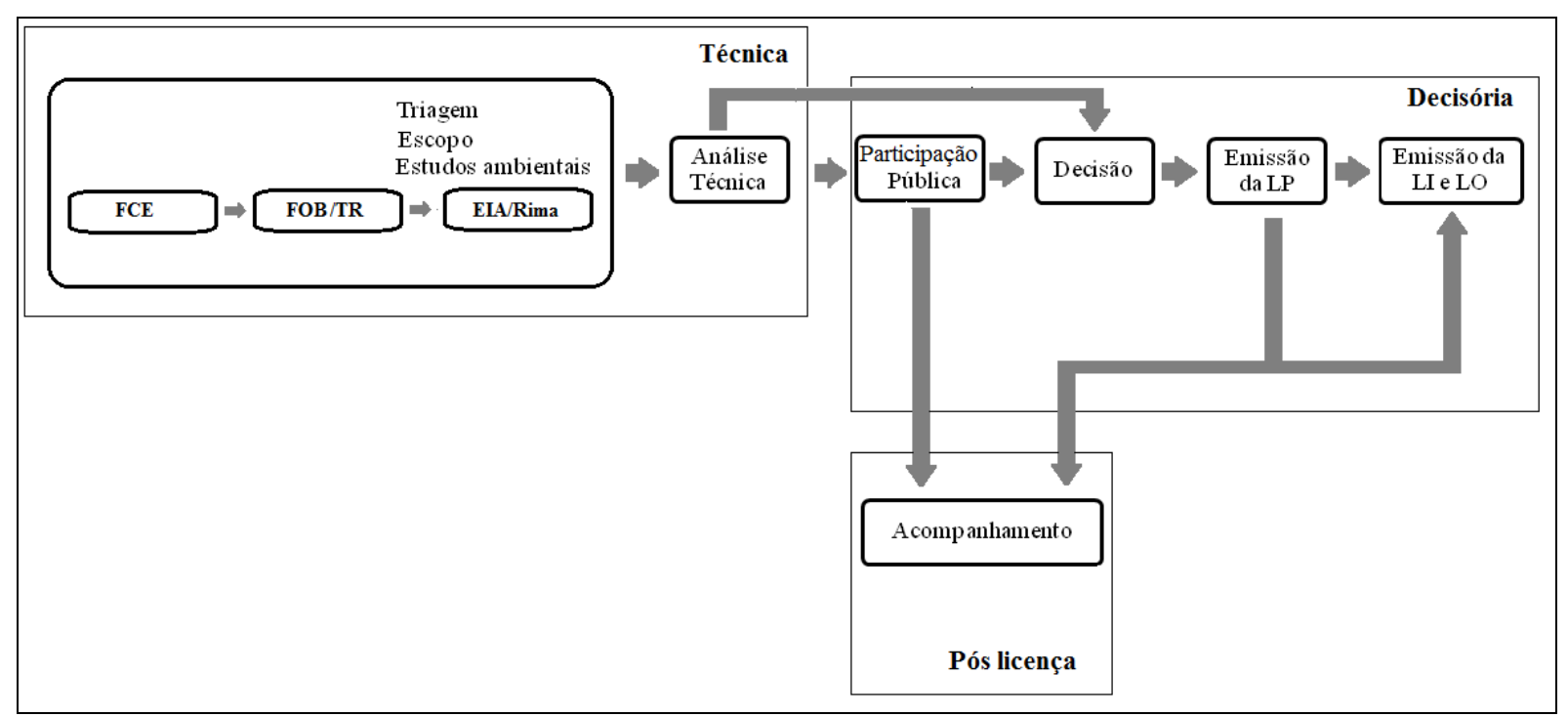

Figura 11 - Processo de Avaliação de Impacto Ambiental e Licenciamento Ambiental em MG.

\subsubsection{Aplicação dos indicadores de efetividade}

Parte da etapa de identificação da situação problema foi realizada através da aplicação de indicadores de efetividade. De certo modo, os indicadores selecionados tentaram abranger as efetividades procedimental e substantiva, combinadas com dados de tempo (efetividade transactiva).

\section{a) São Paulo}

No estado de São Paulo, os indicadores de efetividade foram aplicados a 20 processos de licenciamento com AIA, cujo estudo ambiental componente era o EIA/Rima. A fim de facilitar a análise dos resultados e permitir algumas comparações, os processos foram agrupados em aprovados e reprovados/paralisados/arquivados. Assim, na Figura 12A são 
apresentados os resultados da aplicação dos indicadores para os 14 processos cuja licença ambiental foi deferida e na Figura 12B, os resultados dos 6 processos onde a licença ambiental não foi emitida, sendo que em 3 a licença foi indeferida (Processos 13522/2004, 13702/2005 e 13724/2007), 1 encontra-se paralisado (Processo 13509/2005) e 2 foram arquivados - um por determinação judicial (Processo 13625/2005) e outro pela não entrega do EIA/Rima (Processo 258/2009) - mais informações na Tabela 4.

O "Não se aplica" presente na Figura 12B refere-se aos casos em que o processo de licenciamento não alcançou a etapa do qual o indicador tratava. O resultado completo da aplicação dos indicadores em cada processo é apresentado no Apêndice II.

Na Figura 13 e na Tabela 9 são apresentados os tempos gastos em cada etapa de tramitação do processo de licenciamento em São Paulo. Lembrando que o tempo de tramitação do processo foi dividido em 4 etapas: a análise do PT (período entre o protocolo do PT e a emissão do TR), a elaboração do EIA/Rima (tempo entre a emissão do TR e a entrega do EIA/Rima), a análise do EIA e das IC (tempo entre a entrega do EIA/Rima até a emissão do parecer técnico, incluindo os pedidos de complementação) e a tramitação no Consema (período entre a emissão do parecer técnico até a decisão final). A Tabela 9 também apresenta o número de solicitações de IC que foram feitas.

De acordo com as Figuras 12A e 12B, a etapa de escopo foi bem desenvolvida nos processos de licenciamento em SP: o escopo foi elaborado para cada projeto (Indicador 1) - o que foi garantido pela proposição do PT e emissão do TR - e o TR apresentou-se com o detalhamento necessário para o desenvolvimento do EIA (Indicador 2). Contudo, o escopo estava longe de ser participativo (Indicador 3): apenas 4 processos no total (licença emitida ou não - Figura 12A e 12B) envolveram o Consema na análise do PT e/ou tiveram a realização de audiência para discussão do PT. Entre estes estão o Processo 13522/2004 que contou com a participação do Consema e a realização de audiência pública; o Processo 13545/2007 onde foi realizada a audiência pública, mas sem a participação do Consema; o Processo 13602/2007 que contou com o envolvimento do Consema e com contribuições por escrito da população afetada; e o Processo 1683/2008 apenas com a participação do Consema.

Mesmo havendo estas formas de participação, nem todas resultaram em contribuições para a etapa de escopo (Indicador 4 das Figuras 12A e 12B). Foi o que acorreu com o 1683/2008, onde o envolvimento do Consema em nada agregou ao processo (conforme pode ser evidenciado pela Ata da 39a Reunião Ordinária da Câmara Técnica de Empreendimentos Industriais ou Imobiliários e de Projetos Urbanísticos, realizada no dia 14 de agosto de 2008). 


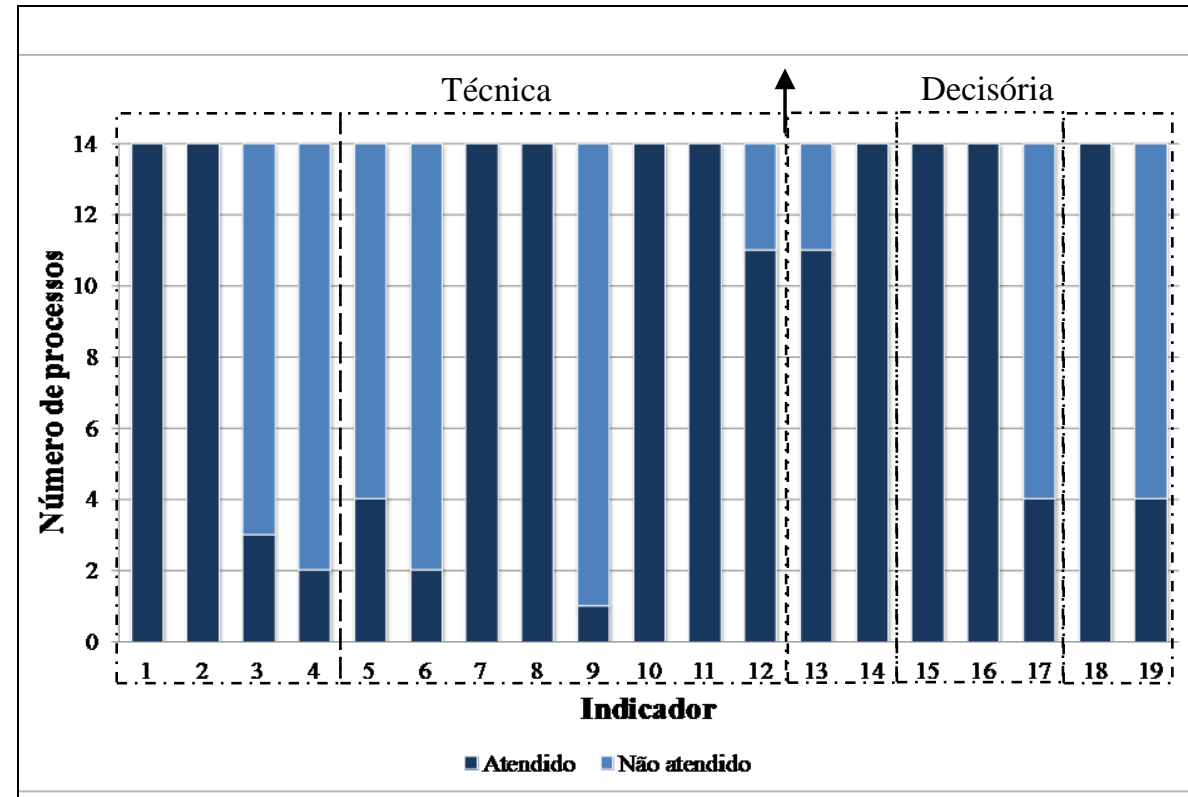

(A)

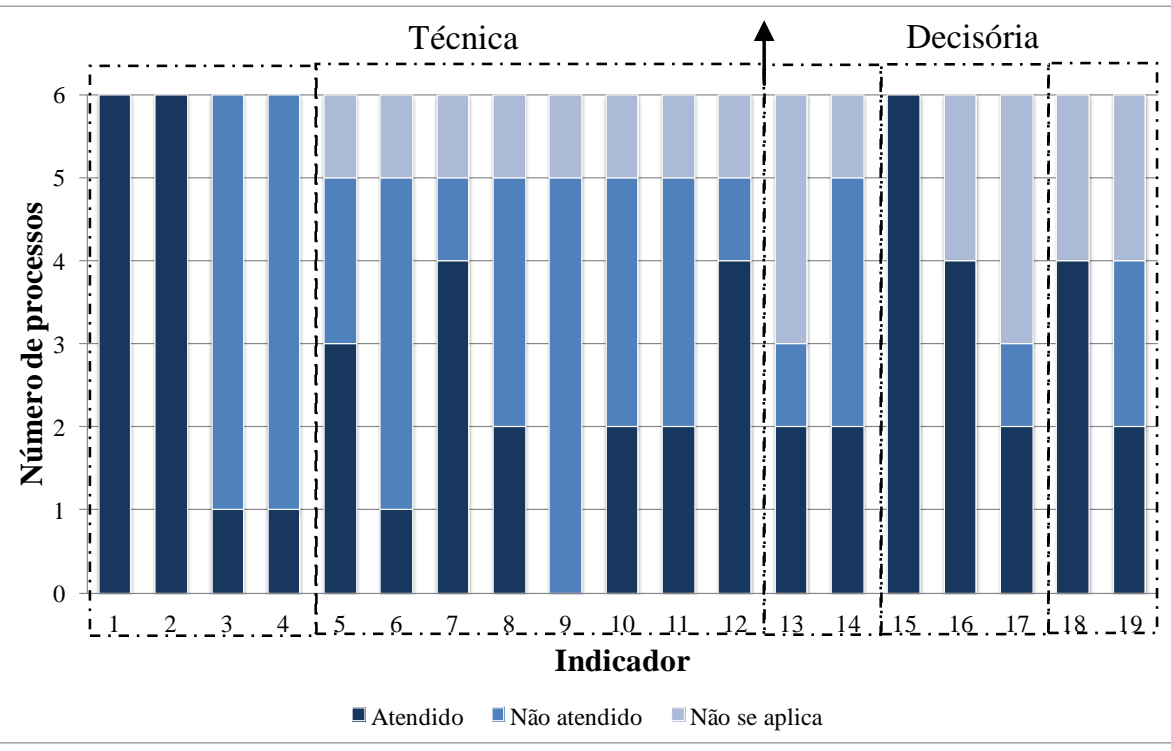

(B)

Figura 12 - (A) Aplicação dos indicadores de efetividade aos processos de SP cuja licença ambiental foi deferida. (B) Aplicação dos indicadores de efetividade aos processos de SP cuja licença ambiental foi indeferida ou o processo arquivado/paralisado.
INDICADORES

Escopo

1: TR elaborado para o projeto

2: TR detalhado

3 - Escopo participativo -

Ocorreu audiência ou consulta pública na etapa de escopo

4: Escopo participativo - A participação resultou em contribuições para o escopo

Elaboração do estudo

5: Consideração de

alternativas - Existiu a consideração de alternativas

6: Consideração de alternativas - As alternativas apresentadas foram plausíveis

7: Delimitação da AI

8: Análise dos principais impactos

9: Mecanismos para avaliação impactos cumulativos

10: Proposição de medidas ambientais para os principais impactos

11: Programas de monitoramento para os principais impactos

12: Rima em linguagem acessível

Análise técnica

13: Realização de vistoria 14: Os estudos ambientais atendem ao escopo (TR)

Participação

15: Publicidade

16: Audiência pública -

Realização de audiência pública

17: Audiência pública Contribuição da audiência

com o processo Decisão

18: Influência da análise técnica

19: Influência da participação

Muitas vezes, a participação dentro do processo de licenciamento é relacionada com dispêndio de tempo para a emissão da licença. Conforme mostrado na Figura 13 e na Tabela 9, comparando-se o número de dias gastos na análise do PT dos processos com escopo participativo (Processos 13522/2004, 13545/2007, 13602/2007 e 1683/2008) e sem qualquer 
forma de participação (demais processos), observou-se que somente havendo a participação do Consema na análise do PT não acarreta alteração no seu tempo de análise (Processos 13602/2007 e 1683/2008) - o tempo gasto nestes processos não diferiu significativamente dos demais; enquanto que a ocorrência de audiência tendeu a dilatar este prazo (Processos 13522/2004 e 13545/2007). Contudo, analisando mais de perto este dois processos, que foram os que gastaram mais tempo para análise do PT, foi verificado que outros fatores contribuíram para isto. No Processo 13522/2004 vários PT foram apresentados até que houvesse a aceitação do órgão ambiental. E no caso do Processo 13545/2007, aconteceu um fato interessante: apesar de mais tempo ter sido gasto na análise do PT por conta da realização de audiência, o tempo total de trâmite do processo foi menor quando comparado com a maioria dos outros processos (Figura 13 e Tabela 9); a participação na fase de escopo parece ter propiciado um estudo de boa qualidade que necessitou apenas de um pedido de IC - Tabela 9 (solicitava o aprofundamento na análise de risco a saúde humana), o que contribuiu para a agilidade na análise técnica e na tramitação do processo. Logo, a realização da audiência na fase de escopo, mesmo dilatando o tempo de análise do PT, ao invés de promover demora na emissão da licença, acabou reduzindo este tempo total, já que, com a participação na fase de escopo existe a possibilidade de diversas questões serem antecipadas.

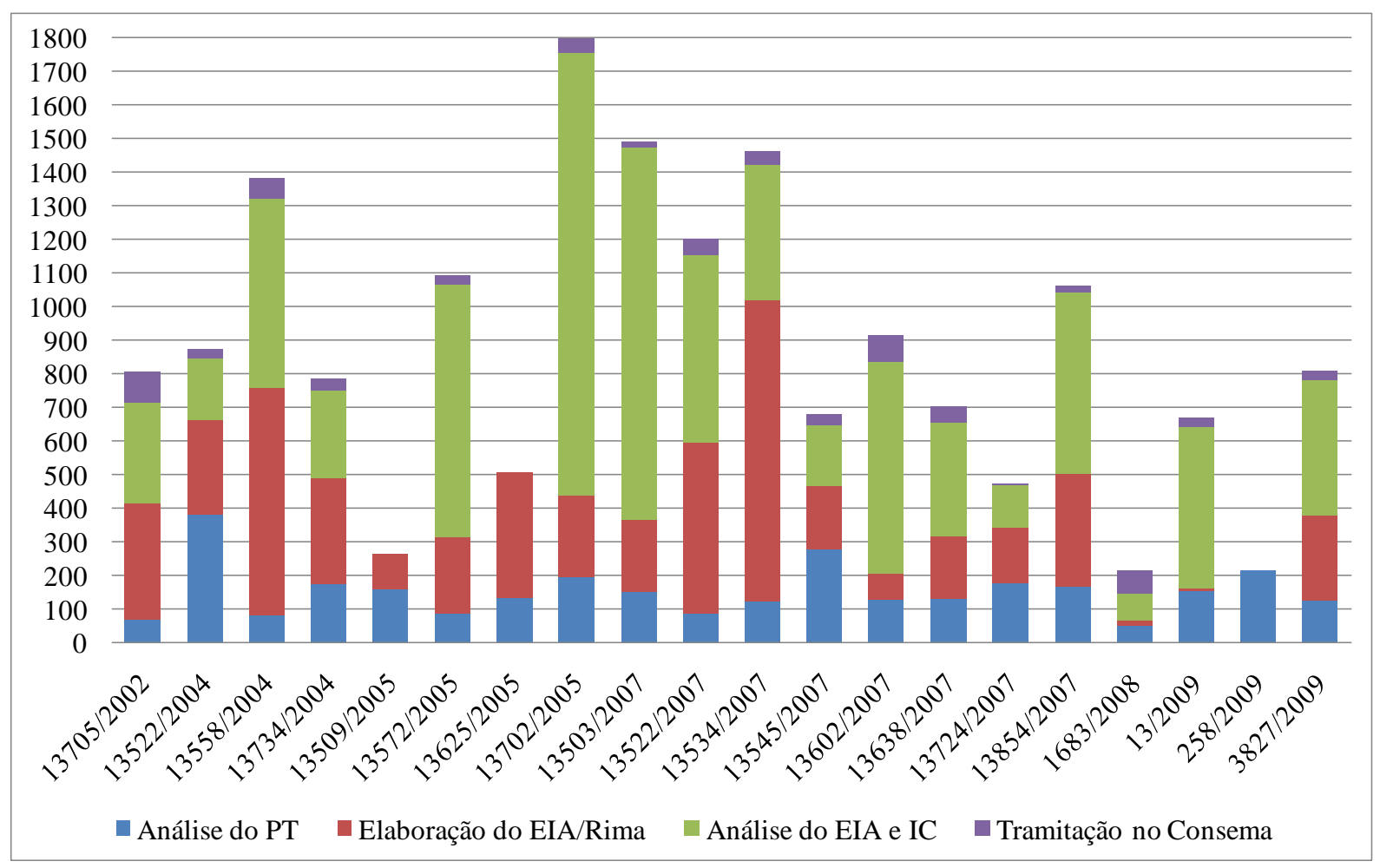

Figura 13 - Tempo de tramitação dos processos de SP. 
Tabela 9 - Tempo de tramitação dos processos de SP.

\begin{tabular}{|c|c|c|c|c|c|c|}
\hline \multirow[b]{2}{*}{ Processo } & \multicolumn{3}{|c|}{ Técnica } & \multirow{2}{*}{$\begin{array}{c}\text { Decisória } \\
\text { Tramitação } \\
\text { Consema (dias) }\end{array}$} & \multirow[b]{2}{*}{ Total (dias) } & \multirow[b]{2}{*}{$\begin{array}{c}\text { Pedidos de } \\
\text { IC } \\
\end{array}$} \\
\hline & $\begin{array}{c}\text { Análise PT } \\
\text { (dias) }\end{array}$ & $\begin{array}{c}\text { Elaboração } \\
\text { EIA/Rima (dias) }\end{array}$ & $\begin{array}{c}\text { Análise EIA e } \\
\text { IC (dias) }\end{array}$ & & & \\
\hline $13705 / 2002$ & 70 & 346 & 300 & 91 & 807 & 1 \\
\hline $13522 / 2004$ & 381 & 283 & 183 & 29 & 847 & 0 \\
\hline $13558 / 2004$ & 83 & 674 & 567 & 60 & 1384 & 3 \\
\hline $13734 / 2004$ & 174 & 316 & 261 & 35 & 786 & 2 \\
\hline $13509 / 2005$ & 158 & 105 & - & - & 263 & - \\
\hline $13572 / 2005$ & 87 & 225 & 756 & 28 & 1096 & 3 \\
\hline $13625 / 2005$ & 135 & 370 & - & - & 505 & - \\
\hline $13702 / 2005$ & 194 & 245 & 1316 & 50 & 1755 & 3 \\
\hline $13503 / 2007$ & 148 & 216 & 1112 & 15 & 1491 & 4 \\
\hline $13522 / 2007$ & 87 & 506 & 562 & 46 & 1201 & 0 \\
\hline $13534 / 2007$ & 120 & 897 & 406 & 40 & 1463 & 1 \\
\hline $13545 / 2007$ & 276 & 192 & 179 & 32 & 679 & 1 \\
\hline $13602 / 2007$ & 127 & 78 & 628 & 81 & 914 & 6 \\
\hline $13638 / 2007$ & 129 & 189 & 336 & 49 & 703 & 1 \\
\hline $13724 / 2007$ & 176 & 167 & 126 & 4 & 469 & 0 \\
\hline $13854 / 2007$ & 166 & 338 & 540 & 18 & 1062 & 6 \\
\hline $1683 / 2008$ & 50 & 14 & 83 & 65 & 212 & 1 \\
\hline $13 / 2009$ & 153 & 7 & 483 & 27 & 670 & 5 \\
\hline $258 / 2009$ & 212 & - & - & - & 212 & - \\
\hline $3827 / 2009$ & 126 & 252 & 405 & 27 & 810 & 4 \\
\hline
\end{tabular}

Ainda com relação ao tempo de análise do PT, verificou-se que o número de dias utilizados nesta etapa não segue um padrão (Figura 13 e Tabela 9). Além dos casos acima discutidos, os Processos 258/2009 e 13702/2005 foram os mais demorados nesta fase. No primeiro caso, este fato ocorreu, pela emissão do TR ter sido conjunta para 3 projetos de Pequenas Centrais Hidrelétricas (PCH) proximamente localizadas; e, no segundo, a demora aconteceu em função da má qualidade do PT apresentado, havendo, inclusive, no parecer de emissão do TR uma nota do órgão ambiental chamando a atenção da consultoria elaboradora do PT para a má qualidade que os estudos por ela desenvolvidos estavam apresentando.

Os indicadores de 5 a 12 tratavam da qualidade apresentada pelos estudos e para avaliá-los também foram consideradas as informações presentes nas IC. Este conjunto de indicadores mostrou que os EIA/Rima eram deficientes na consideração de alternativas (Indicadores 5 e 6 nas Figuras 12A e 12B) e avaliação de impactos cumulativos (Indicador 9 nas Figuras 12A e 12B), sendo que a avaliação de impactos cumulativos foi, de alguma forma, realizada apenas por um único estudo. 
A proposição de alternativas foi contemplada em 4 processos em que a licença foi emitida (Indicador 5 da Figura 12A) e em 3 processos em que a licença não foi emitida (Indicador 5 da Figura 12B). O indicador 6 objetivou verificar a efetividade substantiva das alternativas propostas, ou seja, se o estudo de alternativas realizado realmente propiciou a escolha da alternativa mais viável ambientalmente. Dos 7 processos que realizaram a discussão de alternativas, apenas 3 a fizeram de maneira plausível. Como bons exemplos, estavam o Processo 13522/2007, onde houve o estudo de 9 alternativas de área para o transbordo de resíduos; o Processo 13602/2007 que avaliou duas opções para o transporte de gás (rodoviário e dutoviário) e 3 traçados diferentes para o duto proposto; e o Processo 13522/204 que apresentou um estudo detalhado para a seleção da área para construção do aterro sanitário do município de Piracicaba. Para ilustrar os casos onde a proposição de alternativas foi feita apenas para reforçar a escolha de uma opção previamente preterida, citam-se os Processos 13534/2007, 1683/2008 e 13509/2005. O texto apresentado no EIA do primeiro processo afirmou no capítulo de "Alternativas locacionais e tecnológicas" não ser possível a discussão de alternativas locacionais para a mineração de granito e que a melhor alternativa tecnológica seria o plano de lavra que estava sendo proposto, sem, contudo, apresentar nenhum estudo, comparação ou discussão de opções; no segundo, a análise de alternativas para a implantação de uma unidade industrial de uma empresa automobilística baseou-se apenas em analisar os quesitos econômicos (a bem dizer atrativos e incentivos econômicos) de 3 cidades do interior paulista; e por fim, no terceiro, o grande envolvimento da sociedade que levou a paralisação do processo relaciona-se justamente ao estudo locacional realizado pelo EIA/Rima para ampliação de um aeroporto, que elege como alternativa mais viável aquela que causará mais impactos sobre a cidade e a população, sendo inclusive leis de uso e ocupação do solo alteradas para viabilizar a alternativa proposta pelo estudo.

Também, não foram todos os Rima que possuíam linguagem acessível, apenas 15 processos (Indicador 12 nas Figuras 12A e 12B), constituindo uma lacuna em informar a população e capacitá-la para participação no processo decisório.

Os indicadores 7 (Delimitação da AI), 8 (Análise dos principais impactos), 10 (Proposição de medidas ambientais para os principais impactos) e 11 (Programas de monitoramento para os principais impactos) foram o que diferenciam os processos com a licença deferida (Figura 12A) dos com a licença indeferida (Figura 12B) por má qualidade dos estudos (Processos 13522/2004, 13702/2005 e 13724/2007).

O prazo legal previsto para a elaboração do EIA/Rima é de 180 dias. Contudo, somente 7 processos não solicitaram prorrogação deste prazo (Figura 13), sendo que nos Processos 
13558/2004 e 13534/2007 o tempo gasto na elaboração do EIA/Rima chegou até 897 e 674 dias, respectivamente (Tabela 9).

No outro extremo, os processos 1683/2008 e 13/2009 despenderam, respectivamente, 14 e 7 dias entre a emissão do TR e o protocolo do EIA/Rima (Tabela 9). Isto é um indicativo de que o estudo já estava pronto antes da emissão do TR, ou seja, de que o papel do TR de orientar a elaboração do EIA/Rima não foi levado em consideração. Prova disto é que, no caso do Processo 13/2009, o EIA seguia as orientações do PT e não do TR, o que acarretou em 5 pedidos de IC (Tabela 9) com a solicitação de um grande número de complementações e na dilatação do tempo de análise. Logo, o tempo e os recursos despendidos para a apresentação e análise do PT e elaboração do TR foram desperdiçados, sendo que mais tempo e recursos foram empregados para cumprir as exigências das IC. No caso do Processo 1683/2008, como houve participação do Consema, mesmo antes da emissão do TR já existiram discussões sobre o conteúdo do estudo, permitindo que o mesmo fosse desenvolvido paralelamente à análise do PT. Isto justificou que, mesmo com este pouco tempo, o estudo tenha apresentado boa qualidade e que houvesse apenas um pedido de IC (Tabela 9) para complementação das informações apresentadas no EIA.

Pelo envolvimento dos diversos fatores, conforme descrito, não houve relação aparente do número de dias gastos na elaboração do EIA/Rima com a qualidade do estudo e nem com a posterior necessidade de complementações (número de IC solicitadas).

A análise técnica do EIA no estado de São Paulo também contou com a realização de vistoria (Indicador 13), que ocorreu na grande maioria dos processos (Figura 12A e 12B).

$\mathrm{O}$ atendimento ao TR aconteceu em todos os processos cuja licença foi emitida (Indicador 14 da Figura 12A) e em 2 processos cuja licença não foi emitida (Indicador 14 da Figura 12B), não sendo cumprido justamente pelos 3 processos reprovados pela má qualidade dos estudos e não se aplicando ao processo que foi arquivado pela ausência de entrega do EIA/Rima. Vale ressaltar que em muitos processos o estudo entregue não atendia plenamente ao TR, sendo solicitadas IC.

O tempo de análise dos estudos no estado de São Paulo sofreu influência da quantidade de IC solicitadas (que teve relação direta com a qualidade do estudo apresentado, mas não com a quantidade de dias gastos para a sua elaboração) e, principalmente, com o tempo de resposta aos pedidos de IC. O menor tempo de análise do EIA, 83 dias, foi verificado no Processo 1683/2008 (Tabela 9), sendo muito inferior a todos os outros - as considerações sobre este processo já foram tecidas anteriormente quando foi analisado o tempo de análise do PT. Os maiores tempos foram observados nos Processos 13702/2005 e 13503/2007, sendo de 1316 e 
1112, respectivamente (Tabela 9). Ao tentar identificar as razões para tal demora, notou-se que no Processo 13702/2005 ocorreram inúmeros pedidos de prorrogação de prazo para entrega de IC e que as IC entregues não continham todas as informações solicitadas, sendo necessários outros pedidos de IC para entrega das complementações anteriormente solicitadas e não atendidas. No Processo 13503/2007, a demora na análise também aconteceu devido a pedidos de prorrogação de prazo de entrega de IC, além da demora na manifestação do Comitê de Bacia Hidrográfica sobre o empreendimento. Contudo, outra questão foi observada: existia na área onde se pretendia implantar o empreendimento outro loteamento em cuja licença foi estabelecido que para o licenciamento de outros empreendimentos haveria a necessidade de elaboração de um estudo de impactos cumulativos. Então, o Daia solicitou orientações ao departamento jurídico de como isto interferiria no licenciamento do projeto em questão e como deveria ser atendido. Toda esta comunicação com o jurídico dentro deste processo foi principal fator de influência na demora em sua análise.

A participação dentre do processo foi avaliada através dos indicadores de 15 a 17. Foi verificado que os processos contam com ampla divulgação de todo o seu trâmite (Indicador 15 das Figuras 12A e 12B) através das publicações no Diário Oficial do Estado de São Paulo e em periódicos de circulação local e regional e de radiodifusão, informando a população da existência do processo, da possibilidade de participação através das audiências públicas e das decisões tomadas. A realização da audiência na fase de análise do estudo esteve presente em todos os casos (Indicador 16 das Figuras 12A e 12B), sendo que quando a audiência não era solicitada pela sociedade ou pelo MP, cabia ao Daia/Cetesb este papel.

Contudo, a publicidade e a realização da audiência podem não garantir o real envolvimento da sociedade. Para verificar se houve contribuição da sociedade no processo foi utilizado o Indicador 17. De acordo com ele, somente nas audiências de 4 processos com licença deferida (Figura 12A) e de 2 processos sem a emissão da licença (Figura 12B) ocorreram manifestações que resultaram em contribuições para o processo. Contudo, mesmo com estes indícios de não efetividade, as janelas de participação disponibilizadas dentro do processo (entre elas a audiência pública) permitiram, uma vez que a sociedade queria e tinha interesse em se envolver, que as considerações da população contribuíssem para o processo. Foi o que aconteceu com os Processos 13522/2004 e 13509/2005. No primeiro, houve intensa participação nas fases iniciais do processo - triagem e escopo - e manifestações contrárias ao empreendimento que, aliadas a má qualidade do estudo apresentado, fizeram com que a licença fosse indeferida mesmo antes da realização da audiência de análise do EIA. Já para o segundo processo, o envolvimento e a participação da sociedade (associações civis, 
universidade, entidades ambientais) foram tão intensas que levaram a paralisação do processo; destaque deve ser dado à atuação da universidade que, embasadas em estudos, manifestou-se expressamente contrária ao projeto devido sua inviabilidade ambiental em relação ao fator locacional. Conforme Devlin e Yap (2008), o papel da formação de coalizões entre ativistas locais e intelectuais é destacado como explicação fundamental para o bloqueio de projetos de desenvolvimento em larga escala.

A tomada de decisão por parte do Consema sobre a viabilidade ambiental do empreendimento deve ser orientada pelo parecer técnico e pela participação da sociedade. Contudo, como a participação da sociedade só trouxe contribuições em 6 processos (Indicador 17 das Figuras 12A e 12B), somente nestes casos a participação orientou a decisão (Indicador 19 das Figuras 12A e 12B), sendo que nos demais a decisão foi tomada somente com base no parecer técnico (Indicador 18 das Figuras 12A e 12B).

O prazo de tramitação do processo no Consema aumentou quando existiu a solicitação de apresentação do projeto por parte do empreendedor e consultoria em suas reuniões, a fim de que esclarecimentos sejam prestados e melhor direcionem a decisão. Isto aconteceu nos Processos 13705/2002, 13558/2004, 13602/2007 e 1683/2008 (Tabela 9). Como o tempo gasto nesta fase não foi grande (média de 37 dias), ele acabou por sofrer influência do período entre uma reunião e outra, sendo que normalmente as reuniões são mensais.

\section{b) Sul de Minas Gerais}

No estado de Minas Gerais, apesar de terem sido dadas vistas a 22 processos de licenciamento, os indicadores de efetividade foram aplicados a 17 deles, cujo estudo ambiental componente era o EIA/Rima (vide Tabela 5). Como destes 17 apenas 2 não tiveram a licença deferida, optou-se por outro agrupamento, sendo os processos divididos de acordo com o tipo de licenciamento, em preventivo e corretivo. Assim, na Figura 14A são apresentados os resultados da aplicação dos indicadores para os 11 processos de licenciamento corretivo e na Figura 14B, os resultados dos 6 processos de licenciamento corretivo. O resultado da aplicação dos indicadores em cada processo é apresentado no Apêndice III.

Na Figura 15 e na Tabela 10 são apresentados os tempos gastos em cada etapa de tramitação do processo de licenciamento em Minas Gerais. Conforme descrito e justificado na 
metodologia, o tempo de trâmite do processo pôde ser dividido em apenas 2 etapas: a análise do EIA e das IC (ocorreu desde a entrega do EIA/Rima até a emissão do parecer técnico, incluindo todos os pedidos de complementação) e a tramitação no Consema (se estendeu desde a emissão do parecer técnico até a decisão final do Consema). Ainda na Tabela 10 é apresentado o número de solicitações de IC. Como os documentos componentes do Processo 03522/2008/001/2008 estavam incompletos, não foi possível avaliar os tempos decorridos em cada uma de suas etapas e nem o número de IC solicitadas (Figura 15 e Tabela 10).

A fase de escopo no estado de MG foi definida por TR previamente estabelecidos e, no máximo, apenas específicos para determinadas tipologias de empreendimentos (vide item 5.2.1.1. b). Assim, foi considerado que nenhum TR era específico para o processo em análise (Indicador 1 das Figuras 14A e 14B). Se fossem considerados TR específicos para a tipologia do empreendimento, este número subiria para 2 apenas. Pelos TR não serem específicos para a interação do projeto com o lugar onde se pretende instalá-lo, correu-se o risco de abordar assuntos que não tinham grande importância e, ainda mais grave, deixar de considerar ou de aprofundar em questões que eram específicas para o caso. Ainda, pelo fato dos TR já estarem estabelecidos não houve a possibilidade de participação dos interessados nesta etapa (nenhum processo atendeu aos Indicadores 3 e 4 nas Figuras 14A e 14B). Apesar de não ter tido especificidade e não ter sido participativo, os TR disponibilizados no site do órgão ambiental apresentavam com detalhe as informações que devem ser abordadas no EIA/Rima (Indicador 2 das Figuras 14A e 14B). Considerando o conjunto dos indicadores de 1 a 4 e ainda o mesmo tratamento que foi dado tanto para processos de licenciamento preventivo como corretivo, a etapa de escopo foi deficiente frente às melhores práticas de AIA por não ter uma abordagem dirigida e não ser participativo. Mais que isso, a forma como o escopo é estabelecido em MG não há a possibilidade de ele ser definido de forma específica para o projeto e envolver participação.

A qualidade apresentada pelos EIA/Rima, bem como suas complementações, foram avaliadas pelos indicadores de 5 a 12. Logo de início, ao comparar estes indicadores nas Figuras 14A e 14B, verificou-se que os estudos componentes dos processos de licenciamento preventivo tiveram mais indicadores atendidos e, portanto, melhor qualidade que os de licenciamento corretivo. 

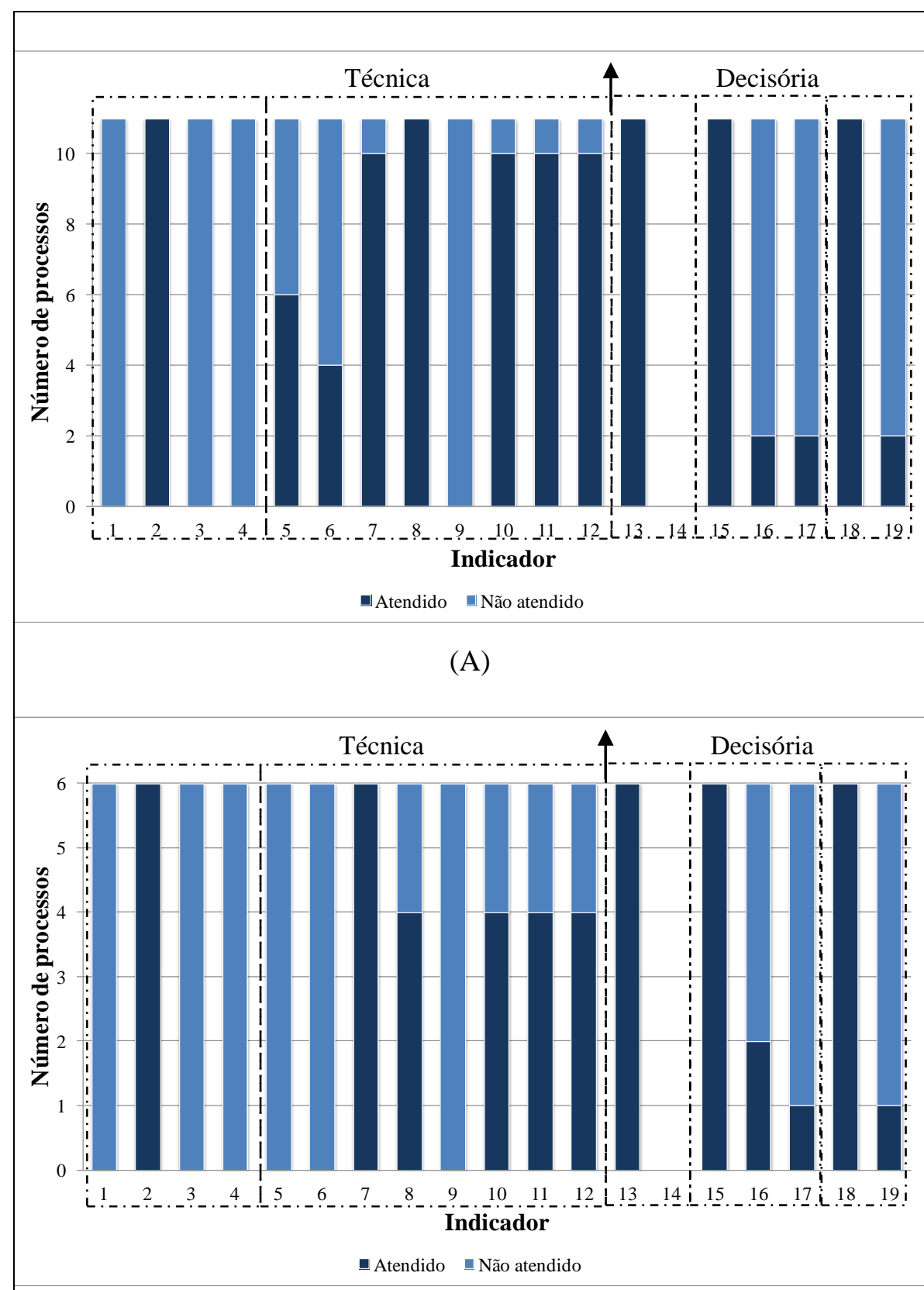

(B)

Figura 14 - (A) Aplicação dos indicadores de efetividade aos processos de licenciamento preventivo no Sul de MG. (B) Aplicação dos indicadores de efetividade aos processos de licenciamento corretivo no Sul de MG.
INDICADORES

Escopo

1: TR elaborado para o projeto

2: TR detalhado

3 - Escopo participativo -

Ocorreu audiência ou consulta pública na etapa de escopo

4: Escopo participativo - A participação resultou em contribuições para o escopo

Elaboração do estudo 5: Consideração de alternativas - Existiu a consideração de alternativas

6: Consideração de alternativas - As alternativas apresentadas foram plausíveis

7: Delimitação da AI

8: Análise dos principais impactos

9: Mecanismos para avaliação impactos cumulativos

10: Proposição de medidas ambientais para os principais impactos

11: Programas de monitoramento para os principais impactos

12: Rima em linguagem acessível

\section{Análise técnica}

13: Realização de vistoria 14: Os estudos ambientais atendem ao escopo (TR)

Participação

15: Publicidade

16: Audiência pública -

Realização de audiência pública

17: Audiência pública Contribuição da audiência com o processo Decisão

18: Influência da análise técnica

19: Influência da participação

A discussão de alternativas (Indicador 5) esteve presente em aproximadamente metade dos estudos de licenciamento preventivo (6 de 11 processos conforme Figura 14A) e em nenhum estudo de licenciamento corretivo (Figura 14B). Mesmo nestes 6 processos, apenas em 4 as alternativas apresentadas no EIA/Rima foram plausíveis (Indicador 6 das Figuras 14A e 14B), 
uma vez que os 2 outros processos (03522/2008//001/2008 e 18872/2009/001/2009) apenas apresentaram critérios de seleção, sem fazer nenhuma comparação de opções, já descrevendo a alternativa selecionada. A análise de alternativas, principalmente locacionais, poderia ser considerada mais importante quando o projeto ainda não foi implementado; contudo, ela não pode ser esquecida nos processos de regularização de empreendimentos (licenciamento corretivo), pois pode ser que a correção de um projeto instalado sem licenciamento seja mais impactante que a mudança de localização do mesmo, isto sem contar na consideração de alternativas tecnológicas.

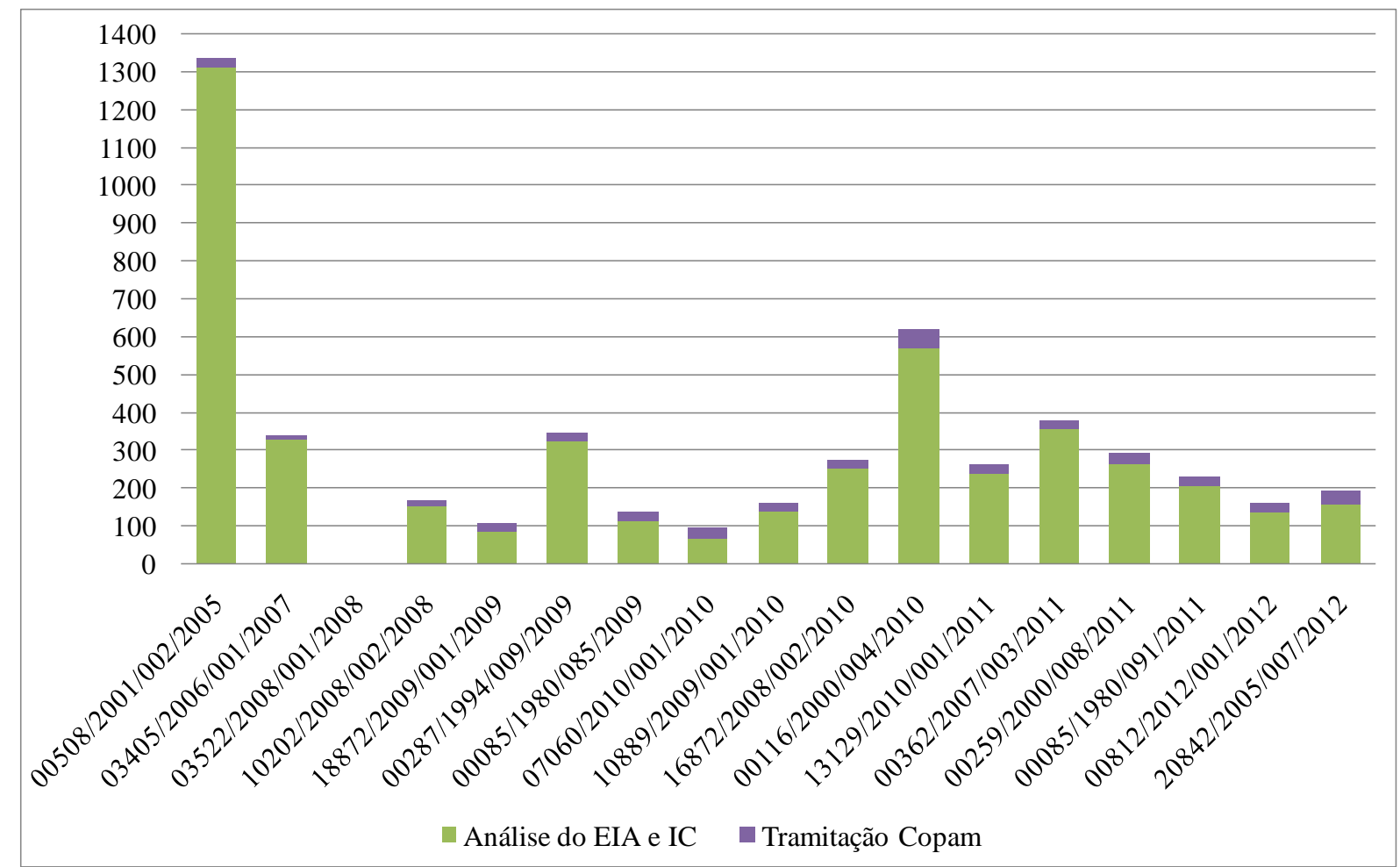

Figura 15 - Tempo de tramitação dos processos do Sul de MG.

Aliada a deficiência na consideração de alternativas, a principal falha dos estudos analisados foi a avaliação de impactos cumulativos (Indicador 9 nas Figuras 14A e 14B) que não esteve presente em nenhum deles.

A delimitação das AI (Indicador 7), a análise dos principais impactos (Indicador 8), a proposição de medidas ambientais (Indicador 10) e programas de monitoramento (Indicador 11) e a elaboração do Rima em linguagem acessível (Indicador 12) foram etapas bem desenvolvidas pelos estudos componentes dos processos analisados. Entretanto, como nenhuma licença foi indeferida pela má qualidade das informações prestadas pelo EIA/Rima e 
pelas IC, estes indicadores deveriam ter sido atendidos por todos os processos analisados, o que não ocorreu. Um processo de licenciamento preventivo não delimitou as AI (Indicador 7 da Figura 14A), 2 processos de licenciamento corretivo não analisaram os principais impactos causados pelo projeto (Indicador 8 da Figura 14B) e a proposição de medidas e programas de monitoramento e a linguagem do Rima não foram atendidas por 1 processo de licenciamento preventivo (Indicadores 10, 11 e 12 da Figura 14A, respectivamente) e 2 de licenciamento corretivo (Indicadores 10, 11 e 12 da Figura 14B, respectivamente).

Tabela 10 - Tempo de tramitação dos processos do Sul de MG.

\begin{tabular}{cccc}
\hline & Técnica & Decisória & \\
\cline { 2 - 4 } Processo & Análise EIA e IC (dias) & $\begin{array}{c}\text { Tramitação Copam } \\
\text { (dias) }\end{array}$ & Pedidos de IC \\
\hline $00508 / 2001 / 002 / 2005$ & 1315 & 25 & 1 \\
\hline $03405 / 2006 / 001 / 2007$ & 329 & 8 & 0 \\
\hline $03522 / 2008 / 001 / 2008$ & - & - & - \\
\hline $10202 / 2008 / 002 / 2008$ & 153 & 14 & 1 \\
\hline $18872 / 2009 / 001 / 2009$ & 85 & 19 & 1 \\
\hline $00287 / 1994 / 009 / 2009$ & 326 & 20 & 1 \\
\hline $00085 / 1980 / 085 / 2009$ & 113 & 26 & 1 \\
\hline $07060 / 2010 / 001 / 2010$ & 66 & 27 & 0 \\
\hline $10889 / 2009 / 001 / 2010$ & 139 & 21 & 1 \\
\hline $16872 / 2008 / 002 / 2010$ & 253 & 20 & 1 \\
\hline $00116 / 2000 / 004 / 2010$ & 570 & 49 & 0 \\
\hline $13129 / 2010 / 001 / 2011$ & 238 & 25 & 2 \\
\hline $00362 / 2007 / 003 / 2011$ & 356 & 24 & 1 \\
\hline $00259 / 2000 / 008 / 2011$ & 262 & 31 & 0 \\
\hline $00085 / 1980 / 091 / 2011$ & 206 & 24 & 1 \\
\hline $00812 / 2012 / 001 / 2012$ & 133 & 25 & 0 \\
\hline $20842 / 2005 / 007 / 2012$ & 155 & 36 & 1 \\
\hline
\end{tabular}

Apesar da maioria dos estudos analisados em MG ter atendido aos indicadores que dizem respeito à sua qualidade, a abordagem dada pelos estudos componentes dos processos de licenciamento em SP foi bem mais robusta, detalhada e aprofundada, conforme pode ser percebido a partir da leitura dos EIA/Rima durante a realização das vistas aos processos. Este fato provavelmente foi reflexo da diferença da definição do escopo nos dois estados. Conforme apontado por Almeida (2010), a má qualidade dos estudos ambientais componentes dos processos de licenciamento em MG pode estar associada a deficiências nas fases de triagem e escopo. 
Vistorias foram realizadas em todos os processos analisados (Indicador 13 nas Figuras 14A e 14B) a fim de subsidiar a análise técnica do EIA. Ainda, considerando as características da análise técnica na Supram Sul de Minas, diferentemente de SP, um número pequeno de IC foram solicitadas e este pedido foi feito somente em 10 dos 17 processos analisados (Tabela 10). O número reduzido de IC solicitadas não foi devido à alta qualidade apresentada pelos EIA/Rima, como visto anteriormente, inclusive alguns estudos aprovados apresentaram falhas relevantes.

O Indicador 14 (Os estudos ambientais atendem ao escopo) não pode ser avaliado, pois os TR utilizados para a elaboração do EIA/Rima não compunham os processos e, ao longo do tempo, os TR disponibilizados na página do órgão ambiental sofreram modificações, não sendo possível precisar a versão do TR usada.

Com relação ao tempo que o órgão ambiental gastou para realizar a análise do EIA/Rima e de suas IC, ele foi variável (Figura 15 e Tabela 10). Embora no terceiro processo mais demorado (Processo 00362/2007/003/2011 - 356 dias) a causa da dilatação do tempo tenha sido os 2 pedidos de IC (maior número de solicitações) e o tempo de análise se dilatou frente a uma solicitação de IC, não houve relação direta entre o tempo de análise e o número de pedidos de IC. Por exemplo, no Processo 00508/2001/002/2005, que foi o mais demorado nesta fase, não houve nenhuma solicitação de IC, enquanto que nos Processos 07060/2010/001/2010 e 18872/2009/001/2009, que foram os mais rápidos, houveram pedidos de IC.

O tempo de análise sofreu influência da realização da audiência pública. Os processos que tiveram a realização da audiência foram 00508/2001/002/2005, 00116/2000/004/2010, 00287/1994/009/2009 e 10889/2009/001/2010; sendo seus tempos de análise de, respectivamente, 1315, 570, 326 e 139 dias (Tabela 10). Os três primeiros estavam entre os processos com análise técnica mais demorada. No caso do último, a agilidade de análise decorreu de uma solicitação do Secretário Estadual de Meio Ambiente, embasado por um ofício do governador a pedido do prefeito municipal de Pouso Alegre (cidade de implantação do projeto). Este pedido foi justificado pela obra ser de interesse social e ser a solução definitiva para os problemas de enchente na cidade (conforme Ofício GAPREF n ${ }^{\circ}$ 395/10 de 26 de abril de 2010, constituinte do Processo 10889/2009/001/2010).

Dentre os processos mais demorados e apesar da variabilidade do tempo de análise, o Processo 00508/2001/002/2005 destoou dos demais (1315 dias). Ao analisar os fatos acontecidos durante a análise técnica, verificou-se que, além da realização da audiência pública e intensa manifestação popular contrária ao empreendimento, houveram a criação de 
leis municipais e federais protegendo o trecho do rio onde a $\mathrm{PCH}$ seria implantado e, ainda, o processo foi transferido da Supram Central Metropolitana para a Supram Sul de Minas, devido a regionalização das decisões sobre os processos de regularização ambiental. A análise deste projeto já de início mostrou-se complicada, pois o mesmo empreendimento já havia passado por outro processo de licenciamento com nome diferente e havia recebido um parecer da Divisão de Infraestrutura, Energia e Irrigação (DIENI) da Feam indeferindo a licença por inviabilidade locacional, sendo interrompido pelo empreendedor que posteriormente iniciou o processo de licenciamento em pauta. A somatória destes fatores foi a responsável pelo longo tempo de análise quando comparado com todos os demais processos.

No caso do Processo 03405/2006/001/2007, que estava entre os mais demorados (329 dias - Tabela 10), não houve realização de audiência pública e nem o pedido de IC, não sendo estas as causas da dilatação do prazo. Nos registros do processo não houve documentos que justifiquem esta demora, que pode ter sido simplesmente devido à complexidade do projeto, que se tratava de uma rede de distribuição de gás natural.

Os menores tempos de análise foram observados nos Processos 07060/2010/001/2010 (66 dias) e 18872/2009/001/2009 (85 dias) - Tabela 10. No primeiro, o processo iniciou-se com a apresentação de um RCA na Supram Central Metropolitana, sendo posteriormente transferido para a Supram Sul de Minas. Após vistoria e reunião do órgão ambiental (Supram Sul de Minas) com o empreendedor, foi solicitada a elaboração de um EIA/Rima. A Supram reconheceu ter havido um erro na emissão do FOB e, devido a localização do empreendimento em área de domínio do Bioma Mata Atlântica, segundo a Resolução Conama $n^{\circ}$ 01/2008, a licença poderia ser emitida somente com base em um EIA/Rima. O prazo de análise considerado foi somente do EIA e como diversas questões já haviam sido antecipadas com o RCA, a análise tornou-se mais rápida. Fato semelhante aconteceu o Processo 18872/2009/001/2009. Para o mesmo projeto, o processo de licenciamento já havia sido iniciado sob outro número (Processo 03522/2008/001/2008), tendo inclusive o parecer favorável a sua viabilidade. Contudo, por falta de pagamento, este primeiro processo foi paralisado. Assim, quando o segundo foi aberto, muitas etapas de análise já haviam sido cumpridas, reduzindo o número de dias gastos.

Todos os processos contaram com a publicidade de seu trâmite (Indicador 15 das Figuras 14A e 14B) através das publicações no Diário Oficial do Estado de Minas Gerais e em periódicos de circulação local, informando a população da existência do processo, da possibilidade de participação através das audiências públicas e das decisões tomadas. Porém, a realização da audiência só foi solicitada em 4 processos, sendo 2 de licenciamento 
preventivo (Processos 00508/2001/002/2005 e 10889/2009/001/2010) e 2 de licenciamento corretivo (Processos 00287/1994/009/2009 e 00116/2000/004/2010) - Indicador 16 das Figuras 14A e 14B. Nos Processos 00508/2001/002/2005 e 00116/2000/004/2010, a solicitação de audiência pública foi feita por uma entidade civil; no Processo 10889/2009/001/2010, pelo presidente da Unidade Regional Colegiada do Copam Sul de Minas; e no Processo 00287/1994/009/2009, pelo Conselho Municipal de Meio Ambiente (Codema) de São Thomé (todos em conformidade com o Art. 3o da DN 12/1994 que regulamenta a audiência pública em MG).

Destas 4 audiências públicas realizadas, somente uma não resultou em contribuições para o processo de licenciamento (Indicador 17 das Figuras 14A e 14B) - Processo 00116/2000/004/2010. Possivelmente justificando este fato, dos 4 processos com audiências, somente este apresentou falhas na disponibilização do EIA/Rima, segundo informações presentes na ata da audiência pública. Assim, não existiu participação efetiva sem a devida informação. Não houve nos processos analisados outra forma de participação que não fosse durante a realização de audiência pública associada à análise técnica do EIA/Rima.

A tomada de decisão sobre a viabilidade ambiental do empreendimento, tomada pela Unidade Regional Colegiado (URC) do Copam Sul de Minas, teve influência da análise técnica - parecer técnico do órgão ambiental - em todos os processos (Indicador 18 das Figuras 14A e 14B) e da participação - audiência - em apenas 3 (Indicador 19 nas Figuras 14A e 14B). A participação somente foi levada em consideração nos casos quando houve a junção da audiência pública com a disponibilização dos estudos para a população (Processos 0508/2001/002/2005, 00287/1994/009/2009 e 10889/2009/001/2010). Logo, para que a participação fosse incluída na tomada de decisão foi necessário dar informações aos interessados para subsidiar o seu envolvimento seja nas audiências ou com contribuições enviadas ao órgão ambiental.

Durante a reunião em que a aprovação do processo esteve em pauta, os membros da URC do Copam (ou conselheiros) puderam solicitar esclarecimentos do empreendedor/consultoria e dos próprios técnicos da Supram (sempre presentes nas reuniões). A presença destes atores na reunião foi um fator que agilizou a etapa de tomada de decisão; se questões fossem levantadas e o empreendedor/consultoria não estivesse presente, o processo poderia ser retirado de pauta e somente seria avaliado em outra reunião. Os conselheiros poderiam pedir vistas ao processo em julgamento, devendo na próxima reunião apresentar suas considerações para que, então, o processo fosse avaliado com o (in) deferimento da licença. 
As complementações ao parecer técnico propostas pelos membros da URC do Copam, geralmente, diziam respeito a inclusão ou alteração de condicionantes, medidas mitigadoras e programas de monitoramento.

De todos os processos analisados, a licença não foi emitida em apenas 2 casos: no Processo 03522/2008/001/2008 que sofreu arquivamento por falta de pagamento; e no Processo 00508/2001/002/2005, onde a licença foi indeferida por inviabilidade ambiental do projeto aliada a intensa manifestação popular contrária à implantação do empreendimento. Esta última situação destaca a importância e a influência da participação nos processos de licenciamento com AIA.

Normalmente, o tempo decorrido entre a emissão do parecer da Supram e a decisão final da URC do Copam (Tramitação Copam na Figura 15 e Tabela 10) foi inferior a 30 dias, sendo este o número de dias entre a realização de uma e outra reunião, que ocorreram mensalmente. Diferenciou-se deste valor de tempo apenas o Processo 00116/2000/004/2010 (49 dias Tabela 10). Como este processo não foi retirado de pauta de outras reuniões, a diferença no tempo pode ter sido ocasionada por questões de datas, que fez com que ele não entrasse em pauta na reunião sequente ao parecer e sim na próxima.

\section{c) Considerações sobre as diferenças e semelhanças entre SP e Sul de MG}

A primeira grande diferença entre os dois estados disse respeito ao escopo. O escopo em São Paulo, pela maneira como foi proposto, tornou o ambiente mais propício à consideração das especificidades, ou seja, de um estudo focado nos pontos significativos para aquele caso. Contudo, o estudo de Barretto e Montaño (2012) mostra que na prática não é isso que acontece: a estrutura preconizada para o escopo no estado de SP, ainda que seja potencialmente diferenciada em relação aos demais estados do país, não tem assegurado a formulação de TR concisos e focados nos impactos significativos dos empreendimentos, pouco contribuindo para a efetividade das avaliações de impacto. Logo, pode-se dizer que, uma boa estruturação para a proposição do escopo, apesar de ser o primeiro passo, não garantiu a efetividade substantiva do sistema. Ainda com relação ao escopo, em São Paulo, embora pouco praticada, existiu a possibilidade de participação dos interessados nesta fase, o que não ocorreu em Minas Gerais. 
A outra grande diferença entre os dois estados esteve relacionada à realização de audiências públicas: em SP, a audiência aconteceu em todos os processos; já, no Sul de MG, esteve presente em poucos casos. Adicionalmente em MG, quando da realização da audiência, existiram reclamações da disponibilização dos estudos. Assim, a participação em MG, na grande maioria das vezes, por não ter existido ou ocorrido de forma inadequada, não trouxe contribuições nem para a análise técnica e nem para a tomada de decisão. Consequentemente, estiveram entre as principais barreiras para uma participação efetiva o pobre fornecimento de informações, a fraca influência na tomada de decisão e a deficiência na execução de metodologias participativas (HARTEY; WOOD, 2005). Em SP, apesar das audiências serem realizadas, esporádicas na fase de escopo e certas na fase de análise dos estudos, a participação não acarretou em contribuições para todos os processos por não ter havido o envolvimento da população: a participação pública, muitas vezes, limitou-se a consulta pontual e realizada como parte de uma obrigação legal (PARTIDÁRIO; SHEATE, 2013).

Mesmo com este cenário desfavorável de participação, a que se notar, em ambos os estados, dois fatos. O primeiro, todas as exigências legais de publicidade e chamamento para a participação ocorreram, ou seja, não foi negado aos interessados o direito de participar. Segundo, quando houve o real envolvimento da população, as janelas de participação disponíveis dentro do processo de AIA foram capazes de promover interferências, seja introduzindo novas questões ou, até mesmo, levando à paralisação de processos e ao indeferimento das licenças. Assim, o que uma participação pública efetiva necessita são novas formas de informação e envolvimento (PARTIDÁRIO; SHEATE, 2013).

Cabe à discussão, o fato de que se realmente deveria acontecer audiência na fase de análise dos estudos em todos os processos de licenciamento com AIA, já que, como observado em SP, a realização de audiência não garantiu contribuições e que, como observado em MG, quando a população tinha a contribuir com o processo ela mesmo fazia a solicitação para a sua realização através dos mecanismos já disponibilizados pelo sistema. Contudo, não se pode esquecer os princípios de boas práticas da AIA que diz que dela deve promover o envolvimento e a participação das comunidades e dos afetados por uma proposta (IAIA, 1999) e que mesmo longe do ideal, degraus inferiores da escada de participação propostas por Arnstein (1969) não deixam de ser formas de participação. Assim, mesmo que apenas para cumprir uma obrigação legal e sem agregar informações ao processo, as janelas de participação devem ser disponibilizadas em todas as etapas da AIA.

A prática de elaboração dos estudos, com exceção da análise de alternativas e a avaliação de impactos cumulativos, esteve bem consolidada nos dois estados; somou-se a isso, a 
influência que a análise técnica teve na tomada de decisão. $\mathrm{Na}$ análise de alternativas predominou o procedimento de avaliação de uma única alternativa, impedindo-se o confronto de opções no processo de análise e configurando um reducionismo da aplicação da AIA, que se torna reativa ao se restringir à identificação de medidas mitigadoras (AGRA FILHO et al., 2012). A avaliação de impactos cumulativos foi pouco praticada, ou seja, os empreendimentos foram analisados como se estivessem implantados isoladamente dos demais e como se suas ações não influenciassem e nem fossem influenciadas pelas demais atividades desenvolvidas na mesma área; por isso, muitos efeitos acabam sendo negligenciados na avaliação da viabilidade ambiental.

Diante de toda esta discussão, os três principais problemas do processo de AIA comuns aos dois estados foram: a efetiva participação, a consideração de alternativas para o projeto e a avaliação de impactos cumulativos. Conforme destacado por Pope et al. (2013), estas são as áreas da AIA que universalmente persistem em ter uma prática deficiente.

Não se pode esquecer, ao avaliar a efetividade dos sistemas de licenciamento com AIA, que o tempo e custo também são fatores de grande importância. Tipicamente, a eficácia tem sido definida como uma medida para alcançar determinada meta, embora esta definição possa ser expandida para incluir noções de eficiência de custos (CASHMORE et al., 2010).

Tempo e custo são ainda mais preponderantes do ponto de vista do empreendedor. Segundo a Confederação Nacional da Indústria (CNI, 2007), os 3 principais problemas encontrados no licenciamento ambiental das empresas foram a demora na análise dos processos, os custos com investimentos necessários para atender às exigências ambientais e a dificuldade de identificar e atender os critérios técnicos exigidos. Resultado semelhante foi encontrado pela Federação das Indústrias do Estado da Bahia (FIEB, 2008), sendo destacadas as dificuldades relacionadas à demora na análise dos pedidos, custo elevado do licenciamento e burocracia. Chega-se ao ponto de que, para a maioria dos empreendedores, a AIA traz mais custos que benefícios (MACINTOSH, 2010).

Diversos fatores (conforme discutido nos itens 5.2.1.2.a e 5.2.1.2.b) influenciaram o tempo gasto nos processos de licenciamento com AIA nos dois estados e, assim como foi encontrado por Cerqueira e Alvez (2010) em Portugal, o valor elevado do desvio-padrão dos tempos médios de tramitação indica que existem diferenças substanciais entre os processos. Apesar destas diferenças, pode-se afirmar que em MG os processos tenderam a ser mais rápidos que em SP. De início, dois fatores podem ser responsáveis por isto, a padronização do escopo e a não realização das audiências públicas, mas é necessário um estudo mais aprofundado de outros fatores. Contudo, não se pode esquecer que a qualidade dos resultados em termos de 
desempenho de sustentabilidade é considerada mais importante do que uma ênfase na velocidade do processo (MORRISON-SAUNDERS; SADLER, 2010).

Como existem poucos dados disponíveis sobre os prazos envolvidos no processo de AIA, torna mais fácil para os críticos dizer que a AIA é um tanto quanto longa e cara (MIDDLE; MIDDLE, 2010), sendo esta responsabilidade atribuída principalmente ao órgão ambiental. Para Montaño et al. (2007), a atual polêmica envolvendo a lentidão no licenciamento ambiental de atividades potencialmente degradadoras se deve, fundamentalmente, a duas razões: 1) os Estudos de Impacto Ambiental, via de regra, são peças sobrecarregadas de informações, muitas das quais sem conexão com o empreendimento a ser licenciado; 2) a inexistência de outros instrumentos da PNMA prejudica o processo de análise sobre o estudo de viabilidade ambiental do empreendimento. Ainda, a análise do licenciamento com AIA nos dois estados mostrou que grande parte da demora nos processos foi devida a má qualidade dos estudos entregues ao órgão ambiental (que necessitam de várias complementações) e ao atraso na resposta das informações complementares solicitadas. Isto não isentou a responsabilidade do órgão ambiental (que muitas vezes burocratizou os processos e, por questões de estruturação interna e relação com outros órgãos, atrasou os processos), mas dividiu-a com os empreendedores/consultoria.

\subsubsection{Relação entre os atores}

\section{a) São Paulo}

Para o processo de licenciamento com AIA no estado de São Paulo foram identificadas 4 Arenas de decisão, presentes nas etapas de: triagem, escopo, seleção de alternativas e decisão. Ainda, poderia ser acrescentada uma quinta arena de decisão, que envolveria a renovação da licença. Contudo, os processos selecionados para análise não possibilitaram a observação desta arena, por esta fase do processo de licenciamento ser de responsabilidade das Agências Regionais da Cetesb e não mais da agência central. 


\section{$\underline{\text { Arena 1: Triagem }}$}

A triagem no estado de SP envolveu a decisão da necessidade da AIA no processo de licenciamento e, para o caso afirmativo, de qual o tipo de estudo a ser elaborado, podendo ser um EAS, um RAP ou EIA/Rima. Lembrando que, a partir da análise do EAS e/ou do RAP, estudos mais aprofundados poderiam tornar-se necessários, partindo-se para a elaboração do EIA/Rima.

Estiveram envolvidos na Arena 1 de decisão - triagem (Figura 16) o corpo técnico do Daia e da Cetesb (incluindo aqui as diferentes divisões e departamentos do Daia e da Cetesb que tratam de assuntos variados como emissões atmosféricas, análise de risco, ruídos e vibrações, efluentes, resíduos, áreas contaminadas, entre outros) e, em alguns casos, pôde ocorrer a intervenção da sociedade através de Organizações não Governamentais (ONG) ou entidades civis sob a forma de documentos enviados ao órgão ambiental. O processo 13522/2004 foi um exemplo da contribuição da sociedade nesta fase: corroborando com o parecer técnico de análise do RAP, houve manifestação de uma entidade civil solicitando a exigência de EIA/Rima para o processo de licenciamento do empreendimento em questão.

Nos processos analisados, as decisões desta arena foram embasadas em canais formais de comunicação e tomadas de acordo com legislações (Resoluções Conama n ${ }^{\circ}$ 001/1986 e n ${ }^{\circ}$ 237/1997 e Resolução SMA n 54/2004), participação e embasamento técnico (Tabela 11).

Figura 16 - Rede de comunicação na Arena 1 de decisão em SP. Círculos simbolizam os atores, as

linhas contínuas relações presentes em todos os processos e as linhas pontilhadas relações que acontecem de forma esporádica. O círculo destacado ilustra o ator responsável pela tomada de decisão.

\section{Arena 2: Escopo}

A definição do escopo no estado de São Paulo englobou a apresentação do PT pelo empreendedor/consultoria e, a partir de sua análise, o órgão ambiental emitiu o TR, com os 
tópicos a serem abordados no EIA/Rima. Foram obrigatoriamente participantes desta arena de decisão o empreendedor/consultoria como propositor do PT; o Consema que pôde ou não avocar sua participação na elaboração do TR, mas que teve que ser consultado em todos os processos (dos 20 processos analisados, o Consema avocou sua participação na análise de apenas 3 PT); e o corpo técnico do órgão ambiental que analisou o PT e emitiu o TR (Figura 17).

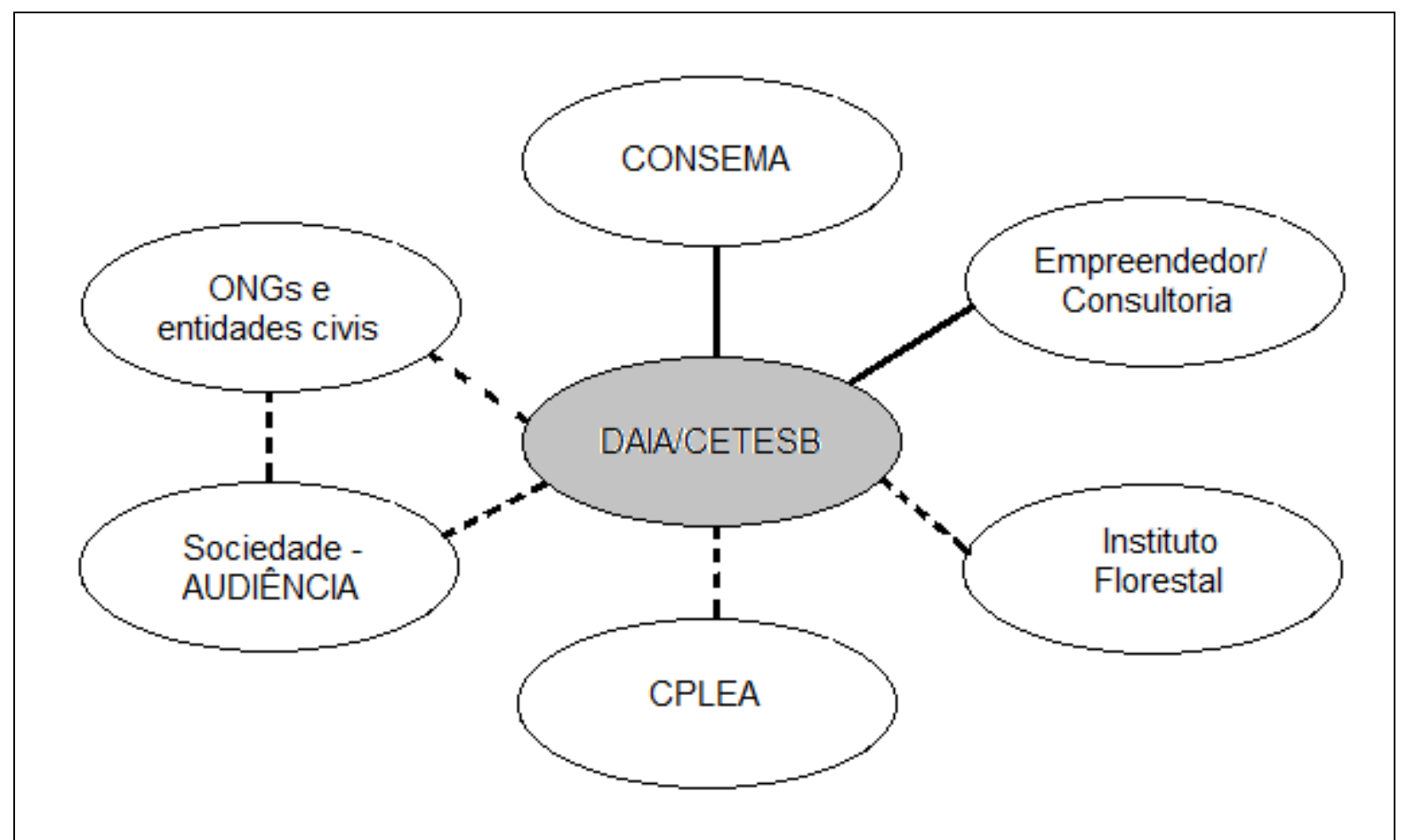

Figura 17 - Rede de comunicação na Arena 2 de decisão em SP. Círculos simbolizam os atores, as linhas contínuas relações presentes em todos os processos e as linhas pontilhadas relações que acontecem de forma esporádica. $\mathrm{O}$ círculo destacado ilustra o ator responsável pela tomada de decisão.

Assim como na Arena 1, o responsável pela decisão foi o corpo do Daia e da Cetesb (novamente envolvendo suas diferentes divisões). Embora tenha ocorrido em poucos processos analisados, existiu a possibilidade de participação da sociedade, seja através de contribuições por escrito diretamente enviadas ao órgão ambiental, seja através da solicitação e participação em audiências públicas para a análise do PT. Ainda, conforme solicitação do corpo técnico, puderam ser envolvidos outros órgãos relacionados com a questão ambiental (Coordenadoria de Planejamento Ambiental Estratégico e Educação Ambiental - CPLEA, Instituto Florestal, entre outros), chamados a dar sua contribuição na análise do PT.

Os canais de comunicação utilizados nesta arena e a competência da decisão foram formais (Tabela 11). 


\section{Arena 3: Seleção de alternativas}

Esta arena envolveu duas decisões e três atores (Figura 18). A primeira foi tomada pelo empreendedor/consultoria ao definir quais as alternativas seriam avaliadas e quais os critérios seriam utilizados para a seleção da alternativa a ser escolhida. O corpo técnico do órgão ambiental pôde ter envolvimento nestas definições através da análise do PT e definição do TR (nesta ação também pôde haver o envolvimento do Consema, uma vez que ele avoque sua participação) e de reuniões de negociação. Contudo, sua participação realmente ocorreu na segunda decisão, quando da análise técnica, sendo ele o responsável por aceitar ou não os critérios de seleção e a alternativa escolhida.

Nos 19 processos analisados que englobavam esta fase (no processo 258/2009 não foi possível avaliar a seleção de alternativas, pois seu arquivamento ocorreu antes disto, por falta de entrega do EIA/Rima), houve a discussão de alternativas, apresentada no EIA, em apenas 8 casos (Indicador 4 nas Figuras 12A e 12B).

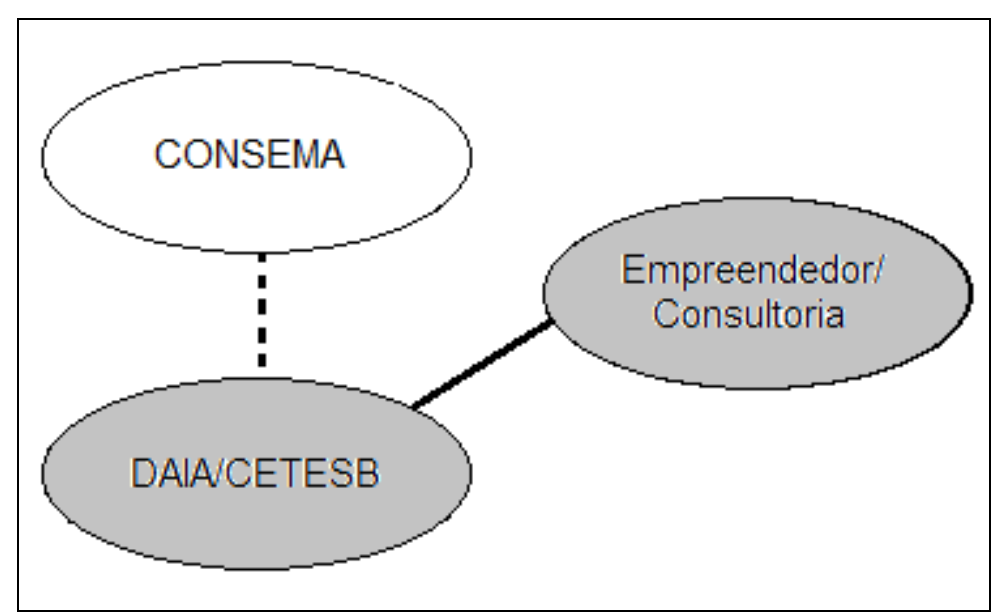

Figura 18 - Rede de comunicação na Arena 3 de decisão em SP. Círculos simbolizam os atores, as

linhas contínuas relações presentes em todos os processos e as linhas pontilhadas relações que acontecem de forma esporádica. O círculo destacado ilustra o ator responsável pela tomada de decisão.

Apesar desta arena já resultar em decisões, quando se passou para a próxima, a da decisão quanto à viabilidade do empreendimento, algumas modificações puderam ser realizadas e foi nesta arena seguinte que a decisão sobre a aprovação da alternativa escolhida foi realmente dada.

Os canais de comunicação e as competências de decisão foram tanto formais como informais nesta arena (Tabela 11). As decisões tomadas quanto à seleção de uma alternativa tiveram embasamento legal e técnico em alguns processos, mas na grande maioria foram feitas pelo empreendedor e focadas em questões que não a ambiental e de cunho econômico. 


\section{Arena 4: Decisão}

Nesta arena, que pôde ser considerada como a arena principal de decisão do processo de licenciamento com AIA, foi onde ocorreu o deferimento ou indeferimento da licença ambiental de acordo com viabilidade ambiental do projeto. Nesta arena também foram definidas as condicionantes para as demais fases do licenciamento - LI e LO.

Vários atores estavam envolvidos nesta arena (Figura 19), sendo que a participação de alguns aconteceu em todos os processos e de outros, apenas em alguns casos. A decisão sobre a viabilidade do projeto envolveu certamente a participação do corpo técnico do Daia e da Cetesb (mais uma vez contando com seus departamentos e divisões), do Instituto do Patrimônio Histórico e Artístico Nacional (Iphan), da Fundação Florestal ou, mais especificamente, de um órgão gestor de uma Unidade de Conservação (UC) próxima ou onde se inseriu o empreendimento, da Coordenadoria de Biodiversidade e Recursos Naturais (CBRN, antigo DEPRN), do empreendedor/consultoria, da sociedade através da audiência pública e do Consema. O tomador de decisão foi o Consema que se apoiou no parecer técnico do Daia/Cetesb e nas contribuições da audiência pública.

O parecer técnico foi emitido pela equipe do Daia/Cetesb, que além das suas considerações também apoiou-se nas contribuições: do Iphan sobre o patrimônio arqueológico, artístico e cultural (neste caso, também houve a atuação do responsável estadual desta área, o Conselho de Defesa do Patrimônio Histórico, Arqueológico, Artístico e Turístico - CONDEPHAAT); da Fundação Florestal sobre as possíveis intervenções em áreas protegidas; e da CBRN sobre os impactos na fauna e flora. Para a emissão deste parecer técnico, em alguns processos, ainda puderam estar envolvidos o Comitê de Bacias (gestão da disponibilidade hídrica em sua unidade de gerenciamento), o Departamento de Águas e Energia Elétrica (DAEE), a CPLEA, o Instituto Florestal, o Departamento de Controle da Qualidade Ambiental (Decont) e o Departamento de Uso do Solo Metropolitano (DUSM) para empreendimentos localizados na região metropolitana da cidade de São Paulo e órgãos setoriais (Departamento Nacional de Produção Mineral - DNPM para empreendimentos minerários, Agência Nacional de Energia Elétrica - Aneel no caso de geração de energia, Instituto de Pesquisas Tecnológicas - IPT quando envolveu gerenciamento de riscos, Fundação Nacional do Índio (Funai) em impactos que afetaram comunidades indígenas e Grupo de Análise e Aprovação de Projetos Habitacionais do Estado de São Paulo - GRAPROHAB em empreendimentos imobiliários). 


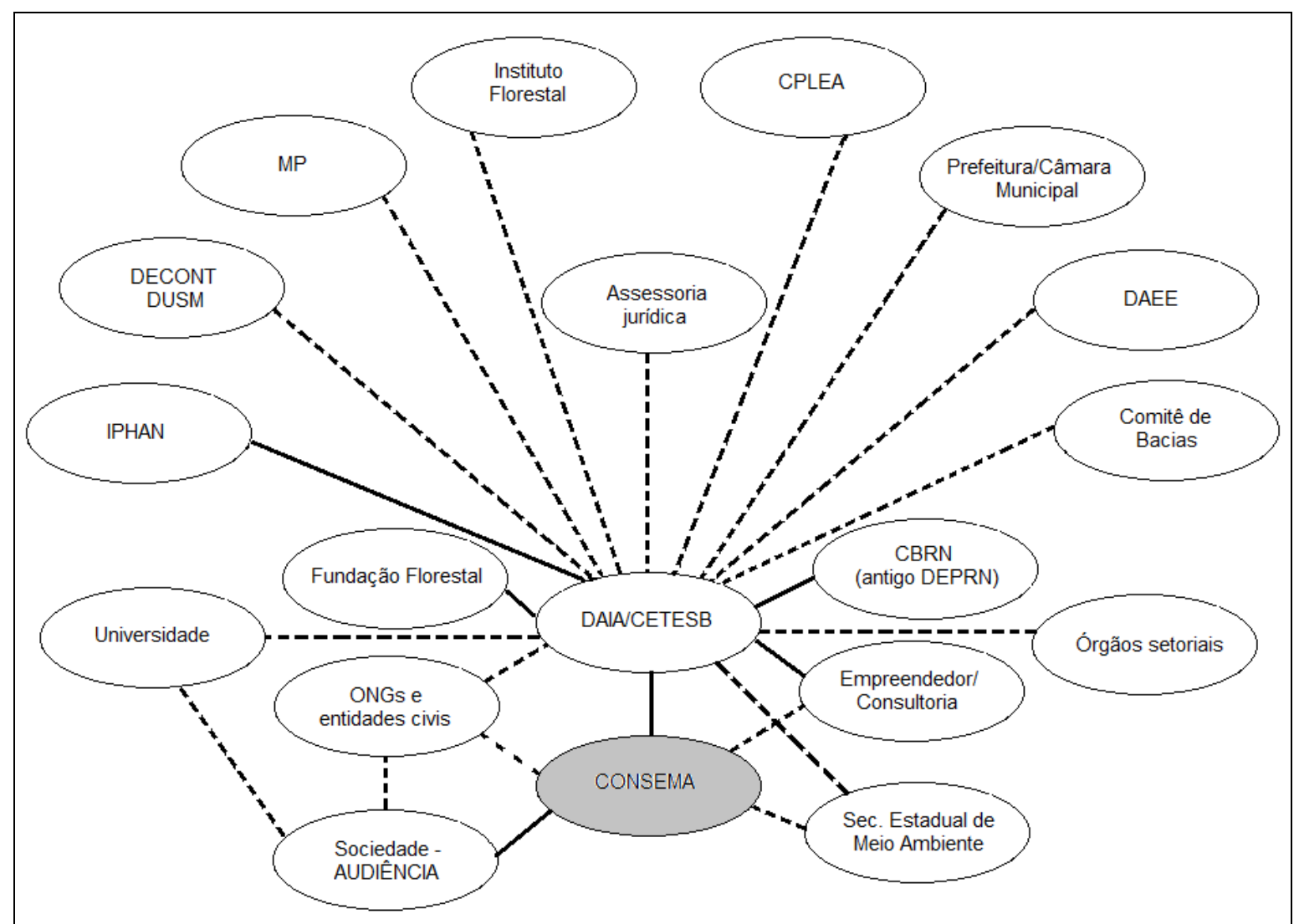

Figura 19 - Rede de comunicação na Arena 4 de decisão em SP. Círculos simbolizam os atores, as linhas contínuas relações presentes em todos os processos e as linhas pontilhadas relações que acontecem de forma esporádica. $\mathrm{O}$ círculo destacado ilustra o ator responsável pela tomada de decisão.

A audiência pública foi solicitada e organizada pelo Consema em todos os processos de licenciamento. Porém, nem todas as audiências resultaram em contribuições para o processo de licenciamento com AIA devido à falta de participação da sociedade. Quando houve participação, muitos benefícios foram trazidos para o processo, ocorrendo o envolvimento de ONGs, entidades civis, universidades e prefeituras e câmaras dos municípios afetados pelo projeto, que além da sua atuação dentro das audiências, puderam fazer suas contribuições diretamente ao corpo técnico do órgão ambiental.

O empreendedor, juntamente com a consultoria elaboradora do estudo, participou desta arena de decisão negociando alternativas, medidas mitigadoras, prazos, entre outros, com corpo técnico do Daia. Além disso, o colegiado do Consema, para os processos em que julgou necessário, pôde solicitar a presença do empreendedor/consultoria em suas reuniões para que informações e esclarecimentos fossem prestados, de modo a contribuir com o processo decisório.

Alguns processos de licenciamento, além de englobar assuntos ambientais, puderam envolver outras questões de cunho legal, o que fez com que participassem desta arena de 
decisão agentes jurídicos. Nestes casos, a decisão pôde ser diretamente direcionada pelo processo de judicialização. Foi o que aconteceu com o processo 13625/2005, onde a empresa vizinha ao empreendimento iniciou e ganhou uma ação judicial a fim de impedir a implantação do empreendimento, alegando a irregularidade do mesmo.

Outro agente que pôde ter envolvimento com a Arena 4 de decisão de SP, ao realizar seu papel de fiscalizador do cumprimento da legislação, foi o Ministério Público (MP). A qualquer sinal de desobediência das leis, principalmente as ambientais, o MP interveio e obrigou o órgão ambiental a adequar o processo ao arcabouço legal.

As atuações dos atores dentro da Arena 4 aconteceram através de canais formais de comunicação e de competências formais de decisão. Contudo, apesar de não estar documentado nos processos, é sabido que muitas vezes as decisões são influenciadas por questões externas. Em algumas conversas exploratórias com atores envolvidos em processos de licenciamento foi possível identificar que acontecimentos de bastidores influenciam a decisão final. Um exemplo foi a atuação do Secretário Estadual de Meio Ambiente em alguns processos solicitando que o trâmite do processo seja acelerado. Assim, para esta arena, as características de comunicação e decisão puderam assumir tanto contornos formais como informais (Tabela 11).

Tabela 11 - Características de competência e comunicação nas Arenas de decisão em SP.

\begin{tabular}{|c|c|c|c|c|c|c|c|c|}
\hline Arenas de decisão & \multicolumn{2}{|c|}{ 1: Triagem } & \multicolumn{2}{|c|}{ 2: Escopo } & \multicolumn{2}{|c|}{ 3: Alternativas } & \multicolumn{2}{|c|}{ 4: Decisão } \\
\hline $\begin{array}{c}\text { Competência } \rightarrow \\
\text { Comunicação } \downarrow\end{array}$ & Formal & Informal & Formal & Informal & Formal & Informal & Formal & Informal \\
\hline Formal & $\mathrm{X}$ & & $\mathrm{X}$ & & $\mathrm{X}$ & $\mathrm{X}$ & $\mathrm{X}$ & $\mathrm{X}$ \\
\hline Informal & & & & & $\mathrm{X}$ & $\mathrm{X}$ & $\mathrm{X}$ & $\mathrm{X}$ \\
\hline
\end{tabular}

\section{b) Sul de Minas Gerais}

As arenas de decisão durante o processo de licenciamento com AIA identificadas para o Sul de Minas Gerais foram 4: triagem, seleção de alternativas, decisão e renovação da licença. A arena de decisão relacionada ao escopo, que esteve presente em São Paulo, não existiu, sendo o escopo definido por TR previamente elaborado. A análise da arena de decisão relacionada à renovação da licença foi possibilitada pelo Processo 00229/1995/005/2005 (vide Tabela 5). 


\section{$\underline{\text { Arena 1: Triagem }}$}

A Arena 1 envolveu as decisões que ocorreram na fase de triagem: necessidade de um processo de AIA e qual o tipo de estudo a ser elaborado, podendo ser um RCA ou um EIA/Rima. Nesta Arena somente o ator Supram esteve envolvido (Figura 20). Com base nas legislações (Resoluções Conama no 001/1986 e n 237/1997 e DN Copam nº 74/2004), o corpo técnico da Supram decidiu se o licenciamento ia ser convencional ou apoiado em um processo de AIA e, para o último caso, com a elaboração de qual tipo de estudo. Portanto, a Arena 1 envolveu competência formal de decisão e comunicação formal (Tabela 12). De acordo com as boas práticas, outros atores poderiam, ou até mesmo deveriam, estar envolvidos nesta fase, entre eles a sociedade (como observado no estado de SP) e outros órgãos envolvidos com a questão ambiental.

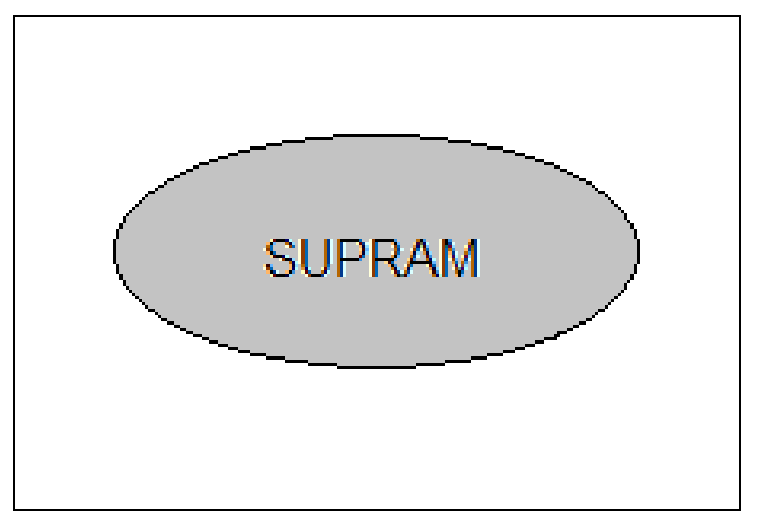

Figura 20 - Rede de comunicação na Arena 1 de decisão no Sul de MG. O círculo simboliza o ator envolvido e o destaque ilustra a responsabilidade pela tomada de decisão.

\section{Arena 2: Seleção de alternativas}

A seleção de alternativas em MG envolveu as mesmas duas decisões de SP, mas contou apenas com dois atores (Figura 21). O empreendedor/consultoria tomou a primeira decisão ao definir os critérios e as alternativas a serem avaliados. A Supram pôde ter envolvimento nesta etapa por meio de reuniões de esclarecimentos e negociação. Mas, foi na arena 3 de decisão que ela pôde optar por aceitar ou não os critérios de seleção e a alternativa escolhida, dentro da análise técnica do EIA/Rima. Para os 17 processos que continham o EIA/Rima, apenas 6 avaliaram diferentes alternativas para o empreendimento proposto, sendo que estes 6 processos tratavam de licenciamento preventivo (Indicador 5 da Figura 14A). 


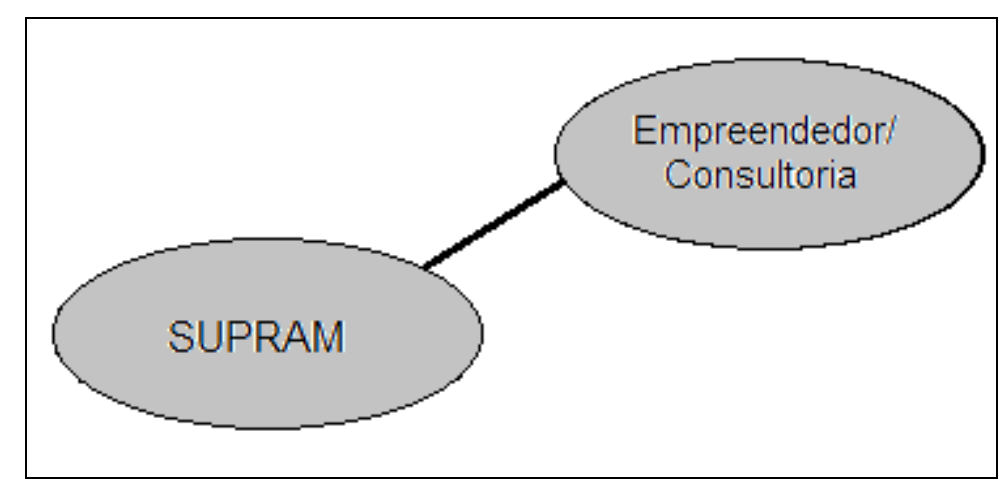

Figura 21 - Rede de comunicação na Arena 2 de decisão no Sul de MG. Círculos simbolizam os atores e as linhas contínuas relações presentes em todos os processos. O círculo destacado ilustra o ator responsável pela tomada de decisão.

Assim como ocorreu em SP, a decisão final sobre a alternativa escolhida somente ocorreu na próxima arena, quando da decisão da viabilidade ambiental do empreendimento.

Os canais de comunicação e as competências de decisão foram tanto formais como informais nesta arena (Tabela 12). As decisões tomadas quanto à seleção de uma alternativa tiveram embasamento legal e técnico em alguns processos, mas na grande maioria foram focadas pelos empreendedores em questões que não a ambiental.

\section{Arena 3: Decisão}

A etapa de decisão foi onde ocorreu o deferimento ou indeferimento da licença ambiental de acordo com viabilidade ambiental do projeto e o estabelecimento de condicionantes para as próximas fases do licenciamento, LI e LO. De certa forma, foi a Arena principal de decisão.

Conforme apresentado na Figura 22, vários atores estiveram envolvidos nesta arena. Contudo, a presença de todos eles não aconteceu em todos os processos. Foi certa apenas a atuação da Supram, Igam, IEF, Copam e empreendedor. No modelo interdisciplinar, a Supram contou com a colaboração da Feam, do Igam, do IEF e do departamento jurídico para a emissão do parecer técnico sobre a viabilidade ambiental do projeto. Foi este parecer que substanciou a participação do Copam que foi o responsável pela tomada de decisão. A função do empreendedor também foi importante, pois através de canais de comunicação formais e informais, o empreendedor pôde negociar tanto com a Supram como com o Copam alguns ajustes na decisão (alternativas de medidas mitigadoras, prazos, entre outros). Foi observado que o canal de comunicação estabelecido entre o órgão ambiental e o Copam com o empreendedor/consultoria foi, na maioria das vezes, bem desenvolvido, permitindo trocas de 
informações de maneira ágil, o que favoreceu o desenvolvimento do processo em menor tempo.

De acordo com as boas práticas, o envolvimento da sociedade (seja ela por meio da realização de audiência ou através da atuação ONGs, entidades civis e Codema) deveria estar presente em todos os processos, estabelecendo relações com a parte técnica (Supram) e com a parte decisória (Copam). Não foi o que ocorreu na prática: menos de um quarto dos processos analisados contou com alguma destas formas de atuação da sociedade (Indicador 12 da Figura $14 \mathrm{~A}$ e $14 \mathrm{~B})$.

A participação de representantes do poder municipal (prefeitura e câmara), do Iphan, de entidades gestoras de UC e de órgãos setoriais foi esporádica. Entendeu-se aqui por órgãos setoriais aqueles que tiveram envolvimento com tipologias específicas de projetos - podendo ser o Departamento Nacional de Produção Mineral (DNPM) no caso de empreendimentos minerários, a Agência Nacional de Energia Elétrica (Aneel) no caso de empreendimentos com geração de energia e a Divisão de Infraestrutura, Energia e Irrigação (DIENI) no caso de empreendimentos de aproveitamento hidrelétrico - ou apresentaram alguma relação com o projeto devido a sua localização - um exemplo foi a participação de administradores de rodovias adjacentes a empreendimentos em processo de licenciamento.

A atuação do Secretário Estadual de Meio Ambiente também se deu de forma esporádica. Ela pôde acontecer de forma formal através da emissão de licenças "ad referendum" ou de formas informais através de pressões para acelerar a análise do processo e a emissão da licença.

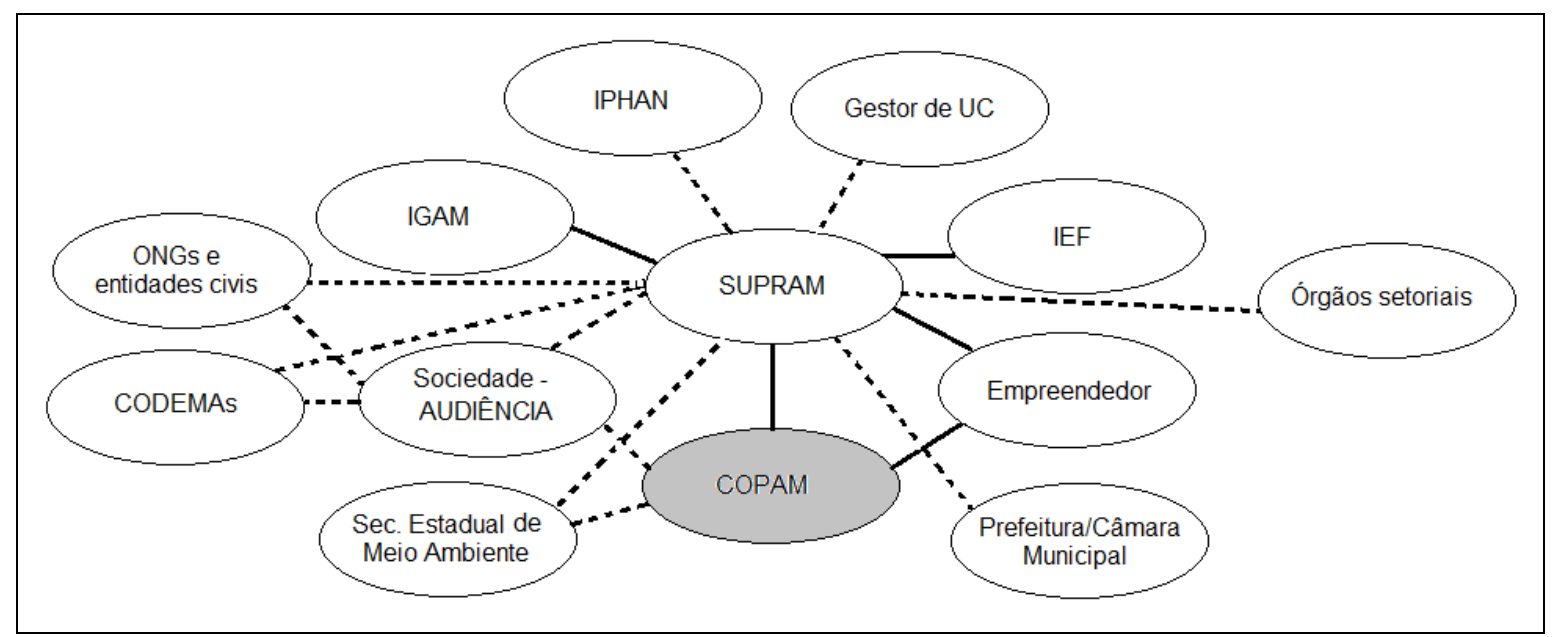

Figura 22 - Rede de comunicação na Arena 3 de decisão no Sul de MG. Círculos simbolizam os atores, as linhas contínuas relações presentes em todos os processos e as linhas pontilhadas relações que acontecem de forma esporádica. $\mathrm{O}$ círculo destacado ilustra $\mathrm{o}$ ator responsável pela tomada de decisão. 
Assim como aconteceu em SP, através de conversas exploratórias com atores envolvidos no processo de tomada de decisão, foi possível identificar que existiram fatores externos norteados por questões políticas e econômicas que acabaram por influenciar esta etapa de decisão. Contudo, estas informações não estavam presentes na documentação dos processos. Assim, é possível dizer que existiu na Arena 3 de decisão características tanto formais como informais de competência e comunicação (Tabela 12).

\section{Arena 4: Renovação da licença}

A licença ambiental deve ser renovada periodicamente. Em Minas Gerais, dentro dos processos de renovação da licença esteve presente o Relatório de Avaliação de Desempenho Ambiental (Rada), que tem por objetivo provar que o empreendimento em questão continua a ter viabilidade ambiental e está de acordo com as normas ambientais vigentes. Nesta arena de decisão estiveram envolvidos a Supram, o Igam, o IEF e o Copam (Figura 23). Assim como na Arena 3, os três primeiros atores foram responsáveis pelo parecer técnico que norteou a tomada de decisão quanto à renovação da licença, por parte do Copam.

A etapa de renovação de licença nos processos analisados envolveu meios formais de comunicação e competência formal de decisão (Tabela 12).

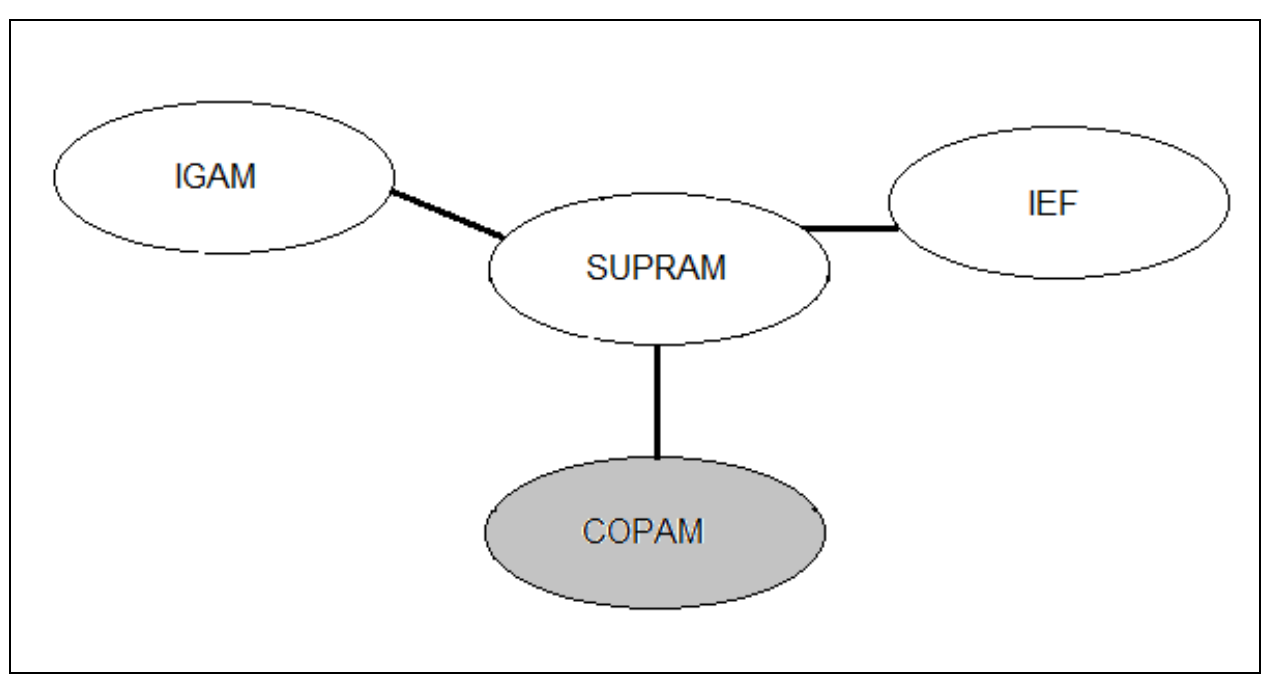

Figura 23 - Rede de comunicação na Arena 4 de decisão no Sul de MG. Círculos simbolizam os atores, as linhas contínuas relações presentes em todos os processos e o círculo destacado ilustra o ator responsável pela tomada de decisão. 
Tabela 12 - Características de competência e comunicação nas Arenas de decisão no Sul de MG.

\begin{tabular}{|c|c|c|c|c|c|c|c|c|}
\hline Arenas de decisão & \multicolumn{2}{|c|}{ 1: Triagem } & \multicolumn{2}{|c|}{ 2: Alternativas } & \multicolumn{2}{|c|}{ 3: Decisão } & \multicolumn{2}{|c|}{ 4: Renovação } \\
\hline $\begin{array}{c}\text { Competência } \rightarrow \\
\text { Comunicação } \downarrow\end{array}$ & Formal & Informal & Formal & Informal & Formal & Informal & Formal & Informal \\
\hline Formal & $X$ & & $\mathrm{X}$ & $\mathrm{X}$ & $\mathrm{X}$ & $\mathrm{X}$ & $\mathrm{X}$ & \\
\hline Informal & & & $\mathrm{X}$ & $\mathrm{X}$ & $\mathrm{X}$ & $\mathrm{X}$ & & \\
\hline
\end{tabular}

\section{c) Considerações sobre as diferenças nas arenas de decisão em SP e Sul de MG}

Para facilitar a comparação das arenas de decisão presentes nos sistemas de licenciamento com AIA de São Paulo e Sul de Minas Gerais, na Figura 24 são apresentadas conjuntamente todas as arenas de decisões de cada um destes estados.

Existiram diferenças significativas entre as arenas de decisão. A primeira grande diferença relacionou-se às arenas: SP teve uma arena a mais de decisão, pois em MG não existiu a arena para a definição do escopo. Comparando as arenas de decisão que foram as mesmas nos dois estados - triagem, seleção de alternativas e decisão, excluindo a arena renovação da licença que em SP não pôde ser analisada - verifica-se que muito mais atores ou grupo de atores estavam envolvidos nas arenas de decisão de SP. Quanto mais envolvidos na decisão, mais informações significativas são trazidas para a avaliação (BARTLETT; BABER, 1989) e maiores as chances de se levar em consideração diferentes abordagens, fazendo com que o processo decisório seja mais robusto. Há uma suposição normativa que a integração de conhecimentos e valores é mais bem alcançada através do envolvimento de uma diversidade de atores no processo de tomada de decisão, que podem contribuir com seu respectivo conhecimento e valores necessários para tornar as decisões eficazes, eficientes, justas e moralmente aceitáveis (RENN; SCHWEIZER, 2009; PARTIDARIO; SHEATE, 2013). No entanto, o engajamento em processos de AIA só tem possibilidades de trazer melhoria se as partes interessadas passarem a atuar no processo e não apenas serem usadas como um mecanismo de verificação, ou seja, mais que envolver todas as partes interessadas em um processo é necessário dar-lhes a oportunidade de ter voz (PARTIDARIO; SHEATE, 2013). Além disso, quanto mais atores envolvidos maiores as chances de que os canais de comunicação e as competências de decisão sejam formais, diminuindo a influência de formas informais de comunicação e de atores que não tem a competência formal de decisão. Em outras palavras, que os instrumentos de política ambiental, licenciamento e AIA, não tenham suas decisões baseadas apenas em fatores de interesses político e econômico, mas que 
efetivamente considerem as variáveis ambientais e sociais. Lembrando que a dependência e a interferência política no processo de licenciamento configuram um problema determinante na eficácia deste instrumento de gestão ambiental (FATORELLI; MERTENS, 2010; THEOPHILOU; BOND; CASHMORE, 2010).

Apesar da diferença no número de grupos envolvidos, houve convergência nos atores responsáveis pela tomada de decisão nos dois estados. Nas arenas da triagem e do escopo (somente para SP) o responsável pela tomada de decisão foi o corpo técnico do órgão ambiental, o Daia/Cetesb em SP e a Supram no caso do Sul de MG. Na arena da seleção de alternativas a decisão foi compartilhada entre empreendedor/consultoria e o órgão ambiental. E nas arenas da decisão e renovação da licença (somente em MG) a decisão final foi dada pelo conselho estadual de meio ambiente, Consema em SP e Copam em MG.

Para os dois estados, nas relações estabelecidas pelos atores dentro das arenas de decisão, não foi verificada a documentação de interações entre o empreendedor/consultoria e a população afetada, mas que mesmo assim poderiam ter ocorrido. A existência desta interação em estágios anteriores de decisão em muito contribui para o processo, pois o empreendedor poderia entender previamente as questões de importância para a população, antecipando-se a elas, não deixando que a discussão ocorresse apenas por ocasião da realização da audiência pública. Isto pode trazer ganhos ambientais e sociais e economia de tempo e recursos.

A análise da relação entre os atores reforçou a deficiência da participação pública ao envolver a população afetada. Em SP, a população teve a oportunidade de participar, embora não se envolveu sempre; de todas as janelas de decisão (de forma direta na triagem, escopo e decisão e, indiretamente, na seleção de alternativas, já que foi na arena da decisão sobre a viabilidade ambiental que a alternativa escolhida pôde ou não ser aprovada definitivamente). Já no Sul de MG, a participação da população afetada ficou restrita à arena da decisão sobre a viabilidade ambiental e, como visto anteriormente, acabou ocorrendo em poucos casos.

Quanto às características de competência e comunicação nas arenas de decisão, a participação informal na AIA recebe pouca atenção na literatura, apesar de sua relevância prática (GLUCKER et al., 2013), sendo preciso alargar o âmbito da investigação para além dos procedimentos formais (CASHMORE; RICHARDSON, 2013). 


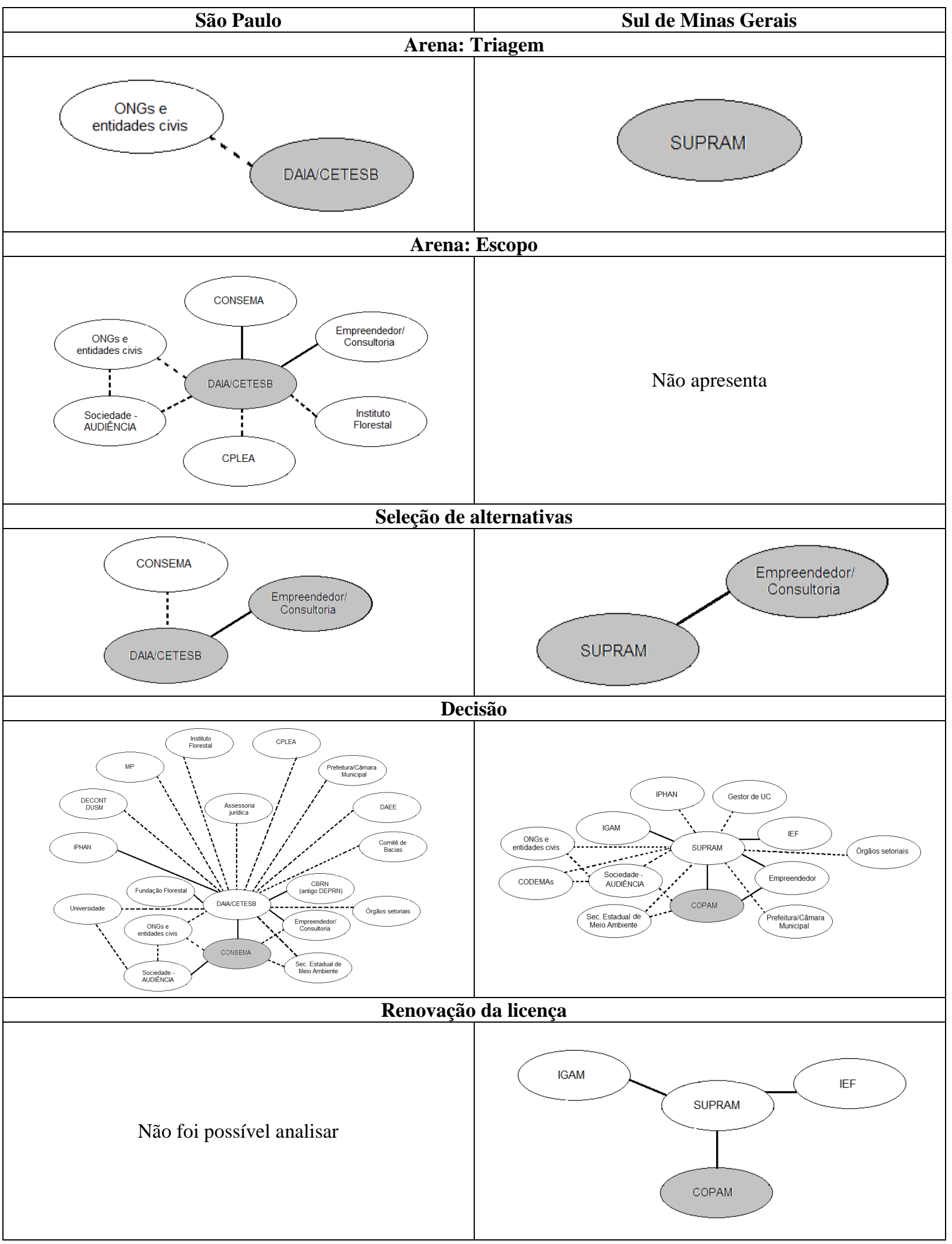

Figura 24 - Comparação entre as arenas de decisão de SP e Sul de MG.

Nas arenas de decisão de SP e MG, que possuíram mecanismos de competência e comunicação iguais (Tabelas 11 e 12), aturam tanto canais formais como informais: nas 
arenas de triagem, escopo (somente em SP) e renovação da licença (somente em MG), as decisões foram tomadas por canais formais de competência e de comunicação; enquanto que nas arenas relacionadas à seleção de alternativas e de decisão final sobre a viabilidade do projeto, ocorreu uma mistura de canais formais e informais tanto de competência como de comunicação. Como encontrado no trabalho de Hansen et al. (2013), a influência dos atores sobre o processo de tomada de decisão foi em grande parte uma função de comunicações informais.

Apesar da importância dos canais informais de comunicação e de competência no processo decisório do licenciamento apoiado na AIA é preciso cuidado ao utilizá-los, uma vez que, principalmente, através de competências informais de decisão a análise da viabilidade ambiental do empreendimento pode dar lugar a uma decisão apoiada em questões meramente econômicas e em interesses políticos. Reforçando esta ideia, Lima e Magrini (2010) destacam que para tornar o processo mais eficiente e simplificado é necessário criar canais formais de comunicação do órgão ambiental com outras agências do governo que são chamados a contribuir durante o processo de licenciamento ambiental e padronizar procedimentos.

\subsubsection{Modelos relevantes para a situação proposta}

O modelo relevante selecionado para avaliar os sistemas de licenciamento com AIA foi um modelo conceitual, desenvolvido a partir da revisão da literatura e apoiado nos princípios e nas melhores práticas internacionalmente disseminadas para estes instrumentos, principalmente, pela International Association for Impact Assessment - IAIA (Associação Internacional para a Avaliação de Impactos), que busca sintetizar as diferentes visões dos atores envolvidos. Com base no modelo de análise apresentado no item 4.1 e ilustrado pela Figura 6, para cada uma das etapas da AIA apresentada foram discutidos quais as características deveriam estar envolvidas para que o funcionamento do instrumento ocorresse de forma efetiva.

A IAIA desenvolveu alguns Princípios da Melhor Prática em AIA com a finalidade de "promover uma prática efetiva da avaliação do impacto ambiental consistente com os sistemas institucionais e processuais em vigor nos diferentes países" (IAIA, 1999, p.2). Estes princípios dividem-se em Princípios Básicos e Princípios Operacionais. Os primeiros aplicamse a todos os estágios da AIA e também à Avaliação Ambiental Estratégica (AAE) e regem 
que a AIA deve ser útil, rigorosa, prática, relevante, custo-eficaz, eficiente, adaptativa, participativa, interdisciplinar, credível, integrada, transparente e sistemática. Os Princípios Operacionais referem-se à aplicação dos Princípios Básicos aos vários passos e às atividades específicas do processo de AIA, tais como seleção de ações, definição do âmbito, exame de alternativas, análise de impactos, mitigação e gestão de impactos, avaliação do significado, elaboração e revisão do EIA, decisão e acompanhamento. Assim, o processo de AIA deve ser aplicado o quanto antes possível no processo de decisão e ao longo do ciclo de vida da atividade proposta; a todas as propostas de desenvolvimento que possam potencialmente causar efeitos significativos; deve considerar os impactos biofísicos e os fatores socioeconômicos relevantes, incluindo a saúde, a cultura, a igualdade de gênero, o estilo de vida, a idade e os efeitos cumulativos consistentes com o conceito e os princípios do desenvolvimento sustentável; deve promover o envolvimento e a participação ativa das comunidades e dos setores econômicos afetados por uma proposta, bem como do público interessado; e estar de acordo com atividades e medidas internacionalmente aceitas.

\section{$\underline{\text { Técnica }}$}

Uma vez conhecida a proposta do projeto em processo de licenciamento, pode-se estimar seu potencial de causar impacto em função do potencial poluidor do empreendimento e da resiliência do meio em que ele será inserido.

Diante deste potencial de causar impacto que se inicia a triagem. A triagem representa uma fase crítica de decisão (WOOD; BECKER, 2005) e reflete o primeiro nível de compromisso da nação com seu sistema de proteção ambiental (RAJARAM; DAS, 2011). Ainda, pode-se dizer que a triagem é, de alguma forma, uma ampliação do conceito de determinação de significância de impacto e, portanto, envolve implicitamente um julgamento sobre as potenciais consequências ambientais de atividades e projetos (PINHO; MCCALLUM; CRUZ, 2010).

Independente dos tipos de critério utilizados para a realização desta etapa (listas positivas, listas negativas, critérios de corte, localização do empreendimento, recursos ambientais potencialmente afetados e análise caso a caso), eles devem ser claros e aplicados de forma sistemática, de modo que ocorra uma padronização do processo. Além disso, os critérios devem ser de tal modo estabelecidos que permitam a separação das atividades ou empreendimentos que têm potencial de causar impacto significativo, e por isso devem ter seus efeitos minuciosamente avaliados, dos que o potencial de causar impacto é insignificante. 
O objetivo fundamental do escopo é o de se concentrar no que importa para os tomadores de decisão para determinar a aprovação ou não de uma proposta (KENNEDY; ROSS, 1992). Além de fazer com que o processo seja focado nas questões relevantes, a fase de escopo torna-se mais enriquecida e robusta quando envolve a participação dos interessados. Assim, aumentam-se as chances de que pontos relevantes para diferentes envolvidos sejam incluídos na análise e discussão.

A padronização dos TR (produto final da fase de escopo), seja para diferentes tipos de empreendimentos ou para diferentes regiões, por um lado torna o processo mais rápido, mas por outro pode fazer com que questões específicas daquela combinação projeto/local sejam desconsideradas e que recursos e tempo sejam desperdiçados com outras questões sem importância.

A elaboração do estudo de impacto ambiental deve ir além de apenas contemplar os tópicos presentes no TR: os itens dos estudos (caracterização do empreendimento, diagnóstico da situação do meio anteriormente a implantação do projeto na área de influência, prováveis impactos ambientais - prognóstico, propostas de medidas de mitigação, importância dos impactos residuais e estudos de acompanhamento) devem estar coerentemente relacionados. De outra forma, é necessário que haja relação entre o diagnóstico, os impactos da alternativa selecionada e a proposição das medidas ambientais e programas de monitoramento.

Se a delimitação do âmbito de abrangência das informações do estudo não é focada, excesso de trabalho e pesquisa pode ser realizado em impactos menores, levando a uma longa preparação e extensos EIA (MIDDLE; MIDDLE, 2010), onde o diagnóstico ocupa a quase totalidade do espaço, sem, contudo, abordar de forma objetiva os fatores relevantes. É o que Sánchez (2008, p.163) chama de abordagem exaustiva, ou seja, o estudo "busca um conhecimento quase enciclopédico do meio e supõe que quanto mais se disponha de informação, melhor será a avaliação".

A proposição de alternativas tecnológicas e locacionais, considerada por Paliwal (2006) como um dos princípios de melhores práticas da AIA, também deve ser considerada na elaboração dos estudos, a fim de que opções mais viáveis ambientalmente sejam escolhidas. Como o potencial de causar impacto é função da tipologia do empreendimento e do local em que se pretende implantar o projeto, sem um estudo de alternativas, principalmente locacionais, a avaliação de impactos fica reduzida apenas a proposição de medidas para remediar impactos que poderiam ser evitados se o local mais adequado houvesse sido escolhido. Neste contexto, torna-se fundamental a integração da AIA com instrumentos de planejamento como o zoneamento ambiental (OLIVEIRA, 2004). 
Por fim, nada adianta o estudo ser bem feito e focado nas questões relevantes se a comunicação dos resultados não é efetiva. O texto do estudo deve ser coerente, claro, objetivo, com padronização de estilo e de acordo com a norma culta da língua portuguesa, assim como as figuras, mapas e anexos devem ser autoexplicativos, correlacionados corretamente no texto e obedecer a normas técnicas relacionadas. Weiss (1989) classificou as deficiências de comunicação dos estudos em 3 categorias: (i) erros estratégicos - ocorrem quando não se compreende as razões pelas quais os estudos estão sendo elaborados e para quem estão sendo destinados; (ii) erros estruturais - ocorre quando existe incoerência entre as partes do estudo ou quando as informações relevantes estão perdidas ou esparsas ao longo do texto; (iii) erros táticos - são os erros de ortografia, pontuação e concordância.

Além disso, existem recursos que facilitam a leitura e o entendimento do conteúdo do estudo e também podem reduzir o tempo de análise, tais como sumário, glossário, lista de figuras, tabelas e anexos; já que estudos mal elaborados dificultam a análise por parte dos órgãos ambientais licenciadores e tendem a tornar mais demorados os procedimentos de avaliação da viabilidade ambiental dos empreendimentos (AGUILAR, 2008).

Além de basear-se no atendimento ao TR, a utilização de listas de verificação da qualidade de estudos seria uma opção viável para utilização e padronização nas avaliações realizadas pelos órgãos ambientais durante a etapa de análise técnica (ALMEIDA et al., 2012).

\section{$\underline{\text { Decisória }}$}

O envolvimento do público no processo de tomada de decisão é o fator mais importante na mudança de concepção do projeto (KOLHOFF; RUNHAAR; DRIESSEN, 2009) e pode ajudar a garantir a abrangência, qualidade e eficácia da AIA, levando a melhores decisões (GLASSON; THERIVEL; CHADWICK, 2005). Daí a importância da etapa de participação dentro do processo de AIA.

A efetiva participação do público deve envolver consultas via comunicação bidirecional entre o desenvolvedor do estudo ambiental ou empreendedor e o público e entre o órgão ambiental ou de Governo e as comunidades locais (PETTS, 1999). Ela serve como ferramenta de negociação e entendimentos entre empreendedor, órgão ambiental e comunidade afetada.

De acordo com os princípios internacionais de boas práticas, a participação do público deve ocorrer o mais cedo possível, começando na pré-avaliação e continuar por todo o processo de AIA (VASCONCELOS; HAMILTON; BARRETT, 2010), já que os vários estágios do processo de AIA fornecem oportunidades para o envolvimento dos diferentes 
atores (DEVLIN; YAP, 2008). Em países avançados com relação à AIA, a participação não só ocorre na tomada de decisão, mas em estágios anteriores como a triagem e o escopo (MORRISON-SAUNDERS; EARLY, 2008). A participação na fase de escopo é crucial para sua qualidade e da AIA como um todo (HOKKANEN; JANTUNEN, 2012). Soneryd (2004) ressalta que o envolvimento público é recomendado não só no escopo e revisão dos estudos, mas também no monitoramento e auditoria, o que confere ao público a oportunidade de participar da verificação dos resultados nos estágios finais do processo.

Vale lembrar que só consegue participar quem tem informação; assim, de alguma forma a população ou qualquer outro envolvido deve receber meios de informar-se sobre como o processo ocorre e sobre o que está acontecendo, sendo uma destas formas a disponibilização dos estudos realizados, principalmente, do Relatório de Impacto Ambiental (Rima).

A Audiência Pública é considerada um mecanismo de participação social, porém a sociedade não tem poder decisório, mas somente consultivo, ainda que possa determinar a necessidade de maiores aprofundamentos de questões assinaladas nas discussões pelos participantes (TAMBELLINI, 2012).

Com a finalidade de melhorar a participação pública na AIA e estimular o debate entre as partes interessadas e obter como resultado melhores projetos, governança participativa e, em última instância, um mundo mais sustentável, a IAIA criou um guia com os Princípios Internacionais da Melhor Prática da Participação Pública (ANDRÉ et al., 2006). Nos Princípios Básicos, a participação pública deve ser adaptada ao contexto, informativa e próativa, adaptável e comunicativa, inclusiva e equitativa, educativa, cooperativa e imputável; e nos Princípios Operacionais, deve ser iniciada cedo no processo e sustentada ao longo dele, bem planeada e focalizada em questões negociáveis, estimulante aos participantes, diferenciada e otimizada, aberta e transparente, orientada para o contexto, credível e rigorosa. Como Orientações de Desenvolvimento, a fim de melhorar os resultados da participação pública, todos os atores devem promover ativamente o acesso à informação útil e relevante, o envolvimento e participação de alto nível na decisão, as formas criativas de envolver as pessoas e a justiça e a equidade de participação.

A decisão resultante do processo de AIA, por estar associada ao licenciamento ambiental, diz respeito à viabilidade ambiental do empreendimento e deveria ser balizada pela opção de projeto mais viável do ponto de vista ambiental. Ela deve ser apoiada nos resultados da análise técnica e também levar em consideração todas as questões abordadas durante a consulta pública. Ainda, é necessário que os fatores ambientais sejam considerados e não sejam sufocados pelos interesses econômicos ou de outra natureza. 


\section{$\underline{\text { Pós-licença }}$}

A eficiência do processo de AIA esta condicionada à aplicação completa das etapas pré e pós-decisão para um projeto (MOREIRA, 1989).

O monitoramento/acompanhamento é a coleta e interpretação de dados para avaliar tendências, visando atingir um objetivo, indicar necessidades de ajustamentos e de correções (TOMMASI, 1994). Tem a função verificar se a previsão dos impactos e se as medidas ambientais propostas estão sendo suficientes para que os impactos causados estejam dentro de limites aceitáveis (ou padrões de qualidade) e, portanto, se o empreendimento continua a ser ambientalmente viável. Por isso, ele é o elemento que pode transformar um estudo ambiental de um processo estático em um processo dinâmico, sendo a lacuna entre os estudos ambientais e a efetiva implementação e administração de um projeto (NOBLE; STOREY, 2005).

\subsubsection{Comparação da situação problema com o modelo}

A seguir será apresentada a comparação entre a situação dos sistemas de licenciamento com AIA nos estados de São Paulo e Sul de Minas Gerais e o modelo conceitual. Serão destacados os pontos que contribuem e os pontos que enfraquecem a efetividade destes sistemas.

\subsubsection{São Paulo}

O sistema de licenciamento de São Paulo, contando ou não com a AIA, foi apoiado em um arcabouço legal, onde as legislações estaduais complementaram as federais e estabeleceram os procedimentos e critérios a serem adotados, adaptando estes instrumentos ao contexto presente no estado. A única ressalva a ser feita na legislação associada à AIA é que não foi estabelecido o prazo para que o órgão ambiental analise o PT e emita o TR. De modo geral, as bases legais foram orientadas pelos princípios e boas práticas da AIA, o que corroborou para uma efetividade do ponto de vista procedimental. Os critérios utilizados foram claros, 
sobretudo na etapa de triagem dos processos. A consulta prévia de quais rumos seguir para a condução do licenciamento e a possibilidade de exigência de estudos de impacto ambiental mais simplificados (EAS e RAP) demonstraram a flexibilidade do sistema e a simplificação do processo de AIA para os casos menos complexos, resultando em economia de tempo e recursos. Contudo, principalmente com a figura do RAP, correu-se o risco de simplificar o licenciamento de projetos capazes de causar significativas intervenções no meio (KIRCHHOFF, 2004; LOPES, 2008).

Os procedimentos adotados para a definição do escopo em SP favoreceram a especificidade para o projeto em questão e o detalhamento das informações que deveriam ser apresentadas. Contudo, como já apontado, na prática a estrutura preconizada não assegurou a formulação de TR concisos e focados nos impactos significativos dos empreendimentos (BARRETTO; MONTAÑO, 2012). Assim, a fase de escopo no estado de São Paulo possuiu efetividade procedimental, mas não substantiva.

O detalhamento das informações solicitadas no TR e que deveriam ser consideradas na elaboração do EIA/Rima foram importantes para diminuir as solicitações de IC e consequentemente agilizar o trâmite do processo. Além disso, o entendimento da função do TR foi de suma importância para a efetividade transactiva da AIA: nos processos onde o TR não foi cumprido, durante a análise técnica foram solicitadas um maior número de IC e para cumpri-las mais tempo foi necessário; por outro lado, a não consideração da função do TR também foi evidenciada no Processo 3827/2009, onde o EIA continha mais tópicos e informações do que solicitava o TR. Surgiu, então, o caráter enciclopédico do EIA, que passa longe de uma abordagem dirigida aos fatores realmente importantes para a tomada de decisão quanto à viabilidade do empreendimento.

O escopo em SP foi definido a partir da interação do empreendedor/consultoria com o órgão ambiental (Daia/Cetesb), com a possibilidade de envolvimento do Cosema e da realização de audiência pública para participação dos interessados. Para que o escopo fosse efetivamente participativo seria necessário que estas duas janelas de participação fossem melhores utilizadas e aproveitadas. Isso contribuiria para as efetividades procedimental, substantiva e transactiva, já que a participação na fase de escopo agilizou o processo ao antecipar questões conforme apontado pelos casos analisados.

A fase de elaboração dos estudos pôde ser considerada bem consolidada, ou seja, os estudos produzidos, em geral, cumpriram as etapas recomendadas pelos princípios de AIA e pelas boas práticas, com exceção para a análise de alternativas e a avaliação de impactos cumulativos que ainda ausentaram-se ou apresentaram-se de modo inadequado na grande 
maioria dos casos. Algumas vezes, o papel do Rima não foi entendido, sendo que os textos apresentados não eram capazes de dar subsídios para que a população pudesse participar do processo, devido, principalmente, a linguagem utilizada. Ainda com respeito à participação, não foram encontradas evidências de interação entre o empreendedor/consultoria e a população afetada, sendo aparentemente os estudos elaborados através de uma abordagem meramente tecnocrática e não participativa.

Chamou atenção que o prazo estabelecido na legislação para a elaboração do EIA/Rima, 180 dias, poucas vezes foi cumprido, indicando que este número poderia ser revisto.

A análise técnica do EIA/Rima por parte do Daia/Cetesb baseou-se estritamente no cumprimento do TR, sendo que também poderiam ser consideradas listas de verificação da qualidade de estudos internacionalmente aceitas (ALMEIDA, et al., 2012).

A conclusão da equipe técnica a respeito da suficiência das informações apresentadas no estudo e da viabilidade ambiental do projeto envolveu vários atores, enriquecendo a qualidade da análise por envolver diversos especialistas e diferentes visões. Contudo, muitas vezes, a tramitação interna de pareceres entre as diferentes áreas da Cetesb e demais entidades envolvidas dilatou o tempo de análise do órgão ambiental. Foi verificado através dos processos analisados que muitas vezes o canal de comunicação entre estes atores não funcionou corretamente, sendo que algumas entidades não se manifestaram ou se manifestaram tardiamente no processo. Assim, tornam-se necessários mecanismos que facilitem a interação dos analistas técnicos para impactar positivamente a qualidade da decisão e o tempo de análise.

Os processos analisados mostraram que a maioria das IC foram requeridas pela baixa qualidade das informações apresentadas nos estudos, sendo que, em alguns casos, as mesmas IC foram solicitadas mais de uma vez por não haverem sido atendidas. Quanto mais pedidos de IC foram feitos, mais tempo demorou a tramitação do processo; logo, quanto maior for a qualidade do estudo apresentado, menor a solicitação de IC e menor o tempo de obtenção da licença. Ainda, as boas práticas na elaboração dos estudos, na maioria das vezes, não foram adotadas, sendo que os estudos apresentaram falta de paginação e índice, erros de digitação, informações repetidas, o que tornou a análise mais demorada. Assim, já que o tempo para obtenção da licença é considerado de extrema importância para o empreendedor/consultoria, um modo de agilizar o processo é considerar o papel do TR e elaborar estudos de boa qualidade tanto no teor das informações quanto na organização do texto.

Uma forma encontrada para agilizar a solicitação e a apresentação de IC simples foi o uso de recursos da internet, como o correio eletrônico. 
A figura da audiência pública associada à análise do EIA/Rima esteve presente em todos os processos analisados no estado de SP: quando a solicitação para a realização da audiência não era realizada por outro ator, o próprio órgão ambiental a fazia. Previamente à realização das audiências, os estudos, além de serem disponibilizados na forma física em lugares de acesso da população interessada, também eram disponibilizados na página do Consema (http://www.ambiente.sp.gov.br/consema/category/audiencias-publicas/). Mais uma vez a efetividade procedimental foi devidamente cumprida, tanto pela realização da audiência como pelo cumprimento de toda previsão legal relacionada à participação. Contudo, apesar de ser uma ferramenta poderosa que a sociedade tem para influenciar a tomada de decisão, a maioria das audiências realizadas não passou de um mecanismo meramente informativo e que, por força de lei, deveria acontecer, onde não houve ou houve pouca manifestação e quase nenhuma contribuição para análise do processo. Contudo, não se pode dizer que a participação dentro dos processos de licenciamento com AIA no estado de SP não tenha tido funcionalidade, pois quando houve o envolvimento, através das janelas de participação disponíveis, a população (sociedade civil, Organizações Não Governamentais, universidade, entre outros) foi capaz de influenciar a tomada de decisão, paralisando processos e/ou inviabilizando a implantação de empreendimentos. Ainda, quando as manifestações foram favoráveis, o processo de licenciamento acabou sendo agilizado.

A tomada de decisão final sobre a (in) viabilidade ambiental, e consequente (in) deferimento da licença, ao ser dado pelo Consema, não deixou de ser uma forma participativa de decisão, pois este conselho envolve em sua composição diversos segmentos da sociedade. Diante da observação e da leitura das atas das reuniões do Consema, foi verificado que alguns conselheiros não têm conhecimento do funcionamento do licenciamento, o que limita suas contribuições à defesa de interesses do segmento da sociedade que representam e que, ainda, pode trazer influência negativa no tempo de tramitação do processo ao serem pedidas, por mero desconhecimento, informações desnecessárias para a tomada de decisão.

Cabe ressaltar a influência que a análise técnica teve na decisão, sendo um canal formal de comunicação e de competência. No entanto, não se pode ignorar a importância que os meios informais, tanto de comunicação como de competência, tiveram na decisão: embora não fossem claramente documentados, a sua existência foi obsevada em alguns processos analisados e em conversas informais com atores envolvidos com o licenciamento e a Avaliação de Impactos Ambientais. As questões informais apresentaram interferência inclusive no tempo de tramitação dos processos: foi constatado que, para projetos que envolveram outros interesses do governo, o tempo para emissão das licenças foi mais curto, 
embora todas as obrigações legais tenham sido cumpridas. Assim, é necessário reconhecer a existência destes canais e monitorá-los para que as decisões tomadas não deixem de lado a função dos instrumentos licenciamento e AIA e baseiem-se em questões estritamente políticas e econômicas.

A etapa do monitoramento, como já justificado anteriormente, não pôde ser analisada. Contudo, a que se criticar o fato de que todos os processos passam a ter os mesmos procedimentos para seu monitoramento, ou seja, o monitoramento dos empreendimentos reconhecidos como capazes de causar impacto significativo (licenciados com elaboração de EIA/Rima) passam a ser tratados do mesmo modo que aqueles reconhecidos como não capazes (licenciados por EAS, RAP e, até mesmo, MCE).

O tempo para tramitação do processo de licenciamento apoiado em AIA em SP foi influenciado de diversas formas: existiram influências externas ao processo, tanto formais como informais, que puderam agilizá-lo (interesses do governo) ou torná-lo mais longo (judicialização), assim como fatores internos de cada etapa (burocratização, demora nas entregas de IC, falta de comunicação entre órgãos, entre outros inúmeros fatores apontados ao longo de todo este trabalho). De extrema importância é destacar que, embora toda a responsabilidade pela demora nos processos seja comumente atribuída ao órgão ambiental, ela foi compartilhada por todos os atores envolvidos. Para Moretto (2008) fica claro que parte da morosidade do licenciamento decorre da própria ineficiência do planejamento de projetos e não por eventuais intransigências e resistência dos órgãos ambientais.

\subsubsection{Sul de Minas Gerais}

O sistema de licenciamento com AIA do Sul de Minas compartilhou algumas características com o sistema de licenciamento paulista. Dos pontos positivos compartilhados pode-se destacar: a base legal apoiada nos princípios e boas práticas da AIA (auxiliou na efetividade procedimental), com clareza dos critérios utilizados, adaptações à realidade do estado e possibilidades de simplificações; os estudos produzidos, com exceção para a análise de alternativas e a avaliação de impactos cumulativos, em geral, cumpriram adequadamente as etapas necessárias; a solicitação e a apresentação de IC simples por correio eletrônico agilizaram o processo; a forma de decisão participativa ao ser tomada pelo Copam; e a 
importância do parecer técnico para a tomada de decisão quanto à viabilidade do projeto e emissão da licença.

Entre os pontos problemáticos compartilhados estavam: os estudos não contemplaram a análise de alternativas e a avaliação de impactos cumulativos; o Rima, em alguns casos, pela maneira como foi apresentado, não capacitou a população para participar da decisão e nem foi devidamente disponibilizado; não foi identificado o envolvimento da população afetada na elaboração dos estudos; a análise técnica restringiu-se ao cumprimento do TR; nem todos os conselheiros do Copam tinham conhecimento do funcionamento do licenciamento, limitando as contribuições que poderiam ser dadas aos processos; a influência de canais informais de comunicação e competência nas arenas de decisão e no tempo de tramitação dos processos, com interferências políticas e econômicas; e os mesmos procedimentos foram adotados na etapa de monitoramento de todos os empreendimentos, sejam eles capazes ou não de causar impacto significativo.

Apesar destas semelhanças com SP, o sistema de licenciamento com AIA do Sul de Minas apresentou características próprias. A primeira delas relacionou-se a estruturação do órgão ambiental que foi regionalizada nas Supram mesmo nos casos de licenciamento apoiados na elaboração de EIA/Rima. Esta descentralização do sistema favoreceu o processo ao gerar maior proximidade do órgão ambiental com o empreendedor/consultoria, acarretando em maior procura por regularização: de acordo com dados do Sistema Integrado de Informação Ambiental (Siam), a descentralização do licenciamento e a criação das Supram aumentou em quase $600 \%$ a procura por regularização ambiental dos empreendimentos que constituem a Agenda Marrom (VIANA, 2007). Ainda, conforme a pesquisa de Viana e Bursztyn (2010), os atores envolvidos com o processo de licenciamento em MG foram unânimes ao dizer que a decisão de regionalizar o sistema ambiental foi um acerto: a regionalização estimula a regularização, um melhor controle ambiental e social, a participação da sociedade, a interiorização das diretrizes ambientais e a capacitação dos municípios, criando massa crítica no interior do Estado, embora aumente a influência de grupos de interesse (em especial, as prefeituras municipais) nas decisões dos conselhos. Por outro lado, com a regionalização o corpo técnico para análise dos processos ficou reduzido, não possuindo especialistas nas diferentes áreas exigidas pela amplitude e multidisciplinaridade envolvida nos estudos.

Com relação às etapas da AIA, a fase de triagem foi regulamentada principalmente pelas classes definidas na DN 74/2004, cujos critérios de porte e potencial poluidor/degradador têm sofrido constantes mudanças (como exemplo, volta-se a citar o Edital de Chamamento Público aberto em 2012). Embora vise o aprimoramento do sistema, a crítica sobre estas 
mudanças recai sobre as pressões sofridas para que o enquadramento dos empreendimentos seja feito em classes inferiores (classes 1 e 2), ou seja, as alterações ampliam os limites para que o empreendimento seja considerado de pequeno porte e com isso passe a ser licenciado sem a AIA. Deste modo, empreendimentos que são capazes de causar alteração ao meio, mesmo que em pequena escala, são licenciados apenas com uma AAF.

Outra proposta de alteração a ser feita na DN 74/2004 e que constituirá um avanço para o sistema de licenciamento em MG foi a introdução de critérios de localização do empreendimento na etapa de triagem dos projetos (definição da classe). Assim, além dos critérios de porte e potencial poluidor, o enquadramento dos empreendimentos em classes levaria em consideração a vulnerabilidade do meio, dada pelo Zoneamento Ecológico Econômico do Estado de Minas Gerais. Esta modificação da legislação teve a minuta proposta em 2011 (SEMAD, 2011), mas até o momento ainda não foi aprovada.

De acordo com a análise dos processos, verificou-se que do modo como a triagem acontece no Sul de Minas não abre espaço para o envolvimento e participação de outros atores além do órgão ambiental. Ainda, os processos de licenciamento corretivo foram tratados da mesma forma que os de licenciamento preventivo.

O escopo no estado de Minas, diferentemente de SP, foi estipulado por TR generalizados e pré-definidos, o que impossibilitou a análise das especificidades do empreendimento em processo de licenciamento, podendo ter ocasionado a abordagem de temas irrelevantes e a omissão de aspectos fundamentais na análise de sua viabilidade ambiental. Além disso, os TR pré-definidos não possibilitaram nenhuma forma de participação e nem o envolvimento dos diferentes atores.

A adoção do modelo interdisciplinar (pareceres conjuntos da Feam, Igam e IEF auxiliados pela realização de vistorias), além de ter possibilitado uma avaliação integrada dos processos, tornou a fase de análise técnica mais ágil ao diminuir o tempo de análise e emissão do parecer. Contudo, em raros casos foram envolvidas outras entidades ambientais, o que empobreceu a etapa que poderia ter sido mais substancial e criteriosa com a participação destas entidades, que possuem maior capacidade técnica na sua área de atuação. Isto pode ter acontecido pelo fato de que a estruturação de Comitês de Bacias, órgãos gestores de Unidades de Conservação, entre outros, é mais incipiente em MG que em SP.

A exigência de qualidade dos EIA/Rima apresentados a Supram Sul de Minas foi menor quando comparado com São Paulo. Alguns estudos não cumpriram ou não cumpriram de forma satisfatória todas as etapas de desenvolvimento necessárias (conforme pode ser notado pelos resultados da aplicação dos indicadores e também pela leitura dos estudos), mas mesmo 
assim poucas IC foram solicitadas e nenhum EIA/Rima foi reprovado por sua má qualidade. Se o órgão ambiental aceita estudos de baixa qualidade que pecam ao fornecer informações para a tomada de decisão, não é da parte do empreendedor/consultor que melhores estudos serão desenvolvidos, uma vez que exigem mais tempo e recursos. Diante deste contexto, apesar dos processos terem se tornado mais ágeis e com menor dispêndio de recursos, aumentando a efetividade transactiva e até podendo ter cumprido a efetividade procedimental, os objetivos do instrumento AIA não foram alcançados - efetividade substantiva. Em outras palavras, priorizou-se o tempo e a agilidade para análise dos processos e esqueceu-se da qualidade das informações que subsidiaram a tomada de decisão.

Ainda, de acordo com os processos analisados, foram verificados alguns fatores que prejudicaram e atrasaram a análise técnica do órgão ambiental, como a apresentação de informações repetidas, estudos com falta de paginação ou paginação incorreta, falta de índice, erros de digitação e de linguagem, a necessidade de solicitação de mesmas IC que não foram previamente atendidas e a demora na entrega das IC. Pedreira (2004) verificou que o não cumprimento dos prazos de análise dos pedidos de licença em MG (que no caso de EIA/Rima seria de 180 dias), provém da união de vários fatores, como: a falta de capacidade técnica dos analistas e recursos humanos dos órgãos; a qualidade insatisfatória dos estudos, projetos e planos propostos pelos empreendedores; desarticulação entre os órgãos; e a falta de comunicação e compreensão entre os órgãos institucionais, ministério público, empreendedor e sociedade.

Como positivo, foi observado que houve uma grande proximidade entre empreendedor/consultoria e técnicos do órgão ambiental. Ocorreram várias reuniões de discussão e esclarecimentos, o que facilitou o andamento do processo, tornando-o mais veloz.

A participação dentro do processo de licenciamento com AIA no Sul de Minas, apesar de ter havido o cumprimento dos requesitos legais, não ocorreu nas etapas anteriores à análise técnica e, nesta fase, aconteceu em poucos casos sob a forma de audiência pública. Diferentemente do que ocorre em SP, se a audiência não foi solicitada pelo MP, entidade civil, Conselho de Meio Ambiente e 50 ou mais cidadãos, o órgão ambiental não o fez. Ainda, quando a audiência foi realizada, houveram reclamações da falta de informação e disponibilização do EIA/Rima para consulta e, com isso, poucos contribuições foram acrescentadas ao processo. Porém, cabe novamente ressaltar que quando houve interesse em participar e envolvimento dos interessados, estas janelas de participação foram suficientes para provocar intervenções nos processos. 
Durante a reunião do Copam para a decisão final sobre a viabilidade ambiental do projeto e emissão da licença ambiental, a presença do empreendedor/consultoria e dos técnicos da Supram agilizou o processo, uma vez que eles puderam esclarecer dúvidas dos conselheiros, não sendo a decisão adiada para as próximas reuniões. Dos processos analisados apenas um teve a licença ambiental indeferida devido à inviabilidade ambiental do projeto no local proposto, sendo que a participação teve influência para esta decisão.

Um fato interessante observado na análise dos processos foi que empreendimentos com a licença indeferida foram submetidos novamente à apreciação do órgão ambiental com nomes diferentes, sem mudanças na concepção e local do projeto, de modo a tentar mudar a decisão e provar uma viabilidade ambiental que não existe. Contudo, não foi possível averiguar se com esta "tática" estes projetos resubmetidos com outro nome tiveram sucesso na obtenção da licença.

O monitoramento/acompanhamento do empreendimento por parte do órgão ambiental no Sul de Minas, conforme apontado pelos técnicos, muitas vezes, não ocorreu na frequência desejada, gerando passivos ambientais que só tentaram ser resolvidos por ocasião da renovação ou do pedido de outra licença. Assim, a etapa de acompanhamento/monitoramento não foi realizada de forma adequada, lembrando que sem ela, a AIA pode ser reduzida a um procedimento meramente formal, em vez de ser um exercício efetivo no gerenciamento ambiental (SADLER, 1996).

A renovação da licença em Minas Gerais teve e tem um estudo envolvido, o Rada. Através deste estudo, o empreendedor deve demonstrar ao órgão ambiental sua regularidade e cumprimento de todas as condições impostas pela licença.

O tempo de tramitação dos processos, assim como em SP, sofreu influência de diversos fatores; contudo, boa parte da demora transcorrida foi de responsabilidade do empreendedor/consultoria que fizeram inúmeros pedidos de prorrogação de prazo para entrega do EIA/Rima e das IC. Ainda com relação ao tempo, foi constatado que para projetos que envolvem outros interesses do governo que não o ambiental, o processo foi agilizado, sendo o tempo para emissão das licenças muito mais curto. Isto ocorreu com os Processos, tanto de LP como de LI, do Sistema integrado de contenção de enchente de Pouso Alegre, onde as licenças foram emitidas primeiramente "ad referendum". Neste caso, as obras exigiam maior agilidade por ser de extremo interesse social e por estarem associadas, até mesmo, a segurança da população. Contudo, existiram casos em que o processo foi acelerado por interesses meramente políticos e econômicos. 


\subsubsection{Proposição de melhorias}

A base para a proposição de melhorias para o sistema de licenciamento com AIA deve ser seus aspectos teóricos e as melhores práticas internacionalmente disseminadas. Neste sentido, é primordial observar como funcionam sistemas eficientes, por exemplo, o finlandês, que segundo Hokkanen e Jantenen (2012) é efetivo e eficiente. Assim, remontar as experiências que estão dando certo ao redor do mundo e adaptá-las para o contexto presente em cada estado é essencial para o aperfeiçoamento dos sistemas.

Encarar as deficiências do processo de forma sistêmica também contribui para a melhora em sua efetividade global. Conforme apontado ao longo deste trabalho, analisar separadamente cada fase e componente do processo, na maioria das vezes, não demonstra a situação real. Ainda, para melhores resultados, os diferentes tipos de efetividade (procedimental, substantiva e transactiva) devem ser analisados em conjunto. Surge o desafio de dosar a padronização e a simplificação do processo com a análise caso a caso, a fim de que não se perca a consideração dos impactos significativos e da especificidade do projeto dentro de um período de tempo considerado razoável. Principalmente o sistema do Sul de Minas deve considerar não só o tempo como indicador da efetividade do sistema, mas também a qualidade dos estudos e das decisões envolvidos.

As principais etapas que necessitam de melhoria tanto no sistema de licenciamento com AIA de São Paulo como do Sul de Minas Gerais podem ser agrupadas de acordo com as ações que podem ser tomadas.

O primeiro grupo, envolvendo a consideração de alternativas, a análise de impactos cumulativos e a linguagem do Rima, diz respeito à qualidade dos estudos apresentados. Neste caso, a melhoria dos sistemas seria ocasionada por TR concisos e focados nos impactos significativos, pelo aumento da exigência de qualidade do órgão ambiental (ênfase para a Supram Sul de Minas que aprovou estudos com sérias deficiências) e pelo reconhecimento da necessidade do estudo de alternativas locacionais. A estrutura proposta para a definição do escopo em SP (apresentação do PT para posterior emissão do TR, com possibilidade de participação), embora na prática careça de aperfeiçoamentos, poderia ser observada por MG. Associada à maior exigência do órgão ambiental, poderiam ser revistos os prazos (elaboração do EIA/Rima e estabelecimento de prazo para que o órgão ambiental analisar o PT e emitir o TR no caso de SP) e adotadas na fase de análise técnica listas de verificação da qualidade de 
estudos, o que segundo Almeida et al. (2012) diminuiria a variabilidade na interpretação das informações e reduziria o tempo de análise dos estudos.

A segunda etapa que necessita de melhorias é a participação. Embora todas as obrigações legais sejam cumpridas e, quando se quer intervir, as janelas de participação disponibilizadas sejam suficientes, faltam mecanismos para gerar o envolvimento dos afetados e permitir a participação nas demais fases do processo além da análise técnica. O principal empecilho para propor mecanismos de participação é a cultura do brasileiro de apatia e comodidade, negligenciando seu direito e poder de cidadão de participar e interferir nos processos decisórios. Alerta maior deve ser dado ao sistema do Sul de Minas, pois nem as audiências, que, segundo Lemos (1999), são o principal mecanismo de participação da sociedade no licenciamento dos empreendimentos e onde ela se esgota, estiveram presentes em todos os processos. É evidente que se o grau de conscientização e envolvimento dos cidadãos fosse elevado, não existiria a obrigação da audiência em todos os processos, pois a não solicitação da realização da mesma seria uma opção dos afetados por não se oporem ao projeto e/ou por não terem contribuições a fazer. Contudo, a participação nos sistemas de licenciamento com AIA de São Paulo e Sul de Minas Gerais ainda está longe de atingir este grau de maturidade.

Aprimoramentos também devem ser feitos nos canais de comunicação entre os atores envolvidos nos processos, a fim de otimizar e agilizar o processo de licenciamento. Conforme apontado pela pesquisa de Sousa e Palhares (2012), sugestões de aperfeiçoamento do processo elencadas pelos técnicos de consultorias ambientais responsáveis por EIA protocolados no Daia/Cetesb giram em torno de três possibilidades: ampliar a relação com o órgão ambiental, consolidação de um contínuo processo de capacitação dos técnicos e da reflexão acerca da relação entre o financiador, os técnicos e o órgão ambiental. Em MG, a melhoria de comunicação deve promover, além da agilização, o envolvimento de mais atores nas janelas de decisão. Quanto mais participantes na decisão, menor tende a ser a influência de fatores externos às questões ambientais, como os interesses políticos e econômicos. Para Zhouri, Laschefski e Paiva (2005), o quadro ora exposto remete ao debate sobre o paradigma da adequação, que trata do jogo político de interesses, destinado a viabilizar o projeto técnico, incorporando-lhe algumas "externalidades" ambientais e sociais, desde que essas, obviamente, não inviabilizem o projeto do ponto de vista econômico-orçamentário. Experiências internacionais indicam que os fatores políticos têm sido as forças motrizes por trás da introdução e prática da AIA (ELLIOTT; THOMAS, 2009). Para ilustrar a influência de fatores externos ao processo de licenciamento pode-se citar o manifesto dos técnicos do Ibama, que apesar de ser uma ocorrência em nível federal, pode ser estendida aos sistemas de 
licenciamento estadual. Neste manifesto ${ }^{2}$, os servidores do Ibama, Instituto Chico Mendes de Conservação da Biodiversidade (ICMBio) e Ministério do Meio Ambiente (MMA) denunciaram a pressão sofrida frente à política de aprovação desenfreada de licenças ambientais de grandes obras do Programa de Aceleração do Crescimento (PAC), alegando falta de autonomia para sua atuação e prazos mínimos sem a real estrutura e tempo suficiente para análises adequadas. Soma-se a isto pressão de: alterar pareceres, diminuir e retirar condicionantes de licenças, evitar vistorias e autuações, e diversas violações ao bom e devido cumprimento do exercício legal de atribuições. Uma vez superada a interferência destes fatores externos às questões ambientais, os sistemas de licenciamento, com ou sem AIA, terão um salto em sua efetividade.

Por fim, de nada adianta todas as etapas técnicas e decisórias serem efetivas, sem que ocorra o monitoramento para verificar o cumprimento de tudo que foi acordado. Como melhoria para esta fase, Viana e Bursztyn (2010) propõem que, aliado a regionalização, poderia haver o aumento e a qualificação do quadro de servidores e a valorização da carreira, bem como o estímulo à adoção de sistema de gestão ambiental pelas empresas e à criação de instrumentos econômicos.

Os próprios órgãos ambientais tem tido iniciativas para identificar as deficiências do seu sistema de licenciamento e propor melhorias. Um exemplo já citado é a proposta de modificação da DN 74/2004 em Minas Gerais, que introduzirá na triagem, além dos critérios de porte e potencial poluidor/degradador, a sensibilidade do local dada pelo ZEE do estado. Faltam a aprovação e a implementação desta proposta.

Outro exemplo de iniciativas foi a realização, em setembro de 2012, na cidade de São Paulo do "I Seminário Internacional Licenciamento com Avaliação de Impacto Ambiental"3, onde foram discutidos a situação, os ganhos e os rumos do sistema de licenciamento de São Paulo. O evento contou ainda com a participação de técnicos do órgão ambiental de Minas Gerais e Espírito Santo.

Algumas sugestões de melhorias podem ser destacadas a partir da fala de alguns palestrantes. Segundo Costa (2012), o sistema paulista carece de aprimoramentos que envolvem tarefas tanto para o órgão ambiental como para o empreendedor. Cabe ao órgão ambiental estabelecer regras e procedimentos claros (roteiros para elaboração de estudos,

${ }^{2} \mathrm{O}$ manifesto data de 31 de maio de 2012 e está disponível no endereço eletrônico http://amazonia.org.br/2012/06/servidores-do-ibama-denunciam-pressoes-de-governo-federal-porlicencas-de-obras-do-pac/.

${ }^{3}$ As apresentações das palestras realizadas podem ser acessadas no endereço eletrônico http://www.cetesb.sp.gov.br/noticia/443,Noticia. 
termos de referência, entre outros) e revisar e atualizar normativas (revogar ou revisar resoluções). Já o empreendedor deve, entre outros apontamentos, participar das negociações do processo de licenciamento (p. ex. alternativas tecnológicas e locacionais), garantir a discussão do projeto na comunidade afetada e incorporar boas práticas ambientais.

Romitelli (2012) apontou que a missão do técnico avaliador é, além de fazer bem feito sua função, ser ágil e eficaz. Para este objetivo seja atingido, o técnico do órgão ambiental e o empreendedor devem entender o projeto proposto/executado, conhecer as peculiaridades do local, usar a experiência acumulada, negociar as soluções através do diálogo entre os diferentes atores e comunicar-se bem na elaboração dos pareceres e estudos. A gerente comentou ainda a questão dos intervenientes (prefeituras, Condema, UC, Comitês, Iphan, DAEE, DNPM, Funai, etc) no processo de licenciamento que acarretam problemas relacionados aos prazos e conteúdo de suas manifestações. Como propostas de melhorias, foram por ela destacadas a necessidade de: criar regras mais claras (novas linhas de corte que estão sendo elaboradas nas Câmaras Técnicas do órgão e TR mais focados nos aspectos significativos); encontrar mecanismos para estimular/premiar a autogestão; estimular avaliações/monitoramentos periódicos e de larga escala; negociações com os demais intervenientes; descentralização do licenciamento (municipalização); banco de dados inteligentes informatizados (organização dos dados existentes nos estudos ambientais); e acompanhamento dos grandes projetos on line.

Santos (2012) destacou que no ES estão sendo utilizados alguns instrumentos adicionais ao processo de licenciamento ambiental, visando o aprimoramento do instrumento. Entre estas iniciativas estão a realização, em caráter facultativo, de Consulta Pública na elaboração do TR; o Diagnóstico Participativo de Percepção Ambiental que contribui para que programas e projetos de Educação Ambiental e Comunicação Social propostos no EIA/Rima possam estabelecer ações em consonância com a percepção local sobre o meio ambiente; a formação de Grupos de Trabalho para análise dos estudos envolvendo diferentes atores; o Termo de Compromisso Sócio Ambiental que estabelece as ações necessárias para a mitigação dos impactos, o responsável pela execução da medida (prefeitura, estado, empreendedor) e o valor estimado; e as Comissões de Acompanhamento das Condicionantes Ambientais.

Por fim, Lapertorsa (2012) salientou que em Minas Gerais estão sendo adotadas ações a médio e longo prazo para melhoria do sistema ambiental, incluindo o licenciamento, dentre as quais estão a padronização de conceitos nos Estados; a dissociação dos fatores subjetivos no processo de Regularização Ambiental; a requalificação do corpo técnico; aproximação com o Ministério Público; visão sistêmica junto aos stakeholders; inteiração sobre os projetos do 
Governo; capacitação dos Gestores Municipais; aproveitamento e consolidação do conteúdo dos EIA e alteração da forma de outorgar os Recursos Hídricos.

Finalizando as iniciativas dos próprios órgãos em propor melhorias para os sistemas de licenciamento, em 2013, a Associação Brasileira de Entidades Estaduais de Meio Ambiente (Abema) criou o documento intitulado "Novas propostas para o licenciamento ambiental no Brasil" (ABEMA, 2013), onde identifica e propõe ações para vencer os desafios da aplicação deste instrumento no Brasil. Foram identificados 11 desafios (Tabela 13), sendo que boa parte deles referem-se às questões institucionais como a falta de clareza nas legislações para estabelecer o que é potencialmente poluidor, o que é impacto significativo, a diferenciação entre o impacto regional e o impacto local e à capacitação do próprio órgão ambiental licenciador. Em comum com a presente pesquisa estão: o desafio da interveniência de outras entidades/instituições no processo; os mecanismos para envolver e fazer com que a população afetada se envolva no processo decisório; a adoção do critério locacional e consequente abordagem de alternativas para o projeto a ser licenciado, sendo que este último de algum modo alinha-se com os desafios do momento da introdução do fator ambiental na tomada de decisão e das metas de qualidade ambiental, em síntese, da interação do licenciamento, com ou sem AIA, com os demais instrumentos da PNMA, principalmente aqueles relacionados ao planejamento ambiental, como o zoneamento, a Avaliação Ambiental Estratégica e a Avaliação Ambiental Integrada. 
Tabela 13 - Desafios e propostas da Abema para a melhoria do licenciamento ambiental no Brasil.

\begin{tabular}{l} 
Desafios \\
1 - Momento da Análise de Impacto Ambiental - AIA: \\
A variável ambiental só aparece no licenciamento. \\
\hline 2 - Fator Locacional: Falta de consideração do local no \\
qual os projetos são implantados e de mecanismos para \\
avaliar os impactos cumulativos e sinérgicos.
\end{tabular}

3 - Subjetividade e Imprecisão: Ausência de clareza ou imprecisão das regras e alto grau de discricionariedade dos analistas e dos gestores.

4 - O que é Significativo? Ausência de definição e listagem das tipologias que podem provocar significativo impacto ambiental, onde tudo passa a ser tratado como significativo, impedindo simplificações.

5 - Interveniência: Os órgãos intervenientes criaram instâncias decisórias paralelas e um quadro de esquizofrenia institucional - (múltiplas licenças e regras próprias).

6 - Compensação Ambiental e Condicionante: Falta de regras claras instituídas em nível nacional. Os órgãos intervenientes impõem compensações que extrapolam os danos ambientais, visando suprir carências institucionais e operacionais de seu funcionamento.

7 - Interdisciplinaridade e Parecer Único: Mesmo com equipes multidisciplinares, a análise pode ser feita de forma fragmentada, por área do conhecimento, resultando em pareceres conflitantes e contraditórios. Quando o Parecer Jurídico é feito após o Parecer Técnico, pode ser apontada alguma inconformidade legal, paralisando o processo.

8 - Consulta Popular e as Audiências Públicas: As audiências em geral funcionam muito mais para manifestações daqueles que se opõem ao projeto do que a oportunidade de discussão das medidas mitigadoras pela comunidade afetada.

9 - Capacidade Institucional e Capacitação Técnica: Fragilidade institucional do Sisnama - falta de meios operacionais, incluindo recursos orçamentários, financeiros, humanos e logísticos. Falta de programas permanentes de capacitação e treinamento de pessoal para manter os quadros competentes e atualizados, abrindo espaço para a atuação do Ministério Público nas lacunas.

10 - Impactos Interestaduais e Locais: Imprecisão dos conceitos de "impactos regionais", possibilitando ao MP exigir o licenciamento no Ibama.

11 - Metas de Qualidade Ambiental: Licenciamento sem o apoio dos instrumentos subsidiários e sem compromisso com as metas de qualidade (água, vegetação, ar, solo). "A sociedade fica com a sensação de que o LA é uma licença para poluir".

\section{Proposta da Abema}

Estimular, sob a coordenação dos governos, a Avaliação Ambiental Estratégica e Avaliação Ambiental Integrada.

Institucionalizar a variável locacional como parâmetro utilizado para classificar os empreendimentos e orientar o licenciamento ambiental.

Estabelecer nova classificação das atividades efetiva e potencialmente poluidoras, levando em conta as tipologias a serem reconfiguradas, conforme o porte, o potencial e a localização.

Definir com o máximo de clareza parâmetros para caracterização de tipologias de significativo impacto, para fins de obrigatoriedade do EIA/Rima como condicionante para o licenciamento ambiental.

Desvincular as anuências de instituições intervenientes que não tratam de assuntos relacionados diretamente ao licenciamento ambiental e regulamentar prazos para matérias relacionadas diretamente a este instrumento.

A adoção deste importante mecanismo do Licenciamento demanda regras claras, nacionalmente estatuídas e fixadas em normas específicas, estabelecendo os procedimentos e a forma de compensação.

Recomenda-se a adoção da análise interdisciplinar, reunindo os especialistas requeridos em cada caso, incluindo, quando exigível o parecer jurídico. Sugerese, também, a capacitação das equipes técnicas em direito ambiental, de modo a não sobrecarregar as assessorias jurídicas, bem como a promoção de encontros regionais de capacitação.

Mudar o formato das audiências públicas e a estratégia de consultar a comunidade: desenvolver sistema de informação ambiental eletrônico que possibilite o acompanhamento de todas as etapas do LA e o acesso aos estudos; regulamentar a realização de oficinas públicas, visando à apresentação do projeto e dos estudos; e regulamentar o funcionamento das audiências públicas, de modo a garantir que elas se restrinjam à discussão de empreendimentos de significativo impacto ambiental.

Estabelecer uma estrutura organizacional e operacional do Sistema que lhe dê a robustez para atender, dentro de padrões de qualidade gerencial satisfatórios, às demandas de regularização ambiental e a implantação integrada dos instrumentos da gestão ambiental. Devem-se instituir novas fontes de financiamento para a gestão ambiental e o fortalecimento institucional dos órgãos.

O encaminhamento adequado desta questão, que é crucial, depende da regulamentação da LC 140/11.

Integrar o Licenciamento com outros instrumentos da política ambiental e outras políticas públicas correlatas, como o Plano Diretor de Bacia Hidrográfica ou instrumento similar, para estabelecer metas de qualidade ambiental. 


\section{CONCLUSÃO}

Este trabalho utilizou os recursos de metodologias de abordagem sistêmica para analisar os sistemas de licenciamento com Avaliação de Impacto Ambiental em alguns estados brasileiros, havendo o aprofundamento nos sistemas dos estados de São Paulo e Sul de Minas Gerais.

Inicialmente, através do uso de questionário, buscou-se delimitar o quadro geral dos procedimentos de AIA e licenciamento no Brasil, procurando-se identificar especificidades e similaridades. O índice de devolução dos questionários foi baixo, o que possibilitou a análise de apenas alguns estados. Os sistemas de licenciamento com AIA presentes nestes estados, apesar de possuírem uma estrutura comum remetida às Resoluções do Conama, sofreram adaptações e flexibilizações de acordo com o contexto da gestão ambiental encontrado em cada um deles. Com base na delimitação do quadro geral dos procedimentos nos estados do Ceará, Espírito Santo, Minas Gerais, Pará, Pernambuco, Paraná, Rio Grande do Sul e São Paulo, foram comuns as etapas de apresentação da proposta, triagem, estudos ambientais, análise técnica, emissão das licenças e acompanhamento. Quanto às especificidades, elas estavam presentes nas fases de escopo, participação e tomada de decisão.

As diferenças encontradas entre estes sistemas reforçaram ainda mais a escolha de São Paulo e Sul de Minas Gerais para uma análise mais aprofundada, uma vez que permitiu a avaliação de um sistema de licenciamento totalmente descentralizado (MG) e outro centralizado quando se tratava de EIA/Rima (SP); e um sistema com a definição padronizada de escopo (MG) e outro com o escopo sendo definido especificamente para cada caso (SP).

No que se refere à aplicação da abordagem sistêmica para a avaliação da efetividade dos sistemas de licenciamento com Avaliação de Impacto Ambiental, a Soft Systems Methodology apresentou-se como um instrumento interessante de avaliação, principalmente, por ter possibilitado um aprendizado sobre os sistemas estudados e a proposição de melhorias. Além disso, a utilização da SSM permitiu um entendimento mais aprofundado sobre estes sistemas, ao incluir na análise uma visão mais abrangente que de outras metodologias. Foi a análise do conjunto de todos os fatores (interação das etapas, do tempo e dos atores) que permitiu estabelecer o funcionamento dos sistemas, enaltecendo a importância da utilização das abordagens sistêmicas e mostrando que a efetividade dos sistemas de licenciamento e Avaliação de Impacto Ambiental é determinada por propriedades que se estabelecem nas relações entre seus componentes. 
Apesar de todas as vantagens, cabe ressaltar a dificuldade em se trabalhar com a abordagem sistêmica, sendo necessário recorrer a simplificações para viabilizar sua aplicação que incluíram, dentre outros aspectos, a delimitação das fronteiras do sistema (ou seja, quais os fatores que seriam incorporados na análise). Neste sentido, diversas variáveis foram desconsideradas do trabalho como, por exemplo, as influências de outros instrumentos de gestão e de política ambiental que, por sua própria atuação, também influenciariam na efetividade da Avaliação de Impacto Ambiental nos processos de licenciamento. Além disso, devido à inexistência de estudos com enfoque similar, boa parte das definições necessárias à aplicação da metodologia SSM foi realizada em caráter exploratório, sendo válido para a verificação das possibilidades de integração entre estes dois campos do conhecimento.

A partir do detalhamento do funcionamento dos sistemas de São Paulo e Sul de Minas Gerais, pôde-se observar que as diferenças não se restringiram às características descritas anteriormente, sendo destacadas as divergências nas janelas de participação, na quantidade de atores envolvidos nas arenas de decisão e no tempo de trâmite dos processos.

As principais deficiências apresentadas pelos dois estados estão em consonância com as deficiências encontradas nos sistemas de Avaliação de Impacto Ambiental divulgadas em âmbito internacional, estando presentes na participação, na consideração de alternativas para o projeto e na avaliação de impactos cumulativos. Em relação à participação, considera-se fundamental que ela ocorra o mais cedo possível dentro processo (já nas etapas de triagem e escopo, permanecendo ao longo do processo) e que se encontre meios de realmente envolver a população afetada e os interessados, a fim de que este atores possam trazer contribuições para o processo, ao invés da participação se restringir às audiências públicas, onde eles apenas recebem informações sobre o empreendimento. Por outro lado, sem a consideração de alternativas a AIA se restringe à busca de medidas paliativas para corrigir impactos a fim de viabilizar a qualquer custo a implantação de projetos desenvolvimentistas em locais inadequados, perdendo sua função de alterar projetos para que eles sejam ambientalmente viáveis. A consideração de alternativas e a avaliação de impactos cumulativos exigem a utilização e a integração com outros instrumentos relacionados ao planejamento, como o zoneamento ambiental e a Avaliação Ambiental Estratégica, para que a questão ambiental seja introduzida o quanto antes na tomada de decisão.

No Sul de MG, também vale destacar a generalização do escopo dos estudos (TR prédefinidos e genéricos) e, principalmente, a modalidade de licenciamento corretivo, que distorce a função e o caráter preventivo do instrumento, ao permitir, sem grandes exigências, a regularização de um empreendimento após a consolidação de seus impactos sobre o meio. 
Ainda que não fosse objetivo deste trabalho, e tomando-se o devido cuidado de evitar generalizações entre sistemas que operam em contextos diferentes, é possível afirmar que, diante do quadro de boas práticas definido para o presente trabalho, o sistema paulista se apresenta mais bem estruturado em comparação com o sistema o mineiro, com destaque para o modo como o escopo é definido, a exigência de qualidade dos estudos apresentados, a participação da sociedade e pelo envolvimento de maior número de atores no processo de decisão. Mesmo assim as contribuições para mudanças na concepção dos projetos em ambos os estados ainda são reduzidas, não sendo explorado todo o potencial dos instrumentos licenciamento e Avaliação de Impacto Ambiental.

Diante dos fatores que influenciaram a efetividade dos dois sistemas de licenciamento com AIA (destaque para o tempo, considerado como fundamental pelos empreendedores), pôde-se notar que seu aprimoramento depende da coordenação entre os atores envolvidos, cabendo a cada um fazer cumprir da forma mais adequada seu papel para que o objetivo de conciliação do crescimento econômico com a preservação ambiental seja alcançado. 


\section{SUGESTÕES DE ESTUDOS FUTUROS}

A aplicação da abordagem sistêmica aos sistemas de licenciamento e Avaliação de Impacto Ambiental pode enriquecer o conhecimento acerca do seu funcionamento e da sua efetividade. Assim, sugere-se que outros estudos com este enfoque sejam realizados, a fim de complementar os resultados obtidos e explorar as limitações do modelo utilizado. Estes estudos devem considerar:

- o envolvimento das visões dos diferentes atores inseridos nestes sistemas;

- a relação destes dois instrumentos com outros instrumentos de política e gestão ambiental e com a própria governança;

- outros modos de aplicação da cada uma das etapas da Soft Systems Methodology; e

- a utilização de outras metodologias sistêmicas.

Além disso, existe carência de estudos realizados para avaliar a efetividade da Avaliação de Impacto Ambiental nos demais estados brasileiros.

Com estudos focados nas características e nas realidades presentes em cada sistema estadual de licenciamento, torna-se possível explorar em mais detalhes as possíveis modificações que os sistemas poderiam sofrer para a superação dos desafios e das deficiências apresentadas. 


\section{REFERÊNCIAS BIBLIOGRÁFICAS}

ABEMA - Associação Brasileira de Entidades Estaduais de Meio Ambiente. Novas propostas para o licenciamento ambiental no Brasil. Associação Brasileira de Entidades Estaduais de Meio Ambiente: Brasília : ABEMA, 2013. 92p.

ACCIOLY, R. C.; FIGUEIREDO, R. S. Análise do complexo agroindustrial citrícola utilizando diagramas de influência. Revista Produção, v.1, n.1, 2001.

AGRA FILHO, S.S. Situação atual e perspectivas da avaliação de impacto ambiental no Brasil. In: SÁNCHEZ, L. E. (Org). Avaliação de impacto ambiental: situação atual e perspectivas. São Paulo: Epusp, 1993. p.153-156.

AGRA FILHO, S. S.; MARINHO, M. M. O.; ORRICO, S. R. M.; SANTOS, F. C. Avaliação de Impactos Ambientais: uma discussão dos procedimentos metodológicos da aplicação no estado da Bahia. In: $1^{\circ}$ Congresso Brasileiro de Avaliação de Impacto. São Paulo, 2012.

AGRA FILHO, S. S.; MARINHO, M. M. O.; SANTOS, J. O. Avaliação de Impacto Ambiental (AIA): uma proposta metodológica para análise de efetividade de aplicação através da avaliação Ex-Post. In: $\mathbf{2 4}^{\circ}$ Congresso Brasileiro de Engenharia Sanitária e Ambiental. Belo Horizonte, 2007.

AGUILAR, G. T. Análise do tempo de tramitação de processo de licenciamento ambiental: estudo de casos de termelétricas no Estado de São Paulo. 2008. 113f. Dissertação (Mestrado em Ciências da Engenharia Ambiental) - Escola de Engenharia de São Carlos, Universidade de São Paulo, São Carlos, 2008.

AHAMMED, A. K. M. R.; NIXON, B. M. Environmental impact monitoring in the EIA process of South Australia. Environmental Impact Assessment Review, v.26, p.426-447, 2006.

AHMAD, B.; WOOD, C. A comparative evaluation of the EIA systems in Egypt, Turkey and Tunisia. Environmental Impact Assessment Review, v.22, p.213-234, 2002.

ALMEIDA, M. R. R. Análise da qualidade de Relatórios de Controle Ambiental aprovados pela Superintendência Regional de Meio Ambiente e Desenvolvimento Sustentável do Sul de Minas Gerais. 2010. 154f. Dissertação (Mestrado em Meio Ambiente e Recursos Hídricos). Instituto de Recursos Naturais, Universidade Federal de Itajubá, Itajubá, 2010.

ALMEIDA, M. R. R.; MALFARÁ, D. T.; MENDES, N. C.; MORAES, M. C. P.; SOUZA, M. P.; MONTAÑO, M. Aplicação de métodos para revisão da qualidade de estudos de impacto ambiental. Revista de Gestão Ambiental e Sustentabilidade, v.1, p.3-31, 2012.

ALMER, H. L.; KOONTZ, T. M. Public hearings for EIAs in post-communist Bulgaria: do they work? Environmental Impact Assessment Review, v.24, p.473-493, 2004.

ANDRÉ, P.; ENSERINK, B.; CONNOR, D.; CROAL, P. Public Participation: International Best Practice Principles. Special Publication Series n. 4. International Association for Impact Assessment. Fargo, USA, 2006. 
ANDROULIDAKIS, I; KARAKASSIS, I. Evaluation of the EIA system performance in Greece, using quality indicators. Environmental Impact Assessment Review, v.26, p.242$256,2006$.

APPIAH-OPOKU, S. Environmental impact assessment in developing countries: the case of Ghana. Environmental Impact Assessment Review, v.2, p.159-71, 2001.

ARNSTEIN, S. R. A Ladder of Citizen Participation. Journal of the American Institute of Planners, v.35, n.4, p.216-224, 1969.

BADR, E. A. Evaluation of the environmental impact assessment system in Egypt. Impact Assessment and Project Appraisal, v.27, n.3, p.193-203, 2009.

BADR, E. A.; ZAHRAN, A. A.; CASHMORE, M. Benchmarking performance:

Environmental impact statements in Egypt. Environmental Impact Assessment Review, v. 31, p.279-285, 2011.

BAKER, D. C.; MCLELLAND, J. N. Evaluating the effectiveness of British Columbia's environmental assessment process for first nations' participation in mining development. Environmental Impact Assessment Review, v.23, p.581-603, 2003.

BARRETTO, F. R. M.; MONTAÑO, M. Avaliação as etapa de delimitação do escopo de Estudos de Impacto Ambiental no estado de São Paulo. In: $1^{\circ}$ Congresso Brasileiro de Avaliação de Impacto. São Paulo, 2012.

BARTLETT, R. V.; BABER, W. F. Bureaucracy or analysis: implications of impact assessment for public administration. In: BARTLETT, R. V. Policy through impact assessment. New York: Greenwood Press; 1989. p. 143-53.

BELLINI, C. G. P.; RECH, I.; BORENSTEIN, D. Soft Systems Methodology: uma aplicação no "Pão dos Pobres" de Porto Alegre. RAE-eletrônica, v.3, n.1, 2004.

BERTALANFFY, L. V. Teoria Geral dos Sistemas. Petrópolis: Vozes, 1975. 351p.

BOTETZAGIAS, I. The environmental impact assessment and auditing process in Greece: evidence from the prefectural level. Impact Assessment and Project Appraisal, v.26, n.2, p.115-125, 2008.

BRASIL. Lei $n^{\circ}$ 6.938, de 31 de agosto de 1981. Dispõe sobre a Política Nacional do Meio Ambiente, seus fins e mecanismos de formulação e aplicação, e dá outras providências.

Diário Oficial da União, Brasília, 2 set. 1981.

CABRERA, D.; COLOSI, L.; LOBDELL, C. Systems thinking. Evaluation and Program Planning, v.31, p.299-310, 2008.

CANELAS, L.; ALMANSA, P.; MERCHAN, M.; CIFUENTES, P. Quality of environmental impact statements in Portugal and Spain. Environmental Impact Assessment Review, v.25, p.217-225, 2005.

CANTER, L. W.; CANTY, G. A. Impact significance determination. Environmental Impact Assessment Review, v.13, n.5, p.275-297, 1993. 
CAPRA, F. Criteria of Systems Thinking. Futures, October, 1985.

CAPRA, F. The web of life. New York: Anchor Books/Doubleday, 1996.

CAPRA, F. The web of life: a new synthesis of mind and matter. London: Flamingo, 1997.

CASHMORE, M.; AXELSSON, A. The mediation of environmental assessment's influence: What role for power? Environmental Impact Assessment Review, v.39, p.5-12, 2013.

CASHMORE, M.; GWILLIAM, R.; MORGAN, R.; COBB, D.; BOND, A. The interminable issue of effectiveness: substantive purposes, outcomes and research challenges in the advancement of environmental impact assessment theory. Impact Assessment and Project Appraisal, v.22, p.295-310, 2004.

CASHMORE, M.; RICHARDSON, T. Power and environmental assessment: Introduction to the special issue. Environmental Impact Assessment Review, v.39, p.1-4, 2013.

CASHMORE, M.; RICHARDSON, T.; HILDING-RYEDVIK, T.; EMMELIN, L. Evaluating the effectiveness of impact assessment instruments: Theorising the nature and implications of their political constitution. Environmental Impact Assessment Review, v.30, p.371-379, 2010.

CERQUEIRA, P.; ALVES, R. P. Regulação de mercados por licenciamento. Economia Global e Gestão, v.15, n.3, p.109-134, 2010.

CETESB - Companhia Ambiental do Estado de São Paulo. Disponível em:

<http://www.cetesb.sp.gov.br/institucional/institucional/1-A-Nova-CETESB>. Acesso em: 06 out. 2011.

CHECKLAND, P. Systems Thinking, Systems Practice. Chichester, West Sussex, England: John Wiley \& Sons, 1981. 330p.

CHECKLAND, P. Achieving 'desirable and feasible' change: an application of soft systems methodology. Journal of the Operational Research Society, v.36, n.9, p.821-831, 1985.

CHECKLAND, P. Systems thinking, systems practice. Includes a 30 years retrospective. New York: John Wiley \& Sons, 1999.

CHECKLAND, P. Soft Systems Methodology: A Thirty Year Retrospective. Systems Research and Behavioral Science, v.17, p11-58, 2000.

CHECKLAND, P.; SCHOLES, J. Soft Systems Methodology in Action: Includes a 30-year retrospective. Chichester: John Wiley \& Sons, 1999.

CHIAVENATO, I. Teoria de Sistemas. In: CHIAVENATO, I. Introdução à teoria geral da administração. 6.ed. Rio de Janeiro: Campus, 2000. p.543-577.

CHRISTOFOLETTI, A. Modelagem de sistemas ambientais. São Paulo: Edgard Blüncher LTDA. 1989. 
CLAUSEN, A.; HOA VU, H.; PEDRONO, M. An evaluation of the environmental impact assessment system in Vietnam: The gap between theory and practice. Environmental Impact Assessment Review, v.31, p.136-143, 2011.

CNI - Confederação Nacional da Indústria. Empresas enfrentam dificuldades no licenciamento ambiental. Sondagem Especial da CNI, Ano 5, n.2, 2007.

CONAMA - Conselho Nacional do Meio Ambiente (Brasil). Resolução n ${ }^{\circ}$ 009, de 03 de dezembro de 1987. Diário Oficial da União, Brasília, 05 dez. 1987.

CONAMA - Conselho Nacional do Meio Ambiente (Brasil). Resolução n ${ }^{\circ}$ 237, de 19 de dezembro de 1997. Diário Oficial da União, Brasília, 19 dez. 1997.

COPAM - Conselho Estadual de Política Ambiental (Minas Gerais). Deliberação Normativa $\mathrm{n}^{\circ} 12$ de 13 dezembro de 1994. Minas Gerais, Belo Horizonte, 13 dez. 1994.

COPAM - Conselho Estadual de Política Ambiental (Minas Gerais). Deliberação Normativa $\mathrm{n}^{\circ} 074$ de 09 de setembro de 2004. Minas Gerais, Belo Horizonte, 02 out. 2004.

CORTNER, H. J. Making sciene relevant to environmental policy. Environmental Sciene and Policy, v.3, p.21-30, 2000.

COSTA, A. C. P. Aprimoramento do licenciamento. In: I Seminário Internacional Licenciamento com Avaliação de Impacto Ambiental. São Paulo, 2012. Disponível em: <http://www.cetesb.sp.gov.br/noticia/443,Noticia>. Acesso em: 30 nov. 2013.

COSTA, N.; MARTINS, R. A.; PEGADO, E. A. C. Análise técnica de estudos ambientais da atividade petrolífera onshore no rio grande do norte. Holos, v.4, n.25, 2009.

DAIA - Departamento de Avaliação de Impacto Ambiental. Disponível em: <http://homologa.ambiente.sp.gov.br/cprn/sobre_daia.htm>. Acesso em: 06 out. 2011.

DANIELS, S. E.; WALKER, G. B. Lessons from the Trenches: Twenty Years of Using Systems Thinking in Natural Resource Conflict Situations. Systems Research and Behavioral Science, v.29, p.104-115, 2012.

DEVLIN, J. F.; YAP, N. T. Contentious politics in environmental assessment: blocked projects and winning coalitions. Impact Assessment and Project Appraisal, v.26, n.1, p.1727, 2008.

DIAS, E. G. C. S.; SÁNCHEZ, L. E. Deficiências na implementação de projetos submetidos à avaliação de impactos ambientais no Estado de São Paulo. Revista de Direito Ambiental, v.6, n.23, p.163-294, 2001.

DONAIRES, O. S. Uma abordagem sistêmica ao mapeamento e melhoria do processo de desenvolvimento de software. In: Congresso Brasileiro de Sistemas, 2008. Franca. Anais... Franca: UNIFACEF, 2008. 
EL-FADL, K.; EL-FADEL, M. Comparative assessment of EIA systems in MENA countries: challenges and prospects. Environmental Impact Assessment Review, v.24, p.553-593, 2004.

EL-GOHARY, N.M.; OSMAN, H.; EL-DIRABY, T.E. Stakeholder management for public private partnerships. International Journal of Project Management, v.24, p.595-604, 2006.

ELLIOTT, M.; THOMAS, I. Environmental impact assessment in Australia: theory and practice. 3 ed. Australia: Federation Press, 2009.

EMIRBAYER, M.; GOODWIN, J. Network analysis, culture and the problem of agency. American Journal of Sociology, v.99, n.6, p.1411-1454, 1994.

EPA - Environmental Protection Authority. Environmental Impact Assessment Procedural Guideline Series 1, 2003.

ESPEJO, R.; SCHUMANN, W.; SCHWANINGER, M.; BILELO, U. Organizational Transformation and Learning: a Cybernetic Approach to Management. Chichester: John Wiey \& Sons, 1996.

EUROPEAN COMISSION. Evaluation of the Performance of the EIA Process. Brussels: European Comission, 1996.

FATORELLI, L.; MERTENS, F. Integração de políticas e governança ambiental: o caso do licenciamento rural no Brasil. Ambiente \& Sociedade, v.13, n.2, p.401-415, 2010.

FIEB - Federação das Indústrias do Estado da Bahia. Análise Comparativa dos Dados Obtidos nas Pesquisas sobre Gestão Ambiental nas Indústrias do Estado da Bahia. Salvador, 2008.

FREEMAN, R. E. Strategic management: A stakeholder approach. Boston: Pitman, 1984.

FURIA, L. D.; WALLACE-JONES, J. The effectiveness of provisions and quality of practices concerning public participation in EIA in Italy. Environmental Impact Assessment Review, v.20, p.457-479, 2000.

GIDDENS, A. Central problems in social theory. Berkeley: University of California Press, 1979.

GIDDENS, A. The constitution of society. Berkeley: University of California Press, 1984.

GLASSON, J.; SALVADOR, N. N. B. EIA in Brazil: a procedures-practice gap. A comparative study with reference to the European Union, and especially the UK.

Environmental Impact Assessment Review, v.20, p.191-225, 2000.

GLASSON, J.; THERIVEL, R.; CHADWICK, A. Introduction to Environmental Impact Assessment. $4^{\text {a }}$ ed. London: Routledge, 2005. 
GLUCKER, A. N.; DRIESSEN, P. P. J.; KOLHOFF, A.; RUNHAAR, H. A. C. Public participation in environmental impact assessment: why, who and how? Environmental Impact Assessment Review, v.43, p.104-111, 2013.

GOMES, R. C. Who are the relevant stakeholders to the local government context? Empirical evidences on environmental influences in the decision-making process of english local authorities. Brazilian Admnistration Review, v.1, n.1, p.34-52, 2004.

GOMES, C. S.; POLAZ, C. N. M.; JORDÃO, C. O. J.; CARVALHO, A. F. C.; MONTAÑO, M. Avaliação da qualidade de estudos de impacto ambiental de Pequenas Centrais Hidrelétricas, 2009. Disponível em: <http://www.ambiente-augm.ufscar.br/uploads/A2052.pdf>. Acesso em: 11 jan. 2010.

GOODMAN, M. R. Study notes in system dynamics. Waltham, Pegasus, 1989. 388p.

GREENE, R.; ELFRERS, J. Power the 48 Laws. London: Profile Boooks, 1999.

HANSEN, A. M.; KØRNØV, L.; CASHMORE, M.; RICHARDSON, T. The significance of structural power in Strategic Environmental Assessment. Environmental Impact Assessment Review, v.39, p.37-45, 2013.

HARRISON, M. I.; SHIROM, A. Organizational diagnosis and assessment: bridging theory and practice. Thousand Oaks: Sage, 1999. 486 p.

HARTLEY, N.; WOOD, C. Public participation in environmental impact assessment: implementing the Aarhus Convention. Environmental Impact Assessment Review, v.25, p.319-340, 2005.

HAUGAARD, M. Reflections on Seven Ways of Creating Power. European Journal of Social Theory, v.6, n.1, p.87-113, 2003.

HAYDAR, F.; PEDIADITI, K. Evaluation of the environmental impact assessment system in Syria. Environmental Impact Assessment Review, v.30, p.363-370, 2010.

HAYES, N.; WESTRUP, C. Powerknowledge and impact assessment: creating new spaces for expertise in international development. New Technology, Work and Employment, v.27, n.1, p.9-22, 2012.

HEINMA, K.; PÕDER, T.. Effectiveness of Environmental Impact Assessment system in Estonia. Environmental Impact Assessment Review, v.30, p.272-277, 2010.

HICKIE, D.; WADE, M. Development of guidelines for improving the effectiveness of environmental assessment. Environmental Impact Assessment Review, v.18, p.267-287, 1998.

HINTE, T. V.; GUNTON, T. I.; DAY, J. C. Evaluation of the assessment process for major projects: a case study of oil and gas pipelines in Canada. Impact Assessment and Project Appraisal, v.25, n.2, p.123-137, 2007. 
HOKKANEN, P.; JANTUNEN, J. A multi-view evaluation of the Finnish EIA system: an 18year success story? Journal of Environmental Assessment Policy and Management, v.14, n. 4, p.1-22, 2012.

IAIA - International Association for Impact Assessment. Principles of environmental impact assessment best practice. Fargo: IAIA, Special Publication v.1, 1999. Disponível em: <http://www.iaia.org/publicdocuments/special-

publications/Principles\%20of\%20IA_web.pdf>. Acesso em: 07 out. 2013.

INELMEN, I. Implementing "system thinking" in the design of a "learning environment". Procedia Social and Behavioral Sciences, v.2, p.501-506, 2010.

JACKSON, M. C. Systems Approaches to Management. New York: Kluwer Academic/Plenum Publishers, 2000. 448p.

JALAVA, K.; PASANEN, S.; SAALASTI, M.; KUITUNEN, M. Quality of Environmental Impact Assessment: Finnish EISs and the opinions of EIA professionals. Impact Assessment and Project Appraisal, v.28, n.1, p.15-27, 2010.

JAY, S.; JONES, C.; SLINN, P.; WOOD, C. Environmental impact assessment: Retrospect and prospect. Environmental Impact Assessment Review. v. 27, n.4, p.287-300, 2007.

KAKONGE, J. O. Environmental impact assessment in sub-Saharan Africa: the Gambian experience. Impact Assessment and Project Appraisal, v.24, n.1, p.57-64, 2006.

KAST, F. E.; ROSENWEIG, J. E. O Conceito Moderno: O Enfoque Sistêmico. In: KAST, F. E.; ROSENWEIG, J. E. Organização e Administração: um enfoque sistêmico. 3. ed. São Paulo: Pioneira, 1987. p.121-152.

KENNEDY, A. J.; ROSS, W. A. An approach to integrate impact scoping with environmental impact assessment. Environmental Management, v.16, n.4, p.475-484, 1992.

KIRCHHOFF, D. Avaliação de risco ambiental e o processo de licenciamento: o caso do gasoduto de distribuição gás brasiliano trecho São Carlos - Porto Ferreira. 2004. 150f.

Dissertação (Mestrado em Hidráulica e Saneamento) - Escola de Engenharia de São Carlos, Universidade de São Paulo, São Carlos, 2004.

KLÜVER, J.; SCHMIDT, J. Social Differentiation as the Unfolding of Dimensions of Social Systems. The Journal of Mathematical Sociology, v.23, n.4, p.309-325,1999.

KOLHOFF, A. J.; RUNHAAR, H. A. C.; DRIESSEN, P. P. J. The contribution of capacities and context to EIA system performance and effectiveness in developing countries: towards a better understanding. Impact Assessment and Project Appraisal, v.27, n.4, p.271-282, 2009.

KRUOPIENĖ, J.; ŽIDONIENĖ, S.; DVARIONIENĖ, J. Current practice and shortcomings of EIA in Lithuania. Impact Assessment and Project Appraisal, v.29, p.305-309, 2009.

LAPERTOSA, M. G. Sistema Estadual de Meio Ambiente e Recursos Hídricos. Aprimoramento do licenciamento. In: I Seminário Internacional Licenciamento com 
Avaliação de Impacto Ambiental. São Paulo, 2012. Disponível em:

<http://www.cetesb.sp.gov.br/noticia/443, Noticia>. Acesso em: 30 nov. 2013.

LEE, N.; BROWN, R. Quality control in environmental assessment. Impact Assessment and Project Appraisal, v.7, n.1, p.41-5, 1992.

LEE, N.; DANCEY, R. The quality of environmental impact statements in Ireland in the United Kingdom: a comparative analysis. Impact Assessment and Project Appraisal, v.8, n.1, p.31-6, 1993.

LEMOS, C. F. Audiências públicas, participação social e conflitos ambientais nos empreendimentos hidrelétricos: os casos de Tijuco Alto e Irapé. 1999. 236 F. Dissertação (Mestrado em planejamento urbano e regional). Universidade Federal do Rio de Janeiro, Rio de Janeiro, 1999.

LEVESON, N. G. Applying systems thinking to analyze and learn from events. Safety Science, v.49, p.55-64, 2011.

LIMA, L. H.; MAGRINI, A. The Brazilian Audit Tribunal's role in improving the federal environmental licensing process. Environmental Impact Assessment Review, v.30, p.108$115,2010$.

LOPES, A. L. O relatório Ambiental Preliminar como Instrumento da Avaliação da Viabilidade Ambiental de Sistemas de Distribuição de Gás. 2008. 225f. Dissertação (Mestrado em Ciências da Engenharia Ambiental) - Escola de Engenharia de São Carlos, Universidade de São Paulo, São Carlos, 2008.

MACINTOSH, A. The Australian Government's environmental impact assessment (EIA) regime: using surveys to identify proponent views on cost-effectiveness. Impact Assessment and Project Appraisal, v.28, n.3, p. 175-188, 2010.

MARARA, M.; OKELLO, N.; KUHANWA, Z.; DOUVEN, W.; BEEVERS, L.;

LEENTVAAR, J. The importance of context in delivering effective EIA: Case studies from East Africa. Environmental Impact Assessment Review, v.31, p.286-296, 2011.

MATURANA, H. R.; VARELA, F. J. Autopoiesis and Cognition: The Realization of the Living. London: Dordrecht, 1980.

MIDDLE, G.; MIDDLE, I. The inefficiency of environmental impact assessment: reality or myth? Impact Assessment and Project Appraisal, v.28, n.2, p.159-168, 2010.

MINAS GERAIS. Lei ${ }^{\circ} 2.606$, de 05 de janeiro de 1962. Cria o Instituto Estadual de Florestas. Minas Gerais, Belo Horizonte, 8 jan. 1962.

MINAS GERAIS. Decreto ${ }^{\circ}$ 18.466, de 29 de abril de 1977. Institui a Comissão de Política Ambiental - COPAM e dá outras providências. Minas Gerais, Belo Horizonte, 30 abr. 1977.

MINAS GERAIS. Lei $n^{\circ} 11.903$, de 6 de setembro de 1995. Cria a Secretaria de Estado de Meio Ambiente e Desenvolvimento Sustentável, altera a denominação da Secretaria de Estado 
de Ciência, Tecnologia e Meio Ambiente e dá outras providências. Minas Gerais, Belo Horizonte, 7 set. 1995.

MINAS GERAIS. Lei delegada $n^{\circ}$ 62, de 29 de janeiro de 2003. Dispõe sobre a Secretaria de Estado de Meio Ambiente e Desenvolvimento Sustentável e dá outras providências. Minas Gerais, Belo Horizonte, 29 jan. 2003.

MINAS GERAIS. Decreto $n^{\circ} 44.667$, de 3 de dezembro de 2007. Dispõe sobre a reorganização do Conselho Estadual de Política Ambiental - COPAM, de que trata a Lei Delegada n n $^{\text {178, de }} 29$ de janeiro de 2007. Minas Gerais, Belo Horizonte, 04 dez. 2007.

MINAS GERAIS. Decreto ${ }^{\circ} 44.814$, de 16 de maio de 2008. Contém o Regulamento do Instituto Mineiro de Gestão das Águas. Minas Gerais, Belo Horizonte, 16 mai. 2008a.

MINAS GERAIS. Decreto ${ }^{\circ} 44.819$, de 28 de maio de 2008. Contém o Estatuto da Fundação Estadual do Meio Ambiente - FEAM. Minas Gerais, Belo Horizonte, 28 mai. 2008b.

MINGERS, J.; WHITE, L. A review of the recent contribution of systems thinking to operational research and management science. European Journal of Operational Research, v.207, p.1147-1161, 2010.

MINISTÈRE DE L'ENVIRONNEMENT. Impact sur I'environnement. Ies measures compensatoires. Neuilly-sur-Seine: Délégation à la Qualité de la Vie, 1985.

MMA - MINISTÉRIO DO MEIO AMBIENTE. Programa Nacional do Meio Ambiente II - PNMA II, Fase 2: 2009 - 2014. Componente Desenvolvimento Institucional, Subcomponente Licenciamento Ambiental. Brasília, 2009.

MONTAÑO, M.; OLIVEIRA, I. S. D.; RANIERI, V. E. L.; FONTES, A. T.; SOUZA, M. P. O zoneamento ambiental e a sua importância para a localização de atividades. Revista Pesquisa e Desenvolvimento Engenharia de Produção, n.6, p.49-64, 2007.

MONTAÑO, M.; SOUZA, M. P. A viabilidade ambiental no licenciamento de empreendimentos perigosos no Estado de São Paulo. Engenharia Sanitária e Ambiental, v.13, n.4, p.435-442, 2008.

MOON, B. Environmental impact assessment in Queensland, Australia: a governmental massacre! Impact Assessment and Project Appraisal, v.16, p.33-47, 1998.

MOREIRA, I. V. D. Avaliação de impacto ambiental - instrumento de gestão. Cadernos FUNDAP. São Paulo, Ano 9, nº 16, p.54-63, 1989.

MOREIRA, I. V. D. Vocabulário básico de meio ambiente. Rio de Janeiro: Feema/Petrópolis, 1992.

MORETTO, E. M. Análise da argumentação dialética que considera o licenciamentro Ambiental um impeditivo ao Desenvolvimento Econômico do país: premissas, interesses e possibilidades de superação. In: IV Encontro Nacional da ANPPAS. Brasília, 2008. 
MORGAN, R. K. Environmental impact assessment: the state of the art. Impact Assessment and Project Appraisal, v.30, n.1, p.5-14, 2012.

MORRISON-SAUNDERS, A; BAILEY, M. Appraising the role of relationships between regulators and consultants for effective EIA. Environmental Impact Assessment Review, v.29, p.284-294, 2009.

MORRISON-SAUNDERS, A.; EARLY, G. What is necessary to ensure natural justice in environmental impact assessment decision-making? Impact Assessment and Project Appraisal, v.26, n.1, p.29-42, 2008.

MORRISON-SAUNDERS, A.; SADLER, B. The art and science of impact assessment: results of a survey of IAIA members. Impact Assessment and Project Appraisal, v.28, n.1, p.77-82, 2010.

MPF - Ministério Público Federal. Deficiências em Estudos de Impacto Ambiental: síntese de uma experiência. Brasília: $4^{a}$ Câmara de Coordenação e Revisão, Escola Superior do Ministério Público da União, 2004.

MUNIZ, E. C. L.; POSSAMAI, O.; ABREU, P. F. Soft System Methodology na resolução de problemas complexos e inovação: uma análise das publicações em periódicos internacionais. Revista GEINTEC, v.3, n.3, p.195-212, 2013.

MWALYOSI, R. HUGHES, R. The performance on EIA in Tanzania: an assessment. International Institute for Envonmental and Development, London, 1998.

NADEEM, O.; FISCHER, T. B. An evaluation framework for effective public participation in EIA in Pakistan. Environmental Impact Assessment Review, v.31, p.36-47, 2011.

NADEEM, O.; HAMEED, R. Evaluation of environmental impact assessment in Pakistan. Environmental Impact Assessment Review, v.28, p.562-71, 2008.

NARDELLI, A. M. B.; GRIFFITH, J. J. Modelo teórico para compreensão do ambientalismo empresarial do setor florestal brasileiro. Revista Árvore, v.27, n.6, p.855-869, 2003.

NOBLE, B.; STOREY, K. Towards increasing the utility of 'follow-up' in Canadian EA. Environmental Impact Assessment Review, v.5. n.2, p.163-180, 2005.

NUTT, P.; BACKOFF, R. Strategic Management of Public and Third Sector Organizations: A Handbook for Leaders. San Francisco, CA: Jossey-Bass, 1994.

O'CONNOR, J.; MCDERMOTT, I. The art of systems thinking. Hammersmith, London: HarperCollins, 1997.

O'FAIRCHEALLAIGH, C. Public participation and environmental impact assessment: Purposes, implications, and lessons for public policy making. Environmental Impact Assessment Review, v.30, p.19-27, 2010. 
OLIVEIRA, I. S. D. (2004) A Contribuição do zoneamento ecológico na avaliação de impacto ambiental: bases e propostas conceituais. 2004. 111f. Dissertação (mestrado) - Escola de Engenharia de São Carlos, Universidade de São Paulo, São Carlos, 2004.

OMENA, M. L. R. A.; SANTOS, E. B. Análise da efetividade da Avaliação de Impactos Ambientais - AIA - da Rodovia SE 100/Sul-Sergipe. Revista Brasileira de Gestão e Desenvolvimento Regional, v.4, n.1, p.221-237, 2008.

OSLOM, W. Systems Thinking. In: ABRAHAM, M. A. (Ed) Sustainability Science and Engineering: Defining principles. Amsterdam: Elsevier B.V., 2006. p.91-112.

PALIWAL, R. EIA practice in India and its evaluation using SWOT analysis. Environmental Impact Assessment Review, v.26, p.492-510, 2006.

PANIGRAHI, J. K.; AMIRAPU, S. An assessment of EIA system in India. Environmental Impact Assessment Review, v.35, p.23-36, 2012.

PARDO, M. Environmental Impact Assessment: myth or reality? Lessons from Spain. Environmental Impact Assessment Review, v.17, p.123-142, 1997.

PARPINELLI, R. F.; LUNARDELLI, M. C. F. Avaliação psicológica em processos seletivos: contribuições da abordagem sistêmica. Estudos de Psicologia, v.23, n.4, p.463-471, 2006.

PARTIDARIO, M. R.; SHEATE, W. R. Knowledge brokerage - potential for increased capacities and shared power in impact assessment. Environmental Impact Assessment Review, v.39, p.26-36, 2013.

PATCHING, D. Seeking out the issues: how soft systems methodology was employed to advise a social services department on the use of information technology. OR Insight, v.5, n.1, p. 9-14, 1992.

PEDREIRA, A. C. Avaliação do processo de licenciamento ambiental para Pequenas Centrais Hidrelétricas no estado de Minas Gerais. 2004. 143f. Dissertação (Mestrado em Engenharia da Energia). Universidade Federal de Itajubá, Itajubá, 2004.

PETERSON, K. Quality of environmental impact statements and variability of scrutiny by reviewers. Environmental Impact Assessment Review, v.30, p.169-176, 2010.

PETTS, J. Public participation and environmental impact assessment. In: Handbook of Environmental Impact Assessment, Vol. 1. Environmental Impact Assessment: Process, Methods and Potential. Oxford: J Petts, 1999. p. 145-177.

PINHO, P.; MAIA, R.; MONTERROSO, A. The quality of Portuguese Environmental Impact Studies: the case of small hydropower projects. Environmental Impact Assessment Review, v.27, p.189-205, 2007.

PINHO, P.; MCCALLUM, S.; CRUZ, S. S. A critical appraisal of EIA screening practice in EU Member States. Impact Assessment and Project Appraisal, v.28, n.2, p.91-107, 2010. 
PIRES, R. P. Anthony Giddens e a teoria da estruturação: apresentação e bibliografia. Sociologia, Problemas e Práticas, v.4, p.231-236, 1988.

PÖLÖNEN, I.; HOKKANEN, P.; JALAVA, K. The effectiveness of the Finnish EIA system: What works, what doesn't, and what could be improved? Environmental Impact Assessment Review, v.31, p.120-128, 2011.

POPE, J.; BOND, A.; MORRISON-SAUNDERS, A.; RETIEF, F. Advancing the theory and practice of impact assessment: Setting the research agenda. Environmental Impact Assessment Review, v.41, p.1-9, 2013.

PRADO FILHO, J. F.; SOUZA, M. P. O Licenciamento Ambiental da mineração no Quadrilátero Ferrífero de Minas Gerais: uma análise da implementação de medidas de controle ambiental formuladas em EIAS/RIMAS. Engenharia Sanitária e Ambiental, v.9, n.4, p.343-349, 2004.

RAHMAN, S. A. Comparative Study of TQM practice and organisation performance of SMEs with and without ISO 9000 certification. International Journal of Quality and Reliability Management, v. 18, n. 1, p. 35-49. 2001.

RAJARAM, T.; DAS, A. Screening for EIA in India: Enhancing effectiveness through ecological carrying capacity approach. Journal of Environmental Management, v.92, p.140-148, 2011.

RAPOPORT, A. General system theory: Essential concepts \& applications. Cybernetics and systems series. Tunbridge Wells, Kent: Abacus Press, 1986.

RENN, O.; SCHWEIZER, P. J. Inclusive Risk Governance: Concepts adn Application to Environmental Policy-Making. Environmental Policy Governance, v.19, p.174-185, 2009.

ROBB, F. F. Operational Research and General Systems Thinking. European Management Journal, v.4, n.1, p.55-62, 1986.

ROBBINS, S. P.; COULTER, M. Administração. 5 ed. Rio de Janeiro: Pearson - Prentice Hall, 1998.

RODRIGUES, G. S. S. C. A análise interdisciplinar de processos de licenciamento ambiental no estado de Minas Gerais: conflitos entre velhos e novos paradigmas. Sociedade $\&$ Natureza, v.22, n.2, p.267-282, 2010.

ROMITELLI, M. S. Licenciamento no estado de São Paulo. Aprimoramento do licenciamento. In: I Seminário Internacional Licenciamento com Avaliação de Impacto Ambiental. São Paulo, 2012. Disponível em:

<http://www.cetesb.sp.gov.br/noticia/443,Noticia>. Acesso em: 30 nov. 2013.

ROSE, J. Soft Systems Methodology as a Social Science Research Tool. Systems Research and Behavioral Science, v.14, n.4, p.249-258, 1997. 
ROSS, W. A.; MORRISON-SAUNDERS, A.; MARSHALL, R. Common sense in environmental impact assessment: it is not as common as it should be. Impact Assessment and Project Appraisal, v.24, n.1, p.3-22, 2006.

ROTHMAN, F. D. A Comparative Study of Dam-Resistance Campaigns and Environmental Policy in Brazil. Journal of Environment \& Development, v.10, n.4, p.317-344, 2001.

ROUNTREE, J. H. Systems Thinking - some fundamental aspects. Agricultural Systems, v.2, p.247-254, 1977.

RUFFEIS, D.; LOISKANDL, W.; AWULACHEW, S. B.; BOELEE, E. Evaluation of the environmental policy and impact assessment process in Ethiopia. Impact Assessment and Project Appraisal, v.28, n.1, p.29-40, 2010.

SADLER, B. (Org.) Environmental assessment in a changeling world, evaluating practice to improve performance. Ottawa: Canadian Environmental Assessment, 1996. 248p.

SÁNCHEZ, L. E. Avaliação de impacto ambiental: conceitos e métodos. São Paulo: Oficina de Textos, 2008. 495p.

SANDHAM, L. A.; PRETORIUS, H. M. A review of EIA report quality in the North West province of South Africa. Environmental Impact Assessment Review, v.28, p.229-240, 2008.

SANTOS, C. D. Licenciamento Ambiental de Grandes Projetos no Espírito Santo. Aprimoramento do licenciamento. In: I Seminário Internacional Licenciamento com Avaliação de Impacto Ambiental. São Paulo, 2012. Disponível em:

<http://www.cetesb.sp.gov.br/noticia/443,Noticia>. Acesso em: 30 nov. 2013.

SÃO PAULO. Lei n 9.509, de 20 de março de 1997. Dispõe sobre a Política Estadual do Meio Ambiente, seus fins e mecanismos de formulação e aplicação. Diário Oficial Estado de São Paulo, São Paulo, 20 mar. 1997.

SÃO PAULO. Lei $n^{\circ} 13.542$, de 8 de maio de 2009. Altera a denominação da CETESB Companhia de Tecnologia de Saneamento Ambiental e dá nova redação aos artigos $2^{\circ}$ e 10 da Lei n ${ }^{\circ} 118$, de 29 de junho de 1973. Diário Oficial Estado de São Paulo, São Paulo, 8 mai. 2009a.

SÃO PAULO. Lei no 13.507, de 23 de abril de 2009. Dispõe sobre o Conselho Estadual do Meio Ambiente - CONSEMA, e dá providências correlatas. Diário Oficial Estado de São Paulo, São Paulo, 23 abr. 2009b.

SCHIUMA, G.; CARLUCCI, D.; SOLE, F. Applying a systems thinking framework to assess knowledge assets dynamics for business performance improvement. Expert Systems with Applications, v.39, p.8044-8050, 2012.

SEMAD - Secretaria de Estado de Meio Ambiente e Desenvolvimento Sustentável. Minuta de Deliberação Normativa, 2011. Disponível em: <http://xa.yimg.com/kq/groups/22094367/1687665165/name/DN_74_quinze_DE_Maio_2011 .pdf>. Acesso em: 07 out. 2013. 
SEMAD - Secretaria de Estado de Meio Ambiente e Desenvolvimento Sustentável. Chamamento público, 2012. Disponível em: <http://www.semad.mg.gov.br/noticias/1/1532edital-de-chamamento-publico-semadcopam-no-012012>. Acesso em: 30 jan. 2013.

SEMAD - Secretaria de Estado de Meio Ambiente e Desenvolvimento Sustentável. Disponível em: <http://www.semad.mg.gov.br/suprams-regionais>. Acesso em: 07 out. 2013a.

SEMAD - Secretaria de Estado de Meio Ambiente e Desenvolvimento Sustentável. Disponível em: <http://www.semad.mg.gov.br/images/stories/supram/as-9-suprams1.pdf>. Acesso em: 07 out. 2013b.

SENGE, P. The Fifth Discipline: The Art and Practice of the Learning Organization. London: Century Books, 1990.

SHEPHERD, A.; BOWLER, C. Beyond the requirements: improving public participation in EIA. Journal of Environmental. Planning and Management, v.40, n.6, p.725-738, 1997.

SMA - Secretaria do Meio Ambiente do Estado de São Paulo. Disponível em: <http://www.ambiente.sp.gov.br/cprnDaia.php>. Acesso em: 25 mai. 2011.

SOCZKA, L. Modelos de Análise de Redes Sociais e Limitações do Modelo de Equilíbrio Estrutural de Heider. Interacções, n.8. p.83-122, 2005.

SONERYD, L. Environmental Conflicts and Deliberative Solutions? A case study of public participation in EIA in Sweden. Örebro: Örebro University Press, 2004.

SOUSA, A. S.; PALHARES, M. Fragilidades da atuação dos técnicos no processo de Avaliação de Impactos Ambientais. In: $1^{\circ}$ Congresso Brasileiro de Avaliação de Impacto. São Paulo, 2012.

STEINEMANN, A. Improving alternatives for environmental impact assessment. Environmental Impact Assessment Review, v.21, p. 3-21, 2001.

TAMBELLINI, A. T. Sobre o Licenciamento Ambiental no Brasil, país - potência emergente. Ciência \& Saúde Coletiva, v.17, n.6, p.1399-1406, 2012.

THEOPHILOU, V.; BOND, A.; CASHMORE, M. Application of SEA Directive to EU structural funds: perspectives on effectiveness. Environmental Impact Assessment Review, v.30, p.136-144, 2010.

TOMMASI, L. R. Estudo de Impacto Ambiental. São Paulo: Terragraph Artes e Informática, 1994. 355p.

TORO, J.; REQUENA, I.; ZAMORANO, M. Environmental impact assessment in Colombia: Critical analysis and proposals for improvement. Environmental Impact Assessment Review, v.30, p.247-261, 2010. 
VASCONCELOS, C; HAMILTON, A.; BARRETT, P. Public participation in EIA: A study from a Portuguese perspective. Journal of Environmental Assessment Policy and Management, v.2, n.4, p.561-582, 2000.

VIANA, M. B. Licenciamento ambiental de minerações em Minas Gerais: novas abordagens de gestão. 2007. 305f. Dissertação (Mestrado em Desenvolvimento Sustentável) - Centro de Desenvolvimento Sustentável, Universidade de Brasília, Brasília, 2007.

VIANA, M. B.; BURSZTYN, M. A. A. Regularização ambiental de minerações em Minas Gerais. Revista Escola de Minas, v.63, n.2, p.363-369, 2010.

WÄRNBÄCK, A.; HILDING-RYDEVIKA, T. Cumulative effects in Swedish EIA practice: difficulties and obstacles. Environmental Impact Assessment Review. v.29, n.2, p.107-115, 2009.

WATER, H.V.; SCHINKEL, M.; ROZIER, R. Fields of application of SSM: A categorization of publications. Journal of the Operational Research Society, v.58, n.3, p.271-287, 2007.

WATHERN, P. An introductory guide to EIA. In: WATHERN, P. (Org). Environmental impact assessment: theory and practice. London: Unwin Hyman, 1988. p.3-30.

WEISS, E. H. An unreadable EIS is an environmental hazard. The environmental professional, v.11, p.236-240, 1989.

WENDE, W. Evaluation of the effectiveness and quality of environmental impact assessment in the Federal Republic of Germany. Impact Assessment and Project Appraisal, v.20, n.2, p.93-99, 2002.

WOOD, C.; DIPPER, B.; JONES, C. Auditing the assessments of the environmental impacts of planning projects. Journal of Environmental Planning and Management, v. 43, p. 2347, 2000.

WOOD, C. Environmental impact assessment in developing countries: an overview. Conference Paper, Conference on New Directions in Impact Assessment for Development: Methods and Practice, 24-25 November 2003, EIA Centre School of Planning and Landscape, University of Manchester, 2003.

WOOD, G.; BECKER, J. Discretionary judgement in local planning authority decision making: screening development proposals for environmental impact assessment. Journal of Environmental Planning and Management, v.48, n.3, p.349-371, 2005.

YUKL. Leadership in Organisations. Sydney: Prentice-Hall, 1998.

ZEREMARIAM, T. K.; QUINN, N. An evaluation of environmental impact assessment in Eritrea. Impact Assessment and Project Appraisal, v.25, n.1, p.53-63, 2007.

ZHOURI, A.; LASCHEFSKI, K.; PAIVA, A. Uma Sociologia do Licenciamento Ambiental: o caso das hidrelétricas em Minas Gerais. In: ZHOURI, A; PERREIRA, D.B.; LASCHFSKI, $\mathrm{K}$. (Orgs). A insustentável leveza da política ambiental: desenvolvimento e conflitos socioambientais. Autêntica: Belo Horizonte, 2005. p. 89-118. 
ZUBAIR, L. Challenges for environmental impact assessment in Sri Lanka. Environmental Impact Assessment Review, v. 21, n. 5, p. 469-478, 2001. 
APÊNDICES 


\section{APÊNDICE I - QUESTIONÁRIO}

\section{INFORMAÇÕES SOBRE OS SISTEMAS DE AVALIAÇÃO DE IMPACTO AMBIENTAL E LICENCIAMENTO AMBIENTAL}

Este questionário faz parte de um projeto de doutorado do Programa de Ciências da Engenharia Ambiental da Escola de Engenharia de São Carlos - Universidade de São Paulo. Ele objetiva obter informações sobre as legislações norteadoras e os procedimentos realizados nas diferentes etapas do processo de Licenciamento Ambiental (LA) e Avaliação de Impacto Ambiental (AIA) em cada estado brasileiro. Pretende-se identificar as especificidades e os pontos de similaridade entre os sistemas estaduais.

Para auxiliar em casos de dúvidas, segue em ANEXO um glossário definindo o que seria cada etapa considerada.

\section{QUADRO LEGAL}

1) Quais as principais legislações estaduais que regulamentam o processo de AIA/LA? QUADRO INSTITUCIONAL

2) Qual agência (corpo técnico) dentro do órgão ambiental estadual é responsável pelo licenciamento e avaliação de impacto ambiental e qual é o conselho ambiental envolvido no processo?

3) O processo de licenciamento é descentralizado, contando com unidades regionais, ou acontece somente em um órgão central? Em quais casos acontece a descentralização?

APRESENTAÇÃO DA PROPOSTA DO EMPREENDIMENTO

4) Como se inicia o processo de AIA/LA? Quais as documentações e procedimentos necessários para a abertura do processo?

TRIAGEM

5) Quais os tipos de estudos ambientais envolvidos no processo de AIA/LA além do Estudo de Impacto Ambiental e respectivo Relatório de Impacto Ambiental (EIA/Rima)?

6) Como é definido se existe a necessidade da elaboração de estudo ambiental para o licenciamento de um empreendimento? E como é definido o tipo de estudo a ser elaborado? 
7) Como é estabelecido o conteúdo a ser abordado no estudo ambiental? Ou como é definido o Termo de Referência?

8) Existem Termos de Referência específicos para cada tipologia de empreendimento?

9) Existe a possibilidade de definição de aspectos ambientais específicos a serem abordados pelo estudo devido à peculariedades de cada tipo de empreendimento e/ou características do meio onde o projeto será instalado?

10) Existe a exigência da consideração de alternativas? Em que casos?

\section{ANÁLISE TÉCNICA DOS ESTUDOS AMBIENTAIS}

11) Como é feita a análise técnica dos estudos ambientais, ou seja, como é verificada a sua qualidade para a definição de sua aprovação? Esta análise baseia-se somente no Termo de Referência ou existem outros critérios como a adoção de listas de verificação?

\section{PARTICIPAÇÃO PÚBLICA}

12) Em que etapas do processo de AIA/LA ocorrem a participação pública? Existe a possibilidade de participação nas fases de triagem (definição do tipo de estudo) e escopo (definição do conteúdo do estudo) ou a participação é restrita às audiências públicas?

13) As audiências públicas só são solicitadas em casos de EIA/Rima?

\section{TOMADA DE DECISÃO}

14) De quem é a decisão final sobre a viabilidade ambiental do empreendimento, aprovando ou rejeitando a emissão da licença?

15) Além da Licença Prévia, Licença de Instalação e Licença de Operação (LP, LI e LO), existe alguma outra categoria de licença?

\section{MONITORAMENTO/ACOMPANHAMENTO}

16) Como é realizado o monitoramento dos empreendimentos licenciados? Ele acontece somente para a renovação da licença de operação?

\section{BOAS PRÁTICAS}

17) É realizada alguma análise da equipe que elaborou o estudo ambiental? É exigida a multidisciplinaridade desta equipe? As consultorias passam por algum processo de cadastramento ou certificação?

18) Existem treinamentos e/ou capacitação dos envolvidos no processo (consultores e técnicos analistas)? 


\section{ANEXO - GLOSSÁRIO}

ANÁLISE TÉCNICA DOS ESTUDOS AMBIENTAIS: Tem o objetivo verificar e determinar se o estudo de impacto ambiental é uma avaliação adequada de relevância dos impactos ambientais a serem causados pelo projeto e se existe qualidade suficiente para a tomada de decisões.

APRESENTAÇÃO DA PROPOSTA DO EMPREENDIMENTO: documentações $\mathrm{e}$ procedimentos necessários para a abertura do processo de AIA/LA dentro do órgão ambiental. ESCOPO: é a definição do conteúdo do estudo a ser elaborado.

MONITORAMENTO/ACOMPANHAMENTO: etapa onde se verifica o cumprimento dos compromissos assumidos pelo empreendedor, quando da implantação do empreendimento, e continuar a validar a licença ambiental emitida, caso o empreendimento persista na condição de adequado e viável ambientalmente.

PARTICIPAÇÃO PÚBLICA: etapas em que a sociedade pode participar do processo.

QUADRO INSTITUCIONAL: considerado, aqui, apenas como sendo o corpo técnico responsável pelo licenciamento e avaliação de impacto ambiental e o conselho ambiental envolvido no processo. A descentralização é entendida como participação de unidades regionais ou municipais no licenciamento.

QUADRO LEGAL: conjunto de normas, portarias, resoluções, deliberações, leis e decretos estaduais que, em complementaridade com as Resoluções CONAMA, regulamentam o processo de licenciamento e avaliação de impacto ambiental no estado.

TOMADA DE DECISÃO: fase em que é definida se o empreendimento recebe ou não a licença ambiental.

TRIAGEM: etapa que define se no licenciamento é necessária a elaboração de estudo ambiental e, em caso afirmativo, qual tipo de estudo. Por exemplo, as resoluções CONAMA 01/86 e 237/97 triam empreendimentos que necessitam de licenciamento e da elaboração de EIA/Rima. 


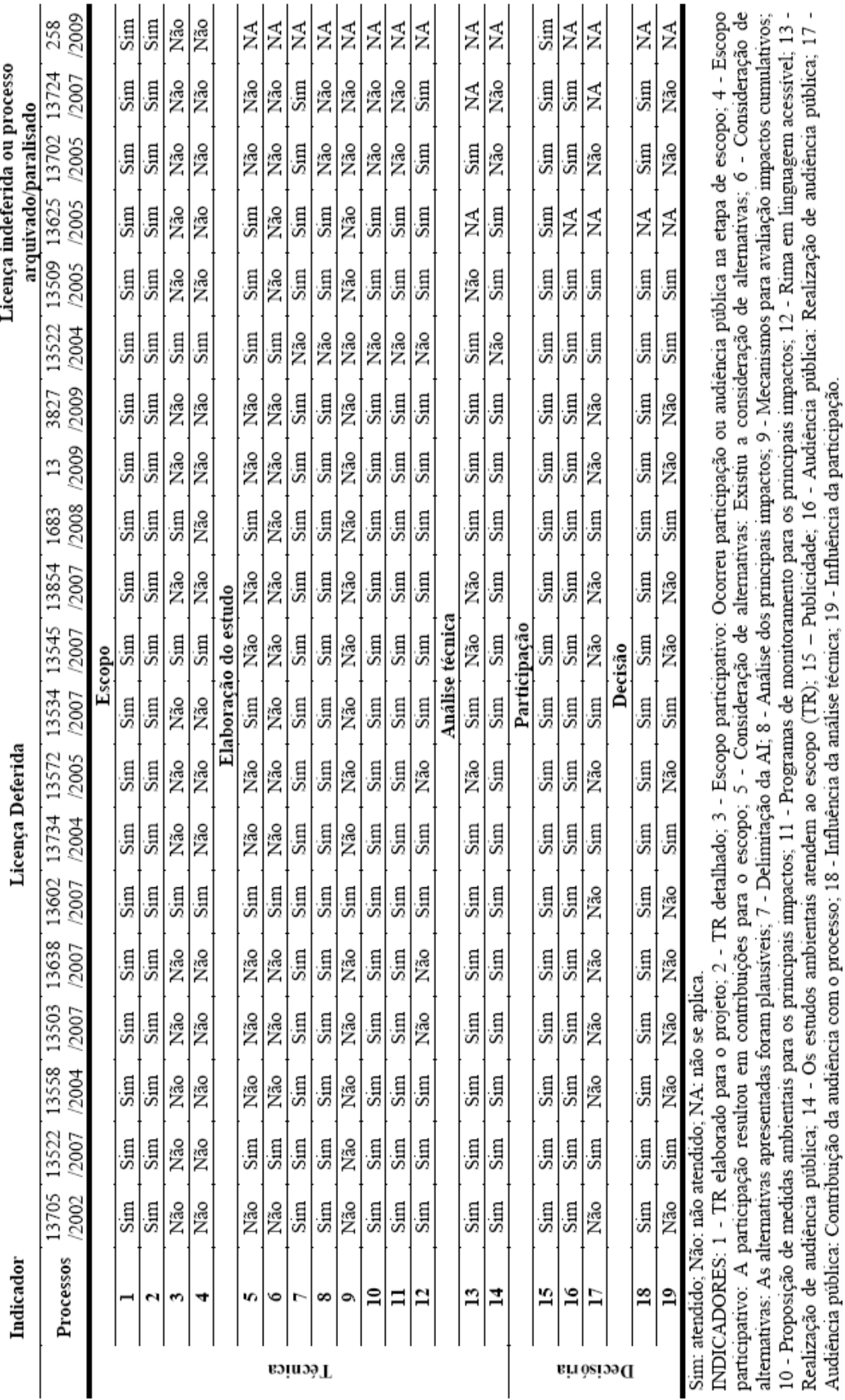




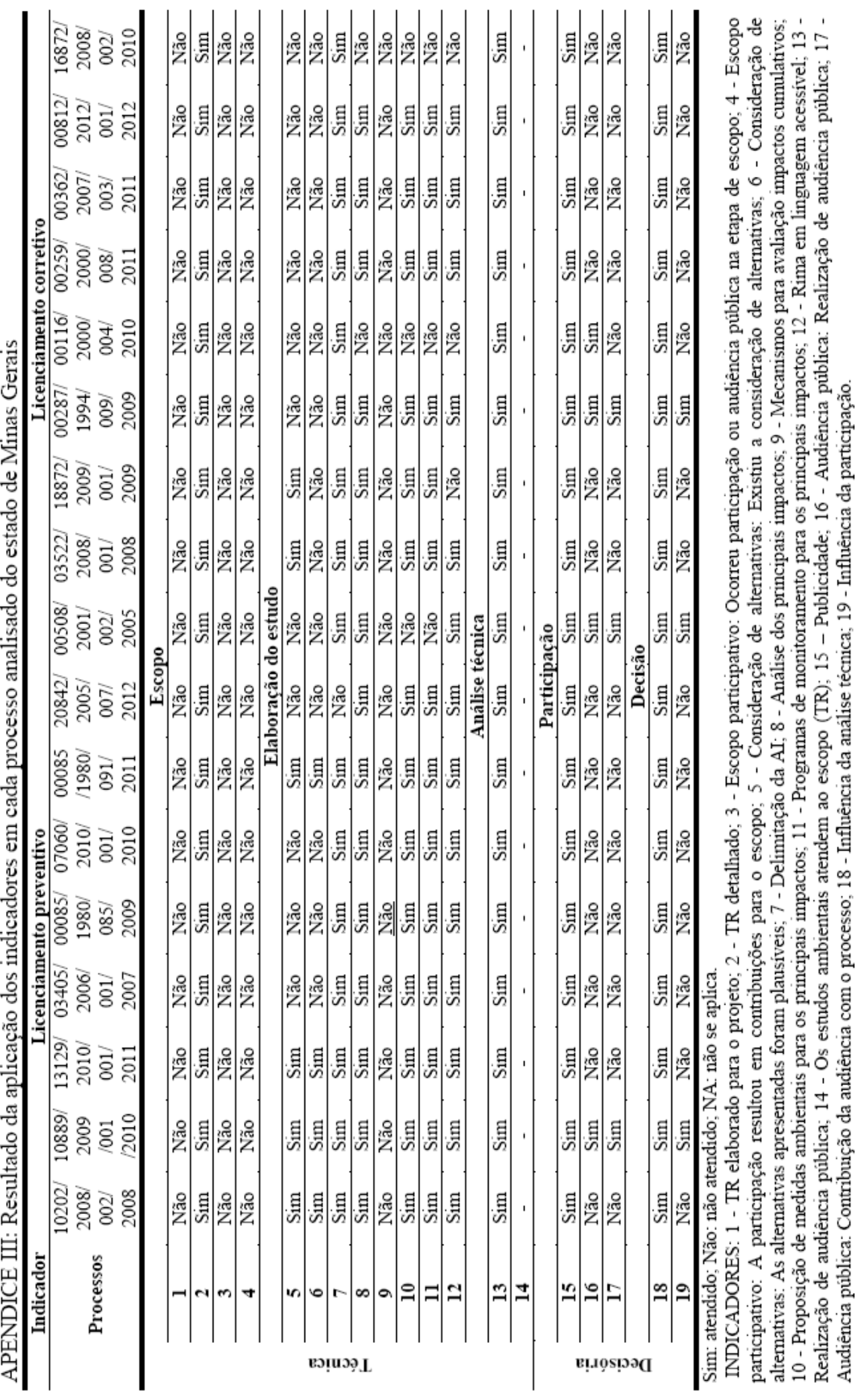

